\title{
The Portrayal of Protagonists with Communication Disorders in Contemporary Award-Winning Juvenile Fiction
}

Jane Lefevre

Follow this and additional works at: https://researchrepository.wvu.edu/etd

\section{Recommended Citation}

Lefevre, Jane, "The Portrayal of Protagonists with Communication Disorders in Contemporary AwardWinning Juvenile Fiction" (2015). Graduate Theses, Dissertations, and Problem Reports. 6054.

https://researchrepository.wvu.edu/etd/6054

This Dissertation is protected by copyright and/or related rights. It has been brought to you by the The Research Repository @ WVU with permission from the rights-holder(s). You are free to use this Dissertation in any way that is permitted by the copyright and related rights legislation that applies to your use. For other uses you must obtain permission from the rights-holder(s) directly, unless additional rights are indicated by a Creative Commons license in the record and/ or on the work itself. This Dissertation has been accepted for inclusion in WVU Graduate Theses, Dissertations, and Problem Reports collection by an authorized administrator of The Research Repository @ WVU.

For more information, please contact researchrepository@mail.wvu.edu. 


\title{
The Portrayal of Protagonists with Communication Disorders in
} Contemporary Award-Winning Juvenile Fiction

\author{
Jane Lefevre \\ Dissertation submitted \\ to the College of Education and Human Services \\ at West Virginia University \\ in partial fulfillment of the requirements for the degree of \\ Doctor of Education in \\ Curriculum and Instruction
Patricia Obenauf, EdD Chair Ardeth Deay, PhD
Barbara Ludlow, EdD
Robert Orlikoff, PhD
Joy Faini Saab, EdD \\ Department of Curriculum and Instruction/Literacy Studies
}

\author{
Morgantown, West Virginia \\ 2015
}

Keywords: Children's Literature, Disabilities, Communication Disorder

Copyright 2015 Jane Lefevre 


\title{
Abstract \\ The Portrayal of Protagonists with Communication Disorders in Contemporary Award-Winning Juvenile Fiction
}

\author{
Jane Lefevre
}

Twenty-six contemporary North American award-winning intermediate children's and young adult fictional books were identified that contained twenty-seven protagonists with communication disorders (CD). These books were evaluated using an adaptation of the Dyches \& Prater (2000) Rating Scale for Quality Characterizations of Individuals with Disabilities in Children's Literature. Each guideline is discussed in detail while examining the quality of portrayed characterizations and literary elements in the eligible literature. The types of CDs depicted were language, speech and hearing disorders. No protagonists with central auditory processing disorders were found. Almost half of the protagonists had language disorders, making it the most commonly portrayed type of CD. Approximately a fourth of the main characters with CDs had autism spectrum disorders. The overall quality of all of the books was positive. The books scored well in categories, such as, social interactions, personal portrayals, exemplary practices and sibling relationships. Within these categories the literature measured well above the acceptable level on such portrayal characteristics as accuracy, realism, character development, interest/strengths, reciprocal and variety of relationships, empathy, respect, valued occupations, promoting self-determination, and full citizenship opportunities. The only area that fell below the $90^{\text {th }}$ percentile was the trait of using nondiscriminatory language that avoids stereotypical portrayals. Within this study two different comparisons were made using the results of the rating scale. In the first comparison, scores of authors who had some personal connection with the primary or secondary disorder that contributed to the $\mathrm{CD}$ were compared to authors who had no personal connection to the $\mathrm{CD}$ being described. The group of books written by authors having connections with disabilities portrayed in their books scored overall at least $10 \%$ higher in topics relating to: primary relationships with paid personnel, caregiver relationships, fear of association by characters without disabilities, receiving appropriate services, and providing additional information for readers to find out more about disabilities. In the other group of books that were written by authors that did not have any connection with the disabilities depicted in their books, score differences higher than at least $10 \%$ were discovered in the following areas: using nondiscriminatory language, relationships with friends and siblings, and being portrayed as victims, initiators and protectors. This group also had two books that had protagonists with CDs whose CDs were irrelevant to the story. In the second comparison in this study, the scores of books that won awards that were created specifically to honor the portrayal of individuals with disabilities were compared to those scores of books that won awards that did not specifically honor disabilities. The group of books that won awards that were created specifically to honor the portrayal of individuals with disabilities scored overall at least $10 \%$ higher in topics relating to: being depicted as initiator and caregiver, receiving appropriate services, portraying attitudes and practices 
congruent with the era, having feelings of guilt toward the protagonist with $\mathrm{CD}$, and providing additional information for readers to find out more about disabilities. In the other group of books that won awards that did not specifically honor individuals with disabilities, score differences higher than at least $10 \%$ were discovered in the following areas: using nondiscriminatory language, being portrayed as victims and protectors and having books that had protagonists with CDs whose CDs were irrelevant to the story. 


\section{Dedication}

This dissertation is dedicated to my parents, Helen H. Lefevre and Medard L. Lefevre.

Thank you for all your support over the years and giving me the valuable gift of a passion to learn. Without your help this dissertation would never have been completed. 


\section{Acknowledgment}

My sincere gratitude and appreciation to my chair and members of my committee,

Patricia Obenauf, Ardeth Deay, Joy Faini Saab, Barbara Ludlow and Robert Orlikoff.

Thank you for all your encouragement, patience, guidance and support over the years. A

special thanks to my family for their enthusiasm, kindness and understanding. I could not have written this dissertation without you. 


\section{TABLE OF CONTENTS}

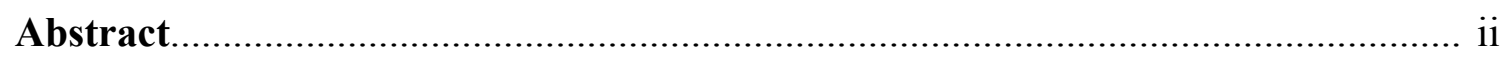

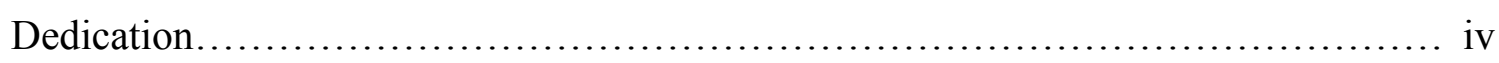

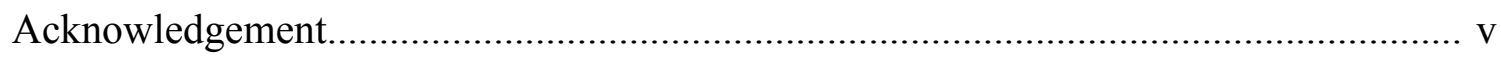

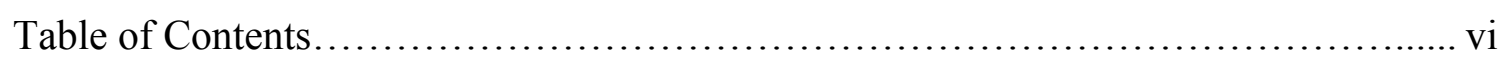

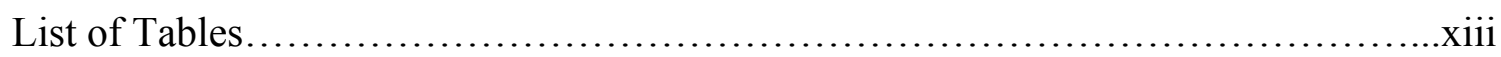

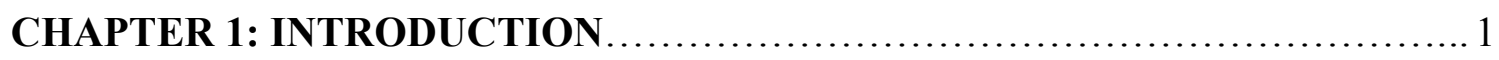

Representation of People with Disabilities in Children's Books............... 2

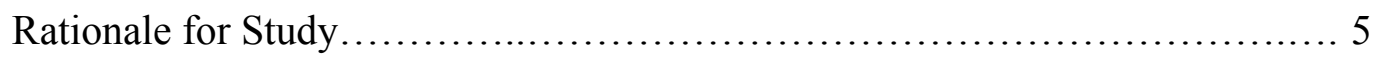

Statement of the Problem............................................. 7



Statement of Research Questions...................................... 10

Justification.................................................... 11

Definitions.......................................................... 12

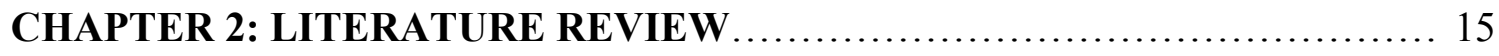

Introduction........................................................... 15

Portrayal of Characters with Disabilities in Children's Literature.............. 16

Introduction................................................. 16

General Literature Investigation................................ 17

Literature Portrayal of Disabilities Over Time $\ldots \ldots \ldots \ldots \ldots \ldots \ldots \ldots \ldots \ldots \ldots$

Empirical Studies of Disabilities Over Time $\ldots \ldots \ldots \ldots \ldots \ldots \ldots \ldots \ldots \ldots \ldots \ldots$

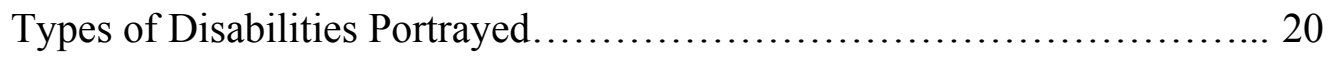


Empirical Studies of Specific Disabilities............................... 21

Disabilities and Award-Winning Books................................ 24

Communication Disorders Studies................................... 26

Book Awards............................................................. 28

Significance of Awards................................................ 28

Types of Book Awards.............................................. 29

Major American Children's Book Awards ............................... 30

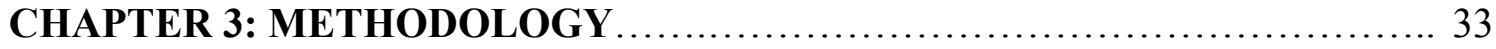

Research Design .................................................... 33

Procedures for Selecting Books . ........................................ 34

Sources of the Titles.................................................... 35

Criteria for Inclusion of the Literature................................. 36

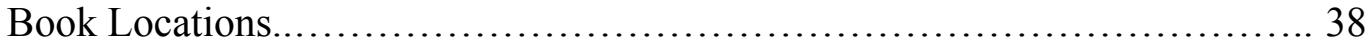

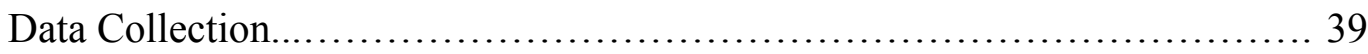

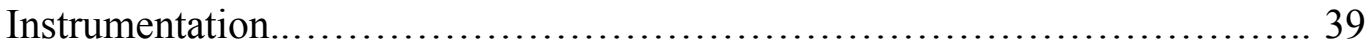

Analysis of the Books..................................................... 41

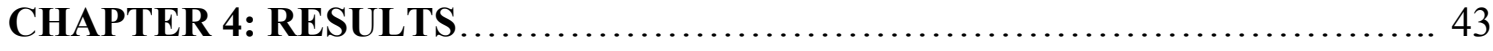

Research Question 1................................................ 43

Contemporary Literature that has Protagonists with $\mathrm{CD} \ldots \ldots \ldots \ldots \ldots \ldots \ldots . \ldots . \ldots 43$

Protagonists, Genres, and Settings.................................... 45

Protagonists/Personal Characteristics............................... 49

Genres............................................................. 49 
Settings.............................................................. 50

Types of Communication Disorders.................................. 51

Speech Disorders................................................ 52

Fluency Disorders......................................... 52

Articulation Disorders............................................. 60

Language Disorders............................................. 64

Pragmatic and Semantic Language Disorders................... 65

Synopsis of Protagonists with ASD .............................. 66

Eye Contact.................................................. 68

Facial Expressions/Body Language........................... 70

Mutism............................................................... 72

Hearing Disorders.............................................. 78

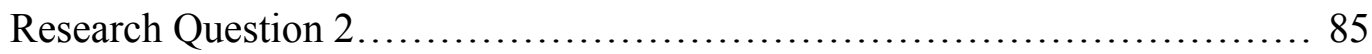

Personal Portrayal................................................... 88

Accuracy, Character Development, Interests/Strengths............ 89

Realism..................................................... 90

Low-Scoring Areas in Personal Portrayal.......................... 91

Emphasizing Similarities..................................... 92

Non-Discriminatory Language..................................... 94

Social Interactions............................................. 98

Reciprocal Relationships...................................... 99

Acceptance....................................................... 100 
Promote Empathy .......................................... 101

Social Contributions....................................... 102

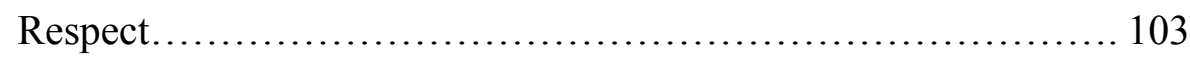

Various Relationships..................................... 104

Primary Relationships......................................... 106

Victim, Perpetrator, Protector, and/or Initiator................... 108

Dependent, Caregiver......................................... 110

Pupil, Instructor............................................... 111

Fear of Association............................................. 113

Feelings of Guilt............................................ 114

Changes with Character without Disabilities..................... 116

Exemplary Practices........................................... 118

Full Citizenship............................................... 119

Receiving Appropriate Services............................... 119

Valued Occupation........................................... 121

Self-Determination.......................................... 121

Sibling Relationships......................................... 122

Impact of CD on Plot............................................ 124

Appropriate Growth....................................... 125

Focus of the Book ......................................... 125

Additional Information Provided............................... 126

Model Strategies................................................ 127 


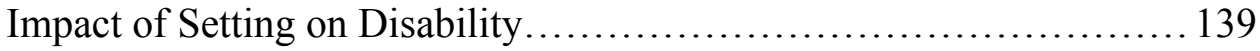

Attitudes and Practices Congruent with Era.................... 140

Story Setting Affects the Life of Character(s) with CD............ 143

Point of View............................................ 143

POV Realistically Told by Character with CD................. 144

POV Realistically Told by Character without CD.............. 145

Illustrations................................................. 145

Portrayal of Characteristics of Disabilities..................... 148

Portrayal of Technology................................. 150

Interpretation of Story .................................. 150

Appropriate Style.................................... 152

Enhancement of Literary Elements....................... 153

Quality Art......................................... 155

Artistic Usage of Various Art Elements..................... 157

Appealing Layout and Design............................ 159

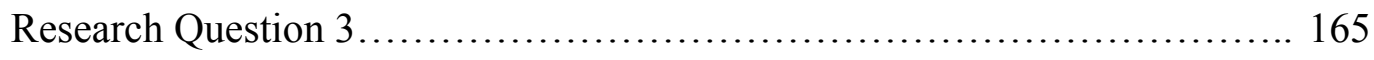

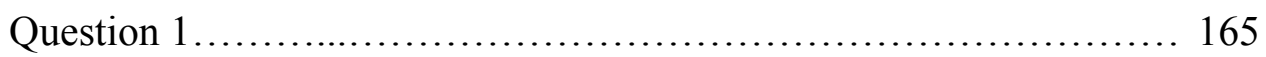

Personal Portrayals......................................... 168

Social Interactions.................................... 169

Various Relationships................................. 170

Exemplary Practices.................................... 173

Sibling Relationships.................................. 173 
Impact of CD on Plot..................................... 175

Impact of Setting on Communication Disorder................. 176

Point of View............................................. 177

Illustrations.............................................. 178

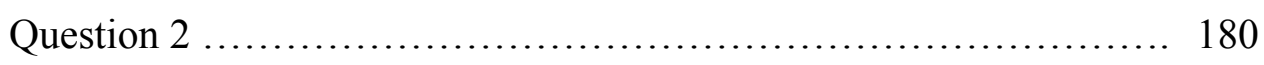

Personal Portrayals.......................................... 182

Social Interactions.......................................... 183

Various Relationships........................................ 184

Exemplary Practices....................................... 187

Sibling Relationships...................................... 188

Impact of CD on Plot......................................... 189

Impact of Setting on Communication Disorder................. 191

Point of View ............................................... 192

Illustrations................................................. 193

CHAPTER 5: DISCUSSION ............................................. 195

Research Question 1............................................. 195

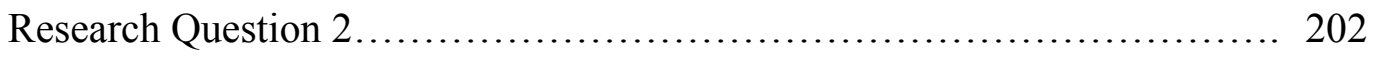

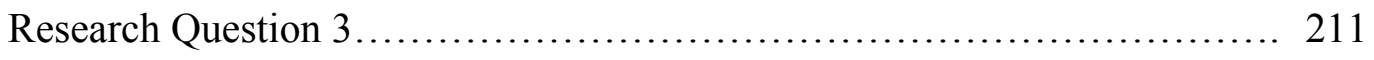

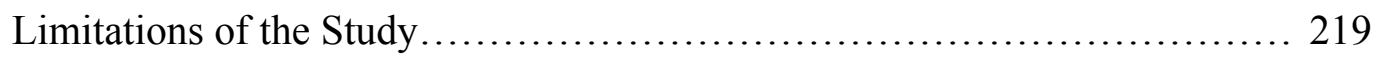

Implications for Teaching ............................................ 220

Future Research................................................ 221

Conclusion.......................................................... 222 
REFERENCES........................................................... 226

\section{APPENDICES}

Appendix A: Rating Scale for Quality Characterization of Individuals with Communication Disorders in Children's Literature....................... 245

Appendix B: National North American Book Awards................... 250

Appendix C: List of Books by Awards Won......................... 281

Appendix D: Children's Literature Comprehensive Database (CLCD)....... 285

Appendix E: Bibliograpical/Demographic Table........................ 286

Appendix F: Authors/Illustrators Who Have Connections with Disabilities... 287

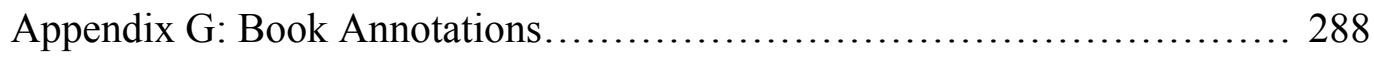




\section{LIST OF TABLES}

Table 1: Award-Winning Books with Protagonists with CDs...................... 44

Table 2: Protagonists' Personal Characteristics, Genres, \& Setting ................. 46

Table 3: Award-Winning Books with Protagonists with Speech Disorders............ 52

Table 4: Award-Winning Books with Protagonists with Language Disorders.......... 65

Table 5: Award-Winning Books with Protagonists with Hearing Disorders........... 79

Table 6: Mean Scores of Books in the Eight Categories of the Rating Scale.......... 87

Table 7: Mean Scores of Books in the Personal Portrayal Category................ 88

Table 8: Mean Scores of Books in the Social Interactions Category .................. 99

Table 9: Mean Scores of Books in the Social Interactions Category 6B............. 105

Table 10: Mean Scores of Books in the Exemplary Practices Category................ 118

Table 11: Mean Scores of Books in the Sibling Relationships Category............. 123

Table 12: Mean Scores of Books in the Impact of CD on Plot Category............ 125

Table 13: Mean Scores of Books in Impact of Setting on Disability Category......... 140

Table 14: Mean Scores of Books in the Point of View Category.................... 144

Table 15: Mean Scores of Books in the Illustrations Category $\ldots . . \ldots \ldots \ldots \ldots \ldots \ldots . . . \ldots 146$

Table 16: Authors/Illustrators Who Have Connections with Disabilities............. 166

Table 17: Mean Scores of Authors/Illustrators Who Have/Do Not Have Connections with Disabilities................................... 167

Table 18: Mean Scores of Group $1 \& 2$ in area of Personal Portrayal................ 169

Table 19: Mean Scores of Group $1 \& 2$ in area of Social Interactions .............. 170

Table 20: Mean Scores of Group $1 \& 2$ in area of Social InteractionsVarious Relationships.......................................... 172 
Table 21: Mean Scores of Group $1 \& 2$ in area of Exemplary Practices 173

Table 22: Mean Scores of Group $1 \& 2$ in area of Sibling Relationships............. 174

Table 23: Mean Scores of Group $1 \& 2$ in area of Impact of CD on Plot............ 175

Table 24: Mean Scores of Group $1 \& 2$ in area of Impact of CD on PlotFocus of Book and Provides Additional Information................... 176

Table 25: Mean Scores of Group $1 \& 2$ in area of Impact of Setting on CD......... 177

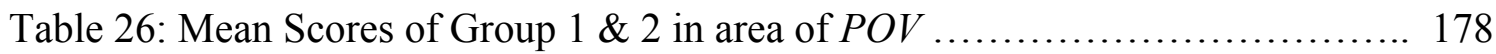

Table 27: Mean Scores of Group $1 \& 2$ in area of Illustrations.................... 179

Table 28: Books that Won Awards that Honor Disabilities....................... 180

Table 29: Mean Scores of Books that Won Awards Which Honor Disabilities \& Books that Won Awards Which Do Not Specifically Honor Disabilities...

Table 30: Mean Scores of Group $3 \& 4$ in area of Personal Portrayal............... 183

Table 31: Mean Scores of Group $3 \& 4$ in area of Social Interactions .............. 184

Table 32: Mean Scores of Group $3 \& 4$ in area of Social Interactions-

Various Relationships............................................. 186

Table 33: Mean Scores of Group $3 \& 4$ in area of Exemplary Practices.............. 187

Table 34: Mean Scores of Group $3 \& 4$ in area of Sibling Relationships............ 189

Table 35: Mean Scores of Group $3 \& 4$ in area of Impact of CD on Plot.............. 190

Table 36: Mean Scores of Group 3 \& 4 in area of Impact of CD on PlotFocus of Book and Provides Additional Information..................... 191

Table 37: Mean Scores of Group $3 \& 4$ in area of Impact of Setting on CD......... 192

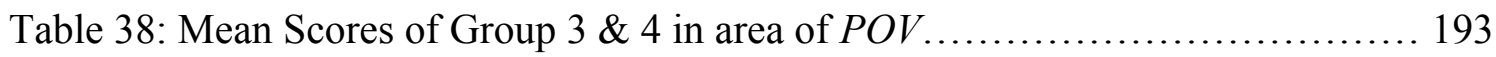

Table 39: Mean Scores of Group $3 \& 4$ in area of Illustrations.................... 194 


\section{Chapter 1 \\ Introduction}

The printed word has always had a powerful influence on society and the world. Since their conception thousands of years ago, books have been an important source in providing information to the public and influencing societal perceptions and values. Books supply avenues to explore not only thoughts and emotions about oneself, friends, family, and community, but also make available information about other places and cultures in the present, past, and even possible future. Almost all individuals can remember a book that has really moved them and/or that has changed their view or even their life in some way. The influential capability of literary genre is found not only within adult books, but also in children's and young adult literature. Langer (2010) communicates the important role of books and the literary experience in people's lives. She states that literature "sets the scene for us to explore both ourselves and others -- to define and redefine who we are, who we might become, and how the world might be" (p. 5). Books allow readers to attain a greater understanding of people, society, and the world in which they live.

Children's and young adult literature can play a significant role in the lives of young readers (Galda \& Cullinan, 2002). It is important for children today to be able to see themselves and the diverse population of the world around them in the books that they read (Short, 1994; Bishop, 1982, 1990; Harris, 1997; and Galda \& Cullinan, 2002). The literature needs to reflect not only the visible diversities, such as, nationality, religion, ethnicity, and social and economic status, but also the less visible or invisible population that are within our diverse world. As Carlisle (1998) observed “children's 
literature often reflects the current society's values and attitudes" (para. 1). Harris \& Baskin (1987) agree with this idea of the power of books adding that they are "a particular kind of cultural artifact" that also "have the power to inform, redirect, and shape understandings and responses" (p.188). Children's literature experts, Galda \& Cullinan (2002), also reiterate this same concept in their statement "literature never grows in a vacuum; it grows as a part of the surrounding world of thought, economics, and customs" (p. 400). This is particularly true when one looks at how people with disabilities have been portrayed during the history of children's and young adult literature. In the past children's and young adult book publishers have avoided certain issues or subject matters that society had difficulty with or that were not considered acceptable for young readers (Carlisle, 1998). The representation of individuals with disabilities in positive, non-stereotypical, and major roles in juvenile literature had been avoided until the last several decades. It is important for children to see all people portrayed in children's and young adult books, including people with disabilities. Representing children with disabilities in literature, helps not only children who have disabilities see themselves in stories, but will also provide children without disabilities a better understanding, knowledge, respect, and sensitivity of disabilities and the people who have them (Dyches \& Prater, 2000; Prater et al., 2006; Wopperer, 2011).

\section{Representation of People with Disabilities in Children's Books}

Until recently most of the people with disabilities appearing in children's and young adult literature were blind or physically disabled (Harrill, J. L. et al., 1993; Baskin \& Harris, 1977; Stroud, J. G., 1980; Goodman, J., 1985). Many times these people were 
stereotyped or minor characters in the stories. More often than not the majority of books with people with disabilities were nonfiction, rather than fiction (Baskin \& Harris, 1977). In the last three decades, the number of children with disabilities represented in children's and young adult literature has increased tremendously. This rise is due mostly to three specific litigation and legislative proceedings: (1) Brown v. Board of Education of Topeka (1954), (2) Public Law (PL) 94-142 (Public Education for All Handicapped Children, 1975), and (3) the Americans with Disabilities Act (ADA)(1990) (Heward and Cavanaugh, 1997). The landmark case of Brown v. Board of Education of Topeka challenged the legitimacy of segregating schools according to race which led the parents of children with disabilities to question the common practice of isolating or excluding their children from the public school setting. PL 94-142 (1975) mandated that all children with disabilities between the ages of three and twenty-one will receive a free and appropriate public education (FAPE) in the least restrictive environment (LRE) regardless of the type or severity of their disability. This act has not only changed drastically the lives of children with disabilities, but it has also affected special and regular education classrooms, the role of teachers, parents, students, and any personnel or people that come in contact with or are involved with children with disabilities in the public school setting. The Americans with Disabilities Act (ADA)(1990) spelled out who was considered as a person with a disability. This act expanded the civil rights protection of people with disabilities not only to all public services and public transportation, telecommunication, and accommodations, but also to the private sector of employment. Thus expanding the need for more awareness beyond the school setting and into the community. 
The changing societal perceptions and values that helped drive this new legislation and proceedings which tremendously expanded services and opportunities for individuals with disabilities, began to be reflected in children's and young adult literature. Children's authors began challenging the social norm and rejected discrimination and racism that had plagued many stories in the past. Prominent writers and/or researchers, such as, Kathy Short (1994), Rudine Sims Bishop (1982, 1990), and Violet Harris (1997) addressed the need for children's and young adult literature to include groups/cultures that had previously been considered outside of the cultural mainstream.

Kathy Short and her co-authors (1994) advocate the need for all children to have the opportunity to see themselves and their "voices" in literature as they search for their own identities. Children with and without special needs should be able to recognize characters similar to themselves represented positively in the literature that they read. Rudine Sims Bishop $(1982,1990)$ also addresses the issue of how stories can help individuals gain insight into their emerging self. This prolific writer, educator and critic states that "children need to be involved with literature which not only allows them to see through the window to the world around them, but also to see themselves mirrored in the texts with which they come into contact” (Smith (1997), p. 62). In a 1990 article entitled "Mirrors, Windows, and Sliding Doors", Bishop observes:

Literature transforms human experience and reflects it back to us, and in that reflection we can see our own lives and experiences as part of the larger human experience... When children cannot find themselves reflected in the books they read, or when the images they see are distorted, negative, or laughable, they learn a powerful lesson about how they are devalued in the society of which they are a part. (ix) 
In her writing and teaching on children's and multicultural literature, Violet Harris (1997) reiterates this same need for all children to see themselves truthfully in books having their own life and experiences represented correctly and without stereotypes.

\section{Rationale for Study}

The educational reform movement of diversity education has helped to bring changes to literature. Supporters of diversity have been focusing on making all groups visible in our schools and society, not just members of the dominant group. In the past less attention has been paid to non-dominant groups leading many times to stereotypes and negative images (Erickson, 1997; Rochman, 1993; Stephan \& Stephan, 2004). By representing our pluralistic society in our literature, students can begin to legitimate and celebrate their experiences and images of themselves. Exposing students to diversity experiences and literature, aids them in making connections with and learning to value other people. Seeing and hearing a variety of perspectives and diverse voices will help them clarify their concepts and understand the culturally pluralistic world in which they live (Galda \& Cullinan, 2002; Norton \& Norton, 2010).

According to the 2010 U. S. Census Bureau, about $18.7 \%$ or 56.7 million Americans of all ages were reported as having a disability. This comes to about one of every five residents in the United States having some type of disability (Brault, 2012). Disabilities do not discriminate and are found to cut across many different lines of identity such as race, age, gender, ethnicity, social class, etc. Among the most familiar of disabilities in the United States is communication disorders (CD) according to the American Speech-Language Hearing Association (ASHA, n.d., Incidence 2008, para. 1). The prevalence of Americans with a CD is believed to be between 5-10\% (Ruben, 2000). 
Estimates of this figure vary depending on the various definitions of communication, speech, and language disorders being used by investigators.

With at least thirteen percent of all of today's school age children having disabilities (U.S. Department of Education, National Center for Educational Statistics (2012, Table 46)) and spending all or a large portion of their school day in the inclusive classroom, it is becoming increasingly important to have inclusive literature that not only reflect these changing school demographics, but also the evolving societal perceptions and accommodations for individuals with disabilities that are occurring. Books have the power to educate, inform, and provide rich experiences for individuals with and without disabilities to learn more about themselves and others. Both children with disabilities and those who do not have disabilities need children's and young adult literature that have main characters, who have disabilities. Inclusive literature that has multi-dimensional characters with disabilities can increasingly play significant roles in the classroom and curriculum in many ways, such as, challenging stereotypical perceptions of what is "normal", accepting individuals as who they are, respecting all people as equal human beings, and developing sensitivity to the needs of all people (Wopperer, 2011; Hollander, 2004).

Books can provide a "mirror" for children with disabilities to see themselves positively and accurately portrayed both personally and socially in the world. Children who do not have disabilities need to experience disabilities fresh and authentically so that they can be more informed about children with special needs with whom they will be interacting (Sapon-Sevin, 1982; Friedberg, Mullins, and Sukiennik, 1985). Allowing children to satisfy their curiosities and fears of the unknown about disabilities safely and vicariously (Prater, 2003) through well-written literature will help foster understanding 
and uncover the fact that there are more human commonalities than differences between people with and without disabilities. Children are not born with prejudices or stereotypical views. If many of the traditional boundaries about disabilities can be eradicated, children with and without disabilities will begin to become aware that they are more similar than different from others. Children's and young adult literature need to responsibly represent people with disabilities in text.

\section{Statement of the Problem}

CDs are one of the highest incidences of disabilities found in school age children. According to the 2009-10 statistics compiled by the US Department of Education of all children and youth receiving services under IDEA, the area of speech or language (communication) disorders is the second most prevalent type of disability $(21.8 \%)$ found in schools with only specific learning disabilities (37.5\%) being higher (U.S. Department of Education, Table 46). With $86.3 \%$ of children with this disability attending the regular/general classroom at least $80 \%$ of the time, more research is needed in the area of CDs and children's and young adult literature (U.S. Department of Education, Table 47).

In children's literature researchers have explored the portrayal of characters with many specific disabilities that could contribute to CD, i.e., deafness (Batson, 1980; Brittain, 2004; Pajka-West, 2007; Golos \& Moses, 2011; Golos, Moses \& Wolbers, 2012), stuttering (Bushey \& Martin, 1988; Logan, Mullins, \& Jones, 2008), emotional disorders (Stroud, 1981), autism/mental retardation/developmental disabilities (Stroud, 1980; Hirshberg, 1982; Sapon-Shevin, 1982; Orr et al., 1997; Prater, 1999; Dyches \& Prater, 2000; Dyches, Prater, \& Cramer, 2001; Christensen, 2001; Mills, 2002; Heim, 2005; Dyches \& Prater, 2005; Dyches, Prater \& Leininger, 2009), physical disabilities 
(Stroud, 1980; Kraus, 1981; Goldman, 1990), and cognitive disabilities (Wagoner, 1984).

Relatively little has been written about the depiction of CDs per se and the portrayal of characters with CDs in contemporary juvenile fiction (Tatelbaum, 1984; Sotto \& Ball, 2006). Furthermore, only one of these bibliographic reviews and resources focused on main characters/protagonists with CDs (Sotto \& Ball, 2006). Also no studies were found that exclusively featured higher reading levels in children's and young adult books that had characters with CDs.

Even though some of the research focused on the portrayal of characters with disabilities in distinguished children's books that were awarded the Randolph Caldecott or the Newbery Honor or Medal (Dyches, Prater, \& Jenson, 2006; Leininger, Dyches, Prater, \& Heath, 2010), none of the reviews/researches were specific to award-winning literature with characters with CDs. The focus of this study was award-winning intermediate children's and young adult fictional books with protagonists who have a CD. This selected quality literature for intermediate children's and young adults was evaluated using a systematic content analysis examination. Identifying and analyzing these books will help provide valuable information to educators, clinicians, librarians, parents, and readers about the depiction of CDs and characters with CDs in contemporary intermediate children's and young adult literature.

\section{Purposes of Study}

There were three major purposes of this study. The first main objective was to find to what extent individuals with CDs were portrayed in award-winning contemporary intermediate children's and young adult fiction. Such issues as role (protagonist/central/ supporting) of the character with the $\mathrm{CD}$ and nature and/or type of $\mathrm{CD}$ represented were 
explored in this genre of books. The second significant area investigated was to measure specific aspects of the portrayal of protagonists with CDs in the selected award-winning intermediate children's and young adult literature from 2000-2012 by utilizing a Rating Scale for Quality Characterization of Individuals with CDs in Children's Literature (see Appendix A). The rating scale used was a modification of Dyches' \& Prater's (2000) Rating Scale for Quality Characterizations of Individuals with Disabilities in Children's Literature. Implementing content analysis on the identified books, the rating scale additionally evaluated not only authors' characterization of these main characters, impact of the various CDs, and the quality of their social interactions and relationships, but also literary elements, such as, literary quality, illustrations, point of view, and setting. Modeling strategies used by protagonists to deal with the CDs was an additional question that had been added in the rating scale. The third and final purpose of this study was to examine the associations/implications/connections that existed between the roles of the authors and reviewers and the scores/evaluations/external evaluations of the books that highlighted CDs in children's and young adult literature. This objective compared the scores of the Rating Scale for Quality Characterization of Individuals with CDs in Children's Literature between literature that won children's and young adult book awards that were created specifically to honor the portrayal of individuals with disabilities (e.g. The Dolly Gray Children's Literature and the Schneider Family Book Awards) with those that were not. Another aspect of this third objective investigated not only whether a personal connection to a disability/CD exists with any authors/illustrators, but also did this connection affect the scoring on the Rating Scale for Quality Characterization of Individuals with CDs in Children's Literature. 


\section{Statement of Research Questions}

Formulated from the purpose of the study, the research questions investigated were:

1. To what extent are individuals with CDs portrayed in award winning intermediate children's and young adult literature?

(a) What 2000-2012 award-winning intermediate children's and young adult literature exists that have protagonists who have CDs?

(b) What types of CDs (e.g., speech, voice, language, hearing impairments) in children's and young adult literature are found in these award-winning books?

2. How are protagonists with CDs portrayed in the selected award-winning children's and young adult literature from 2000-2012 as measured by the Rating Scale for Quality Characterization of Individuals with CDs in Children's Literature?

(a) How were the protagonists portrayed in the sections of the scale including (i) personal portrayal, (ii) social interactions, (iii) exemplary practices, (iv) sibling relationships, (v) impact of CD on plot, (vi) impact of setting on disability, (vii) point of view, and (viii) illustrations?

(b) When the CD is integral to the plot, to what extent does the character with the disability model strategies for solving challenges presented by the disability?

3. What associations/implications/connections exists between the roles of the authors and reviewers and the scores/evaluations/external evaluations of these selected awardwinning books that highlighting $\mathrm{CD}$ in children's literature? 
(a) What if any connections to CDs (e.g., individual with a CD, family member, special education teachers, speech- language pathologists) do authors/illustrators of these books have and is there a relationship between an author's/illustrator's connection to disability and score on the Rating Scale for Quality Characterization of Individuals with CDs in Children's Literature?

(b) What if any differences exist in the portrayal of protagonists with CDs between children's and young adult book awards that were created specifically to honor the portrayal of individuals with disabilities (e.g., The Dolly Gray Children's Literature and the Schneider Family Book Awards) with those that were not?

\section{Justification for the Study}

This empirical research helps fill a gap in the research of identifying and analyzing the portrayal of characters in contemporary children's and young adult literature with disabilities by not only focusing on the specific area of active and dynamic main characters with CDs, but also by narrowing the research to contemporary intermediate children's and young adult literature that have won awards. Individuals with CDs have trouble talking and expressing their thoughts and opinions. However, they do have something to say and to communicate to others. It was important to find and evaluate the portrayal of this population in award-winning children's and young adult literature and to finally "hear" what characters with CDs have to say and to know more about what they feel, think, and experience. 


\section{Definitions}

The term communication disorder encompasses a wide range of problems that deal with the processes of speech, language and/or hearing. According to the American Speech-Language-Hearing Association (ASHA) a "CD is an impairment in the ability to receive, send, process, and comprehend concepts or verbal, nonverbal and graphic symbol systems" (ASHA, 1993, para. 2). A CD would include such impairments as articulation problems, fluency difficulties (stuttering, cluttering), aphasia, mutism, and voice disorders. Other conditions or secondary disabilities can also contribute to CDs, such as, autism, cerebral palsy, cleft lip or palate, hearing loss, auditory processing disorder, mentally impaired, or learning disabilities.

CDs may also range in severity and time of onset. The spectrum of severity can run anywhere between being a mild to a profound disorder. The disorder can be a developmental and/or an acquired one that happens at some time in an individual's life, such as, by an illness or accident (ASHA, 1993).

The term children's or juvenile literature has a variety of definitions and age ranges depending on sources examined. The American Library Association (ALA) defines 'children's literature' as "the body of books published for an intended and potential child audience" (ALA (2008), Terms \& Criteria, para. 5). Others extend the definition to include not only anything written for and/or read by this particular audience, but also any literature that this group "enjoys and has made their own” (Galda \& Cullinan, 2002, p.8). Utilizing this definition the term 'children' must still be defined in literature context. Some experts have a broad definition for children's literature defining it as books for individuals from birth through eighteen. Others have narrowed or split the 
genre of children's literature into two groups -- children's and young adult literature.

These two groups are also hard to define and often overlap in ages. For example, the American Library Association (ALA) gives age range for the area of children's books as birth through fourteen and young adult as twelve through eighteen (ALA (2008), Terms \& Criteria, para. 5; ALA (n.d., About YALSA: Our Mission, para. 1).

Book/reading levels can be categorized by several methods in juvenile literature. One style of classification used by the International Reading Association (IRA) for their book awards are the categories of primary, intermediate, and young adult (IRA, para. 1). In this study, books that are analyzed will fall into the upper two mentioned categories of intermediate and young adult literature. The grade and age levels of these upper level categories are more approximate and flexible having broader audiences than the lower categories. The intermediate classification applies to books that are interesting to middle school readers and/or grades 4-6 (approximate ages 9-12). These books will fluctuate more in their level of difficulty. The age at which readers are ready for the more complex intermediate stories will also vary. The category of young adult is geared for even older readers and deals with more mature issues in their text. The age range for young adult is approximately 12 and up and is for students in the secondary grades. Even though intermediate readers or adults might enjoy these books, they are written and marketed to young adults. Typically young adult books have a teenager (young adult) protagonist.

Characters have different roles in literature. At one end of the spectrum may be a central, major, or main figure. Another term used for the main character is protagonist. Readers usually identify and root for this character seeing the world through his/her eyes. The protagonist is at the center of the story and becomes the "hero" of the literary work. 
These characters are multidimensional/rounded individuals that have been developed by the author by their descriptions, actions, and narrations by or about them. They are dynamic characters that change and grow over the course of the story (Russell, 2005). 


\section{Chapter 2 \\ Literature Review}

\section{Introduction}

Since social, political, and economic conditions played a heavy role in influencing the direction children's literature took, it was awhile before children with disabilities began to be present in children's literature. The growth of representation of children with disabilities in children's and young adult literature has been tremendous the last thirty years. The number of children's books with characters who have disabilities is not as important as the quality of this literature. As with all children's literature, this genre of books needs to have high standards in regards not only to representation of accuracy of individuals with disabilities, but also to quality of writing and its utilization of literary elements, such as, characterization, theme, setting, and plot (Dyches \& Prater, 2000; Norton, 2010; Sawyer, 2000; Prater et al., 2006). Even in fiction, authors have the responsibility to portray individuals with disabilities realistically. This includes not only the disability itself, but also the lives of people with disabilities, their environments, feelings and emotions toward themselves and individuals they interact with (Carlisle, 1998).

The review of the literature pertaining to the portrayal of protagonists with CDs in intermediate children's and young adults literature is divided into the following two categories: 1) Literature Portrayal of Characters with Disabilities in Children's Literature, and 2) Children's and Young Adult Book Awards. The initial section of the literature review concentrated on studies of children's literature that portrayed characters with 
disabilities. To provide a brief historical overview and to investigate other literature and empirical studies on the topic, this segment is broken down further into the following areas dealing with the portrayal of characters with disabilities in children's literature: (a) general literature investigation, (b) studies over a period of time and/or around the specific historical event of PL 94-142, (c) studies about specific disabilities, (d) studies with award-winning children's books, and (e) studies with CDs. The second part of the review focused on literature about children's and young adult book awards. Topics addressed are: (a) significance of awards, (b) types of awards, and (c) major American children's and young adult awards.

\section{Portrayal of Characters with Disabilities in Children's Literature}

Introduction. Over the last thirty-five years, researchers have been examining various trends and changes in the representation of characters with disabilities in children's and young adult literature. Multiple facets on this subject have been explored, such as, specific types of disabilities, gender and ethnic representation, frequency of representation of individuals with disabilities, stereotypical portrayal in literature, representation before and after PL 94-142, and literary quality of children's and young adults literature that have characters with disabilities. As Baskin \& Harris (1977) point out the number of character with disabilities in children's books has been rising since World War II. While the earliest children's literature in the late $18^{\text {th }}-19^{\text {th }}$ century took more of a Puritan didactic approach when it came to story plots, by the early and mid $20^{\text {th }}$ century many juvenile fiction were portraying more nostalgic, carefree and happy 
childhoods and staying away from topics and personal/social issues that did not agree with this protective attitude. With the onset of the World War II, children's literature dismissed with the always "happily ever after" censored story plots and began including previously unapproachable topics like: divorce, death, discrimination, institutionalization and disabilities (p.39-43). Another boom period in the market for this genre of book that these two authors discovered was the 1960s. Many areas of raised public consciousness existed during this decade. As awareness was raised and advocates became more vocal, society began addressing the issue of disability more (Baskin \& Harris, 1977; Carlisle, 1998). Kraus (1981) also noted societal changing perspective in the late 1960s with the increase representation in young adult literature of not only disabilities, but other topics as well, such as, racial conflict, sex, and drugs. PL 94-142, which increased the number of children with disabilities in public schools, was also a major facilitator in the upsurge of portrayal of disabilities in children's and young adults literature (Landrum, n.d.; Baskin \& Harris, 1977; Carlisle, 1998; Sokolski, 1985). As more and more authors tackled this topic, a greater consciousness emerged and researchers began a closer analysis of how literature and other media addressed disability.

General literature investigation. Two early extensive and definitive studies in the area of children's literature portraying characters with disabilities were conducted by Baskin and Harris in their books, Notes from a Different Drummer (1977) and More Notes from a Different Drummer (1984). In their first volume, the authors provided an in depth comprehensive guide with their chronicle of 311 relevant children's fiction books published between 1940 and 1975 which contained character with disabilities. Notes from a Different Drummer examined historically the portrayal of characters with disabilities parallel to societal responses and attitudes toward individuals with disabilities. Reflected 
in the literature, they found stilted, stereotypical treatment of individuals with disabilities, such as, romanticization, pity, avoidance patterns, patronization, spread of severity and limitations of one disability to another, and use of disabilities in figurative or humorous expressions. In their selected compendium of analyzed annotated bibliography and guidelines, Baskin and Harris paid close attention to many details and depictions of character and their disabilities, such as, literary quality, character development, beliefs and attitudes toward individuals with disabilities, roles assigned to the character with a disability, architecture of the story, and accuracy. Notes from a Different Drummer provided the building block for further investigations with its qualitative and quantitative analysis and identification of core themes, patterns, and trends.

In More Notes from a Different Drummer (1984), Baskin and Harris continued their "historic, cultural, and literary" analysis of juvenile fiction books depicting characters with disabilities by extending their research to include the years 1976-1981 (Baskin \& Harris, 1977, p. x). While only 311 books had been identified in this genre in the first 36 years period of their research, in the next six years period of the second volume, 348 books were found to meet the identical criteria.

Literature portrayal of disabilities over time. After the initial investigations by Baskin \& Harris of characters with disabilities in children's and young adult books, several researchers have continued examining the topic of disabilities in general and over different spans of time (Ayala, 1999; Carlisle, 1998; Little, 1986). Other investigators have chosen to center their studies on the effect of disabilities representation in children's literature based around the specific historical event of the passing and/or implementation 
of PL 94-142 (Harrill et al., 1993; Sokolski, 1985). The general area of disabilities in children's and young adult literature has been broken down by researchers into many specific disability areas, such as, deafness, visually impaired, autism, physically disabled, learning disabled, stuttering, etc.

Empirical studies of disabilities over time. Ayala's empirical study in 1999 analyzed both fictional and nonfictional children's books that were published between 1974 and 1996. In the 59 books for younger readers, the research showed that diversity of disabilities was being portrayed, even though orthopedic impairments was overrepresented and the most prevalent disability in the books examined. Caucasian characters with disabilities continued to be portrayed the most, with only a few books including other ethnicities and little if any emphasis was found for "specific cultural practices" (Ayala, 1999, p. 103). However, few of the books showed the characters with disabilities as victims or social outcasts. A variety of settings were represented not only in schools, but also in other areas as well, such as, the home and leisure activities (Ayala, 1999).

Another early empirical study exists where researchers analyzed contemporary characterization of disabilities in children's and adolescent books. In this research study, Harrill et al. (1993) wanted to see if PL 94-142 had any effect on the portrayal of characters with disabilities in children's literature. Utilizing a predetermined set of criteria, teachers rated 45 randomly selecting children's literature with characters with disabilities. Fifteen of the books had been published before PL 94-142, while 30 books 
were written after the new legislation had past and had begun to be implemented (1978). The empirical research showed that not only did the number of characters who had disabilities increased in the post-1978 children's literature, but the variety of disabilities represented also broadened. Also encouraging with the second set of books was that less stereotyping of characters with disabilities occurred and more appropriate and politically correct medical terminology was utilized (Harrill et al., 1993).

Types of disabilities portrayed. Most research shows that before the passage of PL 94-142, the disabilities with the highest frequencies of representation in children and young adult literature were blindness or visually impaired, followed by physical or orthopedic disabilities (Baskin \& Harris, 1977; Harrill et al., 1993; Stroud, 1980; Goodman, 1985). In the 1940s and 1950s, the number of children's and young adult books with characters with disabilities was dramatically increasing. The disabilities that were most popular to depict were poliomyelitis and blindness that were easily depicted/ recognized. After 1975, these two types of disabilities were still the most prevalent in children's and young adult literature with characters with disabilities. Physical disabilities, however, took top billing over blindness now (Baskin \& Harris, 1984; Harrill et al., 1993; Sokolski, 1985).

At this time with the passage of PL 94-142 the frequency of other disabilities in children's literature increased as the number of books with portrayal of characters with disabilities tremendously increased. Some of these disabilities had been mentioned infrequently in the past while others were making their first appearance in children's 
literature. The areas that were beginning to be portrayed more often were: learning disabilities, autism, paralysis, hearing impairment, deafness, amputees, asthma, cerebral palsy, cleft palates, epilepsy, homosexuality, language disabilities, speech impairments, cancer and attention deficit disorder (Baskin \& Harris, 1984; Carlisle, 1998; Friedberg et al., 1985). Two areas that tremendously increased in prevalence in the literature were “emotionally disturbed" and "mentally retarded" (Baskin \& Harris, 1984; Stroud, 1980). The incidence of characters with poliomyelitis decreased over the years as the disease became less common (Baskin \& Harris, 1984).

Empirical studies of specific disabilities. Two researchers in particular have conducted several empirical studies in the area of children's literature involving characters that have disabilities. Dyches and/or Prater have examined the portrayal of characters with specific disabilities, such as, mental retardation, mental retardation \& autism, learning disabilities and developmental disorders (Prater, 1999; Dyches et al., 2001; Prater, 2003; Dyches \& Prater, 2005, Dyches et al., 2009). These researchers also explored the portrayal of characters with disabilities in the prestigious Newbery and Caldecott Medal awards (Dyches et al., 2006; Leininger et al., 2010).

In her earliest empirical study (1999), Prater reviewed 68 children's and young adults books that included characters with mental retardation, which were published during a thirty-one year period from 1965 through 1996. Special attention was paid to the depiction of the characters with the disability in relationship to their role, character development, and narrative point of view. Even though the tone and depictions of the 
characters with mental retardation was generally positive, Prater found that few narratives were written from the perspective of the characters with mental retardation (13\%). Characters with mental retardation generally were static (54\%), but believable, in their development in the story and only had supporting roles (61\%). The study discovered that action rarely occurred in a school setting, but when they did it was most often in segregated as opposed to inclusive classroom. Teachers are seldom depicted, however, when they are present they are generally positively portrayed (Prater, 1999).

In 2001, Dyches, Prater, and Cramer, conducted a similar study involving all children's books published during the two years of 1997 and 1998 that portrayed characters with mental retardation and autism. Twelve books that met the researchers' qualifications were evaluated using Dyches \& Prater Guidelines, 2000. As in the previous study, in these books only a few of the stories were told from the point of view of the character that had the disability. However, this study did differ from the earlier one conducted by Prater in that the majority of depicted characters with mental retardation and autism were educated now in more inclusive educational settings. The characters in this more recent study also were allowed to make more independent choices in their lives and were portrayed more realistically (Dyches et al., 2001).

Building upon similar framework of the two previous empirical studies, Prater (2003) next analyzed the portrayal of characters with learning disabilities (LD) in children's and young adult fiction. Ninety books that met the criteria were evaluated to examine how various authors represented not only characters with the disability, but also 
LD itself, the impact of the disability, and other related LD issues. The majority $(75.3 \%)$ of characters with LD were main characters and dynamic (91.8). Many of the stories are written from the character with LD point of view (58.9). The LD itself played a major part in $52.2 \%$ of the books. Several of the characters with LD exhibited some form of a learning, motor, social or artistic strength, which manifested itself by excelling at certain skills, such as, math, athletics, and the arts. In this study, Prater also found that individuals with LD usually were pulled out of class to receive services in a resource room (Prater, 2003).

In 2005, Dyches and Prater reexamined the area of portrayal of characters with developmental disabilities (DD) in children's literature. Using the same guidelines as before (Dyches and Prater Guidelines, 2000), these two researchers explored the evolution of characterizations of DD by comparing their new results from 34 eligible children's literature published from 1999-2003 to those of an earlier study (Dyches, Prater, \& Cramer, 2001) which analyzed eligible books published from 1997-1998. The comparison showed that the more current fictional children's books generally portrayed individuals with DD in increased positive ways, such as, being more realistic and dynamic, making choices, and maintaining meaningful relations with their peers. On the negative side, the study found a great increase and an overrepresentation of the usually low incidence of autism spectrum disorders (ASD) in the number of characters with this disability (Dyches \& Prater, 2005).

Four years later, Dyches, Prater, and Leininger (2009) returned to this topic to continue their investigation of quality juvenile literature and the portrayal of developmental 
disabilities. In this fourth study, 41 children's and young adult books published between 2004 and 2007were analyzed that met the requirements for eligibility for the Dolly Gray Children's Literature Awards. The evaluation guidelines for this research and the Dolly Gray Children's Literature Award are adaptations based upon Dyches et al. (2001) guidelines. Qualitative, descriptive data from this study were compared with the results of the earlier 2001 and 2005 research studies. The comparisons showed that not only had the number of children's books published with characters with DDs increased, but a rise also existed in representing more culturally diverse and multidimensional characters with DDs. The study revealed a growth in positive portrayals with characters having more selfdetermination, participating in more inclusionary recreational activities and being involved in more teaching and caregiving roles. There still existed an overrepresentation of ASD in the books based on the U.S. school-based data. The researchers found that the trend of these books were progressing toward the recommendations made to authors in their previous 2005 study.

Disabilities and award-winning children's books. Finding no studies that analyzed characters with disabilities in the highly recognized Caldecott Medal and Honor Books, Dyches, Prater, and Jenson (2006) examined the number and portrayal of significant characters in these award-winning picture books. Even though between 1938 and 2005, 276 books had won the Caldecott Medal or Honor Books awards, only 11 books (4\%) had a prominent character with a disability. The researchers also found that several of the award-winning picture books that depicted disabilities were folk tales or had animal or toy characters that had disabilities. Only two of the books had characters 
with disabilities that were children. A majority of the time, characters with disabilities were not typical people that young readers would interact with in their community or school. Another discrepancy discovered about disabilities in these books was that most of the types of disabilities represented were low incident disabilities, like autism, orthopedic impairments, and visual impairments. The only high incident disability portrayed in one of the books was mental retardation. The two disabilities that have the highest incidences rates in public schools, i.e., specific learning disabilities or speech and language impairments, were not even represented in these books. Further some of the literature included unrealistic and inaccurate representations of characters with disabilities, such as, miraculous cures or temporary conditions (Dyches et al., 2006).

In 2010, Leininger, Dyches, Prater, and Heath examined the portrayal of characters with disabilities in the prestigious Newbery Medal and Honor books awarded from 1975-2009. The time period for this study starts in 1975 after the passage of PL 94-142. Leininger et al. found that $24 \%$ of the 131 eligible books contained either main or supporting characters with disabilities. Mental retardation, orthopedic impairment, autism, and multiple disabilities are the most depicted disabilities of schoolage children found in the Newbery books. The researchers discovered that the two highest incidence occurring disabilities in school population students receiving special education services, specific learning disabilities (SLD; 46\%) and speech or language impairment (SLI; 19\%), were significantly disproportional in this award-winning literature. In the Newbery books only $8 \%$ of the characters with disabilities were 
portrayed with SLD and only 4\% with SLI. Other negative results of this study depicting characters with disabilities were that the majority only had supporting roles and often were facilitators to the growth and development of characters without disabilities. In several instances characters with disabilities were either killed off or removed from their homes. Like in the Caldecott books, some characters were unrealistically and miraculously cured. Additionally only a few stories were told from the point of view of the character with the disability. Overall, however, the depiction of characters with disabilities in Newbery books was generally positive, especially when it came to personal portrayals, exemplary practices, and social interactions (Leininger et al., 2010).

CDs studies. Two contemporary studies explore the portrayal of characters with disabilities in children's literature whose primary disability is CDs. Logan et al. (2008) examined the portrayal of stuttering in 29 contemporary juvenile fictional literature to consider whether their potential usefulness as instructional tools in selected intervention, educational, and public-awareness activities by speech-language pathologists and other professionals. In the books selected for the study, the majority of the stories were contemporary realistic fiction with the ages of the characters that stuttered ranging from approximately 6 to 17 years old. The researchers found that even though many of the characters that stuttered were portrayed initially as being unhappy, unsure and isolated, the characterizations were dynamic and growth occurred during the plot with improvements in their communication and/or social skills. Other skills and/or achievements frequently were associated with these characters counterbalancing their CD (Logan et al., 2008). 
Another positive note was that stuttering was often depicted as just one of several developmental, emotional, moral or social challenges that affected the daily lives of characters that stuttered and was not the only focus of the stories. Related stuttering topics, such as, bullying, impatience, ridicule and teasing were portrayed in the majority of the books. Even though a few of the books had some inaccuracies and distortions, overall Logan et al. found that the books were accurate and descriptive enough to be valuable informational tools. The researchers came to the conclusion that not only can the books increase public knowledge of stuttering for individuals without the disability, but they can also be utilized in clinical activities to help build knowledge about the disorder, increase self-disclosure, validate experiences and reduce sensitivity, reframing thoughts and modifying behaviors (Logan et al., 2008).

Sotto \& Ball (2006) also examined in contemporary children's literature the portrayal of characters with CDs and how these books can be used as instructional tools. The purpose of their study was two-fold: 1) to provide a recommended list of quality contemporary children's books with dynamic main characters who have CDs that can be utilized in the general education curriculum and 2) to furnish suggestions to teachers on how to use children's literature to provide positive role models for individuals with CDs and broaden understanding and recognition of diversity in a global society. These researchers focused their study on literature that had the following criteria: 1) published between 1994 and 2001,2) reading levels of preschool to eighth grade (ages 4-14 years old), and 3) main character with speech, language or hearing disorders. Dyslexia, a 
written language disorder, was included in this study as a type of CD. Sotto \& Ball found eighteen books that met their criteria. Dynamic characters were judged as those that "were able to participate in an adventure, interact with others, and show personal growth regardless of their disability" (p.42). The researchers did not want individuals with CDs to identify with characters that were static or weak, but characters that were capable and resourceful problem solvers, heroes, protectors, etc. that could be positive role models who provided hope and raised self-esteem (Sotto \& Ball, 2006).

\section{Book Awards}

Significance of awards. Book awards are an important way to recognize outstanding books in all literature, including the genre of children's and young adult books. In 1212 alone, over thirty two thousand new juvenile book titles and editions were projected to be published in the United States according to Bowker, the global leader in bibliographic information and the official United States ISBN Agency (R. R. Bowker, n.d.). In this enormous ever-growing children's book market, it would be hard to read every new book that publishers released. Since award-winning books are considered to be quality literature for children (Aaron, n.d.), book awards can help greatly in narrowing down the vast number of choices available in contemporary children's and young adult literature.

Professionals and the public have come to rely on these exemplary qualities and the accessibility of award-winning books. These books appeal to children and more often than not become classics (Leininger, 2010; Hill, White, \& Brodie, 2001). Four reasons 
listed by Melissa Leininger (2010) to the importance of children's and young adult book awards are:

1) They represent quality and trusted literature and illustrations (Ouzts, Taylor, \& Taylor, 2003; Storey, 1990).

2) Award-winning books are located on library shelves in most schools and easily accessible (Dyches, Prater, \& Jenson, 2006).

3) Educators are encouraged to use these books in the classroom and are also more familiar with them (Ouzts et al., 2003; Prater, 2000; Richardson \& Miller, 1997).

4) Award-winning books are books that get published by well-known publishing companies and stay in circulation longer (Hill et al., 2001).

Children's book awards aid not only librarians, educators, parents and young readers in choosing quality books to purchase, use in the classroom, and/or read, but they also benefit writers, illustrators, and publishers. The recognized outstanding writing and illustrations of award-winning children's authors and illustrators aid in setting standards for others in the field to strive to obtain (Marks, 2006).

Types of book awards. Many book awards exist today that recognize excellence in children's and young adult literature. The number and variety of awards continues to grow yearly. Created in 1922, the Newbery Medal Award was the first children's literature award. This award honors the author that has made the "most distinguished contribution to American literature for children" (ALA, Newbery, para. 1). Soon to follow 
in 1938 was the Caldecott Medal award, which honors the illustrator that has made the "most distinguished contribution to American literature for children" (ALA, Caldecott, para. 1). The majority of book awards, however, began after 1980 and most are based in the United States (Cullihan, 2003). Even though the awards strive for excellence they can have their own unique focus (Marks, 2006). Awards can vary by who they are presented to (writers, illustrators), who does the judging (other writers, illustrators, teachers, publishers, parents, children, organizations, professionals in specific fields, etc.), to authors/illustrators from a specific geographical region, interest groups (tolerance, religion, mystery, nature) and many other areas (Aaron, n.d.).

Major American children's book awards. Numerous outstanding book awards exist today for children and young adults. As mentioned earlier, the two most prestigious American literary awards are the John Newbery Medal and Caldecott Medal awards which are both presented by the Association for Library Service to Children (ALSC), a division of the American Library Association (ALA). The ALA also presents a variety of book awards each year in the specific area of young adult literature. Young adult books awards, such as, the Michael L. Printz and Alex Awards are given yearly by ALA's Young Adult Library Services Association (YALSA). The Michael L. Printz Award honors exemplary "literary excellence" whose target audience is young adults between the age of twelve and eighteen, while the Alex Awards honors ten adult books that have "special appeal to adolescents ages 12-18" (ALA, Printz Award, n.d., para. 1; ALA, Alex Award, n.d., para. 1). 
Two prestigious book awards that are presented to books that specifically portray characters that have disabilities are the Schneider Family Book and Dolly Gray Awards. Established in 2004, the purpose of the Schneider Family Book Award, which is also administered by ALA, is to "honor an author or illustrator for a book that embodies an artistic expression of the disability experience for child and adolescent audiences" (ALA, Schneider, n.d., para. 1). The disability may be physical, mental, or emotional and must be represented "as part of a full life, not as something to be pitied" (ALA, Schneider Manual, p. 4). Another stipulation of the award is that the character with the disability is portrayed realistically, without stereotypes, and is an integral part of the story (ALA, Schneider Manual, n.d.).

The Dolly Gray Children's Literature award recognizes “authors, illustrators, and publishers of high quality fictional and biographical children, intermediate, and young adult books that appropriately portray individuals with developmental disabilities" (CEC-DADD, n.d., Dolly Gray Award, para. 1). Given biennially every even year, fictional books and or biographies in story format are eligible if they contain either a main or supporting character with developmental disabilities (DD). Like the Printz award, the Dolly Gray award is looking for not only accurate portrayal of the disability, but also sensitivity toward the DD and a story that emphasizes "similarities, rather than differences, between characters with and without DD” (CEC-DADD, n.d., Judging Criteria, para. 6). Another main characterization criterion is that more than just the disabilities of characters are portrayed. Winners of the Dolly Gray award must include a 
character with DD who is an unique individual that has his/her own strengths, interests, and abilities (CEC-DADD, n.d., Judging Criteria). This award is made possible through the collaborative effort of the Division on Autism and Developmental Disabilities (DADD) of the Council for Exceptional Children (CEC) and the Special Needs Project, which is a distributor of books dealing with disabilities issues (CEC-DADD, n.d., Dolly Gray Award, para. 3).

As mentioned earlier, each year numerous organizations present book awards in the area of children's and young adult literature. A brief description has been given above of a few of the major American children's and young adult book awards, but many other national North American books awards have also honored contemporary children's and young adult literature portraying protagonists with CDs. A more detailed explanation of terms/definition and eligibility requirements of the Schneider Family Book and Dolly Gray Awards can be found in Appendix B. Additional awards' details, descriptions and criteria are listed in this appendix as are other various national North American book awards that have been won by books that meet the criteria for this study. In Appendix C this listing of national North American book awards won by the literature in this study is broken down further to include the various titles of these winning books, their authors, the year the award was presented, and category and/or type of award. 


\section{Chapter 3 Methodology}

This research was conducted to analyze the portrayal of protagonists with CDs in contemporary award-winning intermediate children's and young adult literature. As mentioned in the purpose of the study, not only was the extent of representation of individuals with CDs in literature being evaluated, but also other specific aspects and qualities of the identified books, such as, various literary elements, characters' relationships and modeling strategies. The research design additionally investigated two separate comparisons: 1) literature that won book awards that were created specifically to honor the portrayal of individuals with disabilities with those that were not and 2) literature in which the author/illustrator had a personal connection to a disability/CD to those with no connections. Chapter 3 presents the justification of the research design and methodology to be used, the procedure for selecting the books to be analyzed, a description of the data collection process and evaluation instrument, and the procedure for data analysis.

\section{Research Design}

This study utilized a content analysis methodology to analyze award-winning contemporary intermediate children's and young adult fictional literature that portrays protagonists with CDs. Content analysis is a means of objectively and systematically analyzing any type of written, verbal and/or visual communication messages/texts. (Downe-Wamboldt, 1992; Krippendorff, 2004; Sandelowski, 1995; Cole 1988; Berelson, 1952). This research technique has a long historical record of application in many fields 
such as, business, communication, journalism, marketing, media studies, nursing, psychology, and sociology (Neuendorf, 2002; Busch et al., 2012). Utilized now for several decades as a research method in literature and rhetoric, content analysis has many advantages over other approaches in studying both the surface and underlying messages of text and images found in children's literature. The flexibility of this unobtrusive, descriptive methodical approach allows an investigator to focus his/her analysis on specific content, such as, characters, images, relationships, interactions, plots and other literary elements. The closeness to the text allows for the possibility of extraction of a deeper understanding of data and patterns that other approaches might not be as suitable to accomplish (Robinson, 2006). As Busha and Harter (1980) point out not only can content analysis "indicate pertinent features such as comprehensiveness of coverage," but it may also reveal "the intentions, biases, prejudices, and oversights of authors, publishers, creators or other persons responsible for the content of materials" (p. 171). The adaptability of this sound and effective research design allows an investigator to prescribe a specific, preset logical procedure to aid in the identification of variables, categories, and relationships so that valid and reliable data may be inferred from the results.

\section{Procedures for Selecting the Books}

A comprehensive search was made to identify and locate all books that might be included in this study. Since CDs may be the primary or a secondary disability of an individual with a disability, a wide range of possible terminology was generated to 
optimize the search. Key words/phrases that might be effective in the systematic search are: speech disorder, speech impediment, speech impairment, communication disorder, stuttering, mutism, (s)elective mutism, deaf(ness), hearing impaired, cerebral palsy, autism, mentally impaired, mental retardation, and Asperger syndrome, along with broader terminology, such as, disabilities, handicapped, and special needs.

Sources of the titles. To begin identifying literature for the research, a preliminary list of potentially relevant books was created. The search utilized a range of resources including examining (a) standard retrospective references, (b) references/bibliographies of children's books with characters with disabilities, (c) books listed in peer-reviewed journal articles, theses, and dissertations on the subject, (d) various organizations of disabilities/CDs related websites, (e) internet book retailers and (f) internet bibliographical databases. The standard retrospective references that were reviewed were HW Wilson's Middle \& Junior High, and Senior High Core Collection; Barr's and Gillespie's Best Books for Middle \& Junior High Readers: Grades 6-9, and Best Books for High School Readers: Grades 6-9; and Bowker's Children's Books in Print. Also the following contemporary specific disability/children's literature references utilized were: Blaska's Using Children's Literature to Learn About Disabilities and Illness: For Parents and Professionals Working with Young Children; Crosetto's, Garcha's, and Horan's Disabilities and Disorders in Literature for Youth: A Selective Annotated Bibliography for K-12; Prater's and Dyches' Teaching About Disabilities Through Children's Literature; and Ward's Voices from the Margins: An Annotated Bibliography of Fiction on Disabilities and Differences for Young People. Search engines of Internet 
commercial book retailers, such as Amazon and Barnes and Noble, were taken advantage of to aid in the systematic search for not only literature several years old, but more specifically for the more recently published juvenile books in this genre. To aid in the identification, electronic searches also were conducted on bibliographic databases, i.e., WorldCat and Children's Literature Comprehensive Database (CLCD).

Criteria for inclusion of literature. After the extensive preliminary list of potentially relevant books was completed, six criteria were applied to the literature on the generated book list. For the inclusion of children's and young adult literature in this study, target books had all of the following components:

\section{The protagonist of the book portrayed as having a CD.}

This first criterion has two parts dealing with characterization of CDs.

a) Historically characters with disabilities have had static, flat, stereotypical minor or supportive roles that advanced the story's plot and major characters. This research focused on characters at the other end of the spectrum by selecting literature that has characters with a disability that were at the center of the story and were protagonists. So books in which the character with the disability was only a minor, central or supportive character were excluded.

b) The $\mathrm{CD}$ of the protagonist may be a primary or a secondary disability and also either an expressive or receptive CD. For this study, CDs that dealt with writing, i.e., dysgraphia, dyscalculia and/or dyslexia have been 
excluded. These types of disorders are typically included in the area of specific learning disabilities and have been included in other studies.

2. The book had won a national book award in North America.

The award-winning component of this study was decided by whether the books had been recognized for national children's and young adult awards, honors, or prizes in North America in the online Children's Literature Comprehensive Database (CLCD). Literature that has only been awarded for best books, state or regional awards, honors or prizes in the CLCD was not considered for this research. The national book awards found in the CLCD were limited to North America (United States, Canada, and Mexico), because books that won only international awards outside of this continent would be harder to acquire. (More information about the CLCD can be found in Appendix D).

3. The literature needed to be at the intermediate children's or young adult fiction age/grade/reading level.

Since intermediate children's and young adult literature was the focus of this study, only books falling in the category of being written for or read by middle school/ junior high or high school was considered. Thus books having grade levels from 4-12 and age levels 9 and up were included. The reading level of the books was determined by the judges of the award committees of the professional journals/ organizations/etc. presenting the national awards. If the reading levels of the 
award-winning books were not mentioned in the awards, the age/grade/reading levels of the books was determined by the various books reviews in the CLCD.

4. Only contemporary literature was examined.

Contemporary literature for this study was defined as books that were eligible for children's and young adult literature awards between the dates 2000-2012.

5. The children's and young adult literature were classified as fiction and prose.

This excluded books that were in verse and/or fell into the non-fiction categories of biography, autobiography, informational, etc. Biographies written in story format were included.

6. The book was published in English.

The book were either originally published or translated into the English language.

\section{Books Locations}

Community libraries and the university library system were utilized in an attempt to locate books that were believed to possibly meet the six criteria for the study and were identified on the list of potentially relevant juvenile fictional literature. Regional and national interlibrary loans were resorted to for books not found locally. Since the literature was contemporary and had been selected for awards/honors/prizes, the majority of the list was available in nearby libraries. No possibly relevant books on the generated list had to be excluded from the study, since all the books were located from one of the above sources. 


\section{Data Collection}

Once the books with characters with CDs were secured, the literature was read and various bibliographical, demographic and literary elements information was charted for each book using the chart found in Appendix E. This chart included sections for bibliographical information, such as, author/illustrator, title, year (year translated if appropriate), publisher, North American national award(s) included in CLCD, and age/grade/reading level of the book. Other categories assessed the following literary elements: point of view of the story, topics/themes, and setting (place/time). The chart also had additional categories that pertained specifically to the character with the CD, i.e., name, role, age, gender and type of $\mathrm{CD}$. The six criteria for this study can be found in the various categories of this chart. Books that met all the criteria were included in the book sample. All other literature was excluded from the research.

\section{Instrumentation}

Literature from the generated book sample was evaluated using an updated adaptation of the Rating Scale for Quality Characterizations of Individuals with Disabilities in Children's Literature (Dyches and Prater, 2000)(see Appendix A). This evaluation instrument had been utilized in several other studies that examined the portrayal of characters with disabilities in children's literature (i.e., Dyches et al., 2001; Dyches \& Prater, 2005; Dyches et al., 2009; Leininger et al., 2010). Such areas as portrayal of character with a disability, literary quality of the text, and illustrations (if appropriate) were examined with this modified instrument, Rating Scale for Quality 
Characterizations of Individuals with CDs in Children's Literature. The section on the portrayal of the character with a disability is broken down into more detailed areas, such as, personal portrayal, social interactions, exemplary practices, sibling relationships (if appropriate) and point of view. The various sections in the majority of the instrument, not only had a three point agree-disagree rating scale for each question, but also a comment box where additional information, themes, etc. can be noted. An additional question was created under the section Impact of CD on Plot to examine whether the character with the disability models strategies for solving challenges presented by the CD.

For the purpose of increasing the reliability of the findings of the study, inter-rater reliability was established. A second reader, who qualifications included a special education teacher certification, was utilized to read and evaluate a random sample of 50\% of the books $(n=13)$ independently using the Rating Scale for Quality Characterizations of Individuals with CDs in Children's Literature. The ratings of the outside evaluator were then compared to those of the researcher. The two readers met to discuss and resolve any differences on ratings. A third reader was brought in when necessary to resolve any encountered disputes. The final codes were based on the interpretations of two out of the three raters. This method of inter-reliability was utilized by Leininger (2010) in evaluating the portrayal of disabilities in Newbery award-winning books. Describing the procedure Leininger stated: 
Inter-rater reliability was established for $46.7 \%$ of the books $(n=14)$. It should be noted that this number represents the number of books evaluated, some of which contained multiple characters with disabilities. Two readers read and independently evaluated each book, then met and came to agreement on the ratings. A third reader evaluated and resolved any disagreements between the two readers. Once the inter-rater reliability was established, the researcher read and evaluated the reminder of the books. (p. 41)

\section{Analysis of Books}

After the Rating Scale for Quality Characterizations of Individuals with CDs in

Children's Literature was completed on $50 \%$ of the award-winning books by the two readers with an inter-rater reliability of $81.8 \%$, these evaluators met and resolved disagreements on the various differences on ratings on the evaluation form. The researcher then evaluated the remaining books with the instrument. The scores of the various questions in the different sections were compiled and charted for each individual book and protagonist with a CD. The "comments" from the comment boxes were also assembled for later data analysis.

The researcher maintained a journal while analyzing the books, making note of passages that illustrated the characterization of the individual with the $\mathrm{CD}$ and how the disability was portrayed in the literature. This journal provided a location to not only store any immediate thoughts, reactions, or questions that occurred while reading the 
books, but also a place to start identifying patterns, trends or omissions that were occurring. When it came time to record findings in evaluation forms and various lists/charts/tables, the journal was found to be an invaluable tool for the researcher. In the next phase of the study's data analysis, the data was compiled from the various sources (i.e., charts, evaluation forms, and journal) and reduced into needed numerical and descriptive statistics and summaries. From this process informational data displays (i.e., lists and tables) were generated that were necessary to assess the various proposed research questions about the portrayal of protagonists with CDs in the eligible literature. The results of the data integration and analysis are presented in Chapter 4. 


\section{Chapter 4 \\ Results}

This study investigated contemporary award-winning intermediate children and young adult fictional books that portrayed protagonists with CDs. In Chapter 4 recorded information is analyzed from the charts, evaluation forms, and the journal notes kept while reading the selected books. The chapter is broken down into three main sections that answer each of the research questions: 1) extent of portrayal, 2) portrayals as measured by the evaluating tool, and 3) associations/ implications/connections that exist between the roles of the authors and reviewers and the scores/evaluations/external evaluations.

\section{Research Question 1}

To what extent are individuals with CDs portrayed in award winning intermediate children's and young adult literature?

(a) What 2000-2012 award-winning intermediate children's and young adult literature exists that have protagonists who have CDs?

(b) What types of CDs (e.g., speech, voice, language, hearing impairments) in children's and young adult literature are found in these award-winning books?

Contemporary literature that has protagonists with CDs. Twenty-six books were identified that met the six research criteria for this study. A complete listing of the 2000-2012 evaluated North American award-winning intermediate children's and young adult literature that have protagonists with CDs is provided below in Table 1. The book list provides such information as the author, illustrator (if appropriate), year published, publisher, and appropriate reading/interest level of the books. In the eligible literature, eleven books fell into the intermediate category while fifteen of the books were for young adults. 
Table 1

\section{Award-Winning Books with Protagonists with CDs}

\begin{tabular}{|c|c|c|c|c|}
\hline Title & Author/Illustrator & Year & Publisher & $\begin{array}{l}\text { Reading/ } \\
\text { Interest Level }\end{array}$ \\
\hline After Hamelin & Richardson, Bill & 2000 & Annick Press & Intermediate \\
\hline Aftershock & Easton, Kelly & 2006 & $\begin{array}{l}\text { Margaret K. } \\
\text { McElderry Books }\end{array}$ & Young Adult \\
\hline $\begin{array}{l}\text { Alvin Ho: Allergic to } \\
\text { Girls, School, and } \\
\text { Other Scary Things }\end{array}$ & $\begin{array}{l}\text { Look, Lenore; } \\
\text { illustrator, LeUyen } \\
\text { Pham }\end{array}$ & 2008 & $\begin{array}{l}\text { Schwartz \& Wade } \\
\text { Books }\end{array}$ & Intermediate \\
\hline Anything But Typical & $\begin{array}{l}\text { Baskin, Nora } \\
\text { Raleigh }\end{array}$ & 2009 & $\begin{array}{l}\text { Simon \& Schuster } \\
\text { Books for Young } \\
\text { Readers }\end{array}$ & Intermediate \\
\hline $\begin{array}{l}\text { Black Swan Green: A } \\
\text { Novel }\end{array}$ & Mitchell, David & 2007 & Random House & Young Adult \\
\hline Carter Finally Gets It & Crawford, Brent & 2009 & $\begin{array}{l}\text { Disney Hyperion } \\
\text { Books }\end{array}$ & Young Adult \\
\hline $\begin{array}{l}\text { The Curious Incident } \\
\text { of the Dog in the } \\
\text { Night-Time }\end{array}$ & Haddon, Mark & 2003 & Doubleday & Young Adult \\
\hline $\begin{array}{l}\text { The Dark Days of } \\
\text { Hamburger Halpin }\end{array}$ & Berk, Josh & 2010 & Alfred. A. Knopf & Young Adult \\
\hline Deaf Child Crossing & Matlin, Marlee & 2002 & $\begin{array}{l}\text { Simon \& Schuster } \\
\text { Books for Young } \\
\text { Readers }\end{array}$ & Intermediate \\
\hline The Dreamer & $\begin{array}{l}\text { Ryan, Pam Muñoz; } \\
\text { illustrator Peter Sís. }\end{array}$ & 2010 & Scholastic Press & Intermediate \\
\hline Five Flavors of Dumb & Antony, John & 2010 & Dial Books & Young Adult \\
\hline Free as a Bird & $\begin{array}{l}\text { McMurchy-Barber, } \\
\text { Gina }\end{array}$ & 2009 & Dundurn Press & Young Adult \\
\hline Harmonic Feedback & Kelly, Tara & 2010 & Henry Holt & Young Adult \\
\hline Hurt Go Happy & Rorby, Ginny & 2006 & $\begin{array}{l}\text { Tom Doherty } \\
\text { Associates }\end{array}$ & Young Adult \\
\hline $\begin{array}{l}\text { The London Eye } \\
\text { Mystery }\end{array}$ & Dowd, Siobhan & 2007 & $\begin{array}{l}\text { Dick Fickling } \\
\text { Books }\end{array}$ & Intermediate \\
\hline $\begin{array}{l}\text { Marcelo in the Real } \\
\text { World }\end{array}$ & Stork, Francisco & 2009 & $\begin{array}{l}\text { Arthur A. Levine } \\
\text { Books }\end{array}$ & Young Adult \\
\hline
\end{tabular}


Table 1 (continued)

Award-Winning Books with Protagonists with CDs

\begin{tabular}{|c|c|c|c|c|}
\hline Title & Author/Illustrator & Year & Publisher & $\begin{array}{l}\text { Reading/ } \\
\text { Interest Level }\end{array}$ \\
\hline Mockingbird & Erskine, Kathryn & 2010 & Philomel Books & Intermediate \\
\hline Nick's Secret & Blatchford, Claire H. & 2000 & $\begin{array}{l}\text { Lerner } \\
\text { Publications }\end{array}$ & Intermediate \\
\hline Out of My Mind & Draper, Sharon & 2010 & $\begin{array}{l}\text { Atheneum Book } \\
\text { for Young } \\
\text { Readers }\end{array}$ & Intermediate \\
\hline The Pull of the Ocean & $\begin{array}{l}\text { Mourlevat, Jean- } \\
\text { Claude; translated by } \\
\text { Y. Maudet. }\end{array}$ & $\begin{array}{c}2006 \\
(\text { trans })\end{array}$ & Delacourte Press & Intermediate \\
\hline Speak & $\begin{array}{l}\text { Anderson, Laurie } \\
\text { Halse }\end{array}$ & 1999 & $\begin{array}{l}\text { Farrar Straus } \\
\text { Giroux }\end{array}$ & Young Adult \\
\hline Stuck in Neutral & Trueman, Terry & 2000 & $\begin{array}{l}\text { Harper Collins } \\
\text { Publishing }\end{array}$ & Young Adult \\
\hline Sweethearts & Zarr, Sara & 2008 & Little, Brown & Young Adult \\
\hline Tending to Grace & $\begin{array}{l}\text { Fusco, Kimberly } \\
\text { Newton }\end{array}$ & 2004 & Knopf & Young Adult \\
\hline Waiting for No One & Brenna, Beverley & 2010 & Red Deer Press & Young Adult \\
\hline $\begin{array}{l}\text { Wonderstruck: A } \\
\text { Novel in Words \& } \\
\text { Pictures }\end{array}$ & Selznick, Brian & 2011 & Scholastic & Intermediate \\
\hline
\end{tabular}

Protagonists, genres, and settings. A closer examination of the identified

literature showed that this group of books portrayed protagonists with CDs having a range of personal characteristics (i.e., different ages/grades, genders, and a variety of primary disabilities and/or types of communication disorders). Even though this study focused on contemporary fictional literary works, diverse literary genres and settings are represented. This additional analysis of the protagonists, types of literature and backdrops is charted below in Table 2. This table provides content in the following categories: title, protagonist, personal characteristics, genre, and setting. 
Table 2

Protagonists' Personal Characteristics, Genres, \& Setting

\begin{tabular}{|c|c|c|c|c|}
\hline Title & Protagonist(s) & $\begin{array}{c}\text { Personal } \\
\text { Characteristics }\end{array}$ & Genre & Setting \\
\hline After Hamelin & Penelope & $\begin{array}{l}11 \text { and } 101 \text { years } \\
\text { old female who } \\
\text { becomes deaf }\end{array}$ & $\begin{array}{c}\text { Fantasy; (spin- } \\
\text { off of Pied Piper } \\
\text { legend) }\end{array}$ & $\begin{array}{l}\text { Middle Ages; } \\
\text { Hamelin, } \\
\text { Germany; } \\
\text { Span of } 90 \text { years-- } \\
\text { flashbacks }\end{array}$ \\
\hline Aftershock & Adam Walton & $\begin{array}{l}\text { 17-year-old male } \\
\text { with traumatic } \\
\text { mutism }\end{array}$ & Realistic fiction & $\begin{array}{l}\text { Journey from } \\
\text { Idaho to Bristol, } \\
\text { RI; 3-4 months }\end{array}$ \\
\hline $\begin{array}{l}\text { Alvin Ho: } \\
\text { Allergic to } \\
\text { Girls, School, } \\
\text { and Other } \\
\text { Scary Things }\end{array}$ & Alvin Ho & $\begin{array}{l}2^{\text {nd }} \text { grade male } \\
\text { with selective } \\
\text { mutism }\end{array}$ & Realistic fiction & $\begin{array}{l}\text { Concord, MA; } \\
\sim 1 \text { school yr }\end{array}$ \\
\hline $\begin{array}{l}\text { Anything But } \\
\text { Typical }\end{array}$ & Jason Blake & $\begin{array}{l}\text { 12-year-old male } \\
\text { with ASD, NLD, } \\
\text { PDD-NOS, \& } \\
\text { pragmatics/ } \\
\text { semantics language } \\
\text { disorder }\end{array}$ & Realistic fiction & $\begin{array}{l}\text { Weston, CN; } \\
\sim 1 \text { school yr }\end{array}$ \\
\hline $\begin{array}{l}\text { Black Swan } \\
\text { Green: } A \\
\text { Novel }\end{array}$ & Jason Taylor & $\begin{array}{l}\text { 13-year-old male } \\
\text { with ADD \& } \\
\text { fluency disorder }\end{array}$ & $\begin{array}{l}\text { historical } \\
\text { fiction; semi- } \\
\text { autobiographical }\end{array}$ & $\begin{array}{l}\text { 1982/83; Black } \\
\text { Swan Green, } \\
\text { Worcestershire, } \\
\text { England; 1 year }\end{array}$ \\
\hline $\begin{array}{l}\text { Carter Finally } \\
\text { Gets It }\end{array}$ & Will Carter & $\begin{array}{l}\text { 14-year-old } \\
\text { freshman, male } \\
\text { with fluency } \\
\text { disorder }\end{array}$ & $\begin{array}{l}\text { Realistic fiction; } \\
\text { semi- } \\
\text { autobiographical }\end{array}$ & $\begin{array}{l}\text { Merrian (no state } \\
\text { given); } \\
\sim 1 \text { school year }\end{array}$ \\
\hline $\begin{array}{l}\text { The Curious } \\
\text { Incident of the } \\
\text { Dog in the } \\
\text { Night-Time }\end{array}$ & $\begin{array}{l}\text { Christopher } \\
\text { John Francis } \\
\text { Boone }\end{array}$ & $\begin{array}{l}\text { 15-year-old male } \\
\text { with ASD \& } \\
\text { pragmatics/ } \\
\text { semantics language } \\
\text { disorder }\end{array}$ & $\begin{array}{c}\text { Realistic fiction, } \\
\text { mystery }\end{array}$ & $\begin{array}{l}\text { Swindon, } \\
\text { England; } \\
\sim 1 \text { school yr }\end{array}$ \\
\hline $\begin{array}{l}\text { The Dark } \\
\text { Days of } \\
\text { Hamburger } \\
\text { Halpin }\end{array}$ & Will Halpin & $\begin{array}{l}16 \text {-year-old male } \\
\text { who is deaf }\end{array}$ & $\begin{array}{c}\text { Realistic fiction, } \\
\text { mystery }\end{array}$ & $\begin{array}{l}\text { Northeast PA; } \\
\text { Carbon Co.; } \\
\sim 1 \text { school yr }\end{array}$ \\
\hline $\begin{array}{l}\text { Deaf Child } \\
\text { Crossing }\end{array}$ & Megan & $\begin{array}{l}\text { 9-year-old female } \\
\text { who is deaf }\end{array}$ & $\begin{array}{l}\text { Realistic fiction, } \\
\text { semi- } \\
\text { autobiographical }\end{array}$ & $\begin{array}{l}\text { Illinois; } \\
1 \text { summer }\end{array}$ \\
\hline
\end{tabular}


Table 2 (continued)

Protagonists' Personal Characteristics, Genres, \& Setting of Identified Books

\begin{tabular}{|c|c|c|c|c|}
\hline Title & Protagonist(s) & $\begin{array}{c}\text { Personal } \\
\text { Characteristics }\end{array}$ & Genre & Setting \\
\hline The Dreamer & Neftali Reyes & $\begin{array}{l}\text { Young boy (approx. } \\
6 \text { years old) to } \\
\text { young man, male } \\
\text { with fluency } \\
\text { disorder }\end{array}$ & $\begin{array}{l}\text { Fictional } \\
\text { biography }\end{array}$ & $\begin{array}{l}\text { Approx. late } \\
\text { 1900s-1920s; } \\
\text { Temuco, Chile; } \\
\text { Childhood- } \\
\text { adulthood }\end{array}$ \\
\hline $\begin{array}{l}\text { Five Flavors } \\
\text { of Dumb }\end{array}$ & $\begin{array}{l}\text { Piper } \\
\text { Vaughan }\end{array}$ & $\begin{array}{l}\text { 18-year-old female } \\
\text { who is deaf }\end{array}$ & Realistic fiction & $\begin{array}{l}\text { Seattle, WA; } \\
\sim 1 \text { school yr }\end{array}$ \\
\hline $\begin{array}{l}\text { Free as a } \\
\text { Bird }\end{array}$ & $\begin{array}{l}\text { Ruby Jean } \\
\text { Sharp }\end{array}$ & $\begin{array}{l}8 \text { years old to adult; } \\
\text { female with Down } \\
\text { syndrome \& } \\
\text { selective mutism }\end{array}$ & $\begin{array}{l}\text { Historical } \\
\text { fiction }\end{array}$ & $\begin{array}{l}1965 \text { to } \\
\text { contemporary; } \\
\text { New Westminster, } \\
\text { British Columbia; } \\
\sim 3 \text { decades }\end{array}$ \\
\hline $\begin{array}{l}\text { Harmonic } \\
\text { Feedback }\end{array}$ & $\begin{array}{l}\text { Andrea } \\
\text { "Drea" } \\
\text { Horvath }\end{array}$ & $\begin{array}{l}\text { High school junior, } \\
\text { female with ADHD, } \\
\text { GAD, bipolar, } \\
\text { Asperger syndrome } \\
\text { \& pragmatics/ } \\
\text { semantics language } \\
\text { disorder }\end{array}$ & Realistic fiction & $\begin{array}{l}\text { Bellingham WA } \\
\sim 1 \text { school yr }\end{array}$ \\
\hline $\begin{array}{l}\text { Hurt Go } \\
\text { Happy }\end{array}$ & Joey Willis & $\begin{array}{l}13 \text { years old; also } \\
\text { college student at } \\
\text { Gallaudet; female } \\
\text { who is deaf }\end{array}$ & Realistic fiction & $\begin{array}{l}\text { Fort Bragg, CA; } \\
\sim 1 \text { yr for most of } \\
\text { story; jumps ahead } \\
\text { to } 6-7 \text { yrs later }\end{array}$ \\
\hline $\begin{array}{l}\text { The London } \\
\text { Eye Mystery }\end{array}$ & Ted Sparks & $\begin{array}{l}\text { 12-year-old male } \\
\text { with autism/ } \\
\text { Asperger syndrome } \\
\text { \& pragmatics/ } \\
\text { semantics language } \\
\text { disorder }\end{array}$ & $\begin{array}{c}\text { Realistic } \\
\text { fiction, mystery }\end{array}$ & $\begin{array}{l}\text { London, England; } \\
\sim 1 \text { week school } \\
\text { break }\end{array}$ \\
\hline $\begin{array}{l}\text { Marcelo in } \\
\text { the Real } \\
\text { World }\end{array}$ & $\begin{array}{l}\text { Marcelo } \\
\text { Sandoval }\end{array}$ & $\begin{array}{l}\text { 17-year-old male } \\
\text { with pragmatics/ } \\
\text { semantics language } \\
\text { disorder }\end{array}$ & Realistic fiction & $\begin{array}{l}\text { Near Boston, MA; } \\
1 \text { summer }\end{array}$ \\
\hline Mockingbird & $\begin{array}{l}\text { Caitlin } \\
\text { Smith }\end{array}$ & $\begin{array}{l}\text { 10-year-old female } \\
\text { with Asperger } \\
\text { syndrome \& } \\
\text { pragmatics/ } \\
\text { semantics language } \\
\text { disorder }\end{array}$ & Realistic fiction & $\begin{array}{l}\text { community in VA; } \\
\sim 1 \text { school yr }\end{array}$ \\
\hline
\end{tabular}


Table 2 (continued)

Protagonists' Personal Characteristics, Genres, \& Setting of Identified Books

\begin{tabular}{|c|c|c|c|c|}
\hline Title & Protagonist(s) & $\begin{array}{c}\text { Personal } \\
\text { Characteristics }\end{array}$ & Genre & Setting \\
\hline Nick's Secret & Nick Wilder & $\begin{array}{l}13 \text {-year-old } / 7^{\text {th }} \\
\text { grade male who is } \\
\text { deaf }\end{array}$ & Realistic fiction & $\begin{array}{l}\text { New England; } \\
\sim 1 \text { week }\end{array}$ \\
\hline $\begin{array}{l}\text { Out of My } \\
\text { Mind }\end{array}$ & $\begin{array}{l}\text { Melody } \\
\text { Brooks }\end{array}$ & $\begin{array}{l}10 \text {-year-old female } \\
\text { with severe } \\
\text { cerebral palsy \& } \\
\text { dysarthria }\end{array}$ & Realistic fiction & $\begin{array}{l}\text { In southwest Ohio; } \\
\sim 1 \text { school yr }\end{array}$ \\
\hline $\begin{array}{l}\text { The Pull of the } \\
\text { Ocean }\end{array}$ & $\begin{array}{l}\text { Yann } \\
\text { Doutreleau }\end{array}$ & $\begin{array}{l}10 \text {-year-old male } \\
\text { with mutism }\end{array}$ & Realistic fiction & $\begin{array}{l}\text { Approx. } 50 \text { miles } \\
\text { from Perigueux, } \\
\text { France; 1 week }\end{array}$ \\
\hline Speak & $\begin{array}{l}\text { Melinda } \\
\text { Sordino }\end{array}$ & $\begin{array}{l}\text { Freshman in high } \\
\text { school, female with } \\
\text { selective mutism }\end{array}$ & Realistic fiction & $\begin{array}{l}\text { Syracuse, NY; } \\
\sim 1 \text { school yr }\end{array}$ \\
\hline $\begin{array}{l}\text { Stuck in } \\
\text { Neutral }\end{array}$ & $\begin{array}{l}\text { Shawn } \\
\text { McDaniel }\end{array}$ & $\begin{array}{l}\text { 14-year-old male } \\
\text { with severe } \\
\text { cerebral palsy \& } \\
\text { dysarthria }\end{array}$ & Realistic fiction & $\begin{array}{l}\text { Seattle, WA; } \\
\sim 1 \mathrm{yr}\end{array}$ \\
\hline Sweethearts & $\begin{array}{l}\text { Jennifer } \\
\text { Harris/Jenna } \\
\text { Vaughn }\end{array}$ & $\begin{array}{l}17 \text {-year-old female } \\
\text { with articulation } \\
\text { disorder; } \\
\text { flashbacks to when } \\
9 \text { years old }\end{array}$ & Realistic fiction & $\begin{array}{l}\text { Salt Lake City, UT; } \\
\sim \text { a couple of } \\
\text { months for most } \\
\text { story; flashbacks to } \\
\text { grade school; jump } \\
\text { forward to college }\end{array}$ \\
\hline $\begin{array}{l}\text { Tending to } \\
\text { Grace }\end{array}$ & $\begin{array}{l}\text { Cornelia } \\
\text { Thornhill }\end{array}$ & $\begin{array}{l}\text { 14-year-old female } \\
\text { with fluency } \\
\text { disorder }\end{array}$ & Realistic fiction & $\begin{array}{l}\text { Harrisville; New } \\
\text { England; } \\
\sim 1 \mathrm{yr}\end{array}$ \\
\hline $\begin{array}{l}\text { Waiting for } \\
\text { No One }\end{array}$ & $\begin{array}{l}\text { Taylor Jane } \\
\text { Simon }\end{array}$ & $\begin{array}{l}18 \text {-year-old female } \\
\text { with ASD, OCD, \& } \\
\text { pragmatics/ } \\
\text { semantics language } \\
\text { disorder }\end{array}$ & Realistic fiction & $\begin{array}{l}\text { Saskatoon, } \\
\text { Saskatchewan, } \\
\text { Canada; visits } \\
\text { Cody, WY ; } \\
\sim 1 \text { school yr }\end{array}$ \\
\hline \multirow[t]{2}{*}{$\begin{array}{l}\text { Wonderstruck: } \\
\text { A Novel in } \\
\text { Words \& } \\
\text { Pictures }\end{array}$} & Ben Wilson & $\begin{array}{l}\text { Almost 12-year- } \\
\text { old male who } \\
\text { becomes deaf }\end{array}$ & \multirow[t]{2}{*}{$\begin{array}{l}\text { Historical } \\
\text { fiction }\end{array}$} & $\begin{array}{l}\text { 1927, Gunflint } \\
\text { Lake, MN; also } \\
\text { NYC, NY; } \\
\sim 1 \text { summer }\end{array}$ \\
\hline & Rose Kincaid & $\begin{array}{l}\text { Around } 12 \text { years } \\
\text { old; also } 50 \text { yrs } \\
\text { later at } 62 \text {; female } \\
\text { who is deaf }\end{array}$ & & $\begin{array}{l}\text { 1927, Hoboken, } \\
\text { NJ; also } 1977 \text { in } \\
\text { NYC, NY } \\
\sim 1 \text { yr; jumps } \\
\text { forward } 50 \text { yrs later }\end{array}$ \\
\hline
\end{tabular}


Protagonists/personal characteristics. As mentioned earlier, these 26 books contained 27 protagonists with CDs. The age span of the protagonists was from approximately 6 to 101 years old. At some time in the narrations, all of these main characters were depicted as youths ranging between the ages of six to eighteen years old. Two books depict the protagonists both as young eleven- and twelve-year-old girls and also later in life as elderly women (i.e., Rose in Wonderstruck, and Penelope in After Hamelin). The gender of the protagonists with CDs was almost split evenly. Thirteen main characters were female, while the other fourteen protagonists were male. Also listed in the category of personal characteristics for several of the protagonists are other primary disorders or disabilities that might contribute to the CD. For example, of the 27 protagonists with CDs, there were seven protagonists with autism/Asperger syndrome, two main characters with severe cerebral palsy, and one individual with Down syndrome. The type of $\mathrm{CD}$ is also recorded in the personal characteristics category. A more thorough discussion of types of CDs found in this study will be executed in the second part of this research question (see p. 51).

Genres. Although every book for this study was contemporary and narrative in format, the eligible literary works fell into different genres of literature. Three of the books were mysteries (i.e., The London Eye Mystery, The Dark Days of Hamburger Halpin, and The Curious Incident of the Dog in the Night-Time) and a few of the books were semi-autobiographical and/or based on events from the authors' childhood (i.e., Black Swan Green, Carter Finally Gets It, and Deaf Child Crossing). All of the literature may be categorized as realistic fiction, except for two books, After Hamelin and The 
Dreamer. After Hamelin, was more of a fantasy and a surrealistic retelling or continuation of the classic German legend about the Pied Piper of Hamelin. The literary work The Dreamer, was realistic, but fell into the genre of fictional biography. The Dreamer, told the childhood story of the timid, sickly, and daydreaming Neftali Reyes, who grew up to be the Chilean Nobel-winning poet, Pablo Neruda.

Settings. These selected award-winning books that had protagonists with CDs took place in a variety of places, times and durations. The majority of the backdrops for the protagonists in the identified literature took place in the United States $(n=19,70.4 \%)$ and in contemporary times $(n=21,77.8 \%)$. However, eight of the books $(29.6 \%)$ took place in other countries -- England (i.e., Black Swan Green, The Curious Incident of the Dog in the Night-Time, and The London Eye Mystery), Canada (i.e., Free as a Bird and Waiting for No One), Germany (i.e., After Hamelin), Chile (i.e., The Dreamer), and France (i.e., The Pull of the Ocean).

As mentioned previously, several of the settings for the protagonists' stories $(n=6$, $22.2 \%$ ) were non-contemporary/historical. For example, the two non-realistic fiction books that were recently discussed took place decades and/or centuries ago. After Hamelin was set in Hamelin, Germany during the Middle Ages, while The Dreamer took place back in the early 1900s-1920s in the frontier town of Temuco, Chile. In the bildungsroman historical fiction, Black Swan Green, the backdrop was a quiet village in Worcestershire County, England during the dying early 1980s Cold War era of Prime Minister Margaret Thatcher and the Falkland War. The North American continent was the location for two of the historical fiction books in this study. The setting for Free as a 
Bird was from 1965 to the mid 1990s near Vancouver, British Columbia. By staging this narrative in this earlier time frame, the author was able to open readers' eyes to the all to common historical, societal practice that occurred during that era of institutionalizing and isolating individuals with intellectual, behavioral and/or physical disabilities. The other North American historical literature Wonderstruck had a time setting that kept jumping back and forth over a fifty-year period in the $20^{\text {th }}$ century as it related the separate, but intertwined stories of the two protagonists with CDs. In this unique book, Ben's narrative began in 1977 in rural Gunflint Lake, Minnesota while Rose's story started much earlier in 1927 in Hoboken, New Jersey and New York City, New York.

Within these eligible books, the duration of the stories varied greatly. The majority of the books took place during approximately a one-year span and often occurring during an academic school year $(n=57.7 \%)$. However some of the literature's plots lasted for as short as a time as approximately a week (i.e., The London Eye Mystery, Nick's Secret, and The Pull of the Ocean) or over a summer (i.e., Deaf Child Crossing and Marcelo in the Real World). A few of the plots spanned two decades or longer (i.e., After Hamelin, The Dreamer, Free as a Bird, and Wonderstruck).

Types of CDs. In these selected children's and young adult literature, the 27 protagonists displayed a variety of types of CDs. Sometimes the CD itself was the primary disability for the protagonist with the $\mathrm{CD}$. In other cases the $\mathrm{CD}$ was secondary to another disability. The types of CDs portrayed in these books fell into three of the ASHA categories: 1) speech, 2) language and 3) hearing disorders. None of the portrayed protagonists had (central) auditory processing disorders, which is the fourth ASHA category of CD (ASHA, 1993). 
Speech disorders. According to ASHA, a speech disorder is defined as "an impairment of the articulation of speech sounds, fluency and/or voice" (ASHA, 1993). Seven of the protagonists have some type of speech disorder $(n=7,25.9 \%)$. The most prevalent type of speech disorder was a fluency disorder/stuttering $(n=4,14.8 \%)$. The three remaining protagonists with speech disorders had articulation disorders $(n=3$, $11.1 \%)$. Two main characters had an articulation disorder called dysarthria $(n=2,7.4 \%)$, while one protagonist had a lisp $(n=1,3.7 \%)$. A list of the evaluated books whose protagonists had speech disorders is provided below in Table 3. Included in the chart is the title of the book, the reading/ interest level, the protagonist (including name, age, and gender) and the type of speech disorder.

\section{Table 3}

\section{Award-Winning Books with Protagonists with Speech Disorders}

\begin{tabular}{|l|l|l|l|}
\hline Title & $\begin{array}{l}\text { Reading/ } \\
\text { Interest Level }\end{array}$ & Protagonist & $\begin{array}{l}\text { Type of Speech } \\
\text { Disorder }\end{array}$ \\
\hline $\begin{array}{l}\text { Black Swan } \\
\text { Green: A Novel }\end{array}$ & Young Adult & Jason, 13 years old, male & fluency disorder \\
\hline $\begin{array}{l}\text { Carter Finally } \\
\text { Gets }\end{array}$ & Young Adult & Will, 14 years old, male & fluency disorder \\
\hline The Dreamer & Intermediate & $\begin{array}{l}\text { Neftali, 6-year-old boy to } \\
\text { young man }\end{array}$ & fluency disorder \\
\hline $\begin{array}{l}\text { Tending to } \\
\text { Grace }\end{array}$ & Young Adult & Cornelia, 14 years old, female & fluency disorder \\
\hline Out of My Mind & Intermediate & Melody, 10 years old, female & $\begin{array}{l}\text { articulation } \\
\text { disorder/dysarthria }\end{array}$ \\
\hline Stuck in Neutral & Young Adult & Shawn, 14 years old, male & $\begin{array}{l}\text { articulation } \\
\text { disorder/dysarthria }\end{array}$ \\
\hline Sweethearts & Young Adult & $\begin{array}{l}\text { Jenna, 17 years old; flash-backs } \\
\text { to when she was 9, female }\end{array}$ & $\begin{array}{l}\text { articulation } \\
\text { disorder/lisp }\end{array}$ \\
\hline
\end{tabular}

Fluency disorders. Over half of the main characters with speech disorders had fluency disorders. According to ASHA, a fluency disorder "is an interruption in the flow of speaking characterized by atypical rate, rhythm, and repetitions in sounds, syllables, 
words, and phrases" (ASHA, 1993). Included in this category, are "related disorders as stuttering and cluttering as well as the more specific categories of neurogenic stuttering and psychogenic stuttering" (ASHA, 1999, 3.2). In this study, however, all of the protagonists with fluency disorders were portrayed with typical or "developmental" stuttering whose onset was during childhood and was characterized by breaks in fluency or prolongations/repetitions of speech sounds, words, part of words, or phrases. The activities and circumstances in which the main characters that stuttered found difficulty in communicating fluctuated tremendously from story to story.

The four protagonists who stuttered varied greatly not only in the severity of their stuttering, but also by the reactions to their stuttering by their peers, family and/or community. Only one protagonist who stuttered was currently receiving treatment in speech-language therapy. Areas of strengths and/or accomplishments were represented for all the protagonists who stuttered. Additionally, authors portrayed the protagonists' stuttered speech in the text in different methods.

A well-liked high school freshman, Carter (Carter Finally Gets It), had the mildest stuttering of the four protagonists who stuttered. Mostly he was portrayed stuttering in stressful situations that occurred usually when he was with his peers. When he was with his male friends, Carter would sometimes stutter when he tried embellishing dates he had been on and/or was making up other tall tales. However, Carter's stuttering was at its worse when he was trying to fabricate appropriate conversation with females that he liked. "His boys" often would help Carter out if he got into too much trouble 
when he was trying to speak. Carter also stuttered in front of teachers a couple of times. One of these incidence occurred when he was caught day-dreaming in class and the other event was when he unexpectedly found out he had received the male lead in the school play. No one ever laughed or teased Carter about his stuttering during the story. He does relate, however, that after a bad stuttering incidence the prior year he had been afraid his nickname would be changed to "C-C-Carter". Carter unrealistically blamed his stuttering on his older sister. Over a decade ago when he was first learning to talk, his older sister finished any word for objects he was pointing at and trying to sound out. Carter explained he would then try to pronounce the words faster before his sister could speak up, but he ended up stuttering instead of articulating the words correctly.

Another protagonist whose stuttering was not severe the majority of the time was Neftali's (The Dreamer). This main character was a daydreamer, who was often not only insatiably absorbed in observing and collecting objects in nature, but also fascinated by words and surreal images he dreamed of. Being a loner, sickly, and extremely shy, Neftali did not speak to many people other than his immediate family. In the book, the only non-familial individuals that Neftali spoke to were a librarian and the bully who wanted Neftali to write love letters for him. The stuttering was portrayed as mild with everyone except his father, who was verbally abusive and an authoritarian. Neftali's father was embarrassed by his son's stuttering, daydreaming, and slight build. Sometimes when trying to answer a question posed by his father, Neftali was not even able to get past the initial consonant of a single syllable word like "no". The rest of Neftali's family, 
who were also bullied by his father, never teased or commented on his stuttering. His mother, uncle, and younger sister were very kind and supportive toward Neftali. Jason (Black Swan Green) was the only protagonist who stuttered that attended speech-language therapy. He had been going to therapy for 5 years. As Jason informed readers, his speech disorder was stammering and not stuttering. According to ASHA, stammering is a common term used for stuttering in Great Britain. This specific terminology is not often used by professionals in the speech-language field in this continent (ASHA, 1999, 3.5.5, para. 6). To Jason, however, a great difference existed between these two terms. As this thirteen-year-old British boy pointed out, stammering and stuttering are as "different as diarrhea and constipation" (Mitchell, p.25). Jason further explained that the variance of terminology depended on where in a word an individual had a fluency difficulty. Unlike stuttering where someone's excessive or lengthy break is on the first part of the word, Jason's fluency disorder occurred after the initial part of the word (for example, St......AMmer). Jason personified his stammer giving it the name "Hangman." After getting a reprieve from speaking in front of the whole school, Jason described to readers how Hangman had him in a chokehold after this incident.

Hangman wanted revenge for my stay of execution. He'd slid his fingers into my tongue and clasping my throat and pinching the veins that take oxygen to my brain. When Hangman's like that I'd look a total flid if I tried to spit the word out. (Mitchell, p. 42) 
Y-words used to be Hangman's favorite, but as the story progressed, Jason began having trouble with $\mathrm{N}, \mathrm{S}$, and G-words. His stammering difficulty always started flaring up a couple of months after school started. Over the summer the stammering would calm down and Jason could stop speech-language therapy. By February, however, as the stammering became more severe, this protagonist would need to resume his therapy. The difficulty with speech-language therapy for Jason was that his stammering would never occur in the presence of the speech-language pathologist, Mrs. De Roo. In therapy, this protagonist would use a metronome to practice pacing his speech as he read a list of troubled words and paragraphs from a book. Discussing the stammering with Mrs. De Roo, Jason wondered if he would grow out of the fluency disorder or would it be a lifelong problem because his brain was just wired wrong. As the pathologist explained, the speech-language field is an imperfect science with many unanswered questions. Instead of fearing his stammering, Jason needed to respect it and learn compensatory skills for when it flared up. His pathologist used the analogy of a friend with alcoholism, who was not cured of the disease, but just did not drink anymore. The speech-language pathologist in Black Swan Green saw her role as helping clients to "change from being stammering stammers into nonstammering stammerers" (Mitchell, p.32). Being thirteen and a male with a fluency disorder was difficult for Jason. He, like everyone else, was trying to find his place on the social ladder. Once his speech disorder was brought out in the open by a popular student, this protagonist's social standing fell tremendously enabling him to be 
teased and bullied relentlessly. In and out of the classroom, some of his peers cruelly began imitating a stuttered speech pattern that was much worse than Jason's speech. Jason, who thought about his stammering often, had the most extensive and elaborate plans for compensating and/or hiding his stammering when possible. A discussion of some of Jason's and other protagonists various strategies to solve challenges presented by their CDs will be discussed in a later section of this chapter about modeling strategies (Impact of CD on Plot, p.124).

The protagonist who had the severest fluency disorder was fourteen-year-old Cornelia (Taking Care of Grace). Stuttering in all speaking situations and having few if any strategies to navigate these challenges, Cornelia tried to remain invisible and keep silent. She had extreme difficulty even pronouncing her name. Being a bibliophile, Cornelia had read most of the books in the Honors English class. However since this protagonist seldom spoke, Cornelia was always put into the lowest English section. She would continue to refuse to speak or read aloud in these classes where the dummy-down classics were used that were so simplified they were stripped of their soul. Even though, her excessive school absences, home environment, and refusal to talk should have sent up many red flags, no mention was ever made of Cornelia receiving help from a speechlanguage therapist. School officials instead just sent her to a school counselor to discuss her absenteeism where she would withdraw further into herself. From teachers and her mother she has been given such advice as, "try harder", "use simpler words", "slow down", "pull yourself together", "get more backbone”, "take a deep breath", "relax", etc. Cornelia found all of this supposedly helpful information useless, because as she explained: 
They made it sound so easy. Try harder, stutter less. But when I try harder, I stutter more. When I pick easier words, I stutter on easier words. And I can't pick an easier word when someone asks me my name. (Fusco, p. 33)

When her mother abandoned her at her eccentric great aunt's rural home, Cornelia had to start talking again. Finally having a stable home and an adult who would not talk for her, Cornelia was coaxed into speaking up for herself in order that other people would not decide things for her. People reacted differently to her stuttering. Cornelia labeled many people as "look-aways." This was a term this protagonist used for people like her mother and past teachers, who would turn their heads when she would stutter. Cornelia related to readers that this was a main reason her stuttering got worse over the years causing her to quit talking to almost everyone. A few people in Cornelia's new rural community did respond negatively to her stuttering. Becoming impatient, these individuals reacted by turning away, calling her a "dimwit," or saying they didn't have all day. However, many people would look at Cornelia while she was speaking and waited for her to finish her replies. As she gain more confidence and came to terms with her mother not being able to take care of her, Cornelia's life greatly improved.

All the protagonists who stuttered in this study, had areas of strengths or other accomplishments. Carter, who was an extrovert, participated in varsity football and swimming. Not having made the baseball team, his drama teacher encouraged him to participate in the spring play. As a freshman Carter was just thinking about helping with 
lighting during the production, but ended up with the play's lead male role. Participating in plays was not a popular school activity like sports were, however, it was something Carter discovered he excelled at. When speaking lines someone else wrote, this protagonist found that he had no trouble with stuttering. Participating in the play enabled Carter to overcome his worst enemy--himself. It was the first time he did something completely for himself and not because his friends or family wanted him to do it.

While Carter's areas of strengths were sports and acting, all of the three remaining protagonists who stuttered enjoyed reading books. As mentioned earlier, Cornelia had a great love for words and literature. While helping her young neighbor/friend improve her reading, this protagonist realized that her great aunt was illiterate. Teaching literacy skills to these two important people in her life began giving Cornelia more confidence. This teaching experience along with finally expressing in a journal her bottled-up feelings about such issues as her mother, stuttering, and her world per se, enabled Cornelia to become courageous enough to take control of her life and go back to school. With her great aunt's promised financial help, Cornelia began making plans to go on to college and study her passion of literature.

Like Cornelia, Neftali and Jason enjoyed reading tremendously and knew the power of words. They also shared an interest in writing with some of their early works being published in local venues. Neftali's father, however, not sharing the views 
portrayed in his son's article, burned all of Neftali's many journals that contained his thoughts, poetry and prose. After this incident, Neftali decided to adopt the pseudonym, Pablo Neruda. Using a pen name, Neftali could hide his future publications from not only his father, but in subsequent years the Chilean government. Later Neftali's name was legally changed to Pablo Neruda, the name he was known as when he became a wellknown Pulitzer writer.

Jason also loved words and used his extensive vocabulary not only to circumvent words that were problematic to his fluency disorder, but also to express his thoughts and feelings. After winning a poetry competition, Jason also started using a pen name (Eliot Bolivar) in order to hide his identity from his peers in future publications. Having a great appreciation for the outdoors, as did Neftali, Jason decided he would later pursue a career as a forester rather than try to make a living with writing.

Articulation disorder. As mentioned earlier, three of the main characters with speech disorders had articulation disorders. An articulation disorder, according to ASHA, "is the atypical production of speech sounds characterized by substitutions, omissions, additions or distortions that may interfere with intelligibility" (ASHA, 1993). Two protagonists who have speech disorders have a motor speech disorder called dysarthria. This type of speech disorder happens when damage to central or peripheral areas of the nervous system affect the ability to coordinate the muscles of the face, mouth, and 
respiratory system. The severity and type of the dysarthria can vary resulting in the muscles needed to control speech to be either weak, move slowly, or be immobile (ASHA, Dysarthria, para. 1). Different causes of dysarthria exist, but both protagonists in this study who had dysarthria had severe cerebral palsy. Melody (Out of My Mind) and Shawn (Stuck in Neutral) also cannot walk, feed, dress, or take care of any of their personal needs themselves. As the titles of their respective books indicate, these two main characters are quite frustrated with their circumstances and inability to communicate their thoughts with family, teachers, and friends. As Melody describes it to readers in Out of My Mind, It's like I live in a cage with no door and no key. And I have no way to tell someone how to get me out. (Draper, p. 38)

People are always talking down to Melody and Shawn and/or act like they are not present or invisible. Doctors had mistakenly told both sets of these protagonists' parents that their children also had severe intellectual disabilities. Even though Melody and Shawn could not communicate verbally on their own, neither one has difficulty in understanding cognitive language.

Melody's communication skills, abilities, and experiences grew tremendously during the plot of the story. After having been stuck in a self-contained classroom for severely and profoundly disabled students for four years, her school finally started 
inclusion when she was in fifth grade. Her life improved this academic year also with the school providing Melody with a mobility assistant (Catharine) and when she received an electric wheelchair that she could maneuver herself. At the beginning of the story, the only means for Melody to convey her thoughts and wants was by using a simple Plexiglas communication board that had the dual purpose of also being a food tray. Pasted on this communication board were some basic words, necessary phrases, names of key people in her life, and an alphabet strip with numbers so she could spell out words, count or talk about time. After writing a report on Stephen Hawking and seeing all the features on a friend's new laptop, Melody began pondering if a better way existed for her to be able to communicate. With Catharine's assistant, this protagonist researched and purchased a talking electronic communication device (i.e., a Medi-Talker) that she could use with her limited mobility. Upon arrival of the new device, Melody narrates her feelings to the audience about the anticipated ability to actually being able to converse. I feel like Christopher Columbus bumping into America. It had been there all the time, but he was the first one from his world to find it. I wonder if his heart had beat as fast as mind is. (Draper, p. 133)

With her new Medi-Talker, Melody was no longer limited to the words pasted on her old Plexiglas board. Finally this protagonist had a voice for the numerous thoughts going on in her head. With her new assistive technology, Melody was able to participate more in 
school events and even became a member of her school's whiz bowl team. As the protagonist's mother informs a doctor, "a person is so much more than the name of a diagnosis or a chart" (Draper, p. 23).

Even though readers knew that Shawn (Stuck in Neutral) was intelligent, no one else was aware of this fact even those individuals in his immediate family, school, or community. Unlike Melody, Shawn could not control any of his muscles including those needed for swallowing, focusing or blinking his eyes. He also had six to ten grand mal seizures a day. Having a photographic memory, Shawn was able to retain anything he heard and saw. Having picked up reading from his older sister when he was young, this protagonist could read as long as his focus would remain on an item. No one realized Shawn had any receptive language abilities since this character had no way to express himself.

One protagonist that had an articulation disorder had a lisp. As a child Jennifer/ Jenna (Sweethearts) had trouble saying classmates' names that started with "S" and words like possum. With speech-language therapy and practice, Jennifer was able to correct her articulation disorder. In high school, this protagonist reinvented herself and started using the name Jenna instead of Jennifer. Jenna's articulation disorder was not per se really significant or relevant to the story. Flashbacks to her past in elementary school began to occur when a grade school friend that she had thought was dead suddenly 
appeared as a new transfer student in her high school. Elementary school days' memories of being poor, overweight, and having a speech disorder, eating disorder, and a terrifying psychologically abusive incident with her old friend's father began to haunt Jenna. The articulation disorder was portrayed as being more an additional characteristic that helped made this protagonist an outsider when she was young.

Language disorders. A little under half of the CDs of the protagonists fell into the area of language disorders $(n=12,44.4 \%)$. A language disorder, according to ASHA, is an "impaired comprehension and/or use of spoken, written and/or other symbol systems" (ASHA, 1993). The majority of the main characters with language disorders were individuals whose primary disorder was autism/autism spectrum disorder (ASD). The protagonists with ASD $(n=7,25.9 \%)$ had difficulty with the pragmatics of language and with some semantic aspects of language. The other five protagonists with language disorders had some form of mutism (i.e., selective mutism, traumatic mutism, etc.) $(n=5$, $18.5 \%)$. These protagonists with mutism differed greatly from one another not only in their type of mutism, but also in the onset of the language disorder and whether the mutism was constant or only occurred is specific situations/conditions. A list of the books whose protagonists had language disorders is provided below in Table 4. Included in the chart is the title, reading/interest level of the books, the protagonist (including name, age, and gender), and type of language disorder. 
Table 4

\section{Award-Winning Books with Protagonists with Language Disorders}

\begin{tabular}{|c|c|c|c|}
\hline Title & $\begin{array}{l}\text { Reading/ } \\
\text { Interest Level }\end{array}$ & Protagonist & $\begin{array}{l}\text { Type of Language } \\
\text { Disorder }\end{array}$ \\
\hline Anything But Typical & Intermediate & $\begin{array}{l}\text { Jason, } 12 \text { years old, } \\
\text { male }\end{array}$ & $\begin{array}{l}\text { pragmatics/semantics } \\
\text { language disorder }\end{array}$ \\
\hline $\begin{array}{l}\text { The Curious Incident } \\
\text { of the Dog in the } \\
\text { Night-Time }\end{array}$ & Young Adult & $\begin{array}{l}\text { Christopher, } 15 \\
\text { years old, male }\end{array}$ & $\begin{array}{l}\text { pragmatics/semantics } \\
\text { language disorder }\end{array}$ \\
\hline Harmonic Feedback & Young Adult & $\begin{array}{l}\text { Drea, high school } \\
\text { junior, female }\end{array}$ & $\begin{array}{l}\text { pragmatics/semantics } \\
\text { language disorder }\end{array}$ \\
\hline $\begin{array}{l}\text { The London Eye } \\
\text { Mystery }\end{array}$ & Intermediate & $\begin{array}{l}\text { Ted, } 12 \text { years old, } \\
\text { male }\end{array}$ & $\begin{array}{l}\text { pragmatics/semantics } \\
\text { language disorder }\end{array}$ \\
\hline $\begin{array}{l}\text { Marcelo in the Real } \\
\text { World }\end{array}$ & Young Adult & $\begin{array}{l}\text { Marcelo, } 17 \text { years } \\
\text { old, male }\end{array}$ & $\begin{array}{l}\text { pragmatics/semantics } \\
\text { language disorder }\end{array}$ \\
\hline Mockingbird & Intermediate & $\begin{array}{l}\text { Caitlin, } 10 \text { years } \\
\text { old, female }\end{array}$ & $\begin{array}{l}\text { pragmatics/semantics } \\
\text { language disorder }\end{array}$ \\
\hline Waiting for No One & Young Adult & $\begin{array}{l}\text { Taylor Jane, } 18 \\
\text { years old, female }\end{array}$ & $\begin{array}{l}\text { pragmatics/semantics } \\
\text { language disorder }\end{array}$ \\
\hline Aftershock & Young Adult & $\begin{array}{l}\text { Adam, } 17 \text { years } \\
\text { old, male }\end{array}$ & traumatic mutism \\
\hline $\begin{array}{l}\text { Alvin Ho: Allergic to } \\
\text { Girls, School, and } \\
\text { Other Scary Things }\end{array}$ & Intermediate & $\begin{array}{l}\text { Alvin, } 2^{\text {nd }} \text { grader, } \\
\text { male }\end{array}$ & selective mutism \\
\hline Free as a Bird & Young Adult & $\begin{array}{l}\text { Ruby Jean, } 8 \text { years } \\
\text { old to adult, female }\end{array}$ & selective mutism \\
\hline Speak & Young Adult & $\begin{array}{l}\text { Melinda, freshman } \\
\text { in high school, } \\
\text { female }\end{array}$ & selective mutism \\
\hline The Pull of the Ocean & Intermediate & $\begin{array}{l}\text { Yann, } 10 \text { years old, } \\
\text { male }\end{array}$ & mutism \\
\hline
\end{tabular}

Pragmatic and semantic language disorders. Pragmatics refers to the ability to be able to use social language appropriately. According to ASHA, pragmatics involves three major communication skills: 1) using language, 2) changing language, and 3) following 
rules (ASHA, n.d., Pragmatics). When using language, individuals need to understand how to generate it for a variety of social situations (e.g., commenting, requesting, greeting, informing, demanding, etc.) and to change it depending on the specific listener or location (e.g. child vs. adult, inside vs. outside, etc.). Additionally general verbal and nonverbal rules have to be followed to have a successful conversation (e.g., starting conversation, taking turns, staying on topic, maintaining and building on initiated topics, recognizing misunderstandings or breakdowns in conversation and rephrasing them, recognizing correct personal space when speaking, reading body language, having correct facial expression and eye contact, etc.)(Volden (2002); ASHA, n.d., Pragmatics). Individuals with some form of high-functioning ASD or symptoms/characteristics of ASD typically not only have a degree of difficulty with pragmatics/social communication, but also find the semantics of language at times to be problematic in regards to taking words/ expressions literally and having trouble understanding idioms/ figures of speech. Semantics is related to the study of the meanings of words and phrases and the content of language (ASHA, 1993). Semantic ambiguities often occur for individuals with ASD in the case of figurative language because they do not take into account and/or have a complete understanding of the multiple meaning of words/synonyms.

Synopsis of protagonists with ASD. The seven protagonists who displayed pragmatic and semantic language disorders all fell somewhere on the continuum of autism/ASD. This entire group of main characters who had ASD was high functioning with ages ranging from 10 to $183 / 4$. Sometimes the diagnosis of the protagonists seemed straightforward. For example, ten-year-old Caitlin (Mockingbird) simply states she had 
Asperger syndrome. Others like seventeen-year-old Marcelo's (Marcelo in the Real World) diagnosis was more vague and harder to define. Even though he attended a special private school, Marcelo's father always stated nothing was wrong with his son. Ironically when Marcelo had a summer job at his father's law office, Marcelo's father told employees that his son had a cognitive disorder. Marcelo thought of his difficulties as an "excessive attempt at cognitive order" (Stork, p. 55). According to this protagonist, the closest description of his condition would be Asperger syndrome even though he did not have many of the characteristics. Marcelo thought of himself as "different in the way I think, talk, and act, but not as someone who is abnormal or ill” (Stork, p. 55).

Often the protagonists portrayed additional disorders. For example, Taylor Jane (Waiting for No One) was portrayed with ASD and obsessive-compulsive disorder (OCD). Toward the end of the story, she started taking medication for her OCD. The medication helped Taylor Jane's OCD and depression, which enabled her to begin attending her college biology class again. Over the years twelve-year-old Jason (Anything but Typical) had been diagnosed not only with ASD, but also nonverbal learning disorder (NLD) \& pervasive development disorder-not otherwise specified (PDD-NOS). Another protagonist, Drea (Harmonic Feedback), who was a junior in high school, had been diagnosed in kindergarten with attention deficit hyperactivity disorder (ADHD). She took medication to reduce the ADHD symptoms. Through the years Drea had additionally been diagnosed with bipolar disorder, general anxiety disorder (GAD) and Asperger syndrome. As her new doctor explained, Asperger syndrome can be difficult to diagnosis especially with females who have less obvious symptoms. Having only mild symptoms of Asperger syndrome, Drea was able to cope extremely well in school. Sometimes 
protagonists' actual disorders are never disclosed in the text of the stories. This is the case for two of the main characters, Ted (The London Eye Mystery) and Christopher (The Curious Incident of the Dog in the Night-Time). In The London Eye Mystery, the twelveyear-old protagonist Ted explained to readers that he had "a funny brain that runs on a different operating system from other people's" (Dowd, p. 4). However, in both of these books either on the front flap, colophon, back flap, and/or back cover, the terminology autism or Asperger syndrome was used to describe these main characters.

Amongst the protagonists with ASD, the pragmatic and semantic language disorders did vary in severity and characteristics. However, in these two types of language disorders some common weaknesses were prevalent with a majority of the main characters with ASD. For example, in the area of pragmatic language disorders, the biggest issue was nonverbal social rules needed for having a successful conversation. More specifically the most problematic nonverbal communication areas were reading and projecting different modes of body language (i.e., eye contact, facial expressions, gestures, body posture, tone of voice). Some of protagonists also had difficulties with pragmatic verbal skills, such as, generating language (particularly with strangers $\&$ peers) and maintaining a conversation. In regards to semantic language disorders deficiencies, the most common areas of problem for the protagonists with ASD were with understanding figures of speech, exaggerations, and jokes.

Eye contact. Several of the protagonists with ASD pointed out their inability in conversations to look people in the eye. Teachers, counselors, aids, etc. had made these main characters aware of the need to reciprocate eye contact so that it would be more 
comfortable and less confusing for people trying to have a conversation with them. Finding it extremely difficult to concentrate on the words while trying to look at a speaker's face or more specifically their eyes, many of these protagonists with ASD preferred to look away or down while listening. In the book Anything but Typical, Jason explains his frustration at having to make eye contact:

Neurotypicals like it when you look them in the eye. It supposed to mean you are listening, as if the reverse were true, which it is not: Just because you are not looking at someone does not mean you are not listening. I can listen better when I am not distracted by a person's face.

What are their eyes saying?

Is that a frown or a smile?

Why are they wrinkling their forehead or lifting

their cheeks like that? What does it mean?

How can you listen to all those words when you have to think about all that stuff? (Baskin, p. 4-5)

Knowing that they would be in trouble for not acknowledging that they were listening by having normal eye gaze behavior, some of the younger protagonists came up with alternative solutions. For example, ten-year-old Caitlin (Mockingbird) would glance quickly at another part of the speaker's face (i.e., the nose, mouth or an ear) and twelveyear-old Jason (Anything But Typical) would look sideways at the speaker. Additionally these two protagonists had learned to nod while being spoken to in order to show that 
they were listening even if they did not maintain eye contact. Caitlin's school counselor, who was trying to help her with social awareness and making friends, pointed out how looking people in the eyes showed not only that you are listening, but more importantly that you are also interested in the speakers themselves. After discussing the word "finesse", Caitlin and her counselor walked around the playground practicing the subtleties of not staring and glancing away while making eye contact. As Caitlin began making friends and looking at people who were talking to her, she also overcame her dislike of being looked at by others. Another protagonist with ASD Drea (Harmonic Feedback) really wanted to make friends at her new high school. She was extremely surprised when someone told her that she was not being friendly because she did not ever look at other people. Never equating showing perceived disinterest in her peers with this behavior of looking away/down when others were talking to her, Drea tried to increase her eye contact and thus improving her nonverbal social skills. Jason (Anything But Typical) not only had trouble with eye contact, but also had an additional problem of not recognizing many faces. With most of the girls in his class looking the same to him, his eye gaze behavior was exacerbated further.

Facial expressions/body language. As mentioned earlier another main area of contention for the protagonists with ASD in regards to pragmatic language was the inability to understand fully nonverbal signals of facial expressions and other forms of body language. Tending to rely mostly on actual verbal context, the bulk of the emotional meaning of a conversation is lost for these characters with ASD who had deficits in 
reading nonverbal cues. Not comprehending even basic facial emotions and their universal expressions, many of these protagonists with ASD were receiving only parts and/or erroneous messages from speakers. This could be seen in the disjointed thoughts, frustration, and blurting out of off-topic statements during an important job interview by one main character, Taylor Jane (Waiting for No One). She relayed to readers that there needed to be a "Mouth Code" manual so that people could match mouths with emotions. Describing the facial expression of her hopefully future employer, Taylor Jane stated, "her mouth snaps shut in a straight line. It looks like a red subtraction sign" (Brenna, p.1).

The majority of the protagonists with ASD had studied emotion charts at school. In The London Eye Mystery, Ted had been taught to read people expressions using cartoon pictures of the five basic emotions (i.e., pleased, surprised, happy, slightly cross, and angry). By examining mostly the lips, teeth, and eyes of the face, Ted would judge which of the basic emotions a cartoon represented. However he soon realized, as the other protagonists with ASD also had, that all emotions were not represented by this fivepoint basic emotion code. Equating facial expressions with hues on a color wheel, it was hard sometimes for Ted to decode all the various possible mixtures. For this protagonist predicting that the primary colors yellow and blue when combined will make the secondary color green was as hard as predicting new combinations of facial expressions beyond the five basic ones that he had been drilled on. Another protagonist Christopher (The Curious Incident of the Dog in the Night-Time) had kept a piece of paper with different facial expressions drawn by his aid folded up in his pocket to refer to when people began talking to him. However, since speakers' expressions would change too 
fast, Christopher decided it was better just to ask people what they actually meant or sometimes he just walked away if he was too frustrated. Caitlin (Mockingbird) kept studying and reviewing the facial expression chart in her school counselor's office, because when she looked at real faces this protagonist explained she just did not "get it". Even though she was a voracious reader and well above grade-level in her reading ability, this main character was having great difficulty understanding feelings and reading faces. Since her peers did not understand Asperger syndrome or her, Caitlin was trying hard to comprehend their emotions so that she might make some friends.

Mutism. The remaining five protagonists with language disorders had various types of mutism (i.e., selective mutism, traumatic mutism, etc.) $(n=5,18.5 \%)$. As mentioned before, the various protagonists with mutism differed greatly in the type, occurrence, onset, and severity of their mutism. In broad general terms, "mutism" means the absence of speech. It may be caused by a medical or neurological condition where the individual has the inability to speak. Also some underlying psychiatric disorders, such as depression, anxiety or various personality disorders, may not allow a person that has the ability to speak normally to be able or willing to converse (Addepalli, Hoffman, Ladds, Vallabhaneni, \& Hauser, 2009). Even though ASHA included selective mutism (SM) under the category of language disorders (ASHA, Child Speech \& Language), selective mutism and other types of mutisms may be classified and described from multiple perspectives and/or theoretical models. The various mutisms and the individuals who experience them are extremely heterogenous. The term selective mutism (SM) is used where an individual is able to speak in certain venues but not in others. This condition usually manifests itself during childhood. A child who is able to speak at home or in the 
community might not be able to converse at school or other specific situations (ASHA, Selective Mutism). SM is usually associated with fear and/or anxiety. In many cases children with SM also have social phobia or social anxiety (Shipon-Blum, n.d.). SE was formerly known as elective mutism (ASHA, Selective Mutism). Five symptoms that ASHA has for SM are:

1) consistent failure to speak in specific situations (in which there is an expectation for speaking, such as at school) despite speaking in other situations,

2) not speaking interferes with school or work, or with social communication,

3) lasts at least 1 month (not limited to the first month of school),

4) failure to speak is not due to a lack of knowledge of, or comfort, with the spoken language required in the social situation not due to a CD (e.g., stuttering), and

5) it does not occur exclusively during the course of a pervasive developmental disorder (PPD), schizophrenia, or other psychotic disorder (ASHA, Selective Mutism, para. 3).

Three of the five protagonists with language disorders had SM. Only one of these main characters was portrayed as having a more typical manifestation of SM. Alvin (Alvin Ho: Allergic to Girls, School and Other Scary Things) was a second grader with SM that had been occurring since the start of kindergarten. Even though, this protagonist was extremely talkative and active at home, in the neighborhood and on the school bus, once Alvin stepped on school property he could no longer speak. As Alvin explains it, "even when I try with all my might, I 
always manage to say nothing at all” (Look, p. 5). To help him cope with his fear of speaking at school, Alvin carried around a Personal Disaster Kit (PDK) that he assembled himself to be used in case of a stressful emergency when he might be unable to communicate. This PDK box included objects, such as, a whistle, garlic, four-leaf clover, scary mask, etc., and more importantly emergency detailed plans to refer to on how to deal with difficult situations like meeting your new teacher, making friends, surviving show and tell, etc. As the title of the book suggested, Alvin was scared of almost everything and had been diagnosed additionally with a performance anxiety disorder. Being small for his age and unable to speak to others, made it extremely difficult to make friends and fully participate in activities with his classmates. His brother hypothesized that Alvin used up all his words at home where he continuously talked. This protagonist had trouble conversing not only in school, but also in other stressful situations like when he was with his psychotherapist and piano teacher. Toward the end of the story, Alvin finally had a small breakthrough when he accidentally spoke to his psychotherapist while playing cards during a therapy session.

In both of the other books that portrayed protagonists with this language disorder, the onset of the SM was after a traumatic event. In the narrative Free as a Bird, eightyear-old Ruby Jean quit talking to anyone soon after she was placed in an institution. Suffering from many types of abuses in the ward, this young protagonist found that the personnel left her alone if she did not verbalize. In her own unvarnished dialect, Ruby Jean compared her newfound silence to being a small fly on the wall. 
It was like bein invisible. You could hear what others was sayin but they dint bother you -that's cause they dint notice you was there. So after I stopped talking the uniforms dint see me no more - nope, that's cause I was just like a invisible fly on the wall. (McMurchy-Barber, p.18)

Ruby Jean did not speak again until decades later when she was outside the walls of the institution and began feeling safe once more. After her living-skills teacher found her a home in a community setting with an older couple, Ruby Jean began conversing again with people.

The onset of SM for one protagonist was as a young adult. In the book Speak, Melinda quit talking to most students and authority figures at school and home shortly after starting her freshman year of high school. The majority of the students ostracized and/or treated this protagonist badly at her new school, because she had called the police to a party she had attended. As the plots unfolds, readers become aware that Melinda's withdraw and extreme depression is not only from the fact that she is being hazed and is now friendless, but she had also been raped at the party by a popular senior. Not reporting or talking to anyone about the incident, the secret that Melinda kept to herself began tearing her up inside. This protagonist felt that no one would listen to her if she did talk about it. Not diagnosing the SM, the school and Melinda's parents began treating Melinda's reluctance to speak, lack of class participation, absenteeism, and bad grades as a delinquency and behavior problem. However the last weeks of the academic school 
year, Melinda began to fight back and confronted the student rapist when he tried to rape her again. After thwarting the second rape attempt and the story about the party and first rape incident came out, Melinda began talking and becoming more positive about life. Her peers befriended and thanked her for speaking out.

Another protagonist Adam (Aftershock), who had been involved in a horrific accident, had traumatic mutism. This type of mutism develops suddenly after a traumatic event and unlike SM, the individual cannot speak in any situation to anyone (ShiponBlum, para. 14). This was the case for the main character of Aftershock. Seventeen-yearold Adam was heading home with his parents from a cross-country antiwar rally in Seattle. He was the only survivor of a single-car accident in the wooded mountains of Idaho. Stunned, Adam walked away from the crash to notified authorities about his parents. However, after awhile he became totally confused, weak, could not speak or write, and had trouble remembering the accident and his prior life's events. Adam expounded upon his inability to communicate.

It was like the formations, the structures that offered language to my thoughts, had disappeared. I didn't have amnesia exactly. Pieces of my life drifted past me like ices floes on water. It was just that things weren't connecting in my brain, as if the messages in the synapses were asteroids and shooting stars going past each other, none of them making it to their destination. (Easton, p. 39) 
Slowly over several weeks, bits of Adam's memories began coming back in fragments and flashes. Finally remembering where he lived, Adam hitched his way back to his hometown in Rhode Island where he had loved ones waiting for him. In the hospital, doctors were able to clear up an infection and set his broken ribs from a beating. Yet after six weeks of neurological testing and psychological exams, medical personnel still did not know why he was not able to speak. Adam, however, was confident he would talk again, finish high school, go to college, and continue running the family bookstore with his aunt.

The last portrayal of a protagonist with mutism was not realistic or specific. Taking place in rural modern day France, Yann (Pull of the Ocean) was a ten-year-old boy that had never spoken a word. His family and school just seemed to accept the fact that Yann did not talk. No etiological cause for the mutism was ever mentioned in the book. The CD could be either a speech or a language disorder, but since no diagnostic testing, identification, or treatment was given the cause of the mutism remained a mystery to the audience. The mutism seemed to be more just an additional colorful characteristic of the protagonist, as was the character's small stature. Even though he was ten years old and in the sixth grade, Yann was only approximately two feet tall. This protagonist excelled at school, however, no information was ever presented about how he was able to communicate with his teacher and/or other students. Yann's means of communication was a little hazy and explanations varied from narrator to narrator. In 
some cases Yann's mode of communicating seemed more telepathic. Some characters in the book stated that this protagonist signed very quickly and with minimal movement. Supposedly Yann could make himself understood by anyone he wanted to communicate with. Communicating at or above his age level, this protagonist did not appear to have any receptive communication or other sensory problems (i.e. hearing). The story's plot was a take-off of the classic tale of Tom Thumb.

Hearing disorders. According to ASHA, a hearing disorder is "the result of impaired auditory sensitivity of the physiological auditory system." This type of disorder may affect speech or language skills in terms of "development, comprehension, production and/or maintenance" (ASHA, 1993, part C). ASHA subdivides hearing loss into two categories, deaf and hard of hearing. The terminology deaf is the more severe of the two hearing disorders and is "defined as a hearing disorder that limits an individual's aural/oral communication performance to the extent that the primary sensory input for communication may be other than the auditory channel." The second type of hearing disorder, hard of hearing, also impairs an individual ability to communicate. It can be a fluctuating or a permanent hearing loss. According to ASHA an individual who is hard of hearing "relies on the auditory channel as the primary sensory input for communication" (ASHA, 1993, part C).

As was the case with several of the other kinds of CD, the protagonists with hearing disorders differed greatly not only in age and severity of their $\mathrm{CD}$, but also in the 
onset of their disorder $(n=8,29.6 \%)$. A list of the books whose protagonists had hearing disorders and the type of hearing disorder is provided below in Table 5. Included in the table is title of the book, reading/interest level, protagonists' personal characteristics (i.e., name, age, and gender) and type of hearing disorder.

\section{Table 5}

Award-Winning Books with Protagonists with Hearing Disorders

\begin{tabular}{|c|c|c|c|}
\hline Title & $\begin{array}{l}\text { Reading/ } \\
\text { Interest Level }\end{array}$ & Protagonist & Type of Hearing Disorder \\
\hline After Hamelin & Intermediate & $\begin{array}{l}\text { Penelope, } 11 \text { years } \\
\text { old; also at } 101 \text { years } \\
\text { old, female }\end{array}$ & deaf \\
\hline $\begin{array}{l}\text { The Dark Days of } \\
\text { Hamburger Halpin }\end{array}$ & Young Adult & $\begin{array}{l}\text { Will, } 16 \text { years old, } \\
\text { male }\end{array}$ & $\begin{array}{l}\text { deaf; benefited from } \\
\text { hearing aids }\end{array}$ \\
\hline Deaf Child Crossing & Intermediate & $\begin{array}{l}\text { Megan, } 9 \text { years old, } \\
\text { female }\end{array}$ & $\begin{array}{l}\text { deaf; benefited from } \\
\text { hearing aids }\end{array}$ \\
\hline $\begin{array}{l}\text { Five Flavors of } \\
\text { Dumb }\end{array}$ & Young Adult & $\begin{array}{l}\text { Piper, } 18 \text { years old, } \\
\text { female }\end{array}$ & $\begin{array}{l}\text { deaf; benefited from } \\
\text { hearing aids }\end{array}$ \\
\hline Hurt Go Happy & Young Adult & $\begin{array}{l}\text { Joey, } 13 \text { years old; } \\
\text { also when college } \\
\text { student; female }\end{array}$ & $\begin{array}{l}\text { deaf; benefited from } \\
\text { hearing aids }\end{array}$ \\
\hline Nick's Secret & Intermediate & $\begin{array}{l}\text { Nick, } 13 \text { years old, } \\
\text { male }\end{array}$ & $\begin{array}{l}\text { deaf; benefited from } \\
\text { hearing aids }\end{array}$ \\
\hline $\begin{array}{l}\text { Wonderstruck: A } \\
\text { Novel in Words \& } \\
\text { Pictures }\end{array}$ & Intermediate & $\begin{array}{l}\text { Ben, } 12 \text { years old, } \\
\text { male; } \\
\text { Rose, } 12 \text { years old, } \\
\text { also } 50 \text { years later as } \\
\text { an adult, female }\end{array}$ & deaf \\
\hline
\end{tabular}

The age range of protagonists with hearing disorders was from 9 to 101 years old. None of these main characters had been born completely deaf. However, one protagonist, Ben (Wonderstruck), had been born deaf in one ear. Ben, who was almost twelve years 
old, became completely deaf when his other eardrum was damaged by a lightning strike when he was using a telephone during a thunderstorm. The accident occurred early in the story. Doctors were unsure if the damage would be permanent. The onset of his grandmother's (Rose) hearing loss was unknown. In the early 1900s even though Rose's father was a doctor, her family was uncertain of how or when she actually became deaf. Rose's story was told not only when she was twelve years old, but again fifty years later when her grandson (Ben) made a cross-country trip to New York City looking for his father. The only other protagonist who was completely deaf was Penelope (After Hamelin). Penelope was suddenly "struck deaf" on the eve of her elevening (eleventh birthday) and the return of the Pied Piper. After Hamelin is a continuation of the Piped Piper folklore. In the classic tale the piper led the children out of the town with his magical pipe when he was not paid for his services. Unable to hear the magical instrument, the young protagonist remained behind. Penelope relayed her version of the story, continuously slipping back and forth in time from when she was eleven to ninety years later when she was 101.

These three protagonists who were deaf communicated by different means. Penelope (After Hamelin), who lived during the Middle Ages, read lips well. Ben (Wonderstruck) had just become deaf and communicated mostly with other people by writing/reading notes. His new friend was teaching him fingerspelling. Ben had just asked his grandmother (Rose) to teach him American sign language (ASL). When Rose was homeschooled and at the School for the Deaf, she had classes in lipreading and 
speaking, but her preferred method of communication was ASL. Rose's brother would make phone calls and interpret for her.

Five of the protagonists with hearing disorders benefited from hearing aids. However, Will (The Dark Days of Hamburger Halpin), who according to his IEP was profoundly deaf, did not like to wear his hearing aids because they gave him headaches. He had attended a School for the Deaf before he decided to be mainstreamed into public school classes. Will preferred ASL to English. Both of his parents could hear. He had left his old school when he clashed with some of his peers about various Deaf Culture issues. Being proficient at lipreading, Will was trying to get by in public school even though there were no interpreters, closed-captions, and all the teachers did not face him when they talked. As Will explained, attending this school was basically "sink or swim" with sink being a more likely end result. This protagonist had congenital "bad ears" that got worse. Some genetic hearing loss existed in Will's family. During a history lesson, Will learned he had a local semi-famous deaf coal-mining relative.

Another protagonist, Joey (Hurt Go Happy), who was thirteen years old at the onset of the story, had a 70\% hearing loss. Her hearing disorder was caused by physical abuse when she had been hit in the head by her father when she was six years old. Joey's sight returned after the beating, but the hearing loss was permanent. Because of expense, Joey's mother was waiting for her daughter to stop growing before she got Joey hearing aids. A neighbor benefactor, however, helped Joey apply to the School for the Deaf. He also paid for hearing aids, and other school expenses at her new educational setting. Until 
recently, Joey had always been homeschooled. Two years ago she began attending the public school where she was the only student who had a hearing disorder. Joey used a FM system at school that did not always work well. Joey also did not want to use it in all of her classes because it drew attention to her hearing loss. She was attending speechlanguage therapy and spoke well. Her mother did not want her to learn ASL.

Piper (Five Flavors of Dumb) started losing her hearing when she was six years old. She had some residual hearing left, benefited from hearing aids, and was good at reading lips. Piper's family also lived in a school district that had a deaf program in its public schools until her senior year. Even though ASL was her preferred method of communicating, Piper's speech and lipreading skills were adequate enough for her to stay at her current high school for her senior year even without her specialized program. Piper had a genetic disposition (hereditary deafness) for her hearing loss. Her maternal grandparents were deaf and her eleven-month-old sister had just received a cochlear transplant.

Both Megan (Deaf Child Crossing) and Nick (Nick's Secret) had hearing disorders due to childhood illnesses. As a baby Megan had a high fever in which she lost most of her hearing. This nine-year-old protagonist wore hearing aids and started speechlanguage therapy when she was three years old. Even though she preferred ASL, this extrovert protagonist had no reservations about introducing herself and talking to anyone. Nick was the opposite when it came to talking. He was extremely self-conscious of his speech and did not want to talk. Not being able to hear his own voice, he rarely spoke in 
class or any public setting. His severe hearing loss occurred after he got meningitis when he was in the first grade. Nick would wear his hearing aids and had a TTY phone at home.

As mentioned before some of these protagonists had trouble with their family not wanting them to know ASL. Joey's mother wanted her to be able to cope in the hearing world. She believed that if Joey learned ASL it would stunt her development of English and her ability to fit into the hearing world around her. Joey could read her mother's lips well because she had been doing it all her life. Her mother had read silently to her even as a child so as not to make noise and upset her abusive father. However, her mother's lips were the only ones she could read well. Her stepfather had a big moustache that hid not only his poor dental condition, but also his lips. Her younger brother, who was only a toddler, was just learning to talk. He did not enunciate well enough for Joey to be able to read his lips. Joey was mostly isolated when it came to communicating with others. The accidental meeting of a new elderly neighbor, who had a chimpanzee that knew some sign language, changed Joey's world. The neighbor, whose parent's had been deaf, knew not only ASL, but also the importance of a good education and how a hearing disorder could be isolating to an individual. Joey and her mother had always kept secret how Joey had lost most of her hearing. After seeing how much Joey could not communicate or join in on activities at a neighborhood gathering, Joey's mother finally let her daughter go to the School for the Deaf that the neighbor had registered Joey in. She also conceded to letting Joey and the rest of the family learn ASL so that Joey could communicate with all her family without passing notes back and forth. 
Both Megan's and Nick's family all knew ASL. This was not the case in Will's and Piper's family. Will's mother was good at ASL. When communicating with Will, she would stop and use two hands to sign with him since she knew he preferred ASL to lipreading. Will's father was not proficient at sign language. The situation was similar when it came to ASL in Piper's family. Piper's mother and brother could sign, but her father only knew a few signs and refused to use it and/or to learn more. In an argument with her father, Piper pointed out this bone of contention.

And it's not fair you never bothered to learn more than fifteen signs, even though you know it's how I prefer to communicate. All these years and the best you can do is ask how my day went, then pretend to understand my response. You don’t know a single sign to express an emotion ... happiness, sadness . . . nothing! Signing with you is like talking to a computer. (Antony, p. 198)

Another thorn in this father/daughter relationship was her college fund. Piper's grandparents, who had been deaf also, had left their granddaughter money to go Gallaudet University where she could get a good education and fit in. With her father losing his job and having no severance pay, Piper's parents had raided her college fund without telling her so that her younger sister Grace could have cochlear implant surgery. As they explained it to Piper it was a sacrifice that family members made for each other. Grace, who was born profoundly deaf, would never have a chance to learn to speak without the operation. Piper had been speaking and hearing for six years before the onset of her hearing loss. Not only was Piper disappointed about the money, but also that her father did not understand deafness from the Deaf Culture aspect. Deafness was not 
something that needed fixed or was painful. Piper's grandparents had understood that fact. Piper felt that her dad was mortified by his daughters' deafness and believed that they were impaired and had limitations. Grace had been "cured" with her implant. Piper excelled at school and was captain of the chess team. She did not feel inadequate or disabled in any way. Her father had questioned her knowing her limitations when she had become manager of a high school rock band. By the end of the story some of the layers of friction were resolved between Piper and her father. They talked out many of their troubling issues. Piper began realizing that she was "the rock of the family." Piper's father, sister, and boyfriend also began taking ASL at the local community college.

\section{Research Question 2}

How are protagonists with CDs portrayed in the selected award-winning children's and young adult literature from 2000-2012 as measured by the Rating Scale for Quality Characterization of Individuals with CDs in Children's Literature?

(a) How were the protagonists portrayed in the sections of the scale including (i) personal portrayal, (ii) social interactions, (iii) exemplary practices, (iv) sibling relationships, (v) impact of CD on plot, (vi) impact of setting on disability, (vii) point of view, and (viii) illustrations?

(b) When the CD is integral to the plot, to what extent does the character with the disability model strategies for solving challenges presented by the disability? 
The 26 books that met the criteria were read and evaluated using the Rating Scale for Quality Characterization of Individuals with CDs in Children's Literature (see Appendix A). As mentioned before this content analysis instrument was adapted from Dyches' \& Prater's (2000) Rating Scale for Quality Characterizations of Individuals with Disabilities in Children's Literature. The evaluation tool is divided into the following eight sections: 1) personal portrayal, 2) social interactions, 3) exemplary practices, 4) sibling relationships (if applicable), 5) impact of CD on plot, 6) point of view, 7) setting, and 8) illustrations (if applicable). Not only were the quality of various areas of authors' characterization being measured, but also other specific literary elements and the impact of the $\mathrm{CD}$ on the story. As was the observed practice in a prior study of characteristics of awardwinning books (i.e., Leininger et al. (2010)) the "literary quality of text" section was omitted from this rating scale since quality national award-winning books were being examined.

The majority of this characterization evaluation instrument utilized a three-point agree-disagree rating scale in the various sections of the form. An acceptable rating as a whole and for the various questions using this rating scale was any score falling into the neutral (two-point/2.0) to positive/agree (three-point/3.0) rating range. This stipulation allowed any average standard score that was greater than the cutoff of .66 (66.6\%) to be designated as acceptable. Any scores that fell into the negative/disagree range (one- 
point/1.0) were rated as unacceptable. A couple of the sections had a question or two that did not use the three-point rating scale. These questions were noted in the various sections in Table 6. They included such questions as "check all that apply", "A/B/C/D," and "Yes/No" answers. Also two sections, Sibling Relationships and Illustrations, were only used if applicable to the various selected books.

Overall the 26 evaluated award-winning books measured results on the Rating Scale for Quality Characterization of Individuals with CDs in Children's Literature were extremely positive (see Table 6 below). The literature measured well above the acceptable level in all eight categories. The range of average scores in the categories was from $94.3 \%$ to $100.0 \%$. The category that had the highest score was Point of View (100\%). The category with the lowest score (94.3\%) was Social Interactions.

Table 6 Mean Scores of Books in the Eight Categories of the Rating Scale

\begin{tabular}{|l|r|r|}
\hline \multicolumn{1}{|l|}{ Categories } & $\begin{array}{l}\text { Score } \\
\text { (3 pt. scale) }\end{array}$ & Percentage \\
\hline A. Personal Portrayals & 2.85 & $95.1 \%$ \\
\hline B. Social Interactions (B6 does not use scale) & 2.83 & $94.3 \%$ \\
\hline C. Exemplary Practices & 2.93 & $97.7 \%$ \\
\hline D. Sibling Relationships (if applicable) & 2.98 & $99.2 \%$ \\
\hline E. Impact of CD on Plot (E2 \& E3 do not use scale) & 2.88 & $95.9 \%$ \\
\hline F. Impact of Setting on Disability & 2.89 & $96.3 \%$ \\
\hline G. Point of View & 3.00 & $100.0 \%$ \\
\hline H. Illustrations (if applicable) & 2.93 & $97.7 \%$ \\
\hline
\end{tabular}


In order to understand these overall statistical averages more thoroughly, each category was broken down into its individual questions. Character descriptions, narrative excerpts, examples, etc. were used to explain the scores of these various questions in the evaluation form. The results of this closer examination of categories and questions are provided below.

Personal portrayal. Good characterization involved much more than just a description of the appearance, speech, and behaviors/actions of a character. The first section of the evaluation form, Personal Portrayal, measured such aspects of the depiction of the protagonist as: accuracy, realism, character development, interests/ strengths, similarities with others, and nondiscriminatory language. As a whole, the 27 protagonists with CDs scored well above the acceptable level in this section $(n=27$, 95.1\%). The various scores for Personal Portrayal are provided below in Table 7.

\section{Table 7}

\section{Mean Scores of Books in the Personal Portrayal Category}

\section{A. Personal Portrayal Statistics}

\begin{tabular}{|c|c|c|c|}
\hline \multicolumn{2}{|c|}{ Questions } & $\begin{array}{l}\text { Score } \\
\text { (3 pt. scale) }\end{array}$ & Percentage \\
\hline A1 & Portrays characteristics of CD accurately & 3.00 & $100.0 \%$ \\
\hline $\mathrm{A} 2$ & Describe the character(s) with $\mathrm{CD}$ as realistic & 2.95 & $98.8 \%$ \\
\hline A3 & Character(s) with CD are fully developed & 3.00 & $100.0 \%$ \\
\hline A4 & $\begin{array}{l}\text { Does not portray only CD of the character(s), but } \\
\text { portray abilities, interests, and strengths of the } \\
\text { character(s) }\end{array}$ & 3.00 & $100.0 \%$ \\
\hline A5 & $\begin{array}{l}\text { Emphasizes similarities, rather than differences, } \\
\text { between characters with and without CD }\end{array}$ & 2.70 & $90.1 \%$ \\
\hline A6 & $\begin{array}{l}\text { Uses nondiscriminatory language that avoids } \\
\text { stereotypic portrayals }\end{array}$ & 2.44 & $81.5 \%$ \\
\hline AVG & & 2.85 & $95.1 \%$ \\
\hline
\end{tabular}


Accuracy, character development, interests/strengths. All the protagonists with CDs were evaluated as being accurately portrayed (100\%) with their labels, abilities, and disabilities being consistent throughout the narratives. Another aspect that this group of protagonists all had in common (100\%) was that they were portrayed as well-rounded, fully developed, multi-dimensional and dynamic characters. These traits along with their credibility and consistency to their nature and role allowed readers to know and identify with these main characters with CDs. Every protagonist scored positively (100\%) also when looking at whether just the disabilities, deficits, and/or failures were discussed or whether the various authors represented other facets of the protagonists' personalities, lives, and interests. The protagonists were depicted as being much more than their disability. For example, in Mockingbird, readers really got to know the likes, dislikes, aspirations, and goals of the ten-year-old protagonist Caitlin, who had Asperger syndrome. Caitlin was able to grow tremendously during the story and learn about finesse, empathy, and making friends. She has some rather bizarre behaviors (e.g., sucking on her shirt sleeve, having traumatic rage meltdowns (TRMs), finding comfort hiding her head and chest under the sofa cushions, flapping hands wildly, etc.) and trouble with social interactions (e.g., reading emotions, taking words literally, being around crowds and loud noises, looking at people in their eyes, being touched, etc.). Although Caitlin had many failed attempts, in the end she was successful in not only gaining the previously mentioned skills, but also in helping her family and the community find closure after a middle school shooting that left three people dead including her thirteen-year-old brother. 
Realism. In the area of being realistic, all except one of the protagonists were judged as positive (98.8\%). The means of communication for ten-year-old Yann, who was mute, was more telepathic or surreal in the book, Pull of the Ocean, which was a retelling in contemporary times of the folk tale Tom Thumb. Yann's brothers said he could communicate complex ideas easily and quickly in a crystal clear manner with anyone that had gained his confidence. Some people explained Yann's means of communication as small gestures at supersonic speed, while others described his ability to convey information or knowledge with only his eyes or simply a smile as magical or otherworldly. The unusual multiple first person narrative approach the author used to relay the story of these brothers contributed greatly to the question of the book's realism. The story was told not only by the seven brothers, but also by various first person accounts of witnesses that came into contact with or saw the brothers on their westward journey to the ocean. Even though Yann was the undisputed leader and protagonist of the story, his point of view of any events and/or the journey are not presented until a relatively short passage close to the end of the book. Readers never learned first hand anything specific about Yann's goals, dreams, feelings, etc., except for his great desire to escape his unloving and impoverished home and to reach the ocean at all cost. No information was provided about any aspects of the mutism of this youngest and brilliant son of extremely small stature, except the declaration of his mother that "he has a tongue." Another book that had to be examined closer when it came to realism was the protagonist Penelope in After Hamelin. Like the previously acknowledged book, this 
narrative was once again based on an old legend, the story of the Pied Piper. As mentioned earlier, Penelope, the harper's daughter, had suddenly been "struck deaf" on the eve of her elevening (eleventh birthday). Being deaf to the Pied Piper's magical melody, this protagonist was able to resist and later rescue the other children of the village who had followed the musician to his enchanted home. In this story the lines between fiction and fantasy become blurred at times. The narrative showed the protagonist in three different stages or states of life: 1) as a young 11-year-old girl in the town of Hamelin, 2) as a young 11-year-old girl in a state of deep dreaming, and 3) as a 101-year-old woman who is deaf and attempting to write her memoirs. The majority of the story took place when Penelope was deep dreaming and on her quest to save the children. A question of realism was a concern when the main character was in this state since Penelope can suddenly hear again. However, the protagonist was in a fantasy-like visionary condition where she was talking to her cat and a dragon that she even challenged to a skipping rope contest. After Hamelin also had other characters without disabilities that had this gift of deep dreaming, i.e., the Pied Piper and his brother the wise counselor, Cuthbert. Thus the deep dreaming gift was not a supernatural property that only an individual with a disability had in this folk tale.

Low-scoring areas in personal portrayal. Although the overall personal characterization of the main characters had high ratings, this section of characterization received a slightly lower scoring percentage $(95.1 \%)$ than six of the other seven sections. Two questions were more problematic and caused the lower ratings overall in this section 
of Personal Portrayals. These questions dealt with the issues of emphasizing similarities (90.1\%) and non-discriminatory language (81.5\%).

Emphasizing similarities. Throughout entire narratives, several protagonists saw themselves as extremely different than other people without disabilities (e.g., Anything but Typical, Stuck in Neutral, A Curious Incident of the Dog in the Night-Time, Free as a Bird). Another main character (The Dreamer) often doubted his abilities, self-worth, and future, because of his dissimilar personal characteristics and feelings of being an outcast in the eyes of his father and much of the community. These books that received lower ratings on this question about emphasizing similarities, concentrated a major portion of their plots on how much the protagonists were different themselves and/or how dissimilar their personal living conditions and/or life experiences were from others. Being introverts or loners, this set of main characters with CDs did not have any real friends they associated with frequently. They spent much of their time alone or with family members or people they lived with. These protagonists thus scored a negative or neutral score when judging the balance of similarities and differences. Many other books did start out in a similar fashion by describing protagonists' differences more than their similarities, but the plots of these books that scored a positive rating were able to move on more quickly from the focused disability concern and thus delved into a broader array of issues or conflicts that individuals without disabilities might also experience (e.g., loss of a family member, finding closure, making friends, respect/acceptance from peers, sexual abuse, ethical dilemmas). 
An example of this emphasis on dissimilarities rather than similarities can be seen with the protagonist Jason in Anything but Typical. Jason, who had ASD, knew that his brain was different. That is why he decided to write a book/our story from a neurotypical (NT) point of view and not in his preferred personal language. This twelve-year-old protagonist pointed out that he was behind his peers in skills, such as, verbal, social performance and age appropriate behavior. Even more than his odd behaviors like hand flapping and blinking his eyes separately, people seemed to notice his silence. Wanting not to disappear and to be heard, Jason wrote stories and posted them on a monitored online children's storyboard site. The protagonist did want a friend/a girlfriend online, but he was not really interested in having friends at school or individuals he could actually do things with offline. Having difficulty reading facial expressions and body language, Jason does not like face-to-face contact usually. In the beginning of the school year it was a matter of not if, but when he would do something inappropriate. Wanting to be a writer when he grew up, Jason enjoyed creating his stories and had accepted who he was. He confessed to the audience that he knew he would never outgrow most of his labels. In his stories this protagonist could rewrite his work as many times as he needed to make the narratives come out right. As Jason describes his life:

I am like a leaf on a river, riding along the top of the water, not quite floating, not quite drowning. So I can't stop, and I can't control the direction I am going. I can feel the water, but I never know which way I am heading. (Baskin, p.16) 
Non-discriminatory language. As reported earlier, several of the books had some sort of discriminatory language (81.5\%) significant enough to lower their scoring from the positive rating. The majority of the discriminatory language terms found in the literature were much harsher than disrespectfully not using people-first language. In a couple of cases, teachers \& school personnel did emphasize the disability instead of the person and used terminology like "autistic kids" (Mockingbird) and "special needs children" (Alvin Ho: Allergic to Girls, School, and Other Scary Things). A mother also addresses her daughter who was deaf in a note as "a deaf girl" (Wonderstruck). Only one teacher blatantly used cruel and not people-first language. This faculty member, who was later fired for other inappropriate behavior, referred to her new student who was deaf as "hefty deaf newcomer" and "big deaf fatty" when she was addressing the rest of the class about the individual who was deaf (Dark Days of Hamburger Halpin).

At the institution/school in Free as a Bird many of the personnel who worked directly with the residents were extremely derogatory to the individuals. The protagonist Ruby Jean was called such names as "retard", “idiot", “widget”, “cretin", and “imbecile." The staff also made comments like the residents were "no smarter than your run-of-themill mutt" (McMurchy-Barber, p.37). In another instance, children who were walking outside the wall around the facility taunted the residents inside by calling them a "bunch of flat-faced cauliflower ears" (McMurchy-Barber, p. 33). Ruby Jean had been called derogatory names all her life inside and outside the institution. She remembered her grandmother telling her that those names were "just words and couldn't break my bones, but all the same it hurt every time somebody said them to me" (McMurchy-Barber, p.121). 
Other protagonists were also called names, teased and bullied by individuals in their communities. When one protagonist Shawn (Stuck in Neutral) was outside his house on the porch in his wheelchair, two male adolescents at the bus stop started calling him names like "Roller Derby," "Ricky Retardo," "Retardo Montobon” (Trueman, p.89). Getting no response when asking the non-verbal protagonist about the bus schedule, these relentless individuals came up on the porch and continued to taunt Shawn. Threatening to burn him with a lit cigarette lighter they had under his chin, Shawn's brother came to his brother's rescue and almost killed the adolescents. In Marcelo in the Real World, the main character Marcelo was called "a misguided retard", "an idiot", and "an imbecile" (Stork, p.285-286) when he disclosed some information about a company whose defective product disfigured a young teen. Marcelo, however, did not mind these insults and just smiled when the event occurred. When asked what he thought was so funny about the name calling, Marcelo just replied, "you are not telling me anything that you would not tell someone who was normal by your definition” (Stork, p.286). More derogatory language can be found in the book, Mockingbird. Caitlin, who has ASD, was given a hard time by one classmate whose cousin had killed her brother in a school shooting. This peer felt he was being blamed for his cousin's actions and throughout the story would say things to the protagonist like, "freak," "loser," "weirdo," "she has finally cracked," and "like a slobbering dog." As mentioned earlier, Jason (Black Swan Green), another protagonist, was teased mercilessly by a school bully. What had started out as 
harassment for going to the movies with his mother took on a different element by the end of the classmate's ribbing:

"Answer us, then." "Or c c-can't y-y-yer get the w-w-words out, yer st-ststuttery bugger?" That shot this attack into a new dimension. A hollow pit yawned where my answer should've been.

“Dicksquirt stammerstuttery mammyshagging arse-maggot.” I didn’t approach anyone because I know they wouldn’t talk to me. (Mitchell, p.197) After this incident and stickers with the word "maggot" placed on his back unbeknown to him, Jason began thinking of himself as "Jason Maggot" and the "School Stutterer".

All of the discriminatory and derogatory language being used in the narratives was not spoken by characters without disabilities. In several instances protagonists with CDs were discriminatory/derogatory when referring to their peers with special needs or even themselves (i.e., Mockingbird, Black Swan Green, Stuck in Neutral, Curious Incident of the Dog in the Night-Time). For example, in the narrative Mockingbird, Caitlin, who had high-functioning ASD, was insulted when someone called her "autistic." She replied that she was not autistic because she did not eat dirt and could talk unlike a classmate, William, who was autistic. The school counselor had to explain to Caitlin why her statement was insensitive and that she was not better than William. Even though another protagonist, Shawn (Stuck in Neutral), was unable to communicate with other 
people, he was able to express all his thoughts and feelings to readers. In his introduction to the audience, Shawn's description of himself was how he perceived other people saw and treated him in his "useless body" he had no control of. He used terms and phrases, such as, "a total retardate," "dumb as a rock," and "dumb as a fence post" (Trueman, p.4-5). Loving to use sarcasm and having a weird sense of humor, Shawn continued to utilize more derogatory terms throughout the plot, such as, "idiot", "moron", "vegetable", "a celery stalk", and "a chunk of granite". In the severely/profound disabled special education program that he participated in, Shawn knew he and his classmates were different and not "normal." His reference of his program as the "retards' class" was not meant to be cruel in his eyes. The discriminatory term "retards" was the terminology that others used for individuals in his classroom. As the protagonist explained:

Retard means "slow", but it's also a word used for a whole class of human beings who are only slow because normal people try to make everybody do things in the same ways and at the same pace. We retards are retards only because normal people call us that. (Trueman, p. 41)

In Curious Incident of the Dog in the Night-Time, the protagonist Christopher used derogatory terminology about his classmates also. Christopher attended a separate school for individuals with special needs and/or learning disabilities. This protagonist thought his classmates were stupid. Christopher knew that he was being insensitive and was supposed to say that they had special needs. He hated it when the children at the 
“normal” school nearby would call them "Special Needs!". In Christopher's eyes many things were stupid. It was something he thought about often. Christopher was going to take his "A levels" exams in Math when he was only fifteen. Taking the tests ahead of schedule would show everyone he was not stupid.

Of all the protagonists in the eligible books, the two protagonists who had the severest conditions either in terms of living standards, mobility \& non-communication issues, and/or emotional or psychological abuse, also had the lowest percentages in the section of Personal Portrayals on the evaluation form. Ruby Jean (Free as a Bird) had an overall score of $77.7 \%$ while Shawn (Stuck in Neutral) scored an $83.3 \%$. Both of these protagonists fell in the neutral or negative/disagree range on the evaluation form with the two questions of personal portrayal that dealt with emphasizing similarities rather than differences and using nondiscriminatory language. Descriptions and examples of the various emphases on differences and use of the nondiscriminatory language used by the protagonists themselves or other characters in the plot have been presented previously.

Social Interactions. The second section of the evaluation form is Social Interactions. As stated before this section scored the lowest of all sections on the evaluation form (94.3\%). Social Interactions looked at aspects, such as, reciprocal and various relationships of the protagonists, acceptance, empathy (not pity), positive social contributions, and respect. The first five questions utilized the same three-point agreedisagree rating scale used in the first section. The overall average of the 27 protagonists with CDs once again scored will above the acceptable level in this section on Social Interactions for the five questions using the agree-disagree rating scale ( $n=27,94.3 \%)$. 
The sixth question of Social Interactions examined the various kinds of relationships the protagonists with CDs had with others characters. It did not utilize the three-point agreedisagree rating scale. This question on various relationships and the method utilized to collect information will be discussed more thoroughly later in the chapter. The various scores for on the evaluation form for the section Social Interactions can be found below in Table 8 .

Table 8

Mean Scores of Books in the Social Interactions Category

\begin{tabular}{|c|c|c|c|}
\hline \multicolumn{2}{|c|}{ Questions } & \multirow{2}{*}{$\begin{array}{l}\text { Score } \\
\text { (3 pt. scale) } \\
2.85\end{array}$} & \multirow{2}{*}{$\begin{array}{r}\text { Percentage } \\
95.1 \%\end{array}$} \\
\hline B1 & $\begin{array}{l}\text { Depicts character(s) with CD engaging in socially } \\
\text { and emotionally reciprocal relationships with a } \\
\text { wide variety of persons }\end{array}$ & & \\
\hline B2 & Depicts acceptance of the character(s) with CD & 2.70 & $90.1 \%$ \\
\hline B3 & $\begin{array}{l}\text { Promotes empathy, not pity for the character(s) } \\
\text { with CD }\end{array}$ & 2.93 & $97.5 \%$ \\
\hline B4 & $\begin{array}{l}\text { Portrays positive social contributions of person(s) } \\
\text { with CD }\end{array}$ & 2.81 & $93.8 \%$ \\
\hline B5 & Promotes respects for the character(s) with $\mathrm{CD}$ & 2.85 & $95.1 \%$ \\
\hline AVG & & 2.83 & $94.3 \%$ \\
\hline
\end{tabular}

Reciprocal relationships. When it came to reciprocal relationships, the protagonists scored positively $(95.1 \%$ overall) except for two main characters, Shawn (Stuck in Neutral) and Christopher (Curious Incident of the Dog in the Night-Time), who both scored negatively. Having no control of any of his muscles, Shawn was not able to 
express his feelings, ideas, thoughts, etc. himself and his family, classmates, and teachers did not know how much he comprehended receptively. Christopher lived in his own world most of the time and was not really interested in developing relationships. He did communicate with his father and school personnel on a regular basis. This protagonist, who loved Sherlock Holmes mysteries, grew tremendously during the story when he decided to question individuals in his neighborhood to try and find out who had killed his neighbor's dog. His detective skills not only found the dog killer, but also led him to discover and reconnect with his mother, who he had been told had died recently after a stay in the hospital.

Acceptance. The question that examined acceptance of protagonists with CDs scored the lowest in Social Interactions (90.1\%). Even though protagonists with CDs scored overall well above the acceptable level, three main characters scored a "disagree" on the rating scale for this question. Shawn (Stuck in Neutral), Christopher (Curious Incident of the Dog in the Night-Time) and Jason (Anything But Typical) scored negatively when it came to acceptance from other people. As discussed before Shawn and Christopher, who did not have reciprocal relationships with others, were not really accepted by their peers or individuals in the community. Shawn could not communicate with his family or anyone else, while Christopher only communicated minimally with his father. Jason was accepted by his family. However, he only had one person, Aaron, who stood up for him at school. Most of Jason's peers thought this protagonist was weird. 
Many were unfriendly toward Jason and several students teased him. His one online friend, Rebecca, was not accepting of him either when she first met him at a writing conference. Even though Rebecca had been anxious to meet Jason in person, his inability to carry on a conversation and to look at her turned her friendliness off. At the end of the conference, Rebecca did talked to him again to ask him to continue writing to her online. One protagonist, Cornelia (Tending to Grace) scored neutrally when it came to acceptance. Having trouble communicating with others, she had previously been a loner. Some people, accepting of her disfluency, would wait for her to be reply. Others would dismiss her when she had trouble speaking. When Cornelia started speaking and standing up for herself, she began receiving more acceptance from the school and community.

Promote empathy. Overall the protagonists with CDs scored well when it came to empathy (97.5\%). Even in various books like The Curious Incident of the Dog in the Night-Time, Stuck in Neutral, and/or Anything but Typical where main characters scored low in other social interaction skill (i.e., reciprocal relationships and/or acceptance) pity was not felt for these protagonists. Shawn's life seemed harsh without being able to communicate with anyone and not having control of any of his muscles, but the author presented this protagonist's ideas and feelings in such a positive way that readers felt empathy for Shawn and not pity. Shawn loved his life, had a sense of humor, and wanted to keep living and experiencing existing and new situations. The only protagonist that 
pity was felt for was Ruby Jean (Free as a Bird). This main character scored a negative rating on this question. Much of Ruby Jean's life in the institution seemed cruel and hopeless. The descriptions of the living conditions and treatments that this protagonist with CD had to endure on the ward for most of her childhood and early adulthood showed a real lack of compassion by the caregivers. The harsh institutional life of the late $20^{\text {th }}$ century created pity and sorrow for individuals existing in these settings. Ruby Jean's life did become much more positive once she left the institution, began living in a family situation again, and had a job.

Social contributions. The majority of the main characters made noticeable positive contributions (93.8\%) to their families, peers and/or community. For example, Marcelo (Marcelo in the Real World), having found the picture of a young accident victim in his father's law office, diligently pursued the circumstances causing the accident and lawsuit. Even though reporting undisclosed memos about the accident to the prosecuting lawyer caused him to have to leave the private school and its stables that he loved, Marcelo did what he thought was right and helped get the needed insurance money and operations for a victim he had never met. Nick (Nick's Secret) also helped out a stranger. A teenage girl had been left with the care and training of her family's famous pedigree herding dogs while her father took their ailing grandmother back to Scotland. Not only had the girl ran out of money, but a man, who had already stolen one dog, was trying to kidnap the rest of the dogs. Nick not only helped find new shelter and food 
for the dogs, but also aided in getting the man arrested and the girl reunited with her father. Another protagonist, Ted (London Eye Mystery) gained respect from his family and police when he solved the mystery of his cousin's disappearance. Because of his logical brain and deductive reasoning ability, Ted, with the aid of his family, was able to rescue his cousin from an abandoned building on the eve before the dwelling was demolished. In the area of social contributions, Shawn (Stuck in Neutral) and Christopher (The Curious Incident of the Dog in the Night-Time) once again scored negatively on the rating scale. Jason (Anything but Typical) had a neutral score since he helped some writers online with their stories and also his peers a couple of times with their language arts assignments.

Respect. When it came to authors promoting respect for the protagonists with CDs, the overall score was $95.1 \%$. No main characters scored negatively on the question about respect, but four protagonists did have a neutral rating. Jason's (Black Swan Green) respect from his peers varied greatly during the course of the plot. Like many teenagers, Jason was trying to find his social ranking in his peer group. Most of the time this protagonist was neutral or in the middle of the pack when it came to respect. However, during the spring semester Jason was bullied a lot. His personal and peer respect plummeted during this time. Later when the bullying and extortion by Jason's nemesis and his cohorts was brought out in the open, Jason's respect improved was again.

In the area of respect, Alvin (Alvin Ho: Allergic to Girls, School, and Other Scary Things) also received a neutral rating. The esteem of this protagonist, who was unable to 
talk at school, varied in his school and in the neighborhood. Alvin had some friends at school that would stand up for him, but other times he was left out of games at recess because he could not speak up. Alvin also tried to win popularity and friends in his neighborhood by giving away his brother's valuable baseball cards. After having to perform some initiation acts he was opposed to, this young protagonist decided he did not really enjoy being told what to do or the company of these popular peers. Alvin realized that he liked interacting better with his less popular friends, who would stand up for him, not be bossy, and had interests similar to his.

Various relationships. The sixth question of Social Interactions examined the kinds of relationships the protagonists with CDs had with others characters. This question was broken down into seven parts. A combination of multiple choice and yes/no questions were used to collect facts about such information as, primary relationships with others, in what kind of relationship are protagonists primarily portrayed (i.e., dependent, victim, pupil, etc.), do other characters fear associating with or have feelings of guilt relating to the protagonists with CDs, and what kind of changes (i.e., positive, neutral, negative) do characters without disabilities have after interacting with protagonists with CDs. The scores for the sixth question of Social Interactions are found below in Table 9. 
Table 9

Mean Scores of Books in the Social Interactions Category Question B6

\section{B6. Social Interactions Statistics}

B6. Depicts various relationships between character with a CD and others.

\begin{tabular}{|c|c|c|c|}
\hline \multicolumn{2}{|c|}{ Questions } & Number & Percentage \\
\hline \multirow[t]{5}{*}{ B6a } & \multicolumn{3}{|c|}{ Character with a disability has primary relationship with: } \\
\hline & Friend & 20 & $74.1 \%$ \\
\hline & Sibling & 14 & $51.9 \%$ \\
\hline & Paid personnel & 5 & $18.5 \%$ \\
\hline & Other & 26 & $96.3 \%$ \\
\hline \multirow[t]{6}{*}{$\mathrm{B} 6 \mathrm{~b}$} & \multicolumn{3}{|c|}{ Character with a CD is primarily: } \\
\hline & Victim & 12 & $44.4 \%$ \\
\hline & Perpetrator & 0 & $0 \%$ \\
\hline & Protector & 7 & $25.9 \%$ \\
\hline & (Initiator) & 21 & $77.8 \%$ \\
\hline & None & 0 & $0 \%$ \\
\hline \multirow[t]{3}{*}{ B6c } & \multicolumn{3}{|c|}{ Character with a $\mathrm{CD}$ is primarily: } \\
\hline & Dependent & 27 & $100.0 \%$ \\
\hline & Caregiver & 2 & $7.4 \%$ \\
\hline \multirow[t]{4}{*}{ B6d } & \multicolumn{3}{|c|}{ Character with a CD is primarily: } \\
\hline & Pupil & 26 & $96.3 \%$ \\
\hline & Instructor & 0 & $0.0 \%$ \\
\hline & Other & 3 & $11.1 \%$ \\
\hline \multirow[t]{3}{*}{ B6e } & \multicolumn{3}{|c|}{ Do other characters fear associating with the character with a CD? } \\
\hline & Yes & 7 & $25.9 \%$ \\
\hline & No & 20 & $74.1 \%$ \\
\hline
\end{tabular}


Table 9 (continued)

Mean Scores of Books in the Social Interactions Category Question B6

\begin{tabular}{|c|c|c|c|}
\hline \multirow[t]{2}{*}{ B6f } & \multicolumn{3}{|c|}{$\begin{array}{l}\text { Do other characters experience feelings of guilt related to the character with } \\
\text { a CD? }\end{array}$} \\
\hline & Yes & 8 & $29.6 \%$ \\
\hline & No & 19 & $70.4 \%$ \\
\hline \multirow[t]{4}{*}{ B6g } & \multicolumn{3}{|c|}{$\begin{array}{l}\text { What changes take place in character without disabilities as a result of their } \\
\text { interactions with the character with a CD? }\end{array}$} \\
\hline & Positive & 26 & $96.3 \%$ \\
\hline & Neutral & 1 & $3.7 \%$ \\
\hline & Negative & 0 & $0.0 \%$ \\
\hline
\end{tabular}

Primary relationships. The first part of this question examined the meaningful and expanding primary reciprocal relationships the protagonists with $\mathrm{CD}$ had with other individuals. As Dyches \& Prater (2005) stated the deepest relationships between a character with a disability and another character are ones "in which characters share many common experiences and, if possible, they share thoughts and beliefs." This first type of primary relationship theme examined closer primary relationships with friends, siblings, paid personnel and others. The highest incident of primary relationships depicted was with "others" ( $n=26,96.3 \%)$. This category had such a high frequency because almost all the protagonists with $\mathrm{CD}$ being children/adolescents had a primary relationship with their parent(s). Parents were not included in any other category on the evaluation form. The category of "others" not only included parent(s), but grandparent(s), other extended family members (cousins, aunts, uncles, etc.), neighbors, foster parents, etc. Only one protagonist with CD, Yann (Pull of the Ocean), did not have a close 
relationship with his parents or another adult caregiver. Yann's caregivers from the time he had been born were his older brothers. Even though Ruby Jean (Free as a Bird) did not have a reciprocal primary relationship with her mother who had placed her in the institution, she had had a close relationship with her caregiver grandmother and later her foster parents when as an adult she began living in a community setting. The primary relationship with the next highest incident was friends $(n=20,74.1 \%)$, followed by siblings $(n=13,48.1 \%)$, and paid personnel $(n=5,18.5 \%)$. As seen by the statistics, a majority of the protagonists with CDs had at least one close friend that was not a family member or paid personnel. Some main characters made friends easily (i.e., Carter in Carter Finally Gets It, Megan in Deaf Child Crossing), while others had to actively pursue it (Caitlin in Mockingbird, Drea in Harmonic Feedback, Alvin Ho in Alvin Ho: Allergic to Girls, School, and Other Scary Things). A high frequency of the protagonists also had close relationships with siblings. Since only sixteen of the main characters had siblings, all but three individuals currently had a reciprocal primary relationship with their brothers and/or sisters. Only one protagonist, Ruby Jean, was estranged from her sibling. This institutionalized protagonist had only met her baby half-brother once when her remarried mother brought him on her last visit to the institution. In the other two books where the protagonists with CDs did not have a reciprocal primary relationship with their siblings the situation was quite different. In these cases the siblings were not around much, either because an individual was away at college or the plot was taking place a majority of the time away from the setting of the home. Five of the protagonists 
had primary reciprocal relationships with paid personnel. In this study paid personnel included such individuals as teacher aids, counselors, and speech-language pathologists/ audiologists. Having close reciprocal relationships with these paid personnel, provided the main characters with individuals other than their parents to whom they were able to express their feelings and discuss many topics that concerned them, such as, making friends, reading facial and body expressions, closure of sibling/parent death, dealing with their disability, etc.

Victim, perpetrator, protector, and/or initiator. Being dynamic, evolving characters, the protagonists with CDs took on different primary relationship roles/themes with other characters as their lives and stories unfolded. Another of the primary relationship theme that the book evaluation form measured was the area of victim, perpetrator, and/or protector. None of the protagonists with CDs were represented as perpetrators $(n=0,0.0 \%)$. At some point during the plots, however, nearly half of these characters were primarily portrayed as victims $(n=12,44.4 \%)$. The majority of victimizations that occurred were more typical or common forms that are found in other juvenile literature, such as, name-calling, teasing, knocking books out of owner's hands, grabbing book bags, etc. In some cases the bullying did escalate into shoving, kicking, hitting, extortion, and even threats of being burned with a cigarette lighter, etc. (i.e., Black Swan Green, Stuck in Neutral). However, victimization was found to be much worse for a few of the protagonists. For these main characters, occurrences of physical, emotional, and/or sexual abuse was made not only by classmates, but also by parents, peers' parents, and/or 
institutional personnel (i.e., Speak, Hurt Go Happy, Sweethearts, Free as a Bird). The onset of the majority of the victimization occurred at the beginning of the stories and/or in flashbacks to earlier scenes/times in the main characters' lives. Most of the protagonists with CDs were able to grow and move on from these initial victim roles and in some cases take on new roles (i.e., protectors and/or initiators). In other instances, the majority of books' plots centered around the dire conditions of the protagonists' lives, causing the main characters to remain in the victim role for all or the majority of the stories (Stuck in Neutral, Free as a Bird).

Over a fourth of the protagonists with CDs acted as protectors $(n=7,25.9 \%)$. These main characters helped to protect other child characters. They stood up and protected their friends, siblings, and sometimes even strangers that just needed help. For example, Marcelo (Marcelo in the Real World) helped an unknown young female teenager, who had been disfigured in a wrongful accident, to receive further medical help and compensation. As mentioned before, Nick (Nick's Secret) aided a female teenage stranger he met during a blizzard, who not only needed food for herself and dogs, but protection from a thief who was trying to steal her family's valuable dogs.

Another primary role the protagonists played were initiators $(n=21,77.8 \%)$. This term was not included as one of the choices of primary relationships on the evaluation tool, but evolved as the evaluators began comparing scores. Initially for some book evaluators/readers the term "perpetrator" in the evaluation form was not seen as having a negative connotation as is often the case in common American usage. The Oxford 
Learner's Dictionary defines "perpetrator" as "a person who commits a crime or does something that is wrong or evil" (Perpetrater, n.d.). Instead some readers perceived the term "perpetrator" in a more positive and broader light as if a derivative of the Latin word "perpetratus" meaning to "carry through, accomplish" (Glare, Oxford Latin Dictionary, p. 1486). Readers reevaluated all protagonists with CDs using the more common negative definition of "perpetrator". The term "initiator" (defined as an individual who brings about change) was introduced as a primary role choice in response to the more positive reaction to the term "perpetrator". This added term of "initiator" showed which protagonists with CDs had significant initiation that helped them grow, accomplish tasks and have more control of their lives. As noted before, over three-quarters of the protagonists were "initiators" who took control of their lives and grew tremendously during the stories.

Dependent, caregiver. All of the protagonists with $\mathrm{CD}$ were children and/or dependents at some time during the stories $(n=27,100 \%)$. The level of dependency or amount of care needed varied from protagonist to protagonist. Some of the protagonists were in grade school while others were in or had just completed high school. Some main characters also had other disabilities other than a CD. For example, both Melody (Out of my Mind) and Shawn (Stuck in Neutral) had severe cerebral palsy and were dependent on others for extensive care for daily living skills, such as, eating, dressing, going to the bathroom, etc. Only two main characters were depicted as caregivers $(n=2,7.4 \%)$. Even though three protagonists were portrayed as adults also, only one of these adults, Rose 
(Wonderstruck), had a family and was ever a caregiver. One protagonist, Cornelia (Tending to Grace), was both a dependent and simultaneously a caregiver. In grade school she had begun cleaning, cooking and taking care of her depressed mother, who often would not go to work, clean the house, eat, or even get out of bed. Cornelia had continued looking after her mother until her freshman year of high school when her mother and new boyfriend abandoned the teenager at her great aunt's house so that they could try and make a new start in Vegas. Living in a stable home and no longer having to worry about her mother, Cornelia was able to act her age once again and come to terms with her life.

Pupil, instructor. Since most of the selected literature took place in realistic contemporary settings and a majority of the main characters with CDs were children during the entire plots, the frequency of being pupils was very high $(n=26,96.3 \%)$. One of the main characters, Taylor Jane (Waiting for No One) was even taking a college Biology class. Some of the stories did take place over the summer or during a school break/family vacation. In these cases the protagonists with CDs were not actually in school, but would be attending school once it started again (i.e., Deaf Child Crossing, London Eye Mystery, Aftershock, Wonderstruck, etc). Many of the stories did have at least part of the plots taking place in a school setting. None of the main characters with CDs were really instructors in the sense of being classroom teachers $(n=0,0 \%)$. Cornelia (Tending to Grace), however, did teach her illiterate great aunt to read and also helped her young neighbor with her literacy. Even though they spoke and read lips, a couple of 
the protagonists with CDs, who were deaf (Megan in Deaf Child Crossing, Joey in Hurt Go Happy), taught friends and family members some sign language in order to be able to communicate easier. Three of the protagonists with CDs were not only children during the stories, but also adults (Rose in Wonderstruck, Ruby Jean in Free as a Bird, and Penelope in After Hamelin). As adults these main characters fell into the "other" category since they were neither pupils nor instructors $(n=3,11.1 \%)$. Additionally these three books were historical fiction since their settings took place over a quarter of century from when they were written. Living in different settings and times than those of the contemporary realism main characters, these three protagonists with CDs had educational opportunities that contrasted greatly to modern schooling. In the 1920s for Rose, who was deaf, no allowances existed for her to be able to attend regular public school. Therefore, she was home schooled with a tutor, until her older brother found and encouraged their parents to allow his sister to attend a School for the Deaf. Females did not attend school at all in Germany in the Middle Ages, which was the setting for After Hamelin (Penelope). Even though Penelope's father took apprentices to train in the harper's craft, this trade was for males only. Another historical fiction, Free as a Bird, initial setting was a British Columbian institution in the 1950s. This protagonist with CD, Ruby Jean, was only allowed to attend school as a child in the institutional setting for a short time. The reason for her limited schooling was that there was not enough room for all the institutionalized school-age children to be able to attend classes. Once she reached adulthood and institutions began placing individuals back into community settings, Ruby Jean became a pupil/student again and began receiving one-on-one living-skills training. 
Fear of association. Only in approximately one-quarter of the books did any characters fear associating with the protagonists with CDs $(n=7,25.9 \%)$. Individuals may fear associating with individuals for a variety of reasons. Since this study is examining intermediate children and young adult books, many of the main characters and their peers are the same age as the age level the books are intended for. At this age level peer acceptance and finding one's social standing is important. Many of the non-disabled characters in these selected books that feared associating with the protagonists with CDs, are afraid or embarrassed to be around people who are different because people might think they are different also. Other times individuals, who have lived in a micro-culture, are at first uncomfortable associating with people who are unlike them whether it be diversity of race, culture, disability, etc. For example, some students did not want to associate much with Melody (Out of My Mind) because they did not understand her disability. Since she used a wheelchair, could not feed herself, and had difficulty communicating with others, many of Melody's peers at first were not friendly toward her. Many of her peers and even some faculty thought she had an intellectual disability. Ironically some classmates still feared her even after this protagonist received her special computer in which she was finally able to communicate and show the rest of the world all that she knew. This fear of association, however, was for Melody now being able to replace them on the school's quiz bowl. Classmates did not fear associating with Jason 
(Black Swan Green) until he began to get bullied and teased. Then many former friends and peers would avoid him, because they did not want to drop in their social ranking and/or become the next victims of the bully and his friends.

Some fear of association did exist for a few of the protagonists because they exhibited behaviors that were different than their classmates. For example, Both Jason (Anything But Typical) and Caitlin (Mockingbird) not only had some unusual body language, like flapping hands and not making eye contact with people, but they also had tantrums and meltdowns at school. Some children (and parents) at first were afraid of these two main characters with CDs. Another protagonist with ASD, Christopher (Curious Incident of the Dog in the Night-Time), had great difficulty in dealing with new situations and crowds. When Christopher found himself outside his comfort range while traveling alone looking for his mother, this protagonist modeled many bizarre behaviors to avoid and/or keep people away from him. For example, in one instance Christopher hid in the train's small luggage compartment to feel safe. He also barked and growled at people who came too close to him or attempted to talk with him at a station. In these specific instances people did fear associating with Christopher and stayed away from him.

Feelings of guilt. Other characters only exhibited feelings of guilt toward the protagonists with CDs in approximately thirty percent of the books $(n=8,29.6 \%)$. A range of individuals felt these feelings of guilt. Sometimes classmates and/or friends felt guilty for their treatment of the protagonists in specific instances. For example, in Anything but Typical, Jason's close Internet friend, Rebecca, was shocked when she first 
met him in person at a story-writing conference. She talked to Jason's mother instead of to him and even avoided Jason the next several days. At the end of the conference, however, Rebecca began to talk to Jason again and wanted to continue their friendship online on the story-writing website. In Out of my Mind, some of Melody's friends and the faculty member, who was head of the school's quiz bowl, felt bad about not calling and telling Melody and her parents about the earlier flight that needed to be taken to attend the national quiz bowl competition. Only one member of the quiz bowl team wanted to tell Melody about the earlier flight. The rest of the team felt guilty only after they did not win the bowl without Melody, one of their star members. In Mockingbird the physical education teacher felt guilty and apologized to Caitlin and the class for making the statement "Why do they give me all the autistic kids!" (Erskine, p. 182).

In other occurrences individuals felt guilty for the treatment or inappropriate behavior a protagonist with $\mathrm{CD}$ had to endure over time or in a specific situation. For example, various occupational therapists felt awful on how Ruby Jean (Free as a Bird) had been treated in the past and even in the present in the institution. Her foster parents also felt bad when Ruby Jean ran away and lived on the streets for a while when she erroneously thought she might be sent back to the institution after one parent suffered a heart attack. Both a classmate and a mother felt great remorse and guilt for a childhood incident that happened to one protagonist. As children, Jenna and Cameron (Sweethearts) were together when Cameron's father threatened them with inappropriate sexual and physical abuse. Cameron felt bad for not being able to protect his best friend better. 
Jenna's mother felt bad when she learned a decade later about the incident. Her mother also regretted all the afternoons and evenings that she had left her daughter alone in order to get an education and make a better life for them. In The Curious Incident of the Dog in the Night-Time, the protagonist's father felt sorry for lying to his son, Christopher, about his mother. Instead of telling Christopher that his mother had left them, his father told him that his mother had died. Christopher's father regrettably had never given to his son any of his mother's many letters she had sent him after she left.

Several parents had feelings of guilt specifically for the disabilities their children had. For example, Joey (Hurt Go Happy) had lost most of her hearing from physical abuse by her biological father. Her mother not only felt sorry for not having left her husband sooner, but also for not letting Joey learn sign language. In Stuck in Neutral, Shawn's father felt that his son was in great pain and was suffering. He wrote articles and went on talk shows defending another father who had euthanized his son. The feeling of guilt was great for this parent who was contemplating taking Shawn's life. Melody's mother (Out of my Mind) also had feelings of guilt about Melody having severe cerebral palsy. She kept thinking that she might have done something during the pregnancy to cause the cerebral palsy.

Changes with characters without disabilities. Overall the changes that occurred to characters without disabilities from their contact with the protagonists with CDs were found to be rewarding $(n=26,96.3 \%)$. All the protagonists measured positive on the evaluation form when it came to eliciting change in others, except for one main character, 
Christopher (The Curious Incident of the Dog in the Night-Time). This character that preferred to be alone had a neutral rating when examining his affect on other characters. The dynamic and evolving lives of the majority of the protagonists with CDs gave many of the other characters that they had relationships with, whether it be siblings, classmates, friends, teachers, parents, etc. a greater understanding and/or appreciation of the character with CD. For example, Ted's analytical mind (London Eye Mystery) and great observation of details helped this protagonist and his sister solve the mystery of his cousin's disappearance and inevitably saved his life. At one point, Ted's sister even cocked her head sideways to try and see/experience the gathered documentation and notes from her brother's perspective.

During the plots several parents and guardians gained a greater understanding and insights into the lives, thoughts, and feelings of the protagonists with CDs. When Jason (Anything but Typical) and his mother went to the story-writing convention, the two characters had to work together and help each other out to cope with new situations that came up. Jason's mother helped him with meeting new people and attending workshops. Jason aided his mother with the GPS system and electronic card room keys at the hotel. The protagonist, Piper (Five Flavors of Dumb) not only aided her father in developing a greater understanding of the Deaf Culture, but helped pull her family back together after economic hardships. A cohesiveness and greater understanding also developed between the protagonist Cornelia and her great aunt after they had been thrust together unexpectedly (Tending to Grace). These two helped each other establish a better life and 
standard of living. Cornelia was finally given a stable home and learned to stand up and speak for herself again. Cornelia not only helped her great aunt with chores and cleaning up the homestead, but also, as mentioned before, to learn to read. Both of these characters reestablished their expectations of themselves and their family life.

Exemplary Practices. The third section measured by the evaluation form is Exemplary Practices. This section examined opportunities of full citizenship, appropriate services, valued occupation, and self-determination of the protagonists. All four questions utilized the three-point agree-disagree rating scale. The overall average for this section was high (97.7\%). Two of the questions received a perfect score $(100 \%)$. The range of scores was $93.7 \%$ to $100 \%$. The scores for this section can be viewed below in Table 10 .

Table 10

Mean Scores of Books in the Exemplary Practices Category of the Rating Scale

\section{Exemplary Practices Statistics}

\begin{tabular}{|c|c|c|c|}
\hline \multicolumn{2}{|c|}{ Questions } & \multirow{2}{*}{$\begin{array}{l}\text { Score } \\
\text { (3 pt. scale) } \\
2.93\end{array}$} & \multirow{2}{*}{$\begin{array}{r}\text { Percentage } \\
97.5 \%\end{array}$} \\
\hline $\mathrm{C} 1$ & $\begin{array}{l}\text { Depicts character(s) with CD having full } \\
\text { citizenship opportunities in integrated settings } \\
\text { and/or activities. }\end{array}$ & & \\
\hline $\mathrm{C} 2$ & $\begin{array}{l}\text { Depicts character(s) with CD receiving services } \\
\text { appropriate for their age, skill level, and } \\
\text { interests. }\end{array}$ & 2.81 & $93.7 \%$ \\
\hline $\mathrm{C} 3$ & $\begin{array}{l}\text { Depicts valued occupations for character(s) with } \\
\text { CD. (if applicable) }\end{array}$ & 3.00 & $100.0 \%$ \\
\hline $\mathrm{C} 4$ & $\begin{array}{l}\text { Promotes self-determination where choices are } \\
\text { similar to the types of choices given to } \\
\text { nondisabled peers. }\end{array}$ & 3.00 & $100.0 \%$ \\
\hline AVG & & 2.93 & $97.7 \%$ \\
\hline
\end{tabular}


Full citizenship. The majority of the protagonists with CDs were portrayed positively on the rating scale when measuring full citizenship opportunities. Only two main characters received lower scores. Ruby Jean (Free as a Bird) and Shawn (Stuck in Neutral) only scored a neutral on this question. Ruby Jean received a neutral score because she had been in the segregated setting of an institution without any educational options for most of her childhood and young adulthood. Her citizenship opportunities had been poor to non-existence. Shawn had been accepted and treated well by his family and was attending school. However, having to rely totally on others for all his needs and having no means to communicate with people, Shawn did not have recourse for full citizenship.

Receiving appropriate services. The lowest percentage in Exemplary Practices was found in the area of receiving appropriate services (93.7\%). The protagonist in Speak scored negatively because having never been diagnosed by the school or outside services, she went without much needed services/counseling. Also scoring low in this area were the books Free as a Bird and Alvin Ho: Allergic to Girls, School, and Other Scary Things. In the institution, Ruby Jean (Free as a Bird) was mistreated and did not receive the educational and life skill training skills she should have had as a child and teenager. Later as an adult she finally had access to a life-skill instructor, who taught her needed skills to live in the outside world. This instructor also helped initiate Ruby Jean to be moved out of the institution and into a community setting. Once in the community, Ruby Jean received more training from her foster parents and at the sheltered workshop. One 
protagonist, Alvin Ho (Alvin Ho: Allergic to Girls, School, and Other Scary Things), had not ever spoken a word in school. Even though his parents had him receiving help outside of the school with a psychotherapist, the school should have been providing this young student some type of services and accommodations for his selective mutism. Cornelia (Tending to Grace) had not received speech-language therapy in her previous school or in the community. Instead this protagonist had been placed in the lower English classes since she did not talk in class or to most peers and/or teachers. Once Cornelia finally began attending school again after her relocation, she began receiving services.

Several of the protagonists with CDs were not currently receiving services because it was summer and school was not in session (Deaf Child Crossing), the CD had just happened (Wonderstruck), the CD was mild enough that services were not required (Carter Finally Gets It), or the protagonist was from a different time and setting (After Hamelin, The Dreamer). In Pull of the Ocean, Yann's inability to speak was not an issue in school, with his brothers, or when he wanted to communicate with someone. As mentioned before, Yann was unrealistically able to communicate when needed. A social worker did check on his home situation when this protagonist was distraught at school one day because he did not have his schoolbag and books since his father had dropped them in the well. 
Valued occupation. All the protagonists that had part or full-time jobs had depicted valued occupations $(100 \%)$. The two adults who had full time jobs were employed as a designer for a major museum (Rose in Wonderstruck) and a harper during the Middle Ages (Penelope in After Hamelin). As an adult, Ruby Jean (Free as a Bird) worked first at a sheltered workshop and later at a nursery where she built flower boxes and birdhouses. The younger protagonists who had part-time jobs had valued employment also. For example Piper (Five Flavors of Dumb) managed a band, Marcelo (Marcelo in the Real World) worked in the mailroom at his father's law office and had previously worked with the Haflinger ponies in the stables at his private school. As a teenager, Neftali (The Dreamer) had been employed at his uncle's printing company. Later he became a Pulitzer writer. Both Nick (Nick's Secret) and Taylor Jane (Waiting for No One) worked part-time in stores. Nick worked in a pet store, while Taylor Jane was employed at a bookstore.

Self-determination. All 27 protagonists were measured as having selfdetermination (100\%). These main characters with CDs were able to set goals and accomplished them. Several of the plots focused more on characters with CDs making short-term goals. For example, Caitlin (Mockingbird) was able to make friends and find closure for not only herself and her father, but also the community for the recent school shooting. Ten-year-old Yann (Pull of the Ocean), who wanted to get away from his 
parents and dire home life, planned and journeyed to the ocean with his brothers. This protagonist then stowed away on a freighter heading west across the Atlantic. In Wonderstruck, Ben ran away taking a cross-country bus ride alone to try and find the father he had never met. Even though, he did not meet his father who had died, Ben did find and start a relationship with his grandmother and great uncle. Even Shawn (Stuck in Neutral) who could not control any of his muscles voluntarily had goals he wanted to accomplish in his life. The outside world did not know about his goals and selfdetermination, but readers were well aware of them.

Many protagonists were also making long-term goals and looking toward their futures. For example, Ted (London Eye Mystery) was fascinated with weather and wanted to be a meteorologist. Another protagonist, Jason (Black Swan Green) decided he wanted to work outdoors and be a forester. Several of the young adult protagonists were either making higher education plans (i.e., Piper in Five Flavors of Dumb, Cornelia in Tending to Grace, Marcelo in Marcelo in the Real World, Adam in Aftershock) and/or did attend college (i.e., Taylor Jane in Waiting for No One, Joey in Hurt Go Happy, Jenna in Sweethearts, Neftali in The Dreamer).

Sibling Relationships. The next section examined aspects of sibling relationships. Measurements when applicable evaluated siblings' wide range of emotions, opportunities for growth, reciprocal relationships, not being burdened with family duties, 
and awareness and effects of disability. The three-point agree-disagree rating scale is used for all five questions in this section. Scores results for this section can be viewed below in Table 11.

Table 11

Mean Scores of Books in the Sibling Relationships Category

\section{Sibling Relationships Statistics (if applicable)}

\begin{tabular}{|c|c|c|c|}
\hline \multicolumn{2}{|c|}{ Questions } & \multirow{2}{*}{$\begin{array}{l}\text { Score } \\
(3 \text { pt. scale }) \\
3.00\end{array}$} & \multirow{2}{*}{$\begin{array}{r}\text { Percentage } \\
100.0 \%\end{array}$} \\
\hline D1 & $\begin{array}{l}\text { Sibling(s) of the character(s) with CD experience } \\
\text { a wide range of emotions, not just all positive or } \\
\text { all negative emotions }\end{array}$ & & \\
\hline D2 & $\begin{array}{l}\text { Sibling(s) of the character(s) with CD have } \\
\text { opportunities for growth that are not typical for } \\
\text { siblings of children without disabilities }\end{array}$ & 3.00 & $100.0 \%$ \\
\hline D3 & $\begin{array}{l}\text { The sibling relationship is reciprocal, given the } \\
\text { age and development differences between the } \\
\text { siblings. }\end{array}$ & 3.00 & $100.0 \%$ \\
\hline D4 & $\begin{array}{l}\text { The sibling(s) are not given unusually } \\
\text { burdensome household and family duties, but } \\
\text { engage in family work that is typical for children } \\
\text { of the same age and gender that do not have a } \\
\text { sibling with disabilities. }\end{array}$ & 3.00 & $100.0 \%$ \\
\hline D5 & $\begin{array}{l}\text { The sibling(s) appear aware of the nature of the } \\
C D \text { and its effects on the character with CD. }\end{array}$ & 2.87 & $95.6 \%$ \\
\hline AVG & & 2.98 & $99.2 \%$ \\
\hline
\end{tabular}

Even though this section was not applicable to all protagonists, the area of Sibling

Relationships had one of the highest scores (99.2\%). Ten of the protagonists with CDs

did not have any siblings. Another protagonist, Ruby Jean (Free as a Bird), had only seen 
her baby half-brother once when her mother brought him along on a visit to the institution. Also Caitlin (Mockingbird) had recently lost her older brother in a middle school shooting. The siblings scored $100 \%$ when it came to measuring their wide range of emotions, opportunities for growth, reciprocal relationships, and not having unusually burdensome family duties. One question only received $95.6 \%$ because in two cases a neutral rating was given because the siblings were not infants, but were too young to be truly aware of the nature of the disability and its effect (Out of my Mind, and Hurt Go Happy). Some sibling relationships were not evaluated because the siblings were not around most of the time, did not live at home, or were just infants.

Impact of CD on Plot. In this section the impact of the CD on the plot was measured. The three-point agree-disagree rating scale was used for the first and last questions. The other two questions had a multiple choice and a yes/no format. The questions examined the impact on the plot in the area of a) protagonists' appropriate growth throughout the story, b) main focus of the book, c) if additional information is provided about the $\mathrm{CD}$ and d) modeling of strategies for solving challenges presented by the disability. The various scores for Impact of CD on Plot may be viewed in Table 12. 


\section{Table 12}

\section{Mean Scores of Books in the Impact of CD on Plot Category}

\begin{tabular}{|c|c|c|c|}
\hline \multicolumn{4}{|c|}{ E. Impact of CD on Plot Statistics } \\
\hline \multicolumn{2}{|c|}{ Questions } & $\begin{array}{l}\text { Score \&/or } \\
\text { Number }\end{array}$ & Percentage \\
\hline E1 & $\begin{array}{l}\text { Main character with a CD displays appropriate } \\
\text { growth throughout the story }\end{array}$ & 3.00 & $100.0 \%$ \\
\hline E2 & \multicolumn{3}{|l|}{ A main focus of the book appears to be to: } \\
\hline E2-A & (a) teach about a CD & 0 & $0 \%$ \\
\hline E2-B & $\begin{array}{l}\text { (b) include a character with a CD whose } \\
\text { presence does not or minimally impacts the story }\end{array}$ & 0 & $0 \%$ \\
\hline $\mathrm{E} 2-\mathrm{C}$ & $\begin{array}{l}\text { (c) include a character with a CD whose } \\
\text { presence and CD impacts the story }\end{array}$ & 25 & $92.6 \%$ \\
\hline E2-D & $\begin{array}{l}\text { (d) include a character with a CD whose } \\
\text { presence impacts the story, but the CD is } \\
\text { irrelevant }\end{array}$ & 2 & $7.4 \%$ \\
\hline E3 & \multicolumn{3}{|c|}{ Additional information is provided to help readers learn about the CD } \\
\hline $\mathrm{E} 3-\mathrm{Y}$ & Yes & 2 & $7.7 \%$ \\
\hline $\mathrm{E} 3-\mathrm{N}$ & No & 24 & $92.3 \%$ \\
\hline E4 & $\begin{array}{l}\text { When the CD is integral to the plot the character } \\
\text { with the CD models strategies for solving } \\
\text { challenges presented by the disability. }\end{array}$ & 2.76 & $91.7 \%$ \\
\hline
\end{tabular}

Appropriate growth. Being protagonists, all the main characters with CDs displayed appropriate growth during stories' plots (100\%). These dynamic and welldeveloped characters were the focal point of the examined books. The amount of growth varied depending on the reading/grade level and time-span of the literature.

Focus of the book. Over ninety percent of the books included a character with a CD whose presence and CD impacted the story $(n=25,92.6 \%)$. Only two $(7.4 \%)$ of the books had a main character with CD who impacted the story, but whose CD was 
irrelevant to the plot. These two books were Sweethearts and Pull of the Ocean. In both of these books the CD itself was not a main focus of the story line. In Sweethearts, both the protagonist Jenna and a major character Cameron had a CD in grade school. The major part of this book, however, took place in the presence where Jenna no longer had a CD. Even in flashbacks to childhood, the CD of the protagonist did not play a major role. It was portrayed more as one of several characteristics of an unhappy latchkey child. Much of the same was true in Pull of the Ocean. Yann's muteness was not that relevant to the story's plot because everyone who this protagonist came into contact with knew what he was trying to communicate. Even though he could not talk, Yann seemed to have no difficulty in conversing with his teacher, peers, brothers, etc. It was more a uniqueness or another characteristic of this unusual protagonist. Most of the story was told from the point of view of his brothers or individuals who were watching these brothers on their journey.

Additional information provided. The majority of the books did not have additional information for readers to learn more about the primary and/or secondary disability causing the $\mathrm{CD}$. Only two of the 26 books provided additional information to help readers learn more about the $\mathrm{CD}(7.7 \%)$. One book, Wonderstruck, had a selected bibliography that included literature and websites under various topics including the area of Deafness and Deaf Culture. The other book that provided additional content about the primary disabilities of the protagonist is Tara Kelly's Harmonic Feedback. In her Author's Note, Kelly provided url addresses for more information about both Asperger syndrome/autism and attention deficit hyperactivity disorder (ADHD). 
Model strategies. Over ninety percent of the time when the $\mathrm{CD}$ was integral to the plot, the protagonist with the CD provided strategies he/she used for solving challenges presented to them relating to the $\mathrm{CD}(91.7 \%)$. Some of the books offered simple solutions that could be easily accomplished on the spot without any preparation, such as, spelling out problematic words, communicating information in writing, by gestures, or body language, etc. For example, Ben (Wonderstruck), who had become deaf recently and could not read lips, would write questions and conversations in his notebook. Past written explanations of what he was doing or wanted could be shown to new people he tried to communicate with. Even though Adam (Aftershock) was not able to talk or write after the accident, he would still just smile or nod his head to show people he was listening or agreeing with what was being said. In other cases protagonists prepared in advance for foreseen difficulties in communicating with other individuals. For instance, Marcelo (Marcelo in the Real World) had learned a set of responses and several questions that he could use when small talk was required.

The evaluated books that provided the most strategies and/or compensatory skills to handle various situations when communication problems occurred were literature with protagonists who had ASD. All seven of the books with main characters that had ASD provided extensive examples of what the protagonists were thinking and how they coped with difficult communication situations. Many times these protagonists had practiced with counselors, teachers, aids, parents, and/or siblings on how to respond in specific circumstances. In Anything but Typical, Jason, who had trouble responding in new 
situations, had been taught by his aid to try to make eye contact with the person talking to him and to ignore everything else that was going on around him. Also if possible, Jason was supposed to not shake, flap, click his teeth, blink excessively, or lull his head off to the side. This protagonist had additionally rehearsed in class to tell people that he was okay when people tried to help him too much. Since Ted (The London Eye Mystery) had difficulty with phone conversations, his mother had him call Directory Assistance to practice using a phone. Another protagonist, Drea (Harmonic Feedback) had always had trouble knowing what to say when having a conversation with other people. When she was younger, Drea's mother would write skits that they would act out together using Drea's Barbie dolls. The two of them would practice these written conversations that people might actually have to give Drea more confidence and a better understanding of what might be said when conversing with another individual. In the book Mockingbird, before he died in a school shooting, Devon used to spend much time helping and explaining things to his younger sister Caitlin, who had ASD. Devon would take Caitlin shopping for clothes that were not weird. This older brother would also tell his sister things, such as, how to act in public. For example, Caitlin was not supposed to crawl under a table, moan, scream, flap her hands or spin around when she was not at home. As Devon explained it to Caitlin, it was not normal to do most things over and over in public unless it was clapping and/or laughing. Devon clarified that even these two things had to be done in the right place and time.

The majority of protagonists with ASD had trouble at times with not being able to interpret the meaning of questions or explanations. For example, Taylor Jane (Waiting for No 
One) did not understand the word "how." Therefore questions like "How are you?" or "How are you doing?" were very confusing to her. In the past she would just reply "I am Taylor today and Taylor tomorrow" (Brenna, p. 48). Later this protagonist learned just to answer these questions with "Fine." Marcelo (Marcelo in the Real World) also had trouble knowing what to say in conversations because he thought too much about what was said and the meaning of words. This protagonist, however, had learned at school to let people continue talking and often meanings of individual words or even the conversation as a whole would become clearer as it progressed. Marcel explained it had taken him years to not stop a conversation continuously to question every word. Having his laptop with him could help in many circumstances also. At work, school, or home, Marcelo would just look up on the Internet something he had not understood. Additionally at his summer job, Marcelo told his boss to be more literal, since he did not comprehend figures of speech. Both Taylor Jane and Marcelo had learned they could answer a question they did not grasp by asking another question.

Another area that was modeled frequently by protagonists with ASD was small talk strategies. One main character, Drea (Harmonic Feedback), compared the art of having a casual conversation to a game of Ping-Pong in which players had to keep hitting the ball back and forth in order to not offend each other. For people she did not know, this protagonist had learned to keep her answers to a minimum. Giving out too much 
information could freak people out and make her seem clingy. Also having a little mystery about herself would make her seem "cooler" to her peers. Marcelo (Marcelo in the Real World) found having a conversation a very draining experience that required much effort. In his Social Interactions class at school, this protagonist had learned he needed to have 4 or 5 questions ready daily about the day's events. When he got up in the morning, Marcelo would scour the newspaper and/or computer for possible current smalltalk information. This main character would then formulate and memorize a few questions about weather, sports, current events, etc. to be ready if small-talk interactions occurred. Many of the protagonists had topics and areas of interest they were passionate about. Some topics were legitimate small-talk topics with the general public or friends, while other areas would turn most people off. For example, Drea (Harmonic Feedback) was a gifted musician, who later wanted to have a career as a music producer/designer. This protagonist could discuss her love of contemporary rock music with her peers. Marcelo (Marcelo in the Real World), however, had strong interests in classical music and religion. These topics he stayed away from when making small talk. Too many times when Marcelo had talked about topics that others were not interested in, he had experienced a feeling as if a glass wall was coming down between him and the person he was conversing with. Instead this main character would discuss with others more popular topics he knew about like Haflinger ponies and animal assisted therapy. At his school Marcelo cared for and worked with the ponies used in this kind of therapy. In The London Eye Mystery, Ted's teacher taught him to check out the facial expression of 
people he was talking with to see if they were bored. Ted was supposed to observe individuals' faces for some of the signs of boredom, such as, a blank stare and/or facial muscles not doing anything. This protagonist, who wanted to be a meteorologist, had the tendency to talk "too big" and about the weather. When Ted had started secondary school, his mother had told him when he met new people to keep his talk small. He thought at first that she meant for him to use monosyllable words, However after further discussion, he found out that his mother was referring to talking about everyday subjects. Weather could be an acceptable conversational subject matter if it was small weather and not big weather. Ted took this explanation literally and decided he could talk about anticyclones and minor depressions, but could not converse about major storms and global warming when engaged in small talk.

These protagonists with ASD also had difficulty with understanding people's expressions and body language. As had been discussed earlier, the majority of these main characters had used emotion charts with their teachers, aids, counselors, etc. to try to develop more knowledge about the variety of facial expressions and their meaning. In Mockingbird, Caitlin's counselor had not only helped this protagonist with reading facial emotions, but also in developing her comprehension of interpersonal skills and body language of her peers. Walking around in the school's playground, Caitlin and her counselor would observe her classmates and try to read their body language. If this young protagonist could put herself in their shoes and understand what they might be thinking, the school counselor felt Caitlin might have a better understanding of how to communicate 
with her classmates and make some friends. Caitlin was overwhelmed in her classroom and going up to a crowd of children. Her counselor relayed that sometimes it was easier to approach children who were by themselves, because they might like a friend. Using this approach, Caitlin did make a new friend, Michael, who was a younger student at her school. By closely observing how Michael associated with his friends, Caitlin learned many new things about interacting with peers. For example, she saw that Michael just touched his classmates lightly when he wanted their attention and did not grab them. He also would look at them without getting in their personal space. Michael additionally would not only call to people with his voice, but also motioned with his hands to beckon them.

Another protagonist, Ted (The London Eye Mystery), not only had a lot of trouble reading body language, but also knowing what gestures meant, and how to respond to them. His sister often as a matter of course would interpret gestures for him. Like when his cousin made the circling index finger gesture close at the side of his head that signified that someone was crazy. As a way to help him fit in and become friends with his peers, Ted had been taught to just automatically laugh whenever other people did even if he might not understand the humor.

In Harmonic Feedback, another protagonist Drea had strategies for improving her interpersonal body language with people. This main character associated learning and using these common day skills to acting and learning lines for play. Drea knew she needed to smile even when she was not happy. This was difficult to do all the time when 
she was around people, because sometimes she was just mad and it came across on her face. Drea thought people were obsessed with looks. This protagonist was cognizant that she needed to look people in the eye. Both of these skills just mentioned had to be done in the right amount of moderation. Drea recognized that if she smiled too much or looked at someone too long it would seem weird or freaky. Not only did this protagonist have difficulty portraying her feelings toward other people with her facial expressions and/or body language, but she also had trouble expressing verbally her emotions/feelings. Drea discussed this problem with a close friend who thought she was disgusted with him.

That's the problem; sometimes I don't know what to say or the right way to say it. By the time I figure out how to tell you what I was feeling, you had left. Don't assume my thoughts by the look on my face. Don't try and read between my words. At least ask me what I'm thinking or feeling first. It may take me some time, but I will answer you. (Kelly, p. 217)

The majority of these main characters with ASD liked their world to be the same and often enjoyed having a schedule and/or following a routine for doing things. Since life often does not go according to plans, these protagonists had learned skills to help them deal with new or different situations that stressed them out or made them nervous. These protagonists modeled in the literature several strategies they used to calm or comfort themselves. For example, Taylor Jane (Waiting for No One) used familiar strategies like chewing gum and thinking about her pet whenever she was uncomfortable with other people and needed to keep control of her emotions so that she could have 
conversations with them. Christopher (The Incident of the Dog in the Night-Time) had some rather unique calming methods that worked for him like doubling $2 \mathrm{~s}$ in his head. This math genius had gone as high to 2 to the $45^{\text {th }}$ power before, which is over 35 trillion. Doing something with a rhythm also helped Christopher to gain his composure. When he was anxious about being in a noisy crowded train station and having to buy a train ticket from an unfamiliar person, this protagonist pictured a big red line on the floor below him and repeated the words "left, right, left, right, left, right" as he walked through the tunnel to his destination. Ten-year-old Caitlin (Mockingbird) also hated crowds. This was especially true during school recess where classmates were running around with screaming voices and sharp elbows. When she was in this kind of situation, Caitlin had come up with her own coping technique called "stuff animaling" to make her feel safer among her classmates. "Stuff animaling" entailed blurring her eyes until everything appeared soft and fluffy. This strategy would give her a fuzzy and warm feeling like when she was with her stuff animals. Forgetting where she was Caitlin was then able to cope and communicate with her peers and teachers. Jason (Anything but Typical) additionally had trouble dealing with noise and smells. His occupational therapist had taught him how to block out sounds. One by one he would take each sound, hear it, hold it, and then send it away. Jason had also learned to turn off his smell button. By learning to cope with his sensitivity to sound and smell, Jason was able to be less anxious and talk with family and strangers in such places as an airplane, conference and restaurant. This protagonist had an easier time talking with his Storyboard friends on the computer than 
with his classmates at school. Jason enjoyed this method of communication since he did not having to communicate face-to-face in real-time and he had time to compose a message. Unlike talking in person, he did not have to worry about his or theirs body language and he could rewrite his answer as many times as it took to get it right.

Other protagonists with CDs that did not have ASD also modeled strategies for coping with their CDs. In Black Swan Green, Jason demonstrated several compensatory techniques he used when he anticipated he might stutter. For example in school, if he could not "duck or dive" a specific word with a substituted appropriate synonym, this protagonist would say he "did not know" or "wasn't sure" of a word or answer. Another of Jason's strategies was to say "er . .." to try to buy some time in the hope he could sneak one past "Hangman". However as this protagonist pointed out he could not use these methods too often or he would look "like a dimwit". Sometimes even when he knew the correct answer to the teacher's question, Jason would give the wrong answer to avoid a word he couldn't say. In Jason's mind it was better for his teachers and classmates to believe he was unintelligent or not paying attention than to become "labeled 'School Stutterboy"'(Mitchell, p.27). Jason had also learned several other methods that he used when he had to read or recite a specific text and could not make substitutions or avoid difficult words to pronounce. Two of these methods are explained in the passages below when the inexperienced student teacher made Jason read aloud a passage from Lord of the Flies when the classroom teacher stepped out of the room. 
" 'I got the conch -- 'Jack turned fiercely 'You shut up!' " Shit. The word "circle" was coming up. "Piggy wilted. Ralph took the conch from him and looked round the -- " Desperately, I used the Trip Method, where you set the stammer letter (S) but sort of trip over it into the vowel to get the word out. "Sss-ircle of boys." (Mitchell, p. 207-208)

While he was reading, Jason explained that he was able to slip past the s-consonant word, "special" which was easier than s-vowel words. This protagonist also feigned not knowing the word "assented" so that the student teacher would pronounce it for him. However getting stuck on another word, Jason demonstrated his second technique. "Piggy opened his mouth to ssspeak, caught Jack's eye and shut it again." ...I'd just had to use the Punch Method again for "speak". Using brute force to punch the words out's a last resort 'cause your face goes spaz. And if Hangman punches back harder the word gets stuck and that's when you turn into the classic stuttering flid. (Mitchell, p. 208)

Cornelia (Tending to Grace) revealed several of her strategies when she began talking more toward the end of the book. Instead of folding into herself and trying to become a shadow or turn herself into stone, this protagonist began speaking up for herself again. Often Cornelia would try taking a deep breath first. Sometimes it helped and other times a big knot would form in her throat thus locking her voice in silence. In one instance when she was trying to pronounce her name, tapping her finger on her leg helped. Cornelia was able to concentrate on the taps instead of what she was going to say. 
This strategy was similar to Jason's therapist method of using the rhythm of a metronome that was discussed earlier in the chapter. Another time Cornelia took a deep breath and just spelled out her name since she had such trouble saying the initial " $\mathrm{C}$ " in Cornelia. As she explained it was as easy as spelling $J-e-l-l-o$.

Other protagonists had some inventive strategies to use the phone even when they could not talk and/or hear. For instance after the terrifying family accident, Adam (Aftershock), who had traumatic mutism, was able to call his aunt once he regained fragments of his memory. Even though he was not able to talk, this protagonist tried responding to his aunt's questions using the number pad. Adam kept pushing 9, followed by 3 and then 7 to spell out yes. Even though Adam's attempted phone conversation appeared to be a dead air call, his repetitive answer using the phone's button tones gave his aunt hope and belief that he was on the other end of the line. After the call she traveled to his home in Rhode Island to look for her nephew. Another protagonist Joey (Hurt Go Happy) used the phone to send a message to her neighbor even though she was deaf. She placed the call, waited ten seconds so that her friend could answer, then started telling him that her mother would not let her come back over to his house and would he please come and talk to her. She was not sure he got the message since she could not hear him responding, but in this instance the method worked.

Joey had other strategies also. Her mother did not want her to learn fingerspelling or ASL. To practice fingerspelling undetected on the way to school, she would place her hands in her coat pockets while she used the manual alphabet to spell out license plates. Joey 
had another strategy where she listened with her eyes. As this protagonist explained it, she could fill her sight with sounds by watching motion. This strategy did have drawbacks. For example in the school cafeteria, there existed more noise than her eyes could stand with all the scraping chairs and tables, the arm-waving, running, pushing, book tossing, etc.

Will (The Dark Days of Hamburger Halpin) also discussed the overwhelming aspects of a school cafeteria on the eyes. Since Will could not turn off his excellent lipreading skills, fragments of conversations from every direction he looked in this hive-like school setting continuously bombarded him. Will compared this atmosphere to trying to follow a plot while sitting on a fast whirling Sit and Spin toy in a room full of hundreds of televisions with their volumes turned up loud. In order to not be overwhelmed by this cacophony of conversations, this protagonist would concentrate on just one individual and his lips. However, since people do not like to be stared at or to be eavesdropped on, Will had to hide the fact that he was following this classmate's conversation. It took much skill not to get caught. Another atmosphere that Will had to worry about not being disclosed as eavesdropping on conversations was on the school bus. This protagonist could gain much information about his peers and what was going on in their lives simply by observing conversations in the bus driver's overhead rearview mirror. To learn names of his classmates, Will had discovered several means to accomplish this task. Since no one usually introduced themselves to this newcomer at their school, Will began to piece together his classmates' names by such methods as lipreading, observing teachers' 
seating charts, jewelry that had a name spelled out on it, or even from football jerseys that had players' name across the backs of their shirts.

The majority of the time the strategies modeled were positive, but sometimes they were negative. For example, Caitlin had great difficulty speaking to and answering people. Many times individuals would look at her and waited for her to say something. Often instead of coming up with a response or saying, "I don't know", this nervous protagonist would start sucking on her shirt's sleeve. Also if her father was standing close by, Caitlin liked to stick her head under her father's sweater to hide from the crowd of people giving their condolences for her family's loss in the recent school shooting. Caitlin's father did not usually let his daughter attempt to hide in this manner anymore, but since her brother was just killed he made allowances. Another protagonist, Nick (Nick's Secret), did not like to talk, because being deaf he could not hear his speech. At school, Nick would barely ever speak to anyone. If he thought a teacher was looking at him and might call on him, Nick had come up with the technique of pretending to read or to be taking notes to feign talking in front of other people. Alvin (Alvin Ho: Allergic to Girls, School and Other Scary Things) had his personal disaster kit (PDK) that he carried around. It did not really hurt anything, but it was not helpful either. The PDK was more of a security blanket/device for this young protagonist.

Impact of Setting on Disability. Settings can be much more than just establishing the when and where a plot takes place. They can be crucial in influencing children's understanding and responses to the literature they read by establishing the atmosphere and tone, and helping to convey a theme (Joels, 1998). With the use of quality, descriptive, integral settings, readers are drawn into the stories and allowed to navigate around the 
characters' world (Dyches \& Prater, 2000). The sixth section of the evaluation tool, which is comprised of only two questions, examined the Impact of Setting on the CD. Both of the questions use the three-point agree-disagree rating scale. The questions measured the impact of the setting on the disability in the area of a) attitudes and practices congruent with their era, and b) the place of the story affects the life of character(s) with CDs. The overall average percentage of Impact of Setting on the CD was well above the acceptable level with a score of $96.3 \%$. Scores of the Impact of Setting on Disability category can be viewed below in Table 13.

\section{Table 13} Mean Scores of Books in the Impact of Setting on Disability Category
of the Rating Scale

\begin{tabular}{|c|c|c|c|}
\hline \multicolumn{4}{|c|}{ F. Impact of Setting on Disability Statistics } \\
\hline \multicolumn{2}{|c|}{ Questions } & $\begin{array}{l}\text { Score } \\
\text { (3 pt. scale) }\end{array}$ & Percentage \\
\hline $\mathrm{F} 1$ & $\begin{array}{l}\text { The attitudes and practices portrayed are } \\
\text { congruent with attitudes and practices for those } \\
\text { with CDs during that era }\end{array}$ & 2.81 & $93.8 \%$ \\
\hline $\mathrm{F} 2$ & $\begin{array}{l}\text { The place of the story affects the life of } \\
\text { character(s) with CD }\end{array}$ & 2.96 & $98.8 \%$ \\
\hline AVG & & 2.89 & $96.3 \%$ \\
\hline
\end{tabular}

Attitudes \& practices congruent with era. The first question of this section looked at whether the attitudes and practices portrayed in the selected books for the protagonists with $\mathrm{CD}$ were the attitudes and practices for those with $\mathrm{CD}$ during the era that the literature was set in. As mentioned earlier in the chapter, several of the books did not take place in the U.S. $(n=8,29.6 \%)$ and/or were set in non-contemporary times $(n=6$, $22.2 \%$ ). The majority of the books seem to be true in terms of representing past and 
present national and international attitudes and practices toward individuals with CD. This question had an overall average of $93.8 \%$.

All five books that received a neutral rather than a positive rating were set in the United States in contemporary times (i.e., Stuck in Neutral; Carter Finally Gets It; The Dark Days of Hamburger Halpin; Alvin Ho: Allergic to Girls, School, and Other Scary Things; Speak). In Stuck in Neutral, Shawn was attending school in a segregated specialized education classroom for students with severe to profound disabilities. Even though this protagonist could not communicate with others and did not perform well on intelligence tests, Shawn would have benefited greatly from being in an inclusive learning environment along side others who did not have disabilities. In the year 2000 when this story took place, the attitude and practice of the era was not to isolate individuals with severe disabilities all day in a non-learning environment that dealt more with their care and safety. As readers can attest, being in an inclusive general education environment with his peers would have had a positive effect on this protagonist's education and life even if the setting might have been impractical and disruptive in some administrator's/educator's eyes.

Four other books also scored neutral ratings because the protagonists were not receiving any resources/services in school. For example, Carter (Carter Finally Gets It), who had been diagnosed with Attention Deficit Disorder (ADD), had been recommended in junior high for the learning resource center and gifted classes. No accommodations, resources, reevaluation, or IEP was ever provided for this protagonist, even though, he 
was muddling through his classes hoping to pass and could never remember to do his homework. Since Carter's stuttering was mild and occurred mostly just in front of girls he liked, he might not have been eligible for speech-language services. Another protagonist, Alvin (Alvin Ho: Allergic to Girls, School, and Other Scary Things), was not receiving any services in school either. This main character, who was in the second grade, had not been able to speak a word in the school setting since entering school over two years ago. Even though, Alvin was seeing a private psychotherapist about his anxiety and inability to speak in school, some type of educational accommodations should have been made for this young student. The same was true for Will (The Dark Days of Hamburger Halpin). This main character had transferred from a School for the Deaf where he was not getting along anymore with his peers to his local public high school. Being an excellent lip reader and promising to wear his hearing aids, Will was allowed to switch to the regular school. In this new educational setting, Will had to sink or swim since no closed captions, teachers who could sign, strobe lights for when the bell rang, or interpreters existed. Teachers had been notified that this new student had a hearing impairment, but they often turned away from him when they were talking and some male teachers had moustaches that made lip reading impossible. About the only accommodation Will received in his new school was being allowed to sit up front in the corner of the class so he could see his teacher and classmates. In his new educational setting, this protagonist had to get all his class information from lipreading, handouts, and what was written on the board. The last book that received a neutral rating on this question was Speak. As has been mentioned before in this chapter, the school did not notice and/or give any 
counseling or psychological services to this previously outgoing freshman student who was suddenly withdrawn and not speaking much. Melinda was being ostracized and bullied by the students at her new high school. Even though she had stopped talking to most of her teachers, classmates, and parents, no school officials sought help for this student.

Story setting affects the life of character(s) with $C D$. This second question about setting measured whether the time and place that a story took place in affects the life of characters with CDs. A wide variety of contemporary and non-contemporary setting existed in this selection of books that had protagonists with CDs. The settings were integral settings as opposed to backdrop settings that occur often in fairytales and "once upon a time" stories. The average statistical rating for this question as measured by the evaluation form was $98.8 \%$. Only one book, Carter Finally Gets It, received a neutral rating. This book, which never mentioned a state or region, took place in "Merrian." The setting ended up being a freshman year of high school in an unknown location where readers watch an overwhelmed Carter make one misadventure after another as he episodically navigated his way through high school sports, girls, and school plays.

Point of view. An integral tool for portraying a character's emotions, feelings and thoughts is the point of view (POV) an author used. Stories can be narrated using several approaches to POV, such as, first person, third person, and/or alternating. This seventh section of the evaluation tool was comprised of two questions that examined whether the POV was realistic if told from the perspective of either a character with a $\mathrm{CD}$ or from a 
character without a CD. The selected books scored $100 \%$ on this section. The scores for the Point of View Category may be viewed below in Table 14.

\section{Table 14}

Mean Scores of Books in the Point of View Category

\begin{tabular}{|c|c|c|c|}
\hline \multicolumn{4}{|c|}{ G. Point of View Statistics } \\
\hline \multicolumn{2}{|c|}{ Questions } & $\begin{array}{l}\text { Score } \\
\text { (3 pt. scale) }\end{array}$ & Percentage \\
\hline G1 & $\begin{array}{l}\text { The point of view, if told by the character with a } \\
\text { CD, is realistic }\end{array}$ & 3.00 & $100.0 \%$ \\
\hline $\mathrm{G} 2$ & $\begin{array}{l}\text { The point of view, if told from a character } \\
\text { without a } C D \text {, is realistic }\end{array}$ & 3.00 & $100.0 \%$ \\
\hline AVG & & 3.00 & $100.0 \%$ \\
\hline
\end{tabular}

POV realistically told by character with $C D$. A high majority of the evaluated books are narrated solely from the protagonists' POV $(n=25,92.5 \%)$. Twenty-three of these books have the protagonist as the first-person narrator telling his/her own story in words and/or drawings. As mentioned earlier, one book Wonderstruck was an intertwining of two stories both being told by protagonists with CDs. One protagonist Ben told his story in words, while Rose related her tale in drawings. In two other books, the protagonist is portrayed as actually writing the book that the audience is reading. In Anything But Typical, Jason, who fell somewhere on the autism spectrum, wrote his story addressing readers in what he called a "neurotypical" (NT) manner/fashion. Christopher (The Curious Incident of the Dog in the Night-Time), another character who has ASD, composed a murder mystery about how he discovered who killed his neighbor's large poodle. Only two of the books were narrated directly by the protagonist with CD in the 
third-person POV (Nick's Secret and Hurt Go Happy). All of the books were evaluated as having been realistic when told from the POV of the protagonist with CD (100\%).

POV realistically told by character without $C D$. Two of the evaluated books had a character(s) without CD narrating part of the book. One of these texts was Deaf Child Crossing. This book was told in third-person POV by both Megan, the protagonist with CD, and her new friend Cindy, who did not have a CD. Megan's POV was used the majority of the time. The other book that had narrators without CDs was Pull of the Ocean. As mentioned earlier, this book had multiple characters telling the story of the seven brothers' life and their journey to the ocean. Yann, the protagonist with CD, only narrated a small portion of the story. This protagonist's narration was merely $41 / 2$ pages long and was the next to last chapter of the book. The rest of the book was first-person accounts from Yann's brothers, parents, social worker, and the other numerous people that met or saw the brothers on their westward travel. Both of these books were measured as having been realistic when told from the POV of the protagonist without CD (100\%).

Illustrations. Determining quality of portrayal of characters with CD is more than just examining textual elements, such as, characterization, plot, POV, setting, literacy style, etc. How these individuals with CDs are represented visually in illustrations is equally as important. The last area of the evaluation form, Illustrations, measures specific aspects of illustrations, such as, portrayal of characteristics of disabilities accurately; representation of assistive/adaptive technology accurately, realistically and contemporarily; interpretation of the story well; usage of a style that is appropriate to the story and 
age-level; enhancement of the plot, theme, characters, setting, mood, and information; representation of quality art; and usage of color, line, shape, and texture artistically. All eight questions utilized the three point agree/disagree rating system. This section of the evaluation form was applicable to only four of the evaluated books. The overall statistical average of Illustrations was extremely high reaching the 97.7 percentile. The various score results for the Illustrations category can be found below in Table 15 .

Table 15

Mean Scores of Books in the Illustrations Category

\begin{tabular}{|c|c|c|c|}
\hline \multicolumn{4}{|c|}{ H. Illustrations Statistics (if applicable) } \\
\hline \multicolumn{2}{|c|}{ Questions } & \multirow{2}{*}{$\begin{array}{l}\text { Score } \\
\text { (3 pt. scale) } \\
3.00\end{array}$} & \multirow{2}{*}{$\begin{array}{r}\text { Percentage } \\
100.0 \%\end{array}$} \\
\hline H1 & $\begin{array}{l}\text { Portrays characteristics of disabilities accurately } \\
\text { in illustrations. }\end{array}$ & & \\
\hline $\mathrm{H} 2$ & $\begin{array}{l}\text { Portrays assistive/adaptive/technology } \\
\text { accurately, realistically, and contemporarily in } \\
\text { the illustrations. }\end{array}$ & 3.00 & $100.0 \%$ \\
\hline H3 & Illustrations interpret the story well. & 3.00 & $100.0 \%$ \\
\hline $\mathrm{H} 4$ & $\begin{array}{l}\text { Style of illustrations is appropriate to the story } \\
\text { and age-level. }\end{array}$ & 3.00 & $100.0 \%$ \\
\hline H5 & $\begin{array}{l}\text { Plot, theme, characters, setting, mood, and } \\
\text { information are enhanced through the } \\
\text { illustrations. }\end{array}$ & 3.00 & $100.0 \%$ \\
\hline H6 & Illustrations represent quality art. & 2.75 & $91.7 \%$ \\
\hline $\mathrm{H} 7$ & $\begin{array}{l}\text { Illustrations use color, line, shape, and texture } \\
\text { artistically. }\end{array}$ & 2.75 & $91.7 \%$ \\
\hline $\mathrm{H} 8$ & $\begin{array}{l}\text { Layout and design of illustrations and text are } \\
\text { visually appealing. }\end{array}$ & 3.00 & $100.0 \%$ \\
\hline AVG & & 2.93 & $97.7 \%$ \\
\hline
\end{tabular}


As mentioned earlier, not many of the evaluated books had any kind of illustrations. With this study focusing on intermediate children's and young adult literature, only four evaluated books contained illustrations and were applicable to this part of the evaluation tool. The books that had any type of illustrations were: Alvin Ho: Allergic to Girls, School, and Other Scary Things (illustrator, LeUyen Pham), The Dreamer (illustrator, Peter Sís), Wonderstruck: A Novel in Words \& Pictures (author/illustrator, Brian Selznick), and The Curious Incident of the Dog in the NightTime (author, Mark Haddon). Two of the books had illustrators (Pham and Sis) other than the author. Wonderstruck was written and illustrated by Brian Selznick, who had previously won the prestigious ALA Caldecott Medal award in 2008 as the illustrator of the most distinguished American picture book for children. Selznick's Wonderstruck was done in a similar format as his Caldecott winning story The Invention of Hugo Cabret. Both of these books were told in a unique combined word and picture format. The fourth and last book to be included in this section of the evaluation form was The Curious Incident of the Dog in the Night-Time. This book contained several simple diagrams/ illustrations to help explain what the protagonist was seeing and/or thinking. No illustrator was listed for this book. Many of the questions about illustrations for this specific book were not applicable (N/A) since the images were just diagrams drawn by the protagonist with autism to explain some of his logic and complex thoughts. Three of the books scored $100 \%$ in this Illustrations section. The only piece of literature that did not score a perfect score in Illustrations was Alvin Ho: Allergic to Girls, School, and 
Other Scary Things. This book scored neutral on two questions and had a statistical average of $90.3 \%$.

Portrayal of characteristics of disabilities. The first question of Illustrations examined the accuracy of the images in the portrayal of the protagonists with CDs. In both Wonderstruck (Rose and Ben) and Alvin Ho: Allergic to Girls, School, and Other Scary Things (Alvin Ho) the illustrators authentically represented the protagonists with CDs. Even though the illustrator Selznick was placing clues in his illustrations that Rose was deaf, readers did not really know that this $\mathrm{CD}$ was actually the case for this protagonist until approximately half way through the story. When Rose visited her actress mother unannounced at a theatre in NYC, they communicated back and forth in handwritten notes. Her mother stated angrily in one message that Rose was deaf and should not have been out on her own. Just before this event, the illustrator began dropping clues of the possibility that some degree of hearing impairment existed for this protagonist. In a subtler series of images, Selznick portrayed Rose being upset when she read a poster about the cinema closing for installation of a sound system so that silent films could be replaced for “talkies". Immediately after this incident Rose's tutor left a textbook for her called Teaching the Deaf to Lip Read and Speak. After looking at the introductory pages of this textbook, this protagonist promptly cut up the book to make more paper scale model buildings of the NYC skyline that she viewed from her bedroom window. In his detailed illustrations, Selznick portrayed both of the protagonists with CDs, Rose and Ben, accurately. These main characters were represented visually in 
the same manner as characters without CDs. So that readers could locate these protagonists in crowds on the streets of New York City and/or the packed museum, Selznick would subtly spotlight these characters with a glow-like technique. This illumination technique was also used by the illustrator to point out other important details in the images. For example, Selznick highlighted at times such objects as, a shoe, key, face, etc. The illustrator did realistically portray Ben in the end of the story fingerspelling to his grandmother about his new friend from the museum.

In Alvin Ho: Allergic to Girls, School, and Other Scary Things, the illustrator Pham showed many different sides of the second-grade protagonist who had SM. The audience saw Alvin running around, shouting and acting as his made-up superhero Firecracker Man. Pham also portrayed the protagonist with a CD accurately as he interacted with his family and his peers in various settings (i.e., the home, community and on the school bus). In other illustrations, Pham represented realistically the problems and emotions that Alvin experienced by not being able to communicate in school, at his piano teacher's house, and at his psychotherapist's office. In these images emotions, such as, anxiety, fear, and frustration are expressively portrayed on this protagonist's face and in his body language. One picture in particular that illustrated this fear expertly took place on the first day of class in the second grade. Alvin is shown standing in the middle of the classroom looking anxious and clutching his PDK box tightly to his body. His classmates are running all around him yelling and playing. Similar images that portrayed this protagonist anxiety were illustrated when he attended therapy with his psychotherapist and again at his 
first piano lesson. This question was N/A for The Dreamer and The Curious Incident of the Dog in the Night-Time.

Portrayal of technology. The second question pertained to whether assistive/ adaptive technology was portrayed accurately, realistically and contemporarily in the illustrations. None of the five protagonists in these four evaluated books used any assistive or adaptive technology. Therefore, the second question scored N/A (not applicable) across the board.

Interpretation of story. On the evaluation form the question concerning the illustrations' ability to interpret the story well scored $100 \%$. As mentioned before in the book Wonderstruck, one protagonist Rose told her story using images only. Readers had to use their visual skills to carefully discover her story and various elements and relationships of her life. This unusual method of disclosing one protagonist's story in detailed essential images had the audience often revisiting images to look for more details in the illustrations that might had been missed the first time interpreting the story. The illustrations relating Rose's story additionally aided in explaining the other protagonist Ben's story.

In another book The Curious Incident of the Dog in the Night-Time, the drawings/diagrams helped the audience understand the explanations and thought processes of this protagonist with ASD. Fifteen-year-old Christopher excelled at mathematics and loved maps, timetables, logic puzzles, math problems, etc. Some of his 
thinking was rather complex so the diagrams were essential at times to show what this protagonist was discussing.

Sis' illustrations undoubtedly complemented and expanded the author's story in The Dreamer. The images allowed readers to experience the vivid imagination and strong heart and soul of the young Neftali. Even though this protagonist was shy and had difficulty at times expressing himself aloud, the illustrator showed in many images Neftali's great understanding of the power of words. Several times during the plot this main character, who was often bullied and/or belittled by his father or peers, would communicate with a stick his thoughts and emotions in the dirt and/or sand. One picture insert showed Neftali's heart-felt messages of "I am here”. In another illustration, readers see ocean waves slowly approaching cruel words that had been scrawled in giant letters on the beach. Finding his voice, the defiant Neftali had written several of the derogatory terms his father always used to describe him, such as, "worthless", “daydreamer", “absentminded”, “idiot”, etc. In the protagonist's eyes the pounding ocean was applauding his actions as he began taking ownership of his life and no longer believed his father's belittling remarks that were now disappearing in the sand more and more with each lap of the waves. The protagonist's knowledge of the vast potential of the written language was illustrated in other imaginative illustrations that did not contain any text. In one powerful picture Neftali was seen flying on the back of a large winged pen. Another images portrayed this protagonist once again soaring, but this time over the ocean in a basket suspended under a large opened book rather than a hot air balloon. 
Likewise the book Alvin Ho: Allergic to Girls, School, and Other Scary Things also contained quality illustrations that helped in telling the author's story. The illustrator Pham captured perfectly the essence of the main character's story in the visually depicted scenes. The illustrations portrayed the various scrapes, discomforts and adventures that occurred in Alvin's everyday life. For example, Pham had several amusing images showing the incident when Alvin decided to try and grow taller by stretching from a tree in the backyard. This protagonist ended up being stranded in the dark hanging upside down in a tree until his mother rescued him when he did not show up for supper. Pham included several illustrations in each chapter of Alvin Ho. Some of the images were just small inserts while other were half or full page images. The illustrations were humorous and integrated well with the text adding richness to the story.

Appropriate style. The various styles used by the illustrators in their images were measured as being appropriate to the story and targeted age-level of the evaluated books at the 100-percentile level. This question also examined whether the illustrations were appropriate for the type of book they were (chapter book, picture/graphic novel). The book Wonderstruck, which is 638 pages, had 460 illustrations. The eye-popping and unique storytelling style that was used in Wonderstruck made this book more than just an overblown picture book or graphic novel. The large graphic component of the silent illustrated sections helped put readers in the shoes of the two protagonists, who are both deaf and/or becoming deaf. The remarkable illustrations also echoed parallel connections/ 
interests between Ben and Rose in such things as, their love of stars, the pull of New York City, collecting and fascination with museums, trying to find family, and a linkage with wolves. Selznick's illustration style was exceptional in recounting the stories and lives of the two protagonists to the audience.

In The Dreamer, Sis' surrealistic, whimsical-like drawings accentuated the young protagonist's creative nature and thinking. The style was extremely appropriate to represent Neftali's feelings and to show his encounters in such places as the rain forest, beach, home, and community. Not only were readers able to experience the heart, mind, and inner turmoil in this portrait of a young poet, but with these rich and sensual illustrations the audience could also see the world around Neftali through his visionary's eyes.

The cartoonish-like drawings in Alvin Ho: Allergic to Girls, School, and Other Scary Things were suitable to show the humorous antics of the protagonist Alvin. With all the numerous and expressive illustrations inserted in the episodic adventures of this second-grader much of the story was told by the images. The cartoonish-like drawings were appropriate for the targeted age level of the readers.

Enhancement of literary elements. This question of the evaluation form evaluated the ability of the illustrations to enhance various literary elements, such as, plot, theme, characters, setting, mood, and information. The question also examined whether the illustrations were consistent with what was being told in the text. The illustrations in all the selected literature were judged positive (100\%). As mentioned before Selznick's illustrations in Wonderstruck of Rose's story genuinely benefited the 
audience in visualizing not only her story, but additionally aided in the understanding of what was happening in Ben's world. These two protagonists visited many of the same places, felt similar emotions about their unhappy homes, and had hopes of becoming reunited with an absent parent. The similarities in protagonists' stories and the quality and subject of illustrations enabled the seamless shift in moving from one protagonist's story to the other. The illustrations complemented the story and helped to pace the plot. Having a fascination with films, Selznick utilized a cinematic effect with his illustrations that greatly contributed in creating the mood and setting of the story. Such techniques as zooming in on details and panning out to a wider frame added melodrama to the plot. With the progression and precise edits of the illustrations, the book had a stop frame/motion animation feel that is found in early film stills and strengthened the historical fiction aspect of Wonderstruck.

Sis' lyrical drawings that appear throughout The Dreamer enhanced the magical world that the author Ryan wrote about. The dream-like and descriptive commonplace images intensified the mood and setting that Ryan created with her text, sound poems, inserted lines of poetry, and questions at the end of the chapters. Transported by these sensorial illustrations, the audience is encouraged to think more visually and imaginative as they experienced the world through Neftali's eyes. The beauty of the surrounding nature, along with the inner turmoil and the hopeful future dreams of the protagonist were made much richer by the illustrations. 
In Alvin Ho: Allergic to Girls, School, and Other Scary Things, readers watched as the quirky young protagonist made his way through his customary routines of trying to overcome his fear of talking in certain situations, learning how to make friends, while simultaneously trying to follow his familial rules of conduct of being a gentleman. Pham's illustrations expressively showed the protagonist's energy and humor as he made his way awkwardly through life. The well-placed cartoon-like illustrations kept the pace moving in the episodic plots and brought lightness to the mood.

Quality art. When measuring the quality of the art, the examined books scored slightly lower (91.7\%) than on other questions in this section. This sixth question in Illustration evaluated the quality of the illustrations in such principles of design aspects as, rhythm, balance, variety, emphasis, spatial order, unity, etc. One book, Alvin Ho: Allergic to Girls, School, and Other Scary Things, scored a neutral rating when examining the quality of the artwork, while the other selected books scored positive. In Alvin Ho: Allergic to Girls, School, and Other Scary Things, Pham used an illustration style that showed her earlier experience at an animation studio. The many characters portrayed in this book showed much exuberance and personality. Even though, most of the illustrations were minimalistic and the smaller images were without any backgrounds, the images were extremely activated. Every character, object, and line was expressive and animated. In the larger more detailed illustrations, even such objects as, doors, Beethoven's bust, a piano, a piano stool, chalkboards, desks, etc. seemed alive. The characters many times had larger heads, exaggerated body motions and expressions to draw the audience's attention to the scene. Pham sometimes portrayed Alvin's 
exasperations at his dilemmas by including various interjections around his head like “\%\#*!@\&\&@! :?”, “AAAAAAAAAAAAAH!”, or “STUPID!”. Thought bubbles were also occasionally used to reveal some object that a character might be talking about, such as, a plate of brownies or a chicken. These cartoon-like illustrations were effective in accurately portraying the protagonist with the $\mathrm{CD}$ and other characters, enhancing the literary elements and interpretation of the story, and were appropriate for the age/grade level of the targeted audience. However, because of these animation techniques just discussed the images only received a neutral rating when being examined for quality of art.

As mentioned earlier both, Wonderstruck and The Dreamer scored positively when evaluating the quality of the art in their illustrations. Both of these artists, Selznick and Sis, are repeat performers when it comes to winning the Caldecott Medal and/or being selected as a Caldecott Honor Books. All the illustrators in these evaluated books used a simple monochromatic palette in their images, but Selznick and Sis utilized the various rules of the principles of design better. The more detailed and complicated illustrations of these two artists had more balance, emphasis and movement. One of the methods that Selznick used to show emphasis was his technique of slightly illuminating important characters or objects in a scene. This artist also utilized a zooming in of details in sequential images to show emphasis. These techniques along with panning out helped provide movement and focal point areas in the images. All of these illustrator's techniques were discussed earlier in this chapter.

Sis also exhibited quality art and principle of design well. In The Dreamer, this illustrator used a stippling technique. The delicate art style of stippling is unique in that 
small patterns of dots are used to create an image. The proximity of the dots to one another can depict a line, space, shadow, depth, texture, etc. Using dots only, Sis brilliantly produced his green monochromatic images that effectively used design principles, such as, pattern, repetition, rhythm, movement, etc. to evoke both surreal and representational images about the young protagonist's life.

Artistic usage of various art elements. This question is closely tied to the previous question. As mentioned before, when measuring art quality the application of the various principles of design is examined. Principles of design are about the ability to use different elements of art, such as, color, line, shape, and texture artistically. This question also scored a slightly lower score (91.7\%) than the majority of other questions on the evaluation form in Illustrations.

Selznick masterfully used the technique of cross-hatching to develop his incredibly detailed graphite, chiaroscuro images in Wonderstruck. By varying such aspects of the line as length, angle, closeness, etc., the artist was able to create tremendous tone, texture, light, and shadow in his illustrations. As Selznick once described the cross-hatching shading process he used as "drawing light" by "drawing darkness" (Conway, para. 14). His now signature technique provided mood and melodrama to the story by juxtaposing open luminous areas against darker, denser, detailed linear shapes, patterns and objects. Using this careful placement and proximity of 
layered patterns of angled lines helped Selznick achieve the chiaroscuro and richness in texture that he so admired in early black and white silent films (Conway, para. 14).

Color is one of the important elements of art. The Dreamer was printed using green instead of the more typical black ink. This was done to emulate the later usage of writing in green ink that Neftali did as an adult when he became known as Pablo Neruda. This Pulitzer-winning poet believed that green was a nurturing color of hope. Green also reflected and celebrated Neftali's love of nature. This young poet was surrounded by the color green in such places as the rainforest, river, ocean, etc. (Ryan, 2011, Author Interview). The dark green color was carried through into Sis' rich illustrations. Capturing many of the same art and design elements as Selznick's crosshatching, Sis' stippling technique utilized the density of dots to create mood, light and shadow. The tedious use of the many tiny dots helped to give a soft look to Sis' delicate illustration. Using this trademark technique, the images often had a surrealistic and sometimes whimsical effect. The lines, patterns, and rhythms created by the multitude of dots allowed the audience to be transported into the many flights of the vast imagination of the creative spirit of this young child. However, the delicate illustrations not only showed Neftali's dreams and total fascination with nature, but also his feelings. One early powerful and emotional image in The Dreamer was a full-page illustration of Neftali's father in the doorway of his son's bedroom. The backlit chiaroscuro image showed his 
father as a huge, bulky silhouette with a harsh elongated shadow. The artful use of shapes, texture, light and dark enabled readers to feel the force of the unsupportive and domineering father ridiculing as he loomed over the small sickly boy.

In Alvin Ho: Allergic to Girls, School, and Other Scary Things, Pham used a monochromatic color scheme with the energetic black strokes of her brush pen. This artist was able to capture the charm, silliness, and full range of emotions that the exuberant, but sometimes fearful Alvin displayed. As with the previous question, this book once again only scored a neutral rating when examining the illustrator's usage of art elements. This book had a different more animated comic-like style in its approach of various art elements, such as, color, shape texture than the other books.

Appealing layout and design. The last question of the Illustrations section evaluated the overall layout and design of the literature. More than just the internal format and juxtaposition of the illustrations and text were examined. Other factors, such as, the design of the book cover (inside and out, front and back), font size and color, white space, leaf pages, etc. were considered when judging the visually attractiveness of a book design. The layout and design in all the selected literature were judged to be positive (100\%).

All of the book covers were appealing. The book Wonderstruck had a stunning cover that was predominantly blue with a night scene filled with cumulus clouds and the 
small silhouette of a city with skyscrapers at the bottom edge. A bolt of lightning was coming down from the top of the page and traversed the large embossed silver title that was slightly tilted in the center of the page. The cover was enlivened and colorful. The back cover and spine had a colored close up image of Rose as a young girl. Rose was looking at the audience and is showing in her eyes and other facial expressions great concern or almost a frightened expression.

The Dreamer also had a striking book cover. This cover was colorful and has much depth. The upper half of a young boy was silhouetted in the bottom part of the cover. Instead of being filled with a single color, the shape appeared to be an opening to a deep black place containing distant stars, planets, and shooting comets. It is as if the boy's dreams were as big as the universe. The background of the book cover was a shiny blue and green. White stippled trees and a swimming swam were overlaid on this background. The bright iridescent-like covers were reminiscent of the shiny beetles that Neftali was enthralled with in the rain forest. The blue and green background continued to the back cover. In the forefront of the back image was a grid shape containing many small items like Neftali was always collecting from nature. The grid was filled with white stippled drawings of various leaves, bugs, feathers, seashells, snails, etc. The front and back cover showed the wide range of the boy's interests that extended from the small earthly objects that made up his microcosm to dreaming far beyond his world. 
The book cover of The Curious Incident of the Dog in the Night-Time was the simplest. It was minimalistic and monochromatic. The front cover was a light soft orange with a white border and white lettering. The title and author's name was all in lowercase letters. The intriguing part of the cover besides the color was the plain silhouette of a white standard poodle appearing to be standing upside down. The back cover just included short reviews/praises for the book.

Like the illustrations inside, the book cover of Alvin Ho: Allergic to Girls, School, and Other Scary Things was animated. On the front was a scared Alvin. Around him was a blue cloud shape containing many of the things, such as, girls, school, monsters, and teachers that this protagonist was especially scared of. The school building had eyes and the opened front door contained pointed sharp teeth. The same teeth appeared on the monster and teacher. This animated quality was found not only in the pictures, but extended also to the text of the title, author's and illustrator's name. The chartreuse-like green background quickly caught readers' eyes. The green continued on the back cover that included a list of things about Alvin.

The layouts in these four evaluated books that had illustrations/diagrams were not only appealing, but also varied greatly in format. As mentioned several times before, Wonderstruck was unique in its format by telling one protagonist's story only in words while the other protagonist's life tale was expressed solely using visual images. All of the 
illustrations bled to the edge and were two-page spreads. This wide-angle view the illustrations used, also added to the old silent film cinematic feel the author/illustrator was going for. Often Selznick's illustrations progressively zoomed in or out on a subject. He then would dramatically switch to another illustrated scene or to the other protagonist's written story. A good example of this motion picture zooming and panning can be found in the opening illustrations of Wonderstruck. The book began with two wolves running across an opening in a wooded area. In the next spread the wolves have changed directions and are heading toward the audience. Subsequently the illustrator zoomed in until readers are looking directly into one wolf's pair of eyes. Selznick then drew a closeup of just one wolf's eye. The audience gets closer and closer to this eye until it is more like a dark tunnel that lead to a bright light. This tunnel opening that readers were lead down abruptly became a double page title introducing the location and date that the story began at. This title page looked like a title caption one might have seen in the past on a silent movie screen. It had a black background with white lettering and a double line border. The same border that was used in the title captions extended into the format and design of the story's text. This gave the book pages a suitable large area of white spacing which juxtaposed/contrasted to the large illustrations that bled to the edges.

The Dreamer also has several illustrations that were double page spreads. These two-page spreads were interjected with a short poem or a line of verse. The illustrations in The Dreamer were much lighter, more airy and dream-like than those found in 
Wonderstruck. The illustrator Sis additionally utilized single full-page illustrations in this story. Only in a few cases did he incorporate smaller illustrations at the bottom of a page. Sis did this on such occasions like when the readers saw the words "I am here" scrawled in the dirt. Other instances of these small spot images are a distant train traveling through the landscape with smoke bellowing from its stack, Neftali pulling a small toy sheep behind him, and a variety of hopeful words stacked vertically to form a city skyline. At the end of the story, Sis did have a small book that began to fly across the pages. The book became larger and slowly transformed over several pages as it flew higher and farther. In the end the book had a long-necked bird's head and tail. Instead of wings the book pages remained. It was as if the bird with its beating wings/pages was emulating the pulse and dreams of this young writer. A more than sufficient amount of white space existed in these pages and illustrations. Since the targeted audience for this book was younger than most of the evaluated books, both the font and spacing between lines were appropriately larger. An additional visual effect at the beginning of each chapter was three small vertical drawings stacked in the center of the page. Many of the small images were in a square format thus emulating the panes of a window. These pictures were of objects or scenes that foreshadowed what would be happening in the upcoming chapter.

The layout of the book Alvin Ho: Allergic to Girls, School, and Other Scary Things did not have any illustrations spreads. There were only a few full-page images. Some of these large illustrations showed such scenes of Alvin flying in space in an astronaut suit, playing cards with his psychotherapist, being scared of his sister in her Halloween costume, etc. The majority of Pham's illustrations were smaller and inserted among the text. Some were relatively small pictures showing items like a whistle, a magnifying glass, a pair of shoes, a fish, etc. Other were larger and portrayed Alvin, his 
friends, or family member. Illustrations were injected into the pages wherever needed. Often they were at the top or bottom of pages, but sometimes they were placed along the sides. The text would wrap around these smaller images. The targeted audience for this book was also at the intermediate children's level. It had larger font, more kerning, wider borders, and more spacing than some of the other books with illustrations for older readers.

The layout of The Curious Incident of the Dog in the Night-Time was structured and had some different formatting features. The book was portrayed as being written by the protagonist, Christopher. His quasi-murder mystery is semi-journalistic in nature. Having autistic-like behavior, Christopher liked structure, was highly linear and analytical, and had a remarkable eye and memory for details. These characteristics of the protagonist are portrayed in the layout of the book. Christopher was a math genius and loved, such things, as prime numbers, logic problems, organization, and maps. In this book, prime numbers were utilized to number chapters instead of the more usual method of using cardinal numbers, like 1, 2, 3, 4, etc. As explained earlier in the chapter, many of the diagrams/illustrations were such things as graphs, math formulas and problems, star constellations, train timetables, his daily schedule, maps of the zoo, etc. The visual explanations/diagrams enabled readers to become aware of Christopher's unique focus on specific details/patterns in the world around him. The audience was able to visually see these details he was seeing and thinking. He drew diagrams of things like wall and fabric patterns, shapes of clouds, logos and stickers he saw. This protagonist also had precise line drawings of objects, like cows, orangutans, a double-decker bus, etc. All of these diagrams/images were well placed and centered under the text. This book used white space well and appropriately. 


\section{Research Question 3}

What associations/implications/connections exists between the roles of the authors and reviewers and the scores/evaluations/external evaluations of these selected awardwinning books that highlighting CD in children's literature?

(a) What if any connections to CDs (e.g., individual with a CD, family member, special education teachers, speech-language pathologists) do authors/illustrators of these books have and is there a relationship between an author's/illustrator's connection to disability and score on the Rating Scale for Quality Characterization of Individuals with CDs in Children's Literature?

(b) What if any differences exist in the portrayal of protagonists with CDs between children's and young adult book awards that were created specifically to honor the portrayal of individuals with disabilities (e.g., The Dolly Gray Children's Literature and the Schneider Family Book Awards) with those that were not?

The first comparison question investigated the various connections that authors/ illustrators of the eligible books had with CDs. In the evaluated twenty-six books, several authors/illustrators had some connection with the primary and/or secondary disability that contributed to the CD. Fifteen of the authors (57.7\%) of the evaluated books had a CD and/or the primary disability themselves, had a family member with the disability, and/or had taught or worked in the field of CDs/disabilities/special education, etc. (see Table 16 below). A more detailed table with explanations of the authors'/ illustrators' connections 
with disabilities can be found in Appendix E. The illustrator of Wonderstruck, who was also the author, was the only illustrator of these evaluated books known to have a connection with a disability that contributed to the $\mathrm{CD}$.

\section{Table 16}

\section{Authors/Illustrators Who Have Connections with Disabilities}

\begin{tabular}{l|l|l|}
\hline Title & Author/Illustrator & Year \\
\hline $\begin{array}{l}\text { Black Swan Green: A Novel } \\
\text { Carter Finally Gets It }\end{array}$ & Mitchell, David & 2007 \\
\hline $\begin{array}{l}\text { The Curious Incident of the Dog in the } \\
\text { Night-Time }\end{array}$ & Haddon, Mark & 2010 \\
\hline $\begin{array}{l}\text { Deaf Child Crossing } \\
\text { Free as a Bird }\end{array}$ & Matlin, Marlee & 2003 \\
\hline Harmonic Feedback & McMurchy-Barber, Gina & 2010 \\
\hline $\begin{array}{l}\text { The London Eye Mystery } \\
\text { Marcelo in the Real World }\end{array}$ & Kelly, Tara & 2010 \\
\hline Mockingbird & Dowd, Siobhan & 2007 \\
\hline Nick's Secret & Stork, Francisco & 2009 \\
\hline $\begin{array}{l}\text { Out of My Mind } \\
\text { Stuck in Neutral }\end{array}$ & Erskine, Kathryn & 2010 \\
\hline Tending to Grace & Blatchford, Claire H. & 2000 \\
\hline $\begin{array}{l}\text { Waiting for No One } \\
\text { Wonderstruck: A Novel in Words \& }\end{array}$ & Draper, Sharon & 2010 \\
\hline Pictures & Trueman, Terry & 2000 \\
\hline & Fusco, Kimberly Newton & 2004 \\
\hline & Brenna, Beverley & 2010 \\
\hline
\end{tabular}

The various selected books were broken down into two categories/groups. Group 1 was comprised of authors/illustrators that had some kind of connection with disabilities. 
Group 2 members were authors/illustrators that had no connection with disabilities. Score comparisons on the Rating Scale for Quality Characterization of Individuals with CDs in Children's Literature were made between these two groups of books in the eight sections of this evaluation form (see Table 17 below).

Table 17

Mean Scores of Authors/Illustrators Who Have/Do Not Have Connections with Disabilities

\begin{tabular}{|l|r|r|r|r|}
\hline Rating Scale Statistics Averages & \multicolumn{2}{|l|}{$\begin{array}{l}\text { Group 1-- } \\
\text { authors having } \\
\text { connections } \\
\text { w/disability }\end{array}$} & \multicolumn{2}{l|}{$\begin{array}{l}\text { Group 2-- } \\
\text { authors having no } \\
\text { connections } \\
\text { w/disability }\end{array}$} \\
\hline A. Personal Portrayals & 2.83 & $94.4 \%$ & 2.88 & $96.0 \%$ \\
\hline $\begin{array}{l}\text { B. Social Interactions (B6 does not use } \\
\text { scale) }\end{array}$ & 2.79 & $93.0 \%$ & 2.89 & $96.4 \%$ \\
\hline C. Exemplary Practices & 2.95 & $98.3 \%$ & 2.91 & $96.9 \%$ \\
\hline D. Sibling Relationships (if applicable) & 2.98 & $99.3 \%$ & 2.97 & $99.0 \%$ \\
\hline $\begin{array}{l}\text { E. Impact of CD on Plot (E2 \& E3 do not } \\
\text { use scale) }\end{array}$ & 2.94 & $97.8 \%$ & 2.95 & $98.2 \%$ \\
\hline F. Impact of Setting on Disability & 2.91 & $97.0 \%$ & 2.87 & $95.7 \%$ \\
\hline G. Point of View & 3.00 & $100.0 \%$ & 3.00 & $100.0 \%$ \\
\hline H. Illustrations (if applicable) & 3.00 & $100.0 \%$ & 2.86 & $95.2 \%$ \\
\hline
\end{tabular}

Both Group 1 and Group 2 scored well overall in the various sections. The average scores ranged between $93.0 \%$ and $100 \%$. Both groups scored $100 \%$ in one section, Point of View. Two of the sections (Siblings Relationships, and Impact of CD on Plot) had only a $0.3 \%$ to $0.4 \%$ difference between average measurements of the two groups. The other five sections (Impact of Setting on Disability, Exemplary Practices, Personal Portrayals, Social Interactions, and Illustrations) had slightly higher differences in 
average percentile scores. Their differences in average scores ranged from $1.3 \%$ to $4.8 \%$. Group 1 had an equal or higher percentile average scores in over sixty $(62.5 \%)$ of the sections: Point of View (0.0\%), Siblings Relationships (+0.3\%), Impact of Setting on Disability (+1.3\%), Exemplary Practices (+1.4\%), and Illustrations $(+4.8 \%)$. The other group, Group 2, scored higher in three sections, Impact of CD on Plot $(+0.4 \%)$, Personal Portrayals $(+1.6 \%)$ and Social Interactions $(+3.4 \%)$. Deeper examination was completed in the eight sections to explore how the two groups compared on different questions in each section of the evaluation tool.

Personal portrayals. The overall average measurement for Group 2 was slightly higher by $1.6 \%$ in the section on Personal Portrayals. Group 1 and Group 2 overall scores were respectively $94.4 \%$ and $96.0 \%$ in this section. Both groups had perfect marks on three questions. These questions dealt with: 1) accurate portrayal of characteristics of $C D, 2)$ characters with $C D$ are fully developed character $(s)$, and 3) does not only portray the CD, but also abilities, interest and strengths of the character(s). Group 2 measured higher than Group 1 on two questions that explored: 1) emphasizing similarities, rather than differences, between characters with and without $C D(+1.3 \%)$ and 2$)$ using nondiscriminatory language that avoids stereotypic portrayals $(+11.0 \%)$. This last question about using nondiscriminatory language had the greatest discrepancy in scores of the 2 groups in this section on Personal Portrayals. The only question that Group 2 did not score higher on pertained to describing the character(s) with CD realistically. On this topic, Group 2 measured 3.0\% lower. The various score comparisons for these two groups in Personal Portrayal are found in Table 18 below. 
Table 18

Mean Scores of Group 1 \& 2 in area of Personal Portrayal

\begin{tabular}{|c|c|c|c|c|c|}
\hline \multicolumn{6}{|c|}{ A. Personal Portrayal Statistics } \\
\hline \multirow[b]{2}{*}{ A1. } & \multirow[b]{2}{*}{$\begin{array}{l}\text { Portrays characteristics of CD } \\
\text { accurately }\end{array}$} & \multicolumn{2}{|c|}{$\begin{array}{l}\text { Group 1- } \\
\text { authors having } \\
\text { connections } \\
\text { w/disability }\end{array}$} & \multicolumn{2}{|c|}{$\begin{array}{l}\text { Group 2-- } \\
\text { authors having no } \\
\text { connections } \\
\text { w/disability }\end{array}$} \\
\hline & & 3.00 & $100.0 \%$ & 3.00 & $100.0 \%$ \\
\hline $\mathrm{A} 2$. & $\begin{array}{l}\text { Describe the character(s) with } \\
\text { CD as realistic }\end{array}$ & 3.00 & $100.0 \%$ & 2.91 & $97.0 \%$ \\
\hline A3. & $\begin{array}{l}\text { Character(s) with CD are fully } \\
\text { developed }\end{array}$ & 3.00 & $100.0 \%$ & 3.00 & $100.0 \%$ \\
\hline A4. & $\begin{array}{l}\text { Does not portray only CD of the } \\
\text { character(s), but portray } \\
\text { abilities, interests, and strengths } \\
\text { of the character(s) }\end{array}$ & 3.00 & $100.0 \%$ & 3.00 & $100.0 \%$ \\
\hline A5. & $\begin{array}{l}\text { Emphasizes similarities, rather } \\
\text { than differences, between } \\
\text { characters with and without CD }\end{array}$ & 2.69 & $89.7 \%$ & 2.73 & $91.0 \%$ \\
\hline A6. & $\begin{array}{l}\text { Uses nondiscriminatory } \\
\text { language that avoids stereotypic } \\
\text { portrayals }\end{array}$ & 2.31 & $77.0 \%$ & 2.64 & $88.0 \%$ \\
\hline AVG & & 2.83 & $94.4 \%$ & 2.88 & $96.0 \%$ \\
\hline
\end{tabular}

Social interactions. The next section examined was Social Interactions. The first five questions used the three point agree/disagree rating scale. The various scores of the two groups in this section may be seen in Table 19 below. On the whole, Group 2 measured a higher overall average of 3.4\%. This group scored higher on a majority of questions $(80.0 \%)$ in Social Interactions that utilized the three point rating system. The higher scores ranged from $1.3 \%$ to $8.3 \%$ higher than those of Group 1 . The topic with the highest difference (+8.3\%) pertained to the depiction of character $(s)$ with CD engaging in socially \& emotionally reciprocal relationships with a wide variety of persons. The other 3 topics that Group 2 excelled over Group 1 on were: 1) depicting acceptance of 
the character(s) with $C D(+1.3 \%), 2)$ promotes empathy, not pity for the character(s) with $C D(+4.0 \%)$, and 3$)$ portrayal of positive social contributions of person(s) with $C D$ $(+5.3 \%)$. The only question that Group 2 scored lower than Group 1 on assessed the promotion of respect for the character(s) with $C D(-2.0 \%)$.

\section{Table 19}

\section{Mean Scores of Group $1 \& 2$ in the area of Social Interactions}

\begin{tabular}{|c|c|c|c|c|c|}
\hline \multicolumn{6}{|c|}{ B1-5. Social Interactions Statistics } \\
\hline \multirow[b]{2}{*}{ B1 } & \multirow[b]{2}{*}{$\begin{array}{l}\text { Depicts character(s) with CD } \\
\text { engaging in socially \& } \\
\text { emotionally reciprocal } \\
\text { relationships with a wide variety } \\
\text { of persons }\end{array}$} & \multicolumn{2}{|c|}{$\begin{array}{l}\text { Group 1- } \\
\text { authors having } \\
\text { connections } \\
\text { w/disability }\end{array}$} & \multicolumn{2}{|c|}{$\begin{array}{l}\text { Group 2- } \\
\text { authors having no } \\
\text { connections } \\
\text { w/disability }\end{array}$} \\
\hline & & 2.75 & $91.7 \%$ & 3.00 & $100.0 \%$ \\
\hline B2 & $\begin{array}{l}\text { Depicts acceptance of the } \\
\text { character(s) with CD }\end{array}$ & 2.69 & $89.7 \%$ & 2.73 & $91.0 \%$ \\
\hline B3 & $\begin{array}{l}\text { Promotes empathy, not pity for } \\
\text { the character(s) with CD }\end{array}$ & 2.88 & $96.0 \%$ & 3.00 & $100.0 \%$ \\
\hline B4 & $\begin{array}{l}\text { Portrays positive social } \\
\text { contributions of person(s) with } \\
\text { CD }\end{array}$ & 2.75 & $91.7 \%$ & 2.91 & $97.0 \%$ \\
\hline B5 & $\begin{array}{l}\text { Promotes respects for the } \\
\text { character(s) with } \mathrm{CD}\end{array}$ & 2.88 & $96.0 \%$ & 2.82 & $94.0 \%$ \\
\hline AVG & & 2.79 & $93.0 \%$ & 2.89 & $96.3 \%$ \\
\hline
\end{tabular}

Various relationships. While examining the various types of relationships that protagonists with $\mathrm{CD}$ had with other individuals, several differences were discovered between the two groups (see Table 20 below). When looking at primary relationships 
with friends, siblings, paid personnel, and other, Group 2 exceeded Group 1 in the areas of friends (+13.0\%) and siblings relationships (+19.8\%). However, Group 1 surpassed Group 2 when it came to paid personnel relationships (+31.3\%) and other (+9.1\%). No protagonists with CDs in Group 2 were portrayed as having close relationships with paid personnel. Group 2 scored lower in other, since this category included relationships with parents. Two protagonists in the 2 nd group had little if any relationship with their parents. Variances also existed when examining whether the character(s) with CD were victims, perpetrators and/or protectors. In all of these relationships, Group 2 overtook Group 1. The percentage differences were: victims $(+17.1 \%)$, protector $(+23.9 \%)$ and initiator $(+19.3 \%)$. Neither group had characters that were primarily a perpetrator. This question also explored the dependent/caregiver and pupil/instructor relationships. All of the protagonists with CDs were dependents at one time during the story in both Group $1 \& 2$ (100\%). Group 1 had $12.5 \%$ of its protagonists who also were caregivers. On the pupil/ instructor topic in Group 1 all of protagonists with CDs were pupils (100\%) once, while Group 2 only had $92.9 \%$ who were ever pupils. None of the protagonists were classroom teachers/instructors per se in either of the groups. On both of the issues that dealt with how other characters felt when relating to the character with CD, Group 1 measured higher. These topics were: 1) fear of associating with (+13.1\%) and 2) feelings of guilt ( $4 \%)$. In the last topic of various relationships, Group 2 scored higher on character without disabilities that had a positive result as of their interactions with the character with a $C D(6.2 \%)$. 
Table 20

Mean Scores of Group 1 \& 2 in the area of Social InteractionsVarious Relationships

B6. Social Interactions Statistics-

Depicts various relationships between character with a CD and others

Group 1authors having connections w/disability
Group 2authors having no connections w/disability

B6a Character with a disability has primary relationship with:

\begin{tabular}{|c|c|c|c|c|c|}
\hline & Friend & 11 & $68.8 \%$ & 9 & $81.8 \%$ \\
\hline & Sibling & 7 & $43.8 \%$ & 7 & $63.6 \%$ \\
\hline & Paid personnel & 5 & $31.3 \%$ & 0 & $0.0 \%$ \\
\hline & Other & 16 & $100.0 \%$ & 10 & $90.9 \%$ \\
\hline $\mathrm{B} 6 \mathrm{~b}$ & \multicolumn{5}{|c|}{ Character with a CD is primarily: } \\
\hline & Victim & 6 & $37.5 \%$ & 6 & $54.6 \%$ \\
\hline & Perpetrator & 0 & $0.0 \%$ & 0 & $0.0 \%$ \\
\hline & Protector & 2 & $12.5 \%$ & 4 & $36.4 \%$ \\
\hline & (Initiator) & 10 & $62.5 \%$ & 9 & $81.8 \%$ \\
\hline & None & 0 & $0.0 \%$ & 0 & $0.0 \%$ \\
\hline \multirow[t]{3}{*}{ B6c } & \multicolumn{5}{|c|}{ Character with a CD is primarily: } \\
\hline & Dependent & 16 & $100.0 \%$ & 11 & $100.0 \%$ \\
\hline & Caregiver & 2 & $12.5 \%$ & 0 & $0.0 \%$ \\
\hline B6d & \multicolumn{5}{|c|}{ Character with a CD is primarily: } \\
\hline & Pupil & 16 & $100.0 \%$ & 10 & $90.9 \%$ \\
\hline & Instructor & 0 & $0.0 \%$ & 0 & $0.0 \%$ \\
\hline & Other & 2 & $12.5 \%$ & 1 & $9.1 \%$ \\
\hline
\end{tabular}

B6e Do other characters fear associating with the character with a CD?

\begin{tabular}{|l|r|r|r|r|}
\hline Yes & 5 & $31.3 \%$ & 2 & $18.2 \%$ \\
\hline No & 11 & $68.8 \%$ & 9 & $81.8 \%$ \\
\hline
\end{tabular}

B6f Do other characters experience feelings of guilt related to the character with a CD?

\begin{tabular}{|l|r|r|r|r|}
\hline Yes & 5 & $31.3 \%$ & 3 & $27.3 \%$ \\
\hline No & 11 & $68.8 \%$ & 8 & $72.7 \%$ \\
\hline
\end{tabular}

B6g What changes take place in character without disabilities as a result of their interactions with the character with a CD?

\begin{tabular}{|l|r|r|r|r|}
\hline Positive & 15 & $93.8 \%$ & 11 & $100.0 \%$ \\
\hline Neutral & 1 & $6.3 \%$ & 0 & $0.0 \%$ \\
\hline Negative & 0 & $0.0 \%$ & 0 & $0.0 \%$ \\
\hline
\end{tabular}


Exemplary practices. When assessing Exemplary Practices a 1.4\% statistical average difference was found between Group 1 and Group 2 (see Table 21 below). Both groups had perfect scores when rating depicting valued occupation for character(s) with $C D(100.0 \%)$ and promoting self-determination where choices are similar to the types of choices given to nondisabled peers (100.0\%). Group 1 had a higher score by $9.6 \%$ on the issue of depicting character(s) with CD receiving services appropriate for their age, skill level, and interests. However, Group 2 scored higher by a $4.0 \%$ difference when it came to depiction of character(s) with CD having full citizenship opportunities in integrated settings and/or activities.

\section{Table 21}

Mean Scores of Group $1 \& 2$ in the area of Exemplary Practices

\begin{tabular}{|c|c|c|c|c|c|}
\hline \multicolumn{6}{|c|}{ C. Exemplary Practices Statistics } \\
\hline \multirow[b]{2}{*}{$\mathrm{C} 1$} & \multirow[b]{2}{*}{$\begin{array}{l}\text { Depicts character(s) with CD having } \\
\text { full citizenship opportunities in } \\
\text { integrated settings and/or activities. }\end{array}$} & \multicolumn{2}{|c|}{$\begin{array}{l}\text { Group 1- } \\
\text { authors having } \\
\text { connections } \\
\text { w/disability }\end{array}$} & \multicolumn{2}{|c|}{$\begin{array}{l}\text { Group 2- } \\
\text { authors having } \\
\text { no connections } \\
\text { w/disability }\end{array}$} \\
\hline & & 2.88 & $96.0 \%$ & 3.00 & $100.0 \%$ \\
\hline $\mathrm{C} 2$ & $\begin{array}{l}\text { Depicts character(s) with CD } \\
\text { receiving services appropriate for } \\
\text { their age, skill level, and interests. }\end{array}$ & 2.92 & $97.3 \%$ & 2.63 & $87.7 \%$ \\
\hline C3 & $\begin{array}{l}\text { Depicts valued occupations for } \\
\text { character(s) with CD. (if applicable) }\end{array}$ & 3.00 & $100.0 \%$ & 3.00 & $100.0 \%$ \\
\hline $\mathrm{C} 4$ & $\begin{array}{l}\text { Promotes self-determination where } \\
\text { choices are similar to the types of } \\
\text { choices given to nondisabled peers. }\end{array}$ & 3.00 & $100.0 \%$ & 3.00 & $100.0 \%$ \\
\hline AVG & & 2.95 & $98.3 \%$ & 2.91 & $96.9 \%$ \\
\hline
\end{tabular}

Sibling relationships. Only a minor difference $(0.3 \%)$ existed between these two groups in the Sibling Relationships category (see Table 22 below). On $80 \%$ of the 
questions both groups had perfect scores. These questions dealt with siblings of the character(s) with CD 1) experiencing a wide range of emotions, 2) having opportunities for growth, 3) having a reciprocal sibling relationship, and 4) not being given unusually burdensome household and family duties. On the last question pertaining to the sibling(s) appear aware of the nature of the $C D$ and its effects on the character with $C D$, Group 2 scored higher by $2.0 \%$. This category of Sibling Relationships was only applicable when the protagonists with CDs had siblings. In Group 1, 53.3\% of the protagonists with CDs had siblings, while Group 2 had 63.6\% protagonists with CDs who had siblings.

Table 22

Mean Scores of Group 1 \& 2 in the area of Sibling Relationships

\begin{tabular}{|c|c|c|c|c|c|}
\hline \multicolumn{6}{|c|}{ D. Sibling Relationships Statistics (if applicable) } \\
\hline \multirow[b]{2}{*}{ D1 } & \multirow[b]{2}{*}{$\begin{array}{l}\text { Sibling(s) of the character(s) with CD } \\
\text { experience a wide range of emotions, } \\
\text { not just all positive or all negative } \\
\text { emotions }\end{array}$} & \multicolumn{2}{|c|}{$\begin{array}{l}\text { Group } 1- \\
\text { authors having } \\
\text { connections } \\
\text { w/disability }\end{array}$} & \multicolumn{2}{|c|}{$\begin{array}{l}\text { Group 2- } \\
\text { authors having } \\
\text { no connections } \\
\text { w/disability }\end{array}$} \\
\hline & & 3.00 & $100.0 \%$ & 3.00 & $100.0 \%$ \\
\hline D2 & $\begin{array}{l}\text { Sibling(s) of the character(s) with CD } \\
\text { have opportunities for growth that are } \\
\text { not typical for siblings of children } \\
\text { without disabilities }\end{array}$ & 3.00 & $100.0 \%$ & 3.00 & $100.0 \%$ \\
\hline D3 & $\begin{array}{l}\text { The sibling relationship is reciprocal, } \\
\text { given the age and development } \\
\text { differences between the siblings. }\end{array}$ & 3.00 & $100.0 \%$ & 3.00 & $100.0 \%$ \\
\hline D4 & $\begin{array}{l}\text { The sibling(s) are not given unusually } \\
\text { burdensome household and family } \\
\text { duties, but engage in family work that is } \\
\text { typical for children of the same age and } \\
\text { gender that do not have a sibling with } \\
\text { disabilities. }\end{array}$ & 3.00 & $100.0 \%$ & 3.00 & $100.0 \%$ \\
\hline D5 & $\begin{array}{l}\text { The sibling(s) appear aware of the } \\
\text { nature of the CD and its effects on the } \\
\text { character with CD. }\end{array}$ & 2.89 & $96.3 \%$ & 2.83 & $94.3 \%$ \\
\hline AVG & & 2.98 & $99.3 \%$ & 2.97 & $99.0 \%$ \\
\hline
\end{tabular}


Impact of CD on plot. The comparative average statistics for this category of the evaluation form is divided up into two parts. The first table (see Table 23 below) consists of the two questions that utilized the three point agree/disagree rating scale. The average statistical difference between these two groups on these two questions was only $0.4 \%$. When looking at whether the main character with a CD displays appropriate growth throughout the story, both Group $1 \& 2$ scored $100.0 \%$. On the question dealing with the issue of when the CD is integral to the plot the character with the CD models strategies for solving challenges presented by the disability, Group 2 scored $0.6 \%$ higher.

Table 23

Mean Scores of Group 1 \& 2 in the area of Impact of CD on Plot

\begin{tabular}{|c|c|c|c|c|c|}
\hline \multicolumn{6}{|c|}{ E1 \& E4. Impact of CD on Plot Statistics } \\
\hline \multirow[b]{2}{*}{ E1 } & \multirow[b]{2}{*}{$\begin{array}{l}\text { Main character with a CD displays } \\
\text { appropriate growth throughout the } \\
\text { story. }\end{array}$} & \multicolumn{2}{|c|}{$\begin{array}{l}\text { Group 1- } \\
\text { authors having } \\
\text { connections } \\
\text { w/disability }\end{array}$} & \multicolumn{2}{|c|}{$\begin{array}{l}\text { Group 2- } \\
\text { authors having } \\
\text { no connections } \\
\text { w/disability }\end{array}$} \\
\hline & & 3.00 & $100.0 \%$ & 3.00 & $100.0 \%$ \\
\hline E4 & $\begin{array}{l}\text { When the CD is integral to the plot the } \\
\text { character with the CD models } \\
\text { strategies for solving challenges } \\
\text { presented by the disability. }\end{array}$ & 2.87 & $95.7 \%$ & 2.89 & $96.3 \%$ \\
\hline AVG & & 2.94 & $97.8 \%$ & 2.95 & $98.2 \%$ \\
\hline
\end{tabular}

The second table in the category of Impact of CD on Plot consisted on two questions that used either a multiple choice or yes/no format instead of the three point rating scale (see Table 24 below). The main focus of the book for the majority of the books was to include a character with a CD whose presence and CD impacts the story. 
All books from Group 1 had this main focus for their stories, while only $81.8 \%$ of books from Group 2 had this focus. The average statistical difference between these 2 groups on this topic was $18.2 \%$. The other question looked at whether additional information is provided to help readers learn about the CD. Only Group 1 had any books that had additional information for readers about $\mathrm{CD}$ and/or the primary disabilities $(18.8 \%)$.

Table 24

Mean Scores of Group $1 \& 2$ in the area of Impact of CD on PlotFocus of Book and Provides Additional Information

\begin{tabular}{|c|c|c|c|c|c|}
\hline & & \multicolumn{2}{|c|}{$\begin{array}{l}\text { Group 1- } \\
\text { authors having } \\
\text { connections } \\
\text { w/disability }\end{array}$} & \multicolumn{2}{|c|}{$\begin{array}{l}\text { Group 2- } \\
\text { authors having } \\
\text { no connections } \\
\text { w/disability }\end{array}$} \\
\hline \multirow[t]{3}{*}{$\mathrm{E} 2$} & \multicolumn{5}{|l|}{ A main focus of the book appears to be to: } \\
\hline & $\begin{array}{l}\text { (c) include a character with a CD } \\
\text { whose presence and CD impacts the } \\
\text { story. }\end{array}$ & 16 & $100.0 \%$ & 9 & $81.8 \%$ \\
\hline & $\begin{array}{l}\text { (d) include a character with a CD } \\
\text { whose presence impacts the story, but } \\
\text { the CD is irrelevant. }\end{array}$ & 0 & $0.0 \%$ & 2 & $18.2 \%$ \\
\hline \multirow[t]{2}{*}{ E3 } & \multicolumn{5}{|c|}{ Additional information is provided to help readers learn about the CD. } \\
\hline & Yes & 3 & $18.8 \%$ & 0 & $0.0 \%$ \\
\hline
\end{tabular}

Impact of setting on CD. In the category of Impact of Setting on CD, Group 1 had a higher average statistical difference by $1.3 \%$ (see Table 25 below). Group 1 measured higher on the $1^{\text {st }}$ topic of the attitudes \& practices portrayed are congruent with attitudes $\&$ practices for those with $C D$ during that era by $5.0 \%$. When examining the $2^{\text {nd }}$ question 
of how the place of the story affects the life of character(s) with $C D$, a $2.0 \%$ difference existed between the groups. Group 2 had a perfect score (100.0\%) on this question while Group 1 scored $98.0 \%$.

Table 25

Mean Scores of Group $1 \& 2$ in the area of Impact of Setting on CD

\begin{tabular}{|c|c|c|c|c|c|}
\hline \multicolumn{6}{|c|}{ F. Impact of Setting on CD } \\
\hline \multirow[b]{2}{*}{ F1 } & \multirow[b]{2}{*}{$\begin{array}{l}\text { The attitudes \& practices portrayed } \\
\text { are congruent with attitudes \& } \\
\text { practices for those with CD during } \\
\text { that era. }\end{array}$} & \multicolumn{2}{|c|}{$\begin{array}{l}\text { Group 1- } \\
\text { authors having } \\
\text { connections } \\
\text { w/disability }\end{array}$} & \multicolumn{2}{|c|}{$\begin{array}{l}\text { Group 2- } \\
\text { authors having } \\
\text { no connections } \\
\text { w/disability }\end{array}$} \\
\hline & & 2.88 & $96.0 \%$ & 2.73 & $91.0 \%$ \\
\hline F2 & $\begin{array}{l}\text { The place of the story affects the } \\
\text { life of character(s) with } \mathrm{CD} \text {. }\end{array}$ & 2.94 & $98.0 \%$ & 3.00 & $100.0 \%$ \\
\hline AVG & & 2.91 & $97.0 \%$ & 2.87 & $95.7 \%$ \\
\hline
\end{tabular}

Point of view. The category Point of View had a fill-in-the-blank question and two questions that used the three point agree/disagree rating scale. Upon examining the types of POV, both groups of books were narrated mostly from the POV of the protagonist with CD. One book in both groups had more than one person telling the story. In the book that had multiple narrators in Group 2, the protagonist with CD spoke only once toward the end of the story. The book in Group 1 that had multiple narrators was told mostly from the protagonist's POV. A best friend narrated a small portion of the story. The majority of books in both Group $1 \& 2$ were told in first person POV. There was an average difference of $8.3 \%$ when looking at this factor in the 2 groups. Group 1 scored $84.6 \%$, 
while Group 2 scored $92.9 \%$. The two questions in this category that utilized the three point rating scale both scored $100.0 \%$. The questions pertained to the realistic quality when told from the POV of the character with and without a $C D$. The results of these two questions may be viewed in Table 26 below.

Table 26

Mean Scores of Group $1 \& 2$ in the area of $P O V$

\begin{tabular}{|l|l|l|l|l|l|}
\hline G. Point of View & \multicolumn{2}{|l|}{$\begin{array}{l}\text { Group 1- } \\
\text { authors having } \\
\text { connections } \\
\text { w/disability }\end{array}$} & $\begin{array}{l}\text { Group 2- } \\
\text { authors having } \\
\text { no connections } \\
\text { w/disability }\end{array}$ \\
\hline G1 & $\begin{array}{l}\text { The POV, if told by the character with a } \\
\text { CD, is realistic. }\end{array}$ & 3.00 & $100.0 \%$ & 3.00 & $100.0 \%$ \\
\hline G2 & $\begin{array}{l}\text { The POV, if told by the character without } \\
\text { a CD, is realistic. }\end{array}$ & 3.00 & $100.0 \%$ & 3.00 & $100.0 \%$ \\
\hline AVG & & $\mathbf{3 . 0 0}$ & $\mathbf{1 0 0 . 0 \%}$ & $\mathbf{3 . 0 0}$ & $\mathbf{1 0 0 . 0 \%}$ \\
\hline
\end{tabular}

Illustrations. This category was only applicable to four books. Two books with diagrams/illustrations were in each group. The overall average statistical difference between these two groups in the Illustrations category was $4.8 \%$ (see Table 27 below). Group 1 scored an overall statistical average of $100.0 \%$. On five of the questions about illustrations, both groups scored $100.0 \%$. These illustration questions dealt with the issues of: 1) portraying characteristics of disabilities accurately, 2) interpreting the story well, 3) being an appropriate style to the story and age level, 4) enhancing plot, theme, characters, setting, mood, and information, and 5) layout, design, and text are visually appealing. The question pertaining to portrayal of assistive/adaptive technology accurately, realistically, and contemporarily in the illustrations was not applicable to the 
books in either group. Group 2 scored lower than Group 1 on two issues. These questions dealt with illustrations representing quality art and illustrations using color, line, shape, and texture artistically. With Group 2 scoring an average of $83.3 \%$ on both of these questions, the average differences on these two questions was $16.7 \%$.

Table 27

Mean Scores of Group $1 \& 2$ in the area of Illustrations

\begin{tabular}{|c|c|c|c|c|c|}
\hline \multicolumn{6}{|c|}{ H. Illustrations (if applicable) } \\
\hline \multirow[b]{2}{*}{ H1 } & \multirow[b]{2}{*}{$\begin{array}{l}\text { Portrays characteristics of disabilities } \\
\text { accurately in illustrations. }\end{array}$} & \multicolumn{2}{|c|}{$\begin{array}{l}\text { Group 1- } \\
\text { authors having } \\
\text { connections } \\
\text { w/disability }\end{array}$} & \multicolumn{2}{|c|}{$\begin{array}{l}\text { Group 2- } \\
\text { authors having } \\
\text { no connections } \\
\text { w/disability }\end{array}$} \\
\hline & & 3.00 & $100.0 \%$ & 3.00 & $100.0 \%$ \\
\hline $\mathrm{H} 2$ & $\begin{array}{l}\text { Portrays assistive/adaptive technology } \\
\text { accurately, realistically, and } \\
\text { contemporarily in the illustrations. }\end{array}$ & NA & NA & NA & NA \\
\hline $\mathrm{H} 3$ & Illustrations interpret the story well. & 3.00 & $100.0 \%$ & 3.00 & $100.0 \%$ \\
\hline $\mathrm{H} 4$ & $\begin{array}{l}\text { Style of illustrations is appropriate to the } \\
\text { story and age level. }\end{array}$ & 3.00 & $100.0 \%$ & 3.00 & $100.0 \%$ \\
\hline H5. & $\begin{array}{l}\text { Plot, theme, characters, setting, mood, } \\
\text { and information are enhanced through } \\
\text { the illustrations. }\end{array}$ & 3.00 & $100.0 \%$ & 3.00 & $100.0 \%$ \\
\hline H6. & Illustrations represent quality art. & 3.00 & $100.0 \%$ & 2.50 & $83.3 \%$ \\
\hline H7. & $\begin{array}{l}\text { Illustrations use color, line, shape, and } \\
\text { texture artistically. }\end{array}$ & 3.00 & $100.0 \%$ & 2.50 & $83.3 \%$ \\
\hline H8. & $\begin{array}{l}\text { Layout and design of illustrations and } \\
\text { text are visually appealing. }\end{array}$ & 3.00 & $100.0 \%$ & 3.00 & $100.0 \%$ \\
\hline AVG & & 3.00 & $100.0 \%$ & 2.86 & $95.2 \%$ \\
\hline
\end{tabular}


The second comparison question examined if differences existed in the portrayal of protagonists with CDs between children's and young adult book awards that were created specifically to honor the portrayals of individuals with disabilities with those book awards that were not. Out of the 26 books, ten of the evaluated books won awards that were designated for books honoring characters with disabilities. Book awards that specifically honor disabilities are the ALA's Schneider Family Book Award and the CEC/DADD's Dolly Gray Children's Literature Award. The Schneider Award was started in 2004 while the origination date for the Dolly Gray Award was 2000. More about the specifics of the two awards can be found in Appendix B. The ten books that won awards that were designated for books that honor characters with disabilities are listed below in Table 28. The chart includes the title of the book, which of the two awards was won, and the year the award was won. Six of the books won the Schneider Family Book Award, while four won the Dolly Gray Award.

Table 28

\section{Books that Won Awards that Honor Disabilities}

\begin{tabular}{|l|c|c|}
\hline Title & $\begin{array}{c}\text { Year of Schneider } \\
\text { Family Book } \\
\text { Award }\end{array}$ & $\begin{array}{c}\text { Year of Dolly Gray } \\
\text { Children's } \\
\text { Literature Award }\end{array}$ \\
\hline Waiting for No One & 2012 & 2012 \\
\hline Wonderstruck & & \\
\hline Mockingbird & 2011 & \\
\hline Five Flavors of Dumb & 2010 & \\
\hline Anything But Typical & 2010 & \\
\hline Marcelo in the Real World & & 2010 \\
\hline The London Eye Mystery & 2008 & \\
\hline Hurt Go Happy & 2006 & \\
\hline Tending to Grace & & 2004 \\
\hline $\begin{array}{l}\text { Curious Incident of the Dog in the Night- } \\
\text { Time }\end{array}$ & & \\
\hline
\end{tabular}


The examined literature was divided into two categories/groups. Group 3 was composed of books that won awards that were specifically created to honor characters with disabilities. In Group 4 were book that won awards which did not specifically honor characters with disabilities. As mentioned before ten books/eleven protagonists fell into the 3rd group, while the sixteen remaining books/ protagonists were in the 4th group.

Comparison measurements were made for these groups in each category of the Rating Scale for Quality Characterization of Individuals with CDs in Children's Literature. Table 29 below lists both the overall average scores using the three-point agree/disagree rating scale and their equivalent percentages in the various eight categories of the evaluation form.

Table 29

Mean Scores of Books that Won Awards Which Honor Disabilities \& Books that Won Awards Which Do Not Specifically Honor Disabilities

\begin{tabular}{|l|c|c|c|c|}
\hline Rating Scale Statistics Averages & \multicolumn{2}{|l|}{$\begin{array}{l}\text { Group 3: } \\
\text { Book awards } \\
\text { that honor } \\
\text { disabilities }\end{array}$} & \multicolumn{2}{|l|}{$\begin{array}{l}\text { Group 4: } \\
\text { Book awards that } \\
\text { do not specifically } \\
\text { honor disabilities }\end{array}$} \\
\hline A. Personal Portrayals & 2.85 & $95.0 \%$ & 2.86 & $95.3 \%$ \\
\hline $\begin{array}{l}\text { B. Social Interactions (B6 does not use } \\
\text { scale) }\end{array}$ & 2.80 & $93.3 \%$ & 2.85 & $95.0 \%$ \\
\hline C. Exemplary Practices & 3.00 & $100.0 \%$ & 2.88 & $96.0 \%$ \\
\hline D. Sibling Relationships (if applicable) & 2.97 & $99.1 \%$ & 2.98 & $99.2 \%$ \\
\hline $\begin{array}{l}\text { E. Impact of CD on Plot (E2 \& E3 do not } \\
\text { use scale) }\end{array}$ & 3.00 & $100.0 \%$ & 2.88 & $96.0 \%$ \\
\hline F. Impact of Setting on Disability & 3.00 & $100.0 \%$ & 2.81 & $93.7 \%$ \\
\hline G. Point of View & 3.00 & $100.0 \%$ & 3.00 & $100.0 \%$ \\
\hline H. Illustrations (if applicable) & 3.00 & $100.0 \%$ & 2.86 & $95.3 \%$ \\
\hline
\end{tabular}


Both groups of books scored extremely well in the eight categories. This was expected since the majority of the individual books in the study had overall positive scores in the various sections of the evaluation tool. As the chart above showed, the lowest percentile rating was $93.3 \%$. Several of the categories in either Group 3 and/or Group 4 had statistical averages at the $100.0 \%$ level. Both groups scored $100.0 \%$ on the category of Point of View. Group 3 scored equal or higher than Group 4 in the majority $(62.5 \%)$ of the categories. The three categories that books in Group 4 scored slightly higher on were Personal Portrayals (+0.3\%), Social Interactions (+0.1\%), and Sibling Relationships $(+0.3 \%)$. The differences of percentile statistical averages in the eight categories between Group 3 and Group 4 ranged from $0.0 \%$ to $6.3 \%$. Impact of Setting on Disability was the category where the biggest statistical difference between the 2 groups occurred $(6.3 \%)$.

Personal portrayals. In the first category Personal Portrayals, overall Group 4 scored slightly higher than Group 3 by a difference of only $0.3 \%$ (see Table 30 below). Both Group $3 \& 4$ had perfect scores on half of the questions. These three questions dealt with: 1) portraying characteristics of CD accurately, 2) having fully developed character(s) with CD, and 3) not portraying only CD of the character(s), but portray abilities, interests, and strengths of the character(s). Upon closer examination of Personal Portrayals, it was found that Group 3 measured higher than Group 4 on the two questions about realistically portraying the character with $C D(2.0 \%)$ and emphasizing similarities rather that differences between the characters with and without $C D(6.3 \%)$. However, Group 3, scored lower on the question measuring using nondiscriminatory language that avoids stereotypic portrayals. On this question, Group 4 scored 9.6\% higher, which was the highest score differentiation in Personal Portrayals. 
Table 30

Mean Scores of Group $3 \& 4$ in area of Personal Portrayals

\begin{tabular}{|l|l|l|l|l|l|}
\hline A. Personal Portrayal Statistics & \multicolumn{3}{l|}{$\begin{array}{l}\text { Group 3- } \\
\text { Book Awards } \\
\text { That Honor } \\
\text { Disabilities }\end{array}$} & $\begin{array}{l}\text { Group 4-- } \\
\text { Book Awards That } \\
\text { Do Not Specifically } \\
\text { Honor Disabilities }\end{array}$ \\
\hline A1. & $\begin{array}{l}\text { Portrays characteristics of CD } \\
\text { accurately }\end{array}$ & 3.00 & $100.0 \%$ & 3.00 & $100.0 \%$ \\
\hline A2. & $\begin{array}{l}\text { Describe the character(s) with } \\
\text { CD as realistic }\end{array}$ & 3.00 & $100.0 \%$ & 2.94 & $98.0 \%$ \\
\hline A3. & $\begin{array}{l}\text { Character(s) with CD are fully } \\
\text { developed }\end{array}$ & 3.00 & $100.0 \%$ & 3.00 & $100.0 \%$ \\
\hline A4. & $\begin{array}{l}\text { Does not portray only CD of the } \\
\text { character(s), but portray } \\
\text { abilities, interests, and strengths } \\
\text { of the character(s) }\end{array}$ & 3.00 & $100.0 \%$ & 3.00 & $100.0 \%$ \\
\hline A5. & $\begin{array}{l}\text { Emphasizes similarities, rather } \\
\text { than differences, between } \\
\text { characters with and without CD }\end{array}$ & 2.82 & $94.0 \%$ & 2.63 & $87.7 \%$ \\
\hline A6. & $\begin{array}{l}\text { Uses nondiscriminatory } \\
\text { language that avoids stereotypic } \\
\text { portrayals }\end{array}$ & 2.27 & $75.7 \%$ & 2.56 & $85.3 \%$ \\
\hline AVG & & $\mathbf{2 . 8 5}$ & $\mathbf{9 5 . 0 \%}$ & $\mathbf{2 . 8 6}$ & $\mathbf{9 5 . 3 \%}$ \\
\hline
\end{tabular}

Social interactions. The three point agree/disagree rating scale was utilized for the first five questions of this category. The various scores of the two groups in this section may be seen in Table 31 below. In the Social Interactions category, Group 4 again had an overall statistical average higher than Group 3 by 1.7\%. The questions that Group 4 had a higher percentile scores on dealt with the following issues in portraying character(s) with CD: 1) engaging in socially \& emotionally reciprocal relationships with a wide variety of persons $(+2.0 \%), 2)$ positive social contributions $(+5.0 \%)$, and 3) acceptance $(+8.7 \%)$. This last issue that dealt with portraying acceptance of the 
character(s) with CD was the topic that these two groups differed on the most. Even though Social Interactions was the category that Group 3 scored the lowest on (93.3\%), Group 3 still was assessed higher on two questions than Group 4. These questions dealt with 1) promoting empathy (not pity) and 2) respect. The percentile differences on these two questions were $4.0 \%$ and $3.3 \%$ respectively. Group 3 had a perfect score on the question about promoting empathy.

\section{Table 31}

\section{Mean Scores of Group $3 \& 4$ in area of Social Interactions}

\begin{tabular}{|l|l|l|l|l|l|}
\hline B1-5. Social Interactions Statistics & \multicolumn{2}{|l|}{$\begin{array}{l}\text { Group 3- } \\
\text { Book Awards } \\
\text { That Honor } \\
\text { Disabilities }\end{array}$} & \multicolumn{2}{|l|}{$\begin{array}{l}\text { Group 4- } \\
\text { Book Awards That } \\
\text { Do Not Specifically } \\
\text { Honor Disabilities }\end{array}$} \\
\hline B1 & $\begin{array}{l}\text { Depicts character(s) with CD } \\
\text { engaging in socially \& } \\
\text { emotionally reciprocal } \\
\text { relationships with a wide variety } \\
\text { of persons }\end{array}$ & 2.82 & $94.0 \%$ & 2.88 & $96.0 \%$ \\
\hline B2 & $\begin{array}{l}\text { Depicts acceptance of the } \\
\text { character(s) with CD }\end{array}$ & 2.55 & $85.0 \%$ & 2.81 & $93.7 \%$ \\
\hline B3 & $\begin{array}{l}\text { Promotes empathy, not pity for the } \\
\text { character(s) with CD }\end{array}$ & 3.00 & $100.0 \%$ & 2.88 & $96.0 \%$ \\
\hline B4 & $\begin{array}{l}\text { Portrays positive social } \\
\text { contributions of person(s) with CD }\end{array}$ & 2.73 & $91.0 \%$ & 2.88 & $96.0 \%$ \\
\hline B5 & $\begin{array}{l}\text { Promotes respects for the } \\
\text { character(s) with CD }\end{array}$ & 2.91 & $97.0 \%$ & 2.81 & $93.7 \%$ \\
\hline AVG & & $\mathbf{2 . 8 0}$ & $\mathbf{9 3 . 3 \%}$ & $\mathbf{2 . 8 5}$ & $\mathbf{9 5 . 0 \%}$ \\
\hline & & & & & \\
\hline
\end{tabular}

Various relationships. The sixth question in Social Interactions used mostly a multiple-choice format to assess depiction of various relationships between character with a $C D$ and others. When examining the kinds of primary relationships that 
protagonists with CDs had, some differences existed between the two groups. Group 4 measured higher when it came to primary relationships both with friends $(+2.3 \%)$ and paid personnel $(+0.6 \%)$. Group 3 scored higher on the primary relationships dealing with siblings $(+4.5 \%)$ and others $(+6.2 \%)$. The most significant difference in relationships between Group 3 and Group 4 was with the question about character with a CD being primarily victim/perpetrator/protector/initiator. Group 4 depicted more characters as being victims $(+13.6 \%)$ and protectors $(+22.2 \%)$. However, Group 3 had a greater percentage of characters with CDs portrayed as initiator ( $+34.7 \%)$. Neither group had characters that were primarily perpetrators. In both groups all of the protagonists with CDs had been dependents at one time during the story. Only Group 3 had any main characters with CDs who had been caregivers $(+18.2 \%)$. On the question dealing with primarily a pupil (+6.3\%), Group 3 also scored higher. Group 3 had a perfect score on this question. Neither of the groups had any characters that were primarily an instructor. Group 3 measured higher on both of the negative relationship questions that dealt with such topics as fearing to associate with character with $C D(+2.3 \%)$ and experiencing feelings of guilt related to the character with a $C D(+11.4 \%)$. When assessing changes that took place in character without disabilities as a result of their interactions with the character with a CD, Group 4, which had a perfect score, measured 9.1\% better than Group 3. 
Table 32

Mean Scores of Group $3 \& 4$ in the area of Social InteractionsVarious Relationships

B6. Social Interactions Statistics-

Depicts various relationships between character with a $\mathrm{CD}$ and others.

Group 3-
Book Awards
That Honor
Disabilities

Group 4-

Book Awards That Do

Not Specifically Honor

Disabilities

B6a Character with a disability has primary relationship with:

\begin{tabular}{|l|r|r|r|r|}
\hline Friend & 8 & $72.7 \%$ & 12 & $75.0 \%$ \\
\hline Sibling & 6 & $54.5 \%$ & 8 & $50.0 \%$ \\
\hline Paid personnel & 2 & $18.2 \%$ & 3 & $18.8 \%$ \\
\hline Other & 11 & $100.0 \%$ & 15 & $93.8 \%$ \\
\hline
\end{tabular}

B6b Character with a CD is primarily:

\begin{tabular}{|l|r|r|r|r|}
\hline Victim & 4 & $36.4 \%$ & 8 & $50.0 \%$ \\
\hline Perpetrator & 0 & $0.0 \%$ & 0 & $0.0 \%$ \\
\hline Protector & 1 & $9.1 \%$ & 5 & $31.3 \%$ \\
\hline (Initiator) & 10 & $90.9 \%$ & 9 & $56.3 \%$ \\
\hline None & 0 & $0.0 \%$ & 0 & $0.0 \%$ \\
\hline
\end{tabular}

B6c Character with a CD is primarily:

\begin{tabular}{|l|r|r|r|r|}
\hline Dependent & 11 & $100.0 \%$ & 16 & $100.0 \%$ \\
\hline Caregiver & 2 & $18.2 \%$ & 0 & $0.0 \%$ \\
\hline
\end{tabular}

B6d Character with a CD is primarily:

Pupil

Instructor

11

Other

\begin{tabular}{|r|r|r|r|}
\hline 1 & $100.0 \%$ & 15 & $93.8 \%$ \\
\hline 0 & $0.0 \%$ & 0 & $0.0 \%$ \\
\hline 1 & $9.1 \%$ & 2 & $12.5 \%$ \\
\hline
\end{tabular}

B6e Do other characters fear associating with the character with a CD?

\begin{tabular}{|l|r|r|r|r|}
\hline Yes & 3 & $27.3 \%$ & 4 & $25.0 \%$ \\
\hline No & 8 & $72.7 \%$ & 12 & $75.0 \%$ \\
\hline
\end{tabular}

B6f Do other characters experience feelings of guilt related to the character with a CD?

\begin{tabular}{|l|r|r|r|r|}
\hline Yes & 4 & $36.4 \%$ & 4 & $25.0 \%$ \\
\hline No & 7 & $63.6 \%$ & 12 & $75.0 \%$ \\
\hline
\end{tabular}

B6g What changes take place in character without disabilities as a result of their interactions with the character with a CD?

\begin{tabular}{|l|r|r|r|r|}
\hline Positive & 10 & $90.9 \%$ & 16 & $100.0 \%$ \\
\hline Neutral & 1 & $9.1 \%$ & 0 & $0.0 \%$ \\
\hline Negative & 0 & $0.0 \%$ & 0 & $0.0 \%$ \\
\hline
\end{tabular}


Exemplary practices. In the area of Exemplary Practices, Group 3 scored an overall perfect score (100.0\%), while Group 4 scored at the $96^{\text {th }}$ percentile (see Table 33 below). The overall statistical average difference between these groups was 4.0\%. Group 4 scored $100 \%$ on two questions that dealt with depicting valued occupations for character(s) with $C D$ and promoting self-determination where choices are similar to the types of choices given to nondisabled peers. The two questions that Group 3 measured better on than Group 4 on were about depicting character(s) with $\mathrm{CD}$ as: 1) having full citizenship opportunities in integrated settings and/or activities $(+4.0 \%)$ and also 2$)$ receiving services appropriate for their age, skill level, and interests $(+12.0 \%)$.

\section{Table 33}

Mean Scores of Group $3 \& 4$ in the area of Exemplary Practices

\begin{tabular}{|c|c|c|c|c|c|}
\hline \multicolumn{6}{|c|}{ C. Exemplary Practices Statistics } \\
\hline \multirow[b]{2}{*}{$\mathrm{C} 1$} & \multirow[b]{2}{*}{$\begin{array}{l}\text { Depicts character(s) with CD } \\
\text { having full citizenship } \\
\text { opportunities in integrated } \\
\text { settings and/or activities. }\end{array}$} & \multicolumn{2}{|c|}{$\begin{array}{l}\text { Group 3- } \\
\text { Book Awards } \\
\text { That Honor } \\
\text { Disabilities }\end{array}$} & \multicolumn{2}{|c|}{$\begin{array}{l}\text { Group 4- } \\
\text { Book Awards That Do } \\
\text { Not Specifically Honor } \\
\text { Disabilities }\end{array}$} \\
\hline & & 3.00 & $100.0 \%$ & 2.88 & $96.0 \%$ \\
\hline $\mathrm{C} 2$ & $\begin{array}{l}\text { Depicts character(s) with CD } \\
\text { receiving services appropriate } \\
\text { for their age, skill level, and } \\
\text { interests. }\end{array}$ & 3.00 & $100.0 \%$ & 2.64 & $88.0 \%$ \\
\hline $\mathrm{C} 3$ & $\begin{array}{l}\text { Depicts valued occupations } \\
\text { for character(s) with CD. (if } \\
\text { applicable) }\end{array}$ & 3.00 & $100.0 \%$ & 3.00 & $100.0 \%$ \\
\hline $\mathrm{C} 4$ & $\begin{array}{l}\text { Promotes self-determination } \\
\text { where choices are similar to } \\
\text { the types of choices given to } \\
\text { nondisabled peers. }\end{array}$ & 3.00 & $100.0 \%$ & 3.00 & $100.0 \%$ \\
\hline AVG & & 3.00 & $100.0 \%$ & 2.88 & $96.0 \%$ \\
\hline
\end{tabular}


Sibling relationships. The category, Sibling Relationships, was only applicable in books where protagonists with CDs had siblings. The category pertained to $63.6 \%$ of the protagonists in Group 3 and only $56.3 \%$ of the protagonists in Group 4. A slight overall statistical difference existed between the two groups' scores. Group 4 scored $0.3 \%$ higher than Group 3 in this category (see Table 34 below). As in the last comparison several of the questions were not applicable even when the protagonists with CDs had siblings. The setting of the story and/or the age of the sibling sometimes did not allow a sibling to be involved sufficiently enough in the plot to be measured on the evaluation form. Both of the groups scored $100 \%$ on the first four questions about sibling(s) relationships. The leading three questions examined if the sibling(s) of the character(s) with CD experienced 1) a wide range of emotions, not just all positive or all negative emotions, 2) had opportunities for growth that are not typical for siblings of children without disabilities, and 3) were not given unusually burdensome household and family duties, but engaged in family work that is typical for children of the same age and gender that do not have a sibling with disabilities. Both groups also had a perfect score on the fourth question that looked at whether the sibling relationship was reciprocal, given the age and development differences between the siblings. The fifth and last question of Sibling Relationships was the inquiry that the two groups measured lower on. This question investigated whether the sibling relationship was reciprocal, given the age and development differences between the siblings. The scores for Group 3 and Group 4 were 95.3\% and 96.0\% respectively. The statistical average difference for this question was $0.7 \%$. 
Table 34

Mean Scores of Group $3 \& 4$ in the area of Sibling Relationships

\begin{tabular}{|c|c|c|c|c|c|}
\hline \multirow[b]{2}{*}{ D1 } & \multirow[b]{2}{*}{$\begin{array}{l}\text { Sibling(s) of the character(s) with } \\
\text { CD experience a wide range of } \\
\text { emotions, not just all positive or } \\
\text { all negative emotions }\end{array}$} & \multicolumn{2}{|c|}{$\begin{array}{l}\text { Group 3- } \\
\text { Book Awards } \\
\text { That Honor } \\
\text { Disabilities }\end{array}$} & \multicolumn{2}{|c|}{$\begin{array}{l}\text { Group 4- } \\
\text { Book Awards That } \\
\text { Do Not Specifically } \\
\text { Honor Disabilities }\end{array}$} \\
\hline & & 3.00 & $100.0 \%$ & 3.00 & $100.0 \%$ \\
\hline D2 & $\begin{array}{l}\text { Sibling(s) of the character(s) with } \\
\text { CD have opportunities for growth } \\
\text { that are not typical for siblings of } \\
\text { children without disabilities }\end{array}$ & 3.00 & $100.0 \%$ & 3.00 & $100.0 \%$ \\
\hline D3 & $\begin{array}{l}\text { The sibling relationship is } \\
\text { reciprocal, given the age and } \\
\text { development differences between } \\
\text { the siblings. }\end{array}$ & 3.00 & $100.0 \%$ & 3.00 & $100.0 \%$ \\
\hline D4 & $\begin{array}{l}\text { The sibling(s) are not given } \\
\text { unusually burdensome household } \\
\text { and family duties, but engage in } \\
\text { family work that is typical for } \\
\text { children of the same age and } \\
\text { gender that do not have a sibling } \\
\text { with disabilities. }\end{array}$ & 3.00 & $100.0 \%$ & 3.00 & $100.0 \%$ \\
\hline D5 & $\begin{array}{l}\text { The sibling(s) appear aware of the } \\
\text { nature of the CD and its effects on } \\
\text { the character with CD. }\end{array}$ & 2.86 & $95.3 \%$ & 2.88 & $96.0 \%$ \\
\hline AVG & & 2.97 & $99.0 \%$ & 2.98 & $99.3 \%$ \\
\hline
\end{tabular}

Impact of CD on plot. Both of the groups scored well in the category, Impact of

CD on Plot. The comparative average statistics for this category of the evaluation form was once again divided up into two parts. The first chart consists of the two questions that utilized the three point agree/disagree rating scale (see Table 35 below). The statistical average difference between these groups on these two questions was $4.0 \%$. Group 3 scored $100 \%$ on both of these questions. The questions examined whether 
1) the main character with a CD displayed appropriate growth throughout the story and

2) when the CD is integral to the plot, does the character with the CD modeled strategies for solving challenges presented by the disability. Group 4 scored lower than Group 3 on both of these issue by $4.0 \%$.

Table 35

Mean Scores of Group $3 \& 4$ in the area of Impact of CD on Plot

\begin{tabular}{|c|c|c|c|c|c|}
\hline \multicolumn{6}{|c|}{ E. Impact of CD on Plot Statistics } \\
\hline \multirow[b]{2}{*}{ E1 } & \multirow[b]{2}{*}{$\begin{array}{l}\text { Main character with a CD displays } \\
\text { appropriate growth throughout the } \\
\text { story. }\end{array}$} & \multicolumn{2}{|c|}{$\begin{array}{l}\text { Group 3- } \\
\text { Book Awards } \\
\text { That Honor } \\
\text { Disabilities }\end{array}$} & \multicolumn{2}{|c|}{$\begin{array}{l}\text { Group 4- } \\
\text { Book Awards That } \\
\text { Do Not Specifically } \\
\text { Honor Disabilities }\end{array}$} \\
\hline & & 3.00 & $100.0 \%$ & 2.88 & $96.0 \%$ \\
\hline E4 & $\begin{array}{l}\text { When the CD is integral to the plot } \\
\text { the character with the CD models } \\
\text { strategies for solving challenges } \\
\text { presented by the disability. }\end{array}$ & 3.00 & $100.0 \%$ & 2.88 & $96.0 \%$ \\
\hline AVG & & 3.00 & $100.0 \%$ & 2.88 & $96.0 \%$ \\
\hline
\end{tabular}

The second table in the category of Impact of CD on Plot also consisted of two questions (see Table 36 below). These questions used either a multiple choice or yes/no format instead of the three point agree/disagree rating scale. For the majority of the evaluated books the main focus of book was to include a character with a CD whose presence and CD impacts the story. All of the books from Group 3 had this main focus for their stories. Only $87.5 \%$ of the books from Group 4 had this focus. The statistical average difference between these 2 groups on this topic was $12.5 \%$. The second question looked at whether additional information was provided to help readers learn about the 
$C D$. Both Group 3 and Group 4 had book(s) that had additional information for readers about CDs and/or the primary disabilities. The scores for these two groups were $18.2 \%$ and $6.3 \%$ respectively. The statistical average difference for these groups on this question was $11.9 \%$. Group 3 measured higher on both of these questions.

Table 36

Mean Scores of Group 3 \& 4 in the area of Impact of CD on PlotFocus of Book and Provides Additional Information

\begin{tabular}{|c|c|c|c|c|c|}
\hline & & \multicolumn{2}{|c|}{$\begin{array}{l}\text { Group 3- } \\
\text { Book Awards } \\
\text { That Honor } \\
\text { Disabilities }\end{array}$} & \multicolumn{2}{|c|}{$\begin{array}{l}\text { Group 4- } \\
\text { Book Awards That } \\
\text { Do Not Specifically } \\
\text { Honor Disabilities }\end{array}$} \\
\hline \multirow[t]{3}{*}{ E2 } & \multicolumn{5}{|c|}{ A main focus of the book appears to be to: } \\
\hline & $\begin{array}{l}\text { (c) include a character with a CD } \\
\text { whose presence and } C D \text { impacts } \\
\text { the story. }\end{array}$ & 11 & $100.0 \%$ & 14 & $87.5 \%$ \\
\hline & $\begin{array}{l}\text { (d) include a character with a } \\
\text { CD whose presence impacts the } \\
\text { story, but the CD is irrelevant. }\end{array}$ & 0 & $0.0 \%$ & 2 & $12.5 \%$ \\
\hline \multirow[t]{2}{*}{ E3 } & \multicolumn{5}{|c|}{ Additional information is provided to help readers learn about the $\mathrm{CD}$. } \\
\hline & Yes & 2 & $18.2 \%$ & 1 & $6.3 \%$ \\
\hline
\end{tabular}

Impact of setting on CD. In the category of Impact of Setting on $C D$, the average statistical difference between Group 3 and 4 was $6.3 \%$ (see Table 37 below). The overall scores for the groups were $100.0 \%$ and $93.7 \%$ respectively. Group 3 scored $100.0 \%$ on both questions in this category. On the first question that dealt with the attitudes and practices portrayed were congruent with attitudes \& practices for those with CD during that era, Group 3 scored 10.3\% higher. The group scores on this question were $100 \%$ and $89.7 \%$ respectively. With Group 4 measuring only $93.7 \%$ on the second question about 
the place of the story affected the life of character(s) with $C D$, the score for Group 3 on this $2^{\text {nd }}$ topic was $6.3 \%$ higher.

Table 37

Mean Scores of Group $3 \& 4$ in the area of Impact of Setting on CD

\begin{tabular}{|l|l|l|l|l|l|}
\hline F. Impact of Setting on CD & \multicolumn{3}{|l|}{$\begin{array}{l}\text { Group 3- } \\
\text { Book Awards } \\
\text { That Honor } \\
\text { Disabilities }\end{array}$} & $\begin{array}{l}\text { Group 4- } \\
\text { Book Awards That } \\
\text { Do Not Specifically } \\
\text { Honor Disabilities }\end{array}$ \\
\hline F1 & $\begin{array}{l}\text { The attitudes \& practices } \\
\text { portrayed are congruent with } \\
\text { attitudes \& practices for those } \\
\text { with CD during that era. }\end{array}$ & 3.00 & $100.0 \%$ & 2.69 & $89.7 \%$ \\
\hline F2 & $\begin{array}{l}\text { The place of the story affects } \\
\text { the life of character(s) with CD. }\end{array}$ & 3.00 & $100.0 \%$ & 2.94 & $98.0 \%$ \\
\hline AVG & & $\mathbf{3 . 0 0}$ & $\mathbf{1 0 0 . 0 \%}$ & $\mathbf{2 . 8 1}$ & $\mathbf{9 3 . 7 \%}$ \\
\hline
\end{tabular}

Point of view. The Point of View category consisted of a fill-in-the-blank question about the actual location/setting of the book and also two questions that used the three point agree/disagree rating scale. All the books in Group 3 were narrated solely from the POV of the protagonist with a CD. In Group 4, even though two books were told by multiple narrators, the majority of the literature was also narrated from the POV of the protagonist with $\mathrm{CD}(87.5 \%)$. Both groups scored $100 \%$ on the first question about the $P O V$, if told by the character with a $C D$, is realistic (see Table 38 below). The second question was only applicable to Group 4. This question dealt with the issue of the POV, if told by the character without a $C D$, is realistic. A perfect score (100\%) was measured by Group 4 for this question. Since the question did not apply to Group 3 no statistical average difference existed between the two groups. 
Table 38

Mean Scores of Group $3 \& 4$ in the area of $P O V$

\begin{tabular}{|l|l|r|r|r|r|}
\hline G. Point of View & \multicolumn{2}{l|}{$\begin{array}{l}\text { Group 3- } \\
\text { Book Awards } \\
\text { That Honor } \\
\text { Disabilities }\end{array}$} & $\begin{array}{l}\text { Group 4- } \\
\text { Book Awards That } \\
\text { Do Not Specifically } \\
\text { Honor Disabilities }\end{array}$ \\
\hline G1 & $\begin{array}{l}\text { The POV, if told by the character with } \\
\text { a CD, is realistic. }\end{array}$ & 3.00 & $100.0 \%$ & 3.00 & $100.0 \%$ \\
\hline G2 & $\begin{array}{l}\text { The POV, if told by the character } \\
\text { without a CD, is realistic. }\end{array}$ & NA & NA & 3.00 & $100.0 \%$ \\
\hline AVG & & $\mathbf{3 . 0 0}$ & $\mathbf{1 0 0 . 0 \%}$ & $\mathbf{3 . 0 0}$ & $\mathbf{1 0 0 . 0 \%}$ \\
\hline
\end{tabular}

Illustrations. The category of Illustrations was only applicable to four books.

Once again two books with diagrams/illustrations were in each group. For these two groups the overall average statistical difference in the Illustrations category was $4.8 \%$ (see Table 39 below). Group 3 had a perfect overall average score in this category. The question pertaining to portrayal of assistive/adaptive technology accurately, realistically, and contemporarily in the illustrations was not applicable to books in either group. On five of the questions about illustrations, both Group $3 \& 4$ scored 100\%. These illustration questions dealt with issues of; 1) portraying characteristics of disabilities accurately, 2) interpreting the story well, 3) being an appropriate style to the story and age level, 4) enhancing plot, theme, characters, setting, mood, and information, and 5) layout, design, and text are visually appealing. On two topics Group 3 scored higher than Group 4. These questions dealt with illustrations representing quality art (83.3\%) and illustrations using color, line, shape, and texture artistically (83.3\%). The average difference on both of these two questions between Group $3 \& 4$ was $16.7 \%$. 
Table 39

Mean Scores of Group $3 \& 4$ in the area of Illustrations

\begin{tabular}{|c|c|c|c|c|c|}
\hline \multicolumn{6}{|c|}{ H. Illustrations (if applicable) } \\
\hline \multirow[b]{2}{*}{$\mathrm{H} 1$} & \multirow[b]{2}{*}{$\begin{array}{l}\text { Portrays characteristics of } \\
\text { disabilities accurately in } \\
\text { illustrations. }\end{array}$} & \multicolumn{2}{|c|}{$\begin{array}{l}\text { Group 3- } \\
\text { Book Awards } \\
\text { That Honor } \\
\text { Disabilities }\end{array}$} & \multicolumn{2}{|c|}{$\begin{array}{l}\text { Group 4- } \\
\text { Book Awards That } \\
\text { Do Not Specifically } \\
\text { Honor Disabilities }\end{array}$} \\
\hline & & 3.00 & $100.0 \%$ & 3.00 & $100.0 \%$ \\
\hline $\mathrm{H} 2$ & $\begin{array}{l}\text { Portrays assistive/adaptive } \\
\text { technology accurately, realistically, } \\
\text { and contemporarily in the } \\
\text { illustrations. }\end{array}$ & NA & NA & NA & NA \\
\hline $\mathrm{H} 3$ & Illustrations interpret the story well. & 3.00 & $100.0 \%$ & 3.00 & $100.0 \%$ \\
\hline $\mathrm{H} 4$ & $\begin{array}{l}\text { Style of illustrations is appropriate } \\
\text { to the story and age level. }\end{array}$ & 3.00 & $100.0 \%$ & 3.00 & $100.0 \%$ \\
\hline H5. & $\begin{array}{l}\text { Plot, theme, characters, setting, } \\
\text { mood, and information are enhanced } \\
\text { through the illustrations. }\end{array}$ & 3.00 & $100.0 \%$ & 3.00 & $100.0 \%$ \\
\hline H6. & Illustrations represent quality art. & 3.00 & $100.0 \%$ & 2.50 & $83.3 \%$ \\
\hline H7. & $\begin{array}{l}\text { Illustrations use color, line, shape, } \\
\text { and texture artistically. }\end{array}$ & 3.00 & $100.0 \%$ & 2.50 & $83.3 \%$ \\
\hline H8. & $\begin{array}{l}\text { Layout and design of illustrations } \\
\text { and text are visually appealing. }\end{array}$ & 3.00 & $100.0 \%$ & 3.00 & $100.0 \%$ \\
\hline AVG & & 3.00 & $100.0 \%$ & 2.86 & $95.3 \%$ \\
\hline
\end{tabular}




\section{Chapter 5 \\ Discussion}

The purpose of this study was three-fold. The first main objective was to find to what extent protagonists with CDs are portrayed in award-winning contemporary intermediate children's and young adult fiction from 2000-2012. The second area investigated was to measure specific aspects of the portrayal of protagonists with CDs in the selected award-winning intermediate children's and young adult literature from 20002012 by utilizing a Rating Scale for Quality Characterization of Individuals with CDs in Children's Literature. The third and final purpose of this study was to examine the associations/implications/connections that exist between the roles of the authors and reviewers and the scores/evaluations/external evaluations of the books that highlight CDs in children's and young adult literature. This chapter discusses various results, instructional implications, and limitations of the study, along with suggestions for future research on this topic.

\section{Research Question 1}

Twenty-six North American award-winning intermediate children's and young adult fictional books were found that not only had protagonists with CDs, but also won these awards between the years of 2000 to 2012 . This literature contained twenty-seven protagonists whose CDs were either the primary or secondary disability. The various types of CDs portrayed in these books fell into the three ASHA categories of: 1) speech, 2) language and 3) hearing disorders.

The highest incident of portrayals of protagonists with CDs was found in the category of language disorders ( $n=12)$. In the study, a little under half (44\%) of the CDs 
of the protagonists were included in the category of language disorders. The types of language disorders the main characters with CDs had were in the areas of pragmatics/ semantics and mutism.

The majority (58.3\%) of these main characters with language disorders were individuals whose primary disorder was autism/autism spectrum disorder (ASD) $(n=7)$. All the protagonists with ASD had various degrees of difficulty with both pragmatics and semantic aspects of language. This included such issues as generating and maintaining a conversation, and understanding figures of speech and body language (e.g., eye contact, facial expressions, gestures, body posture, tone of voice, etc.). These main characters with ASD were between the ages of 10 to $18^{3} / 4$. They were all depicted as having Asperger syndrome and/or high-functioning autism (HFA). Even though the diagnosis of some of these protagonists with ASD was straightforward, others were more vague and harder to define. In a few cases, some of these characters had been diagnosed with additional disorders as well (e.g., ADHD, PDD-NOS, OCD, etc.). In two cases the actual disorders of the protagonists with ASD were never disclosed in the text of the stories.

The remaining five protagonists with language disorders had some type of mutism (e.g., SM, traumatic mutism, etc.). The age range of these characters was from approximately 8 years old to young adulthood. These protagonists with mutism differed greatly not only in their types of mutism, but also in the onset of their language disorder and whether the mutism was constant or only occurred in specific situations/conditions. Three of the five protagonists with mutism had SM. Only one of these main characters was portrayed as having a more typical manifestation of SM whose onset of the CD was when the young protagonist started kindergarten. In this case, the usually active and 
verbose protagonist was unable to speak any place on school grounds. This condition also manifested itself when he began seeing a psychotherapist and taking piano lessons. For the other two main characters with SM, the onset of the language disorder occurred under different and more traumatic circumstances. For one character the SM began after being raped, while for the other individual the SM started shortly after being taken from her home and placed in an institution. The last two characters with mutism were unable to talk to anyone in any setting. After being involved in a traumatic fatal car accident that killed his parents, one protagonist found he was unable to speak to any person in any circumstances. This inability to talk continued even after this individual recovered his memory and had extensive testing in the hospital to try and find help for his traumatic mutism. The remaining protagonist with mutism had never spoken a word. No diagnostic testing and/or etiological reason for the mutism were ever disclosed in the story for this individual.

The second most common type of CD depicted in the books was hearing disorders $(n=8,29.6 \%)$. The protagonists with hearing disorders also had a wide range of characteristic differences especially when it came to ages, severity of their $\mathrm{CD}$, and the onset of their disorder. The age range of the protagonists with hearing disorders was from 9-101 years old. Two of the main characters with hearing disorders were portrayed both as children and as older adults. Even though mild/moderate hearing losses and/or hearing losses in only one ear are the more prevalent types of hearing disorders (as opposed to profound or severe hearing losses in both ears) (NIDCD, 2005), none of the protagonists were represented with these higher incident/more common types of hearing disorders. All 
of the characters were portrayed as having more severe or total hearing losses. Three of the characters with hearing disorders could not hear any sounds. Five other protagonists benefited from hearing aids, but relied heavily on lipreading and utilized for phone conversations Telecommunications Devices for the Deaf (TDD). The preferred language of these individuals who used hearing aids was sign language. None of the characters with hearing disorders were portrayed as being born completely deaf. However, one protagonist was congenitally deaf in one ear and later became completely deaf in both ears after an accident. For two characters the cause of the hearing disorders was unknown. The other characters' hearing disorders were familial or caused by childhood illnesses and/or physical abuse.

The type of CD that was least portrayed in the literature was speech disorders (25.9\%). The types of speech disorders that the seven protagonists with CDs had were: 1) fluency disorder/stuttering and 2) articulation disorders.

The most prevalent type of speech disorder was a fluency disorder/stuttering $(n=4$, $14.8 \%$ ). The four protagonists who stuttered varied greatly in the severity of their stuttering and the activities and situations in which the stuttering difficulty presented itself. Some main characters were portrayed as stuttering rarely or in specific situations like when talking to girls or an authoritarian father. One protagonist's disfluency worsened as the school year progressed. Another main character barely spoke to anyone because of the severity of her stuttering difficulty. Peers, family, teachers and the community had various reactions toward the protagonists when they stuttered. These 
responses ranged from negative reactions (e.g., teasing, looking away, or leaving) to more positive attitudes (e.g., listening, keeping eye contact, and giving the individual time to speak). Only one of these main characters that stuttered was currently receiving speech-language therapy. All the protagonists who stuttered were depicted with areas of strengths or accomplishments. The authors also used different methods in the text to represent the stuttered speech of the protagonists with CD.

Three protagonists with speech disorders had articulation disorders (11.1\%). Two protagonists with articulation disorders had dysarthria (7.4\%). Both of these characters had severe cerebral palsy and were unable to control the muscles needed to speak. These protagonists also could not walk, feed, dress, or take care of any of their personal needs themselves. At first one of the characters that had dysarthria could only make her wants known with a basic communication board comprised of pictures, simple words/commands, numbers (0-9), and letters of the alphabet. After acquiring a sophisticated computer system that enabled her to encode messages that could then be spoken by the computer, this individual finally had a voice in which she communicated to the world with. For the other protagonist with dysarthria, no means of communication was ever found for him to be able to express his thoughts or needs.

In this study one protagonist with an articulation disorder had a lisp $(n=1,3.7 \%)$. This articulation disorder was only mentioned occasionally during flashbacks. At times the high school main character re-experienced some personal events that occurred in elementary school. Some of these flashbacks recalled memories of having trouble saying 
the "s" sound and taking speech-language therapy with her close grade school friend. Being portrayed more as a former characteristic of the individual, this speech disorder was not really relevant to the story.

No award-winning books were found which portrayed protagonists with Central Auditory Processing Disorder (CAPD). This is a fourth type of CD listed by ASHA. According to ASHA, CAPD "are deficits in the information processing of audible signals not attributed to impaired peripheral hearing sensitivity or intellectual impairment" (ASHA, 1993, Definition of CD, part D). CAPD is a low incidence disorder. According to Chermak and Musiek (2002) only about $2-5 \%$ of school-aged children are estimated as having this type of disorder.

In the evaluated books of this study, the vast majority of portrayals of protagonists with CDs were discovered to be low incidence primary or secondary disorders that contributed to the $\mathrm{CD}$. For example, current trends showed the prevalence of autism/ASD in children in the United States to be only 0.74-1.47\% (Boyle, Boulet, Schieve, Cohen, Blumberg, Yeargin-Allsopp, Visser, \& Kogan (2011); Centers for Disease Control and Prevention (CDC) (2014), ASD). This low incidence occurrence was also the case for SM, cerebral palsy, moderate to profound hearing loss, and stuttering/stammering. In reviewing the past 15 years of research in the area of SM, Viana, Beidel and Rabian (2009) found the worldwide prevalence rate of this rather rare disorder to usually fluctuate between the ranges of $0.47 \%$ to $0.76 \%$ when studying children from different countries, settings, and ages. The 1997-2008 National Health Interview Surveys, 
disclosed the following trends of prevalence in American children between the ages of 3-17 years in select disabilities: cerebral palsy $(0.39 \%-0.43 \%)$, moderate to profound hearing loss (0.45\%-0.55\%), and stuttering/stammering (1.40\%-1.68\%) (Boyle et al. (2011)). All of these just mentioned low incidence disorders that were portrayed and contributed to CDs in this research have prevalence percentages lower than CAPD that was not found to be depicted in any award-winning literature.

Several other past studies in the area of children's/adolescents literature and disabilities also have discovered an overrepresentation of several lower incidence disabilities. Early research in this field found that such low incident disabilities as physical/orthopedic impairments and blindness/visual disabilities were the most frequent types of disabilities depicted in juvenile literature (Ayala, 1999; Baskin \& Harris, 1977; Carlisle, 1998; Harris \& Baskin, 1988). Recent empirical studies of the portrayal of disabilities in both Caldecott Medal and Honor books and Newbery Medal and Honor books revealed that most types of disabilities represented in this award-winning literature were also low incident disabilities. In their 2006 Caldecott literature study, Dyches et al. found that the disabilities portrayed in these high quality Medal and Honor books published from 1938 to 2005 were not the type of disabilities that most children would come across in their everyday school and/or community lives. While comparing the kinds and incidence of disabilities portrayed by school age characters with disabilities in 19752009 Newbery-winning literature with those of the current U.S. population of students receiving special education services, Leininger et al. (2010) also found that discrepancies existed in this comparison with a disproportional number of low incidence disabilities being represented in Newbery award-winning books. 


\section{Research Question 2}

Overall the 26 evaluated award-winning books measured results on the Rating Scale for Quality Characterization of Individuals with CDs in Children's Literature were extremely positive. The eligible literature measured well above the acceptable level in all eight categories. The range of average scores in the categories was from $94.3 \%$ to $100 \%$. The category that had the highest score was Point of View (100\%). The category with the lowest score (94.3\%) was Social Interactions. The scores in the other categories were: Personal Portrayals (95.1\%), Exemplary Practices (97.7\%), Sibling Relationships (if applicable) (99.2\%), Impact of Communication Disorder on Plot (95.9\%), Impact of Setting on Disability (96.3\%), and Illustrations (if applicable) (97.7\%).

The category Personal Portrayals had the second lowest scores of all the categories of the evaluation form. The evaluated books did extremely well in areas measuring such aspects of the depiction of the protagonist as: accuracy (100\%), realism (98.8\%), character development (100\%), and interests/strengths (100\%). The two areas in Personal Portrayals that were the most problematic in these award-winning books were: emphasizing similarities, rather than differences (90.1\%), and using nondiscriminatory language that avoids stereotypic portrayals (81.5\%). Throughout entire narratives, several protagonists saw themselves as extremely different than other people without disabilities (e.g., Anything but Typical, Stuck in Neutral, The Curious Incident of the Dog in the Night-Time, Free as a Bird). These books that received lower ratings on this question about emphasizing similarities, concentrated a major portion of the plot on how much the protagonists, their personal living conditions and/or life experiences were dissimilar from others. Being introverts or loners, this set of main characters did not have any real friends that they associated with frequently. They spent much of their time alone or with family members and/or people they lived with. 
Several of the eligible books had some sort of discriminatory language (18.5\%) dominant enough to lower their scoring from the positive rating. The majority of the discriminatory language terms found in the literature were much harsher than disrespectfully not using people-first language. In a couple of cases teachers \& school personnel did emphasize the disability itself instead of the individual and used terminology like "autistic kids" (Mockingbird) and "special needs children" (Alvin Ho: Allergic to Girls, School, and Other Scary Things). Characters without disabilities were not the only characters in the literature using the discriminatory and derogatory language. In several instances protagonists with CDs were being discriminatory/derogatory when referring to their peers with special needs or even themselves (i.e., Mockingbird, Black Swan Green, Stuck in Neutral, Curious Incident of the Dog in the Night-Time).

As stated before, the section Social Interactions scored the lowest of all sections on the evaluation form $(94.3 \%)$. The scores ranged from $90.1 \%$ to $97.5 \%$. The literature did extremely well on aspects such as reciprocal and various relationships of the protagonists (95.1\%), empathy (not pity) (97.5\%), respect (95.1\%) and positive social contributions (93.8\%). Even though the question about empathy (not pity) had the highest score in Social Interactions, one protagonist with a CD did receive a negative score, because much of the plot depicted pity more prominently rather than empathy (Ruby Jean in Free as a Bird). The question in Social Interactions that had the lowest score examined acceptance $(90.1 \%)$ of protagonists with CDs. Protagonists with CDs scored overall well above the acceptable level with regards to acceptance, however, three main characters were measured with a "disagree" (negative) score on the rating scale for this question (i.e., Shawn in Stuck in Neutral, Christopher in Curious Incident of the Dog in the NightTime, and Jason in Anything But Typical). 
This category also examined the types of various relationships protagonists with CDs had with other individuals. These main characters with CDs scored highest in the area of "Other" relationships $(96.3 \%)$, because this was the only place a relationship with parent(s) was included. A high percentage of the protagonists had friends (74.1\%). A majority of the protagonists also had close relationships with their siblings $(51.9 \%)$, but this score is much lower because only approximately $60 \%$ of the protagonists had siblings. About one fifth of the main characters were portrayed as having close relationships with paid personnel (18.5\%). All of the main characters with CDs were dynamic characters that had different roles during the plots. None of the protagonists were portrayed as perpetrators, but $44.4 \%$ were victims and $25.9 \%$ were protectors. Over three-quarters of the main characters with CDs were initiators $(77.8 \%)$ who brought about change in their lives and/or community. On the issue of dependent/caregiver, all of the protagonists were dependents at one time during the plot. Two main characters had roles as caregivers $(7.4 \%)$, either when they were children or later in the story as adults. When it came to attending school and the pupil/instructor role, all except one character, who grew up during the Middle Ages, were depicted as attending school (96.3\%). Even though none of the protagonists with CD were instructors in a school setting, one character helped a neighbor and also a family member learn to read.

The category of Social Interactions also examined the areas of fear of association, feelings of guilt, and changes taking place in characters without disabilities as a result of interacting with a character that had a CD. In approximately one fourth of the books $(25.9 \%)$, other characters feared associating with the protagonists with $\mathrm{CD}$ for various reasons such as embarrassment, bizarre behaviors, meltdowns, etc. A little under one third (29.6\%) of the literature had characters that had feelings of guilt toward the protagonists with CDs. 
Reasons for feeling of guilt varied. Some peers' and parents' consciously regretted their treatment at times toward a character with a CD. Several parents also felt guilty for possibly causing the medical or environmental condition that contributed to the $\mathrm{CD}$. In almost all the books $(96.3 \%)$ characters without disabilities had positive changes take place in their lives as a result of interactions and associations with the protagonists with CDs.

The category Exemplary Practices scored extremely high (97.7\%). On the questions dealing with depicting valued occupations (100\%) and promoting self-determination where choices are similar to types of choices given to nondisabled peers $(100 \%)$, the evaluated books had perfect scores. The protagonists with CDs also measured high when it came to having full citizenship opportunities in integrated settings and/or activities (97.5\%). The lowest score in Exemplary Practices was in the area of depicting the main characters with CDs receiving services appropriate for their age, skill, level and interests (93.7\%). Three of the characters were found not to be receiving the appropriate services and/or accommodations in their educational or institutional setting.

Even though the category Sibling Relationships was only applicable to approximately $60 \%$ of the evaluated literature, this area was one of the higher scoring categories $(99.2 \%)$. The majority of questions dealing with sibling relationships had perfect scores. These questions dealt with such issues as having a wide range of emotions (100\%), opportunities for growth (100\%), reciprocal relationships (100\%), and not being burdened with family duties $(100 \%)$. The one question that had a slightly lower score $(95.6 \%)$ examined whether sibling(s) appeared aware of the nature of the CD and its effects on the character with $C D$. This question scored lower because some of the siblings were too young at the time to fully comprehend the total ramification of the $\mathrm{CD}$ and/or the other primary disorder. 
The fifth category, Impact of CD on Plot, showed that in these award-winning books all the protagonists with CDs displayed appropriate growth throughout the story $(100 \%)$. A vast majority (92.6\%) of the books also included main character(s) with $C D$ whose presence and $C D$ impacted the story. In none of the literature was a main focus of a book about teaching about a CD. Only $7.4 \%$ of the books had a protagonist's with a $C D$ whose presence impacted the story, but the CD was irrelevant. This research also showed that when the $\mathrm{CD}$ was integral to the plot, a high majority of the main characters with the CD modeled strategies for solving challenges presented by the disability (91.7\%). Only a few books provided additional information to help readers learn about the $C D(7.7 \%)$.

This research revealed that quality contemporary award-winning books portraying protagonists with CDs have definitely moved away from the earlier $20^{\text {th }}$ century didactic approach of depicting characters with disabilities in juvenile literature. Even though an emphasis existed in a majority of the books to include protagonists with CDs whose character and $\mathrm{CD}$ both impacted the story, the breadth of the representation of the disability itself in this group of books varied greatly. As mentioned previously all of the protagonists with CDs showed growth in their stories and none of the literature's main focus was to only teach about the $\mathrm{CD} /$ disability, however, several authors seemed to have a stronger directive of educating and informing readers about the disability than other authors did. This happened especially with the literature that contained protagonists with ASD. With the growing number of children in the U.S. having ASD and almost $90 \%$ of the authors writing about protagonists with ASD in this study having some type of connection with the disability itself, this group of authors might have been addressing a more specific audience and/or issues than authors writing about protagonists with other types of CDs. These books with main characters with ASD were more informative about the disability 
itself and provided/modeled more strategies for dealing with specific aspects of their disability than the majority of books with protagonists with other types of CDs.

In the evaluated literature it was informative to learn what various main characters with CDs were thinking, believing and feeling, but as mentioned earlier sometimes differences were emphasized more than similarities (i.e., Anything but Typical, Curious Incident of the Dog in the Night-Time, Stuck in Neutral, Free as a Bird). Several books started by focusing/explaining about the disability and how the characters themselves or lives were different. However, many plots quickly grew from these beginning explanatory chapters to include similarities and interests that many readers with and/or without CDs might also experience in their lives. These books included such topics as helping other people/animals, making friends, importance of family, survival, finding one's place in the world, etc. (e.g., Alvin Ho, Black Swan Green, The Dark Days of Hamburger Halpin, Deaf Child Crossing, Hurt Go Happy, Wonderstruck, Out of my Mind).

On the other end of the spectrum where both the main character and CD impacted the story, a few books existed in this study that wrote less about the disability and more about the protagonists. Not dwelling as much on differences and the disability, but having an increased interest on similarities and abilities, allowed these books to be more compelling to most audiences. Main characters, who fell into this category, were individuals that readers would want to meet, get to know better, and maybe seek friendships with. In this research, the two best examples of this type of book were Carter Finally Gets It and Five Flavors of Dumb. The CDs in these books were relevant to the plots, but did not play as major a role as many of the CDs were in other texts. These protagonists did not let their disabilities define who they were or their experiences. In both of these books the main characters made mistakes and got into scrapes, but they were continually growing, trying unfamiliar things, developing new skills, making friends, etc. 
Only two texts were found that had protagonists with CDs where the CDs were irrelevant (i.e., Sweethearts and The Pull of the Ocean). In these books the CDs were depicted more as an added present and/or past characteristic of the main characters and did not play a significant part in the stories. To help children/adolescents relate better to characters with disabilities in juvenile books, Leininger et al. (2010) saw a need for authors to write more children's literature set in contemporary times and to include characters "whose disability is not the focus of the book but just part of the description of who they are" (p. 593).

Even though the eligible books took place in a variety of places and times, a preponderance of the stories took place both in the United States $(70.4 \%)$ and in contemporary times $(77.8 \%)$. The overall average percentage of the category, Impact of Setting on the $C D$, was well above the acceptable level with an overall score of $96.3 \%$. A high majority of the books (93.8\%) represented accurately past and present national and international attitudes and practices toward individuals with CDs during the eras they were set in. The stories' settings had high scores when examining how the various backdrops affected protagonists with CDs lives (98.8\%).

Having perfect scores on both questions, The Point of View category had the highest scores when measuring the eligible literature with the evaluation form. All the books scored positively when assessing whether the $P O V$ was realistic when told by the main character with a $C D$ or by another character without a $C D$. A high majority of the books were narrated solely from the protagonists' POV (92.5\%). Only a couple of books had more than one narrator.

Since this study targeted reading levels were intermediate children and young adult literature, the numbers of books that the Illustration category was applicable to was rather low. Only four (15.4\%) of the books had any type of illustrations and/or diagrams. 
The illustrations in these books did have an overall positive score reaching the 97.7 percentile. The books scored $100 \%$ in the area of enhancing the plot, theme, characters, setting, mood, and providing additional information. All the literature also had a perfect score when examining portraying characteristics of disabilities accurately, interpreting the story well, being appropriate to the story and age-level of the targeted audience and having an appealing layout and design. One book scored slightly lower (91.7\%) in the areas of: 1) representation of quality art and 2) usage of color, line, shape, and texture artistically.

As mentioned before several empirical studies have used the Dyches \& Prater Guidelines (2000) and/or modifications of these guidelines to evaluate quality and general literary standards that focused on the portrayal of characters with disabilities in children's literature (i.e., Dyches et al., 2001; Dyches and Prater, 2005; Dyches et al., 2009, Leininger et al., 2010). Three of these studies focused on the characterization/ portrayal of characters with development disorders, while the fourth study examined the portrayal of characters with disabilities in Newbery Award and Honor books. All four of these studies reported a general positive portrayal of characters with disabilities.

Instead of investigating the same wide range of categories in the Dyches \& Prater Guidelines (2000) that were used in this study on the portrayal of protagonists with CDs, researchers in the four previous studies focused more on issues in the first four categories of the guidelines (i.e., Personal Portrayal, Social Interactions, Exemplary Practices, and Sibling Relationships) These previous studies also examined how the portrayal of disabilities in Newbery Award winning books and/or characters with DDs changed/ progressed over time. Utilizing adaptations of the Dyches \& Prater Guidelines (2000) to evaluate systematically the depiction of Newbery characters with disabilities, Leininger et al. (2010) found that Newbery Award and Honor books from 1975-2009 had an increasing 
positive portrayal of characters with disabilities. The trend analysis for this 35 years period was in the four categories of personal portrayal, social interactions, exemplary practices and sibling relationships. Dyches et al. (2009) discovered several trends that existed across this and two older studies that investigated the portrayal of characters with DDs (Dyches et al., 2001; Dyches \& Prater, 2005). Several of the increasing trends that these researchers revealed related to this current research on the portrayal of protagonists with CDs. For instance, Dyches et al. (2009) found an increase in characters with ASD (i.e, $25 \%$ (2001) to $52 \%$ (2009)) with almost half of these characters having Asperger syndrome. The research also showed an upward trend of more positive portrayals of characters with DDs (i.e., 71\% (2001) to 81\% (2009)). This included traits like being more self-determined, enjoying more reciprocal relationships with a wider range of individuals, and participating in more teaching and caregiving roles in society. As reported earlier, this research on the portrayal of protagonists with CDs also identified a high percentage of portrayal of characters with ASD. Almost $60 \%$ of characters with language disorders were characters with ASD (58.3\%). Although these earlier studies that used these guidelines had generally positive scores that showed an increasing positive trend, none of the scores in the previous research were as high $(96.6 \%)$ as the average score for protagonists with $\mathrm{CDs}$ in these same four categories. The extremely positive score of portrayal of characters with CDs was probably due in part to the fact the criteria was more focused and contemporary. The previous studies evaluated both main characters and supporting characters. The percentage of main characters/protagonists in the three DD studies ranged from $44-50 \%$ and only $12 \%$ of the Newbery characters with disabilities were main characters/protagonists. 


\section{Research Question 3}

Utilizing the measured results/evaluations/external evaluation of the selected award-winning books that highlighted CDs in children's literature, two comparisons were made between various groups of books to see what associations/implications/connections existed between the roles of the authors and reviewers. The first comparison examined the score differences on the evaluation form of books with author/illustrators that had some connection to the protagonist's disability with literature of those authors/illustrators that had no connections to the disability. Fifteen authors $(57.7 \%)$ were found to have had at some time a connection with the $\mathrm{CD}$ and/or the primary disability depicted in their books. These authors may have had the $\mathrm{CD}$ and/or primary disability themselves, had a family member with the disability, and/or had taught or worked in the field of disabilities/ CDs/ special education, etc. The overall percentage scores between the literature of authors that had connections with the disability and those that did not have a connection were the same or fairly close in the various eight categories of the evaluation form. The range of percentage score differences in the categories was from $0 \%$ to $4.8 \%$. A closer examination was made of specific categories and/or questions on the evaluation form to examine which areas these two groups had the greatest differences in.

The books of authors who had connections to the disability scored higher than the books of authors who did not have any connections to the disability in a little over half of the categories $(57.1 \%)$. The area that authors who had connections with the disability had the greatest score percentage difference in was Illustrations $(+4.8 \%)$. This category had an extremely small sample size with only two books being eligible in both groups. The higher scores in Illustrations were measured in the areas of representing quality art $(+16.7 \%)$ and using color, line, shape and texture artistically $(+16.7 \%)$. The other three 
categories this group excelled in were much closer in statistical average differences with the scores ranging only from $0.3 \%$ to $1.4 \%$.

The category Social Interactions had the second highest overall percentage score differences between these two groups. However in this category, books of authors without connections to the disability scored $3.4 \%$ higher. On the evaluation form, the category of Social Interactions had the most questions/topics with at least $5 \%$ score differences. The books of authors without connections to the disability had more positive changes taking place in character without disabilities as a result of their interactions with the character with a $C D(+6.3 \%)$. The books of these authors were also better at depicting character(s) with CD engaging in socially and emotionally reciprocal relationships $(+8.3 \%)$ and portraying positive social contribution of person(s) with $C D$ $(+5.3 \%)$. When accessing the various primary and other relationships that protagonists with CDs had, this group of authors' literature excelled in several areas, such as, friends $(+13.1 \%)$, siblings $(+19.9 \%)$, victims $(+17.1 \%)$, protectors $(+23.9 \%)$, and initiators $(+19.3 \%)$. Each of these higher scores in relationships with other individuals were positive, except for the escalation of being victimized.

All topics' and various relationships' scores in the category of Social Interactions were not dominated by books of authors without connections to the disability. In several of the various primary and other relationships of protagonists with CDs, increased score differences were discovered in books by authors having connections with the disability they portrayed. This group had percentage score differences that were at least $5 \%$ higher when exploring primary associations with paid personnel $(+31.3 \%)$ and other $(+9.1 \%)$. Both the paid personnel (e.g., counselors, teacher aids, speech-language pathologists, teachers, etc.) and the other category (e.g., parents, grandparents, grown-up neighbors, 
other extended family members, etc.) were composed mostly of adults. These percentage score differences showed that books written by authors having a connection with the disability more often portrayed protagonists with CDs having a greater number of primary relationships with adults and less with children (e.g., peers, siblings) than literature written by authors having no connections with the disability. This set of books, additionally had more protagonists with CDs represented as caregivers $(+12.5 \%)$, and pupils (+9.1\%). In the category of Social Interactions, most of the higher percentage score differences by this group of authors would be viewed as positive. However, one area that had a negative connotation that this set of books excelled at was more characters feared associating with the protagonist with a $C D(+13.1 \%)$.

Some additional higher scores were found for this group in other categories on the evaluation form. Books by authors who had connections to the disabilities they portrayed also scored higher than 5\% on depicting protagonists with CDs receiving services appropriate for their age, skill level, and interests (+9.7\%) and portraying attitudes and practices that were congruent with attitudes and practices for those with CD during that era $(+5.0 \%)$. In the category of Impact of CD on Plot, two additional higher percentage score differences were discovered. In this group of literature when assessing the main focus of the book, a higher percentage of books were discovered that included a character with a CD whose presence and $C D$ impacted the story $(+18.2 \%)$. In the group of literature by authors without connections to the disability, two of the books examined did have protagonists with CDs whose presence impacted the story, however the CD was irrelevant. All the books that included any additional information (e.g., internet addresses, professional organizations, author's notes, etc.) to aid the audience in finding out more about the $C D(+18.8 \%)$ were discovered in the set of books by authors with connections to the disability. 
The group of authors that did not have any known connections with the disability surpassed the other group of authors in the category of Personal Portrayals, but only by $1.6 \%$. However, on one question this group measured much higher than a $5 \%$ score difference. When dealing with the issue of using nondiscriminatory language that avoided stereotypic portrayals, books written by authors without connections to the disability exceeded the other group by $11.0 \%$.

A closer examination was also made to see which awarding-winning books and what types of CDs had authors that had connections with the disability that they portrayed. All of the books that won the Dolly Gray Children's Literature Award and $50 \%$ of the books that won the Schneider Family Book Award had authors that had connections with the portrayed disabilities. These book awards that were created to specifically honor characters with disabilities composed $46 \%$ of the set of books by this group of authors. When investigating what percentage of books in each of these three general categories of CDs represented in this study had authors who have connections with the disability, the following percentages were discovered: 1) speech disorders $(71.4 \%), 2)$ language disorders $(58.3 \%)$, and 3$)$ hearing disorders $(42.9 \%)$. Breaking these categories into smaller units of specific types of CDs portrayed, the percentages of authors with connections to these CDs represented in the study were: ASD (85.7\%), disfluency/stuttering (75.0\%), articulation disorder (66.7\%), and mutism (20\%).

The second comparison in this study investigated whether differences existed in the portrayal of protagonists with CDs between children's and young adult book awards that were created specifically to honor the portrayals of characters with disabilities with 
those books awards that were not. In one category Point of View, both groups scored $100 \%$. The group of books that won awards that were created specifically to honor the portrayals of characters with disabilities scored higher than books awards that were not in a little over half of the categories (57.1\%). This group of books measured better in the four categories of Exemplary Practices (+4.0\%), Impact of Communication Disorder on Plot (+4.0\%), Impact of Setting on Disability (+6.3\%), and Illustrations $(+4.7 \%)$. The differences in scores of these two groups in these four categories ranged from $4.0 \%$ to $6.3 \%$. The other group of books who won awards that were not created specifically to honor the portrayal of characters with disabilities did slightly better that this group in the categories Personal Portrayals (+0.3\%), Social Interactions (+1.7\%), and Sibling Relationships $(+0.1 \%)$. The percentile differences in scores of these two groups in these three categories were much smaller ranging only from $0.1 \%$ to $1.7 \%$. A closer investigation of the specific categories and/or questions on the evaluation form revealed additional percentile score differences between these two groups.

Even though the category Social Interactions only had an overall percentage score differences between these two groups of $1.7 \%$, this category had the most topics that had percentile score differences greater than $5 \%$. The books that won awards that were not created to honor characters with disabilities did better on Social Interactions' issues dealing with portraying positive social contributions of persons with $C D(+5.0 \%)$ and depicting acceptance of the characters with $C D(+8.7 \%)$. This set of books also had more positive changes taking place in characters without disabilities as a result of their interactions with the characters with disabilities $(+9.1 \%)$. When accessing the various primary and other 
relationships that protagonists with CDs had, this group of literature also excelled in the areas of protector $(+22.2 \%)$ and victim $(+13.6 \%)$. The other group of books in this comparison that won awards that were specifically created to honor characters with disabilities, also scored higher on several questions dealing with Social Interactions. This set of literature had more relationships as initiators $(+34.7 \%)$ and caregivers $(+18.2 \%)$. On a negative note about relationships, however, this group of books written by authors with connections to the disabilities portrayed additionally excelled on other characters experiencing more feelings of guilt related to the characters with CDs $(+11.4 \%)$.

This same group of books also had higher percentile score differences on several specific questions in other categories of the evaluation form. This body of literature that won awards created specifically to honor the portrayal of characters with disabilities scored by at least 5\% higher in emphasizing similarities, rather than differences, between characters with and without $C D s(+6.3 \%)$. The group also triumphed when depicting characters with $C D$ receiving services appropriate for their age, skill level and interests (+12.0\%) and portraying attitudes \& practices that are congruent with attitudes \& practices for those with $C D$ during that era $(+10.3 \%)$. In the category Impact of CD on Plot, this body of books scored higher than the other group by $6.3 \%$. This was due in part to the higher scores in the areas of providing additional information to help readers learn about the $C D(+11.9 \%)$ and having a main focus of the book appearing to be to include a character with a $C D$ whose presence and CD impacts the story $(+12.5 \%)$. All the books in this category had this same main focus. Higher scores were also tallied on two questions in the category of Illustrations by the collection of books that won awards that were created specifically to honor characters with disabilities. Once again only two books were eligible in each group in 
this category. The higher scores in Illustrations were measured in the areas of representing quality art $(+16.7 \%)$ and using color, line, shape and texture artistically $(+16.7 \%)$.

When examining the group of books that won awards that did not specifically honor characters with disabilities, another area of strength was discovered others than the majority of ones in the category of Social Interactions. This set of literature also scored at least 5\% higher when examining an issue in the category of Personal Portrayal of main characters with CDs. Award-winning books in this group scored higher when measuring the use of nondiscriminatory language that avoided stereotypic portrayals (9.7\%).

Other studies in the area of multicultural children's literature have also examined the portrayals/perceptions of authenticity/realism of characters and cultures when written by authors of the culture versus authors of a different culture. Pajka West (2007) examined a similar issue in her study on perceptions of deaf characters in contemporary adolescent realistic fiction literature. This study used a Reader Response survey to compare the perceptions of readers who read books on this topic when they were written by hearing authors versus deaf authors. Three different categories/groups of readers (i.e., deaf, familiar, and unfamiliar) were chosen to participate in this study. In the deaf category were participants who identified themselves as deaf. The familiar category was composed of readers that were familiar with or had acquaintances with deaf people. Individuals that had never associated with deaf individuals were in the unfamiliar category. This study found that as a whole all three groups of readers preferred and made more positive comments about the literature with deaf characters that was written by 
hearing authors than those books written by deaf authors. This preference included not only the familiar and unfamiliar participatory readers, but surprising also the deaf participants that rated the books. Overall the three groups of readers enjoyed the literature by hearing authors more because they believed these books more realistically portrayed their personal perceptions of deaf individuals. It was noted that deaf participants rated deaf authors harder. However, hearing participants were more critical of hearing authors. Since the three groups of participants favored a spectrum of deaf characters in book, Pajka West speculated that some of the preference for books by hearing authors might be because these authors included not only more, but a wider variety of deaf characters. In the monograph Shadow and Substance: Afro-American Experience in Contemporary Children's Fiction, Rudine Sims Bishop (1982) investigated not only how a specific culture was being portrayed in juvenile books, but who was the intended audience and from whose perspective was the book written. This significant and extensive study in the area of children's literature, analyzed 150 realistic fiction books about African Americans. The books were published from 1965-1979 and were for children preschool-eighth grade. Bishop addressed many issues about perspective, authenticity, and audience in her question: "To whom are books about Afro-Americans primarily addressed?" (p. 5). Within this body of literature, the researcher identified three categories of African American books: 1) social conscience books, 2) melting pots books and 3) culturally conscious books. These categories are reasonably self-explanatory and deal 
more with content, themes, and prospective audience than who wrote them. Sims Bishop, however, did reflect on how the perspective one is writing from can give a frame of reference that comes from personal life experiences. Without having shared collective memories, authors outside a culture can only infer experiences instead of actually reflecting on them.

Limitations of the study. Limitations in this study can be found in areas, such as, researchers, the instrument tool, locating authors' connections with disabilities, and publishers'/editors' influence on the text. First, opinions of researchers may color the judgments made in this dissertation. These judgments and analysis of the books are only as accurate as researchers reading them. In this study, as Goldman (1990) noted accuracy will depend in part on researchers' knowledge of and sensitivity to both the content and the form of the literature being analyzed. Biases toward certain books may also occur from factors, such as, some personal awareness, background experience, etc. of researchers or influence by other authors/researchers, thus not allowing each book to be judged on its own merit.

Second, as mentioned before adaptations of the of Dyches' \& Prater's (2000) Rating Scale for Quality Characterizations of Individuals with Disabilities in Children's Literature have been used in several empirical studies and also as guidelines for selecting the biennial Dolly Gray Children's Literature Awards. However, some of the questions on the rating scale/evaluation form allowed for more leeway in subjective rating than others.

Third, it is possible that identification was not made of all authors/illustrators who had some type of a connection to the primary and/or secondary disability that contributed to the $\mathrm{CD}$ 
portrayed in their books. Trying to avoid omission of any author/illustrator that had a possible connection, a thorough search was made in multiple sources, such as, the books, websites, interviews, videos, etc. of the various authors and illustrators in this study. This information, however, might not have been included in the sources consulted by the researcher.

Finally, publishers and/or editors often influence language descriptors and choices used by authors. The editor's choices may override the author's preferences.

Implications for Teaching. This research on the portrayal of protagonists with CDs in intermediate children's and young adults literature has many implications in a variety of educational and other human services settings. Identification and analysis of this body of literature can help provide valuable information about individuals with CDs to students, parents, educators, clinicians, librarians, counselors, and other professionals in the field.

In the classroom setting, books with characters with disabilities can benefit both students with and without CDs. This body of literature has an extremely positive portrayal of characters with CDs. They can be used as a teaching tool to provide positive and dynamic role models for students with CDs, while simultaneously promoting authentic and fresh experiences for students without CDs to understand better their peers with CDs. These books can be valuable in not only providing an increased and broader perspective of knowledge about CDs and other contributing disorders to CDs, such as ASD, deafness/hearing impairments, etc., but this literature can also enable students with CDs to experience vicariously possible compensatory modeling strategies for dealing with the $\mathrm{CD}$ itself and/or other CD-related social and emotional issues like bullying/teasing, making friends, etc. 
To aid in the promotion of understanding of diverse populations, books with protagonists with CDs may be integrated into the general education curriculum, as is the practice of other multicultural literature. Some of the various themes/genres found in this body of literature is family/sibling relationships, friendship, survival, bullying, loneliness/withdrawal, mysteries, historical fiction, realistic fiction, and international literature. Many of these books with protagonists with CDs also have teacher's/discussion guides that may be used by teachers. Links for these supporting materials are included with the book annotations in Appendix G.

Future Research. This study focused on evaluating contemporary national North American award-winning intermediate children's and young adult fictional books with protagonists who have CDs. For future research several of the criteria used in this study can be broadened and/or the research can be analyzed to see what trends might emerge when looking at this genre of books over an expanded period of time. For example, instead of having the narrow criteria of protagonists only, future studies in the area of the portrayal of characters with CDs in children's literature may be expanded to include both main characters and supportive characters, as did the previous four empirical studies discussed that used adaptations of the Dyches and Prater Guidelines (2000).

These previous studies (i.e., Dyches et al., 2001; Dyches and Prater, 2005; Dyches et al., 2009; Leininger et al., 2010) that used adaptations of the 2000 guidelines to examine the portrayal of disabilities had several additional aspects of their studies that could be incorporated into future studies in the area of portrayal of characters with CDs. 
For example, issues dealing with gender, age, and race/ethnicity could be explored. Another possible issue for continuation of this research would be to concentrate on the first four categories (Personal Portrayals, Social Interactions, Exemplary Practices, and Sibling Relationships) of the Dyches and Prater Guidelines (2000).

This research on the portrayal of protagonists with CDs also only examined award-winning books from 2000-2012. A continuation of this study could investigate award-winning books from 1975 when PL 94-142 was signed to 2015. With an expanded timeline, an evaluation of the books over time could be completed to explore the various analytical trends that occurred with this population of characters with CDs.

Another possible study could be to broaden the grade/age/reading level criteria to preschool-young adult. This research would then include younger children's books, such as, picture books, easy readers and transitional books. Comparisons could then be made between the younger and older books that include portrayal of the protagonists with CDs.

Research could additionally be done on using the various teacher's/discussion guides that are available for this literature portraying protagonists with CDs. Investigators could examine the value of using these guides to change the attitudes and behaviors of children and young adults reading these books.

Conclusion. Twenty-six contemporary North American award-winning intermediate children's and young adult fiction books were identified that contained twenty-seven protagonists with CDs. The types of CDs depicted were language, speech and hearing disorders. No protagonists with central auditory processing disorders were found. Almost 
half of the protagonists had language disorders, making it the most commonly portrayed type of CD. Approximately a fourth of the main characters with CDs had ASDs.

The overall quality of all of the books was positive. The books scored well in categories such as social interactions, personal portrayals, exemplary practices and sibling relationships. Within these categories the literature measured well above the acceptable level on such portrayal characteristics as accuracy, realism, character development, interest/strengths, reciprocal and variety of relationships, empathy, respect, valued occupations, promoting self-determination, and full citizenship opportunities. The areas with the lowest scores were emphasizing similarities rather than differences, using nondiscriminatory language that avoids stereotypical portrayals, and acceptance.

Within this study two different comparisons were made using the results of the rating scale. In the first comparison, scores of authors who had some personal connection with the primary or secondary disorder that contributed to the $\mathrm{CD}$ were compared to authors who had no personal connection to the CD being described. The group of books written by authors having connections with disabilities portrayed in their books scored overall at least $10 \%$ higher in topics relating to: primary relationships with paid personnel $(+31 \%)$, caregiver relationships $(+13 \%)$, fear of association by characters without disabilities $(+13 \%)$, receiving appropriate services $(+10 \%)$, and providing additional information for readers to find out more about disabilities $(+19 \%)$. In the other group of books that were written by authors that did not have any connection with the disabilities depicted in their books, score differences higher than at least $10 \%$ were discovered in the 
following areas: using nondiscriminatory language $(+11 \%)$, relationships with friends $(+13 \%)$ and siblings $(+20 \%)$, and being portrayed as victims $(+17 \%)$, initiators $(+19 \%)$ and protectors $(+24 \%)$. This group also had two books that had protagonists with CDs whose CDs were irrelevant to the story.

In the second comparison in this study, the scores of books that won awards that were created specifically to honor the portrayal of individuals with disabilities were compared to those scores of books that won awards that did not specifically honor disabilities. The group of books that won awards that were created specifically to honor the portrayal of individuals with disabilities scored overall at least $10 \%$ higher in topics relating to: being depicted as initiator $(+35 \%)$ and caregiver $(+18 \%)$, receiving appropriate services $(+12 \%)$, portraying attitudes and practices congruent with the era $(+10 \%)$, having feelings of guilt toward the protagonist with $\mathrm{CD}(+11 \%)$, and providing additional information for readers to find out more about disabilities (12\%). In the other group of books that won awards that did not specifically honor individuals with disabilities, score differences higher than at least $10 \%$ were discovered in the following areas: using nondiscriminatory language $(+10 \%)$, being portrayed as victims $(+14 \%)$ and protectors $(+22 \%)$, and having books that had protagonists with CDs whose CDs were irrelevant to the story $(+13 \%)$.

Predominantly the portrayals of these protagonists with CDs in this body of literature were extremely positive. Both children and adolescents with and without CDs/disabilities will enjoy the stories of these multidimensional and dynamic characters. 


\begin{abstract}
Almost all of the stories are told from the first person point of view of the protagonist with a CD. Individuals with CDs will be able to see individuals like themselves in many different situations, such as, making friends, finding strategies to cope with their disabilities, learning how to deal with bullying/ teasing/name calling, making social contributions in their family and/or community, etc. These main characters had ups and downs, but they kept growing and changing throughout the plots. Student without disabilities that read these books will learn more about their peers with CDs and realize that these individuals are more similar than different from themselves.
\end{abstract}




\section{References}

Aaron, I. E. (n.d.). Awards. In B. E. Cullinan \& D. G. Person (Eds.), The continuum encyclopedia of children's literature (pp. 51-53). New York City, NY: The Continuum International Publishing Group, Inc.

Addepalli, R., Hoffman, A., Ladds, B., Vallabhaneni, S. \& Hauser, D. (2009). Assessment of dangerousness complicated by mutism associated with psychosis. The Internet Journal of Psychiatry. 1(1). Retrieved date April 14, 2014 from http://ispub.com/IJPSY/1/1/54050.

American Booksellers Association. (n.d.). Indies choice book awards/ E.B. White readaloud awards. Retrieved November 23, 2014 from http://www.bookweb.org/btw/ awards/ICBA.html.

American Library Association. (n.d.). About YALSA: Our mission. Retrieved October 12, 2013 from http://www.ala.org/yalsa/aboutyalsa.

American Library Association. (n.d.). Alex awards. Retrieved October 15, 2013 from http://www.ala.org/awardsgrants/awards/231/apply.

American Library Association. (n.d.). John Newbery medal. Retrieved October 15, 2013 http://www.ala.org/awardsgrants/john-newbery-medal-2.

American Library Association. (n.d.). Michael L. Printz award. Retrieved October 15, 2013 from http://www.ala.org/awardsgrants/michael-1-printz-award.

American Library Association. (n.d.). Michael L. Printz award policies and procedures. Retrieved September 20, 2014 from http://www.ala.org/yalsa/booklistsawards/ bookawards/printzaward/aboutprintz/criteria

American Library Association. (n.d.). Mildred L. Batchelder award. Retrieved September 20, 2014 from http://www.ala.org/awardsgrants/awards/3/apply. 
American Library Association. (n.d.). Pura Belpre award. Retrieved September 20, 2014 from http://www.ala.org/awardsgrants/awards/4/apply.

American Library Association. (n.d.). Randolph Caldecott medal. Retrieved October 15, 2013 from http://www.ala.org/awardsgrants/randolph-caldecott-medal-1.

American Library Association. (n.d.). Schneider family book award. Retrieved October 15, 2013 from http://www.ala.org/awardsgrants/schneider-family-book-award. American Library Association. (n.d.). Schneider family book award manual. Retrieved October 15, 2013 from http://www.ala.org/ala/awardsgrants/awardsrecords/ schneideraward/schneider_award_manua1-6-2012.doc

American Library Association. (2008). Terms \& criteria. Retrieved October 7, 2013 from http://www.ala.org/alsc/awardsgrants/bookmedia/sibertmedal/sibertterms/sibertm edaltrms.

American Speech-Language-Hearing Association. (n.d.). Child speech and language. Retrieved March 20, 2014 from http://www.asha.org/public/speech/disorders/ ChildSandL.htm.

American Speech-Language-Hearing Association. (n.d.). Dysarthria. Retrieved March 20, 2014 from http://www.asha.org/public/speech/disorders/dysarthria/. American Speech-Language-Hearing Association. (n.d.). Incidence and prevalence of communication disorders and hearing loss in children - 2008 edition. Retrieved November 20, 2012 from http://www.asha.org/research/reports/children.htm.

American Speech-Language-Hearing Association. (n.d.). Selective mutism. Retrieved March 20, 2014 from http://www.asha.org/public/speech/disorders/SelectiveMutism/. 
American Speech-Language-Hearing Association. (n.d.). Social language use (pragmatics). Retrieved March 20, 2014 from http://www.asha.org/public/speech/ development/Pragmatics/.

American Speech-Language-Hearing Association. (1993). Definitions of communication disorders and variations [Relevant Paper]. Retrieved October 6, 2013 from http://www.asha.org/policy/RP1993-00208.htm.

American Speech-Language-Hearing Association. (1999). Terminology pertaining to fluency and fluency disorders: guidelines [Guidelines]. Retrieved March 15, 2014 from http://www.asha.org/policy/GL1999-00063.htm.

Anderson, L. H. (1999). Speak. New York: Farrar Straus Giroux.

Antony, J. (2010). Five flavors of dumb. New York: Dial Books.

Ayala, E. C. (1999). "Poor little things" and "brave little souls": The portrayal of individuals with disabilities in children literature. Reading Research and Instruction, 39, 103-117.

Bankstreet College of Education. (n.d.). Awards. Retrieved November 23, 2014 from http://www.bankstreet.edu/center-childrens-literature/childrens-bookcommittee/awards/.

Bankstreet College of Education. (n.d.). Children's book committee review guidelines. Retrieved November 23, 2014 from https:/s3.amazonaws.com/bankstreet_web/ media/filer_public/filer_public/2013/05/23/cbc-book-review-guidelines.pdf.

Barr, C. \& Gillespie, J. T. (2009). Best books for middle school and junior high readers: Grades 6-9 (2 ${ }^{\text {nd }}$ ed.). Westport, CT: Libraries Unlimited.

Barr, C. \& Gillespie, J. T. (2009). Best books for high school readers: Grades 9-12 (2 ${ }^{\text {nd }}$ ed.). Westport, CT: Libraries Unlimited. 
Baskin, B. H. \& Harris, K. H. (1977). Notes from a different drummer: A guide to juvenile fiction portraying the handicapped. New York, NY: R. R. Bowker Company.

Baskin, B. H. \& Harris, K. H. (1984). More notes from a different drummer: A guide to juvenile fiction portraying the disabled. New York, NY: R. R. Bowker Company.

Baskin, N. R. (2009). Anything but typical. New York: Simon \& Schuster Books for Young Readers.

Batson, T. (1980). The deaf person in fiction-From sainthood to Rorschach blot. Interracial Books for Children Bulletin, 11(1\&2), 16-18.

Berelson, B. (1952). Content analysis in communications research. Glencoe, Ill., Free Press.

Berk, J. (2010). The dark days of Hamburger Halpin. New York: Alfred. A. Knopf.

Bishop, R. S. (1982). Shadow and substance: Afro-American experience in contemporary children's fiction. Urbana, Illinois: National Council of Teachers of English.

Bishop, R. S. (1990). Mirrors, windows, and sliding glass doors. Perspectives: Choosing and using books for the classroom 6(3), ix-xi. Retrieved April 27, 2013 from http://www.rif.org/us/literacy-resources/multicultural/mirrors-windows-andsliding-glass-doors.htm.

Blaska, J. K. (2003). Using children's literature to learn about disabilities and illness: For parents and professionals working with young children. (2nd ed.). Troy, NY: Educator's International Press, Inc.

Blatchford, C. H. (2000). Nick's secret. Minneapolis, MN: Lerner Publications. 
Boyle, C., Boulet, S., Schieve, L., Cohen, R., Blumberg, S., Yeargin-Allsopp, M., Visser, S., \& Kogan, M. (2011). Trends in the prevalence of developmental disabilities in US children, 1997-2008. Pediatrics, 127(6), 1034-42.

Brault, M. W. (2012). Americans with disabilities: 2010. Current populations reports, p.70-131, U.S. Census Bureau, Washington, DC. Retrieved August 14, 2014 from http://www.census.gov/prod/2012pubs/p70-131.pdf.

Brittain, I. (2004). An examination into the portrayal of deaf characters and deaf issues in picture books for children. Disability Studies Quarterly, 24(1). Retrieved September 15, 2012 from http://dsq-sds.org/article/view/841/1016.

Brenna, B. (2010). Waiting for no one. Brighton, MA: Red Deer Press.

Busch, C., De Maret, P., Flynn, T., Kellum, R., Le, S., Meyers, B., Palmquist, M., Saunders, M. \& White, R. (2012). Content analysis. Retrieved October 16, 2013, from http://writing.colostate.edu/guides/guide.cfm?guideid=61.

Busha, C. H., and Harter, S. P. (1980). Research methods in librarianship. New York: Academic Press.

Bushey, T. and Martin, R. (1988). Stuttering in children's literature. LSHSS, 19(3), 235-250.

Canada Council for the Arts. (n.d.). Governor general's literary award. Retrieved December 1, 2014 from http://canadacouncil.ca/council/prizes/find-aprize/prizes/governor-generals-literary-awards.

Canadian Library Association. (n.d.). Amelia Frances Howard-Gibbon illustrator's award. Retrieved December 1, 2014 from http://www.cla.ca/AM/Template.cfm? $\underline{\text { Section=Amelia_Frances_Howard_Gibbon_Illustrator_s_Award. }}$ 
Canadian Library Association. (n.d.). Awards. Retrieved December 1, 2014 from http://www.cla.ca/Content/NavigationMenu/CLAatWork/AwardsScholarshipsGra nts/default.htm.

Canadian Library Association. (n.d.). Book of the year for children award. Retrieved December 1, 2014 from http://www.cla.ca/AM/Template.cfm?Section=Book of the Year_for_Children_Award\&Template=/TaggedPage/TaggedPageDisplay. $\underline{\mathrm{cfm} \& T P L I D=28 \& \text { ContentID }=11527 .}$.

Canadian Library Association. (n.d.). CLA young adult book award. Retrieved December 1, 2014 from http://www.cla.ca/AM/Template.cfm?Section=Young_Adult Canadian_Book_Award.

Carlisle, M. (1998). Portrayal of people with disabilities in children's literature: 1940s to 1980s. Beta Phi Mu - Chi chapter, student award for scholarship. Retrieved May 20, 2010 from http://bpm.slis.indiana.edu/scholarship/carlisle.shtml.

Center for Disease Control and Prevention. (2014). Prevalence of autism spectrum disorder among children aged 8 years — Autism and developmental disabilities monitoring network, 11 sites, United States, 2010. Surveillance Summaries. March 28, 2014 / 63(SS02); 1-21.

Chermak, G. and Musiek, F. (2002). Auditory training: Principles and approaches for remediation and managing auditory processing disorders. Seminars in Hearing, 23(4), 297-308.

Children's books in print. (2004). New Providence, NJ: R. R. Bowker. Children's Literature Comprehensive Database (CLCD). (n.d.). Retrieved August 7, 2011 from http://www.clcd.com/. 
Christensen, N. (2001). What's the difference? The depiction of down syndrome in picture books. Bookbird, 39(1), 17-22.

Cole, F.L. (1988). Content analysis: Process and application. Clinical Nurse Specialist 2(1), 53-57.

Consortium of Latin American Studies Programs (CLASP). (n.d.). Americas award. Retrieved December 1, 2014 from http://claspprograms.org/americasaward. Conway, T. (2014, October 21). The amazing world of Brian Selznick at the Delaware Art Museum. Newswork.org. Retrieved October 24, 2014, from http://www.newsworks. org/index.php/local/delaware/74121-the-amazing-world-of-brian-selznick-at-thedelaware-art-museum- .

Council for Exception Children - Division on Autism and Development Disabilities. (n.d.). Dolly Gray award - About the award. Retrieved October 15, 2013 from http://daddcec.org/ArticleDetails/tabid/76/ArticleID/368/Dolly-Gray-AwardAbout-the-Award.aspx.

Council for Exception Children - Division on Autism and Development Disabilities. (n.d.). Judging criteria. Retrieved October 15, 2013 from http://daddcec.org/Portals/0/CEC/ Autism_Disabilities/Research/Awards/Dolly_Gray/DGA Judging Criteria.pdf.

Crawford, B. (2009). Carter finally gets it. New York: Disney Hyperion Books.

Crosetto, A., Garcha, R., \& Horan, M. (2009). Disabilities and disorders in literature for youth: A selective annotated bibliography for $k$-12. Lanham, MD: Scarecrow Press, Inc. 
Cullinan, B. \& Person, D. (Eds.). The continuum encyclopedia of children's literature. New York City, NY: The Continuum International Publishing Group, Inc. Cybils. (n.d.). Frequently Asked Facts. Retrieved November 22, 2014 from http://www.cybils.com/about-the-cybils-awards/frequently-asked-questions.

Dowd, S. (2007). The London eye mystery. London: David Fickling Books.

Downe-Wamboldt, B. (1992). Content analysis: Method, applications and issues. Health Care for Women International 13, 313-321.

Draper, S. (2010). Out of my mind. New York: Atheneum Book for Young Readers.

Dyches, T. T., \& Prater, M. A. (2000). Developmental disability in children's literature: Issues and annotated bibliography. Reston, VA: The Division on Mental Retardation and Developmental Disabilities of the Council for Exceptional Children.

Dyches, T. T., \& Prater, M. A. (2005). Characterization of developmental disability in children's fiction. Education and Training in Developmental Disabilities, 40, 202-216.

Dyches, T. T., Prater, M. A., \& Cramer, S. F. (2001). Characterization of mental retardation and autism in children's books. Education and Training in Mental Retardation and Developmental Disabilities, 36, 230-243.

Dyches, T. T., Prater, M. A., \& Jenson, J. (2006). Portrayal of disabilities in Caldecott books. TEACHING Exceptional Children Plus, 2, Article 2. Retrieved April 17, 2009 from http://escholarship.bc.edu/education/tecplus/vol2/iss5/art2.

Dyches, T. T., Prater, M. A., \& Leininger, M. (2009). Juvenile literature and the portrayal of developmental disabilities. Education and Training in Developmental Disabilities, 44(3), 304-317.

Easton, K. (2006). Aftershock. New York: Simon Pulse. 
Erickson, F. (1997). Culture in society and educational practices. In J. Banks and C. Banks (Eds.), Multicultural education: Issues and perspectives, ( ${ }^{\text {rd }}$ ed.). Boston, MA: Allyn and Bacon.

Erskine, K. (2010). Mockingbird. New York: Philomel Books.

ForeWord Review. (2015). About us. Retrieved December 1, 2014 from https://www.forewordreviews.com/about/.

ForeWord Review. (2014). IndieFab Award. Retrieved December 1, 2014 from https://indiefab.forewordreviews.com/.

ForeWord Review. (2015). Win a book award. Retrieved December 1, 2014 from https://publishers.forewordreviews.com/awards/.

Friedberg, J., Mullins, J. B., \& Sukiennik, A. W. (1985). Accept me as I am: Best books of juvenile nonfiction on impairments and disabilities. New York City, NY: R. R. Bowker Company.

Fusco, K. N. (2004). Tending to Grace. New York: Alfred A. Knopf.

Galda, L., \& Cullinan, B. E. (2002). Cullinan and Galda's literature and the child (5th ed.). Belmont, CA: Wadsworth/Thomson Learning.

Glare, P. G. (2012). Oxford Latin dictionary. ( $2^{\text {nd }}$ ed.). Oxford, United Kingdom: Oxford University Press.

Goldman, L. M. (1990). The portrayal of physically disabled children in realistic fiction since 1975. Master's thesis. Laramie, WY: University of Wyoming.

Golos, D. B., \& Moses, A. M. (2011). The representation of deaf characters in children's picture books. American Annals of the Deaf, 156(3), 270-282. 
Golos, D. B., Moses, A. M., \& Wolbers, K. A. (2012). Culture or disability? Examining deaf characters in children's book illustrations. Early Childhood Education Journal, 40(4), 239-249.

Goodman, J. (1985). Focusing on the handicapped: Their portrayal in children's books. Kentucky Libraries, 49(1), 10-17.

Haddon, M. (2003). The curious incident of the dog in the night-time. New York: Doubleday.

Harrill, J. L., Leunge, J. J., McKeag, R. A., \& Price, J. (1993). Portrayal of handicapped/ disabled individuals in children's literature: Before and after public law 94-142. In ERIC: ED \#357557.

Harris, K. H., \& Baskin, B. H. (1987). Evolution of disability characterization in young adult fiction. Educational Horizons, 65(Sum), 188-191.

Harris, V. J. (Ed.) (1997). Using multiethnic literature in grades in the $k$ - 8 classroom. Norwood, MA: Christopher Gordon.

Heim, A. B. (2005). Living with dignity: Characters with developmental disabilities in children's literature. Catholic Library World, 75(4), 289-295.

Heward, W. L., \& Cavanaugh, R. A. (1997). Educational equality for students with disabilities. In J. Banks and C. Banks (Eds.), Multicultural education: Issues and perspectives, ( $3^{\text {rd }}$ ed.). Boston, MA: Allyn and Bacon.

Hill, M., White, M., \& Brodie, C. (2001, July). Selecting and promoting young adult and children's award-winning books: What this means for publishers, authors, teachers, librarians and the consumer. Paper presented at the European Reading Conference, Dublin, Ireland. 
Hirshberg, R. (1982). The developmentally disabled in literature for young people. Catholic Library World 53(9), 391-394.

Hollander, S. A. (2004). Inclusion literature: Ideas for teachers and teacher educators. Electronic Journal for Inclusive Education, 1(8). Retrieved May 5, 2009 from http://corescholar.libraries.wright.edu/cgi/viewcontent.cgi?article=1052\&context=ejie.

Horn Book. (n.d.). BGHB submission guidelines. Retrieved December 1, 2014 from http://www.hbook.com/boston-globe-horn-book-awards/bghb-submissionguidelines/ - .

Horn Book. (n.d.). Boston Globe-Horn Book awards. Retrieved December 1, 2014 from http://www.hbook.com/boston-globe-horn-book-awards/

International Reading Association. (n.d.). IRA children's and young adults book awards. Retrieved May 14, 2013 from http://reading.org/Resources/AwardsandGrants/ childrens_ira.aspx.

International Reading Association. (n.d.). Detailed guidelines for submissions: IRA children's and young adults' book award 2015. Retrieved November 23, 2014 from http://www.reading.org/Libraries/awards/children-ya-book-awardguidelines-for-submissions.pdf

Joels, R. W. (1998). The significance of setting in award-winning children's books from selected English-speaking regions. Literacy 32(2), 32-35.

Kelly, T. (2010). Harmonic feedback. New York: Henry Holt and Company.

Kraus, W. K. (1981). Adolescent novels about physical handicaps: The beginning of long term therapy. Catholic Library World, 53(2), 78-80. 
Krippendorff, K. (2004). Content analysis: An introduction to its methodology (2nd Edition). Thousand Oaks, CA: Sage Publications, Inc.

Landrum, J. E. (n.d.). The disabled in children's and young adult literature. In B. E. Cullinan \& D. G. Person (Eds.), The continuum encyclopedia of children's literature (pp. 51-53). New York City, NY: The Continuum International Publishing Group, Inc.

Langer, J. A. (2010). Envisioning literature: Literary understanding and literature instruction. $2^{\text {nd }}$ ed. New York City, NY: Teachers College Press.

Leininger, M. (2010). Portrayal of characters with disabilities in Newbery books. Unpublished master's thesis. Provo, Utah: Brigham Young University.

Leininger, M., Dyches, T. T., Prater, M. A., \& Heath, M. A. (2010). Newbery award winning books 1975-2009: How do they portray disabilities? Education and Training in Autism and Developmental Disabilities, 45(4), 583-596.

Little, G. D. (1986). Handicapped characters in children's literature: Yesterday and today. Children's Literature Association Quarterly, 10(4), 181-184.

Logan, K. J., Mullins, M. S., \& Jones, K. M. (2008). The depiction of stuttering in contemporary juvenile fiction: Implications for clinical practice. Psychology in the Schools, 45(7), 609-626.

Look, L. (2008). Alvin Ho: Allergic to girls, school, and other scary things. (P. LeUyen, Illus.). New York: Scholastic Inc.

Marks, D. F. (2006). Children's book award handbook. Libraries Unlimited.

Matlin, M. (2002). Deaf child crossing. New York: Simon \& Schuster Books for Young Readers. 
McMurchy-Barber, G. (2009). Free as a bird. Toronto: Dundurn Press.

Middle and junior high school core collection (10 ${ }^{\text {th }}$ ed.). (2009). New York: H.W. Wilson. Mills, C. (2002). The portrayal of mental disability in children's literature: An ethical appraisal. Horn Book Magazine 78(5), 531-542.

Mitchell, D. (2007). Black swan green: A novel. New York: Random House.

Mourlevat, J. C. (2006). The pull of the ocean. (Y. Maudet, Trans.). New York: Delacourte Press.

Museum of Tolerance. (n.d.). Book award submissions for 2014. Retrieved November 23, 2014 from http://www.museumoftolerance.com/site/c.tmL6KfNVLtH/b.5208009/

Mystery Writers of America. (2015). Edgar award category information. Retrieved December 1, 2014 from http://mysterywriters.org/edgars/edgar-awardcategory-information/.

Mystery Writers of America. (2015). Edgar submission information. Retrieved December 1, 2014 from http://mysterywriters.org/edgars/edgar-submission-information/.

Mystery Writers of America. (2015). MWA history. Retrieved December 1, 2014 from http://mysterywriters.org/about-mwa/mwa-history/.

National Book Foundation. (n.d.). 2014 national book awards entry rules \& guidelines. Retrieved November 23, 2014 from http://www.nationalbook.org/nbaentry.html. National Book Foundation. (n.d.). How the national book award works. Retrieved November 23, 2014 from http://www.nationalbook.org/nba_process.html.

Neuendorf, K. A. (2002). The content analysis guidebook. Thousand Oaks, CA: Sage Publications Inc. 
Norton, D. E., \& Norton, S. (2010). Through the eyes of a child: An introduction to children's literature. (8th ed.). New York City, NY: Macmillan Publishing Co.

Orr, L. E., Craig, G. P., Best, J., Borland, A., Holland, D., Knodel, H., Lehman, A., Mathewson, C., Miller, M., \& Pequignot, M. (1997). Exploring developmental disabilities through literature: An annotated bibliography. Teaching Exceptional Children, 29(6), 14-17.

Ouzts, D. T., Taylor, M. K., \& Taylor, L. A. (2003). A learner-centered curriculum based on award-winning literature. Education 124, 76-85.

Pajka-West, S. (2007). Perceptions of deaf characters in adolescent literature. The ALAN Review 34(3), 39-45.

Parents' Choice. (n.d.). Parents' choice awards. Retrieved November 22, 2014 from http://www.parents-choice.org/aboutawards.cfm.

Parents' Choice Awards. (n.d.). Books. Retrieved November 22, 2014 from http://www.parents-choice.org/callforentries/book.cfm.

Parents' Choice Awards. (n.d.). Call for entries. Retrieved November 22, 2014 from http://www.parents-choice.org/callforentries/default.cfm.

Perpetrator. (n.d.). In Oxford learner's dictionary. (2014). Retrieved June 20, 2014 from http://oald8.oxfordlearnersdictionaries.com/dictionary/perpetrator.

Poetry Center at Passaic County Community College. (n.d.). Support. Retrieved November 24, 2014 from http://www.pccc.edu/home/cultural-affairs/poetrycenter/support. 
Poetry Center at Passaic County Community College. (2014). Paterson Prize. Retrieved November 24, 2014 from http://www.pccc.edu/uploads/4f/9b/4f9bb12b495d0e 43f0155988396d49d3/Paterson_Prize_for_books_for_young_people_rules.pdf.

Prater, M. A. (1999). Characterization of mental retardation in children's and adolescent literature. Education and Training in Mental Retardation and Developmental Disabilities, 34, 418-431.

Prater, M. A. (2000). Using juvenile literature with portrayals of disabilities in your classroom. Intervention in School \& Clinic, 35(3), 167-177.

Prater, M. A. (2003). Learning disabilities in children's and adolescent literature: How are characters portrayed? Learning Disability Quarterly, 26(winter), 47-62.

Prater, M. A., and Dyches, T .T. (2008). Teaching about disabilities through children's literature. Westport, CT: Libraries Unlimited.

Prater, M. A., Dyches, T. T., \& Johnstun, M. (2006). Teaching students about learning disabilities through children's literature. Intervention in School and Clinic 42(1), 14-24.

Quicke, J. (1985). Disability in modern children's fiction. Cambridge, MA: Brookline Books. R. R. Bowker, LLC. (n.d.). New book titles and edition, 2002-2012. Retrieved May 22, 2013 from http://www.bowker.com/assets/downloads/products/isbn_output_2002 _2012.pdf.

Richardson, B. (2000). After Hamelin. New York: Annick Press Ltd.

Richardson, M. V., \& Miller, M. B. (1997). Using picture books kindergarten through high school. Unpublished manuscript, University of South Dakota, Vermillion, SD. 
Robinson, L. (2006). Why content analysis should be used more in library and information studies research. Library Student Journal 2006. Retrieved October 16, 2013 from http://www.librarystudentjournal.org/index.php/lsj/article/view/33/34.

Rochman, H. (1993). Against borders: Promoting books for a multicultural world. Chicago, IL: American Library Association.

Rorby, G. (2006). Hurt go happy. New York: Tom Doherty Associates Books.

Ruben, R. J. (2000). Redefining the survival of the fittest: Communication disorders in the $21^{\text {st }}$ century. The Larynoscope 110(2), 241-245.

Russell, D. L. (2005). Literature for children: A short introduction. Boston, MA: Pearson Education, Inc.

Ryan, P. M. (2010). The dreamer. (Illus. P. Sís). New York: Scholastic Press.

Ryan, P. M. (2011). Author interview: The Dreamer. Retrieved November 13, 2014 from http:/www.pammunozryan.com/pages/novels/interviewDreamer.pdf.

Sandelowski, M. (1995) Qualitative analysis: What it is and how to begin? Research in Nursing \& Health 18, 371-375.

Sapon-Shevin, M. (1982). Mentally retarded characters in children's literature. Children's Literature in Education 13(1), 19-31.

Sawyer, W. (2000). Growing up with literature (3rd ed.). Albany, NY: Delmar. Selznick, B. (2011). Wonderstruck: A novel in words and pictures. New York: Scholastic Press. Senior high school core collection (18 ${ }^{\text {th }}$ ed.). (2011). New York: H.W. Wilson. 
Shipon-Blum, E. (n.d.). What is selective mutism? Retrieved February 25, 2014 from http://www.selectivemutismcenter.org/aboutus/WhatisSelectiveMutism.

Short, K. G., \& Pierce, K. M. (Eds.). (1994). Finding ourselves as people and as learners. The Reading Teacher 48(1), 64-74.

Simon Wiesenthal Center. (n.d.). Once upon a world children's book award. Retrieved November 23, 2014 from http://www.wiesenthal.com/site/pp.asp?c= 1sKWLbPJLnF\&b=4441347\#.VTvVo61Vikp.

Smith, E. A. (1997). Reflections and visions: An interview with Rudine Sims Bishop. Journal of Children's Literature 23(Spr), 62-65.

Society of Children's Book Writers and Illustrators. (n.d.). The golden kite awards. Retrieved November 23, 2014 from http://www.scbwi.org/awards/golden-kite-award/. Society of School Librarians International. (n.d.). Welcome. Retrieved November 24, 2014 from http://www.freewebs.com/societyofschoollibrarians/.

Sokolski, C. (1985). Image and identity: Handicapped characters in children's realistic fiction, before and after P.L. 94-142. Dissertation. College Park: University of Maryland.

Sotto, C. D. \& Ball, A. L. (2006). Dynamic characters with communication disorders in children's literature. Intervention in School and Clinic, 42(1), 30-45.

Stephan, W. G., \& Stephan, C.W. (2004). Intergroup relations in multicultural education programs. In J. A. Banks \& C. A. M. Banks (Eds.), Handbook of research on multicultural education ( $2^{\text {nd }}$ ed., pp. 782-798). San Francisco: Jossey-Bass. 
Storey, D. (1990). Which award books would you buy: Caldecott/Newbery or state award books? Unpublished manuscript, Saginaw Valley State University, University Center, MI.

Stork, F. (2009). Marcelo in the real world. New York: Arthur A. Levine Books.

Stroud, J. G. (1980). Portrayal of physically handicapped characters in adolescent fiction. Top of the News, 36(4), 363-367.

Stroud, J. G. (1981). Characterization of the emotionally disturbed in current adolescence fiction. Top of the News, 37(3), 290-295.

Tatelbaum, B. L. (1984). Contemporary juvenile literature depicting the communicatively impaired individual: A bibliography and implications for therapy. Language, Speech \& Hearing Services in Schools, 15, 137-139.

Trueman, T. (2000). Stuck in neutral. New York: HarperCollins Publishing.

U.S. Department of Education, National Center for Education Statistics. (2012). Digest of Education Statistics, 2011 (NCES 2012-001), Table 46. Retrieved May 1, 2013 from http://nces.ed.gov/programs/digest/d11/tables/dt11_046.asp?referrer=list.

U.S. Department of Education, National Center for Education Statistics. (2012). Digest of Education Statistics, 2011 (NCES 2012-001), Table 47. Retrieved May 1, 2013 from http://nces.ed.gov/programs/digest/d11/tables/dt11_047.asp.

Viana, A., Beidel, D., \& Rabian, B. (2009). Selective mutism: A review and integration of the last 15 years. Clinical Psychology Review 29(1), 57-67.

Volden, J. (2002). Nonverbal learning disability: What the SLP needs to know. The ASHA Leader. Retrieved April 1, 2014 from http://www.asha.org/Publications/leader/ 2002/021022/f021022.htm. 
Wagoner, S. A. (1984). The portrayal of the cognitively disabled in children's literature. The Reading Teacher, 37, 502-508.

Ward, M. (2002). Voices from the margins: An annotated bibliography of fiction on disabilities and differences for young people. Westport, CT: Greenwood.

Wayne State College Lib Guides. (n.d.). Children's award-winning books, indie choice. Retrieved November 23, 2014 from http://libguides.wsc.edu/content.php?pid= $\underline{404952 \& \operatorname{sid}=3915659}$.

Wopperer, E. (2011). Inclusive literature in the library and the classroom: The importance of young adult and children's books that portray characters with disabilities. Knowledge Quest, 39(3), 26-34.

Zarr, S. (2008). Sweethearts. New York: Little, Brown \& Co. 


\section{Appendix A}

Rating Scale for Quality Characterizations of

Individuals with Communication Disorders in Children's Literature

Rater's Name:

Date:

Book Title:

Author/Illustrator: Publication Date:

Age/Grade Level:

\section{A. Personal Portrayal}

1. Portrays characteristics of communication disorder accurately (e.g., abilities/ $\begin{array}{lll}1 & 2 & 3\end{array}$ disabilities are consistent throughout the story; if label is used, it is accurate and current).

2. Describe the character(s) with communication disorder as realistic (e.g., not superhuman or subhuman; avoids miraculous cures).

3. Character(s) with communication disorder are fully developed (e.g., credible, multidimensional, show change or development throughout the story).

4. Does not portray only communication disorder of the character(s), but portray abilities, interests, and strengths of the character(s) (e.g./ avoids undue emphasis on the disability; characters have unique personalities, interests, and struggles that may not be related to the disability; characters experience success as well as failure).

5. Emphasizes similarities, rather than differences, between characters with and without communication disorder (e.g., similar physical and personality characteristics are described with equal emphasis).

6. Uses nondiscriminatory language that avoids stereotypic portrayals (e.g., does not use language such as suffers from, afflicted with, stricken with, confined to $\stackrel{1}{0} \quad \stackrel{2}{0} \stackrel{3}{0}^{2}$ a wheelchair). This criterion includes the use of person-first language (e.g., uses language such as person who stutters rather than stutterer).

Comments: 


\section{B. Social Interactions}



1. Depicts character(s) with communication disorder engaging in socially and emotionally reciprocal relationships (e.g., not always being cared for, but allowed to care for others; teaches and assists others) with a wide variety of persons (e.g., family, nondisabled peers, friends with disabilities, support personnel).

2. Depicts acceptance of the character(s) with communication disorder (e.g., $\begin{array}{lll}1 & 2 & 3\end{array}$ character isn't helpless against ridicule, teasing, bullying, abuse; character is not just tolerated, but a valued member of a group; is part of the "in" group rather than on the fringe or on the outside).

\section{Promotes empathy, not pity for the character(s) with communication disorder} (e.g., other characters act on their feelings to help in appropriate ways rather than just feeling sorry for the character with disabilities).

4. Portrays positive social contributions of person(s) with communication disorder (e.g., contributes to more than emotional growth of other characters).

5. Promotes respects for the character(s) with communication disorder (e.g., treated similar to others of same age, as appropriate; not "babied;" avoids condescending language and actions).

6. Depicts various relationships between character with a communication disorder and others. (Please check all that apply.)

a. Character with a disability has primary relationship with:

$\square$ Friend $\square$ Sibling $\square$ Paid Personnel $\square$ Other

b. Character with a communication disorder is primarily:

$\square$ Victim $\square$ Perpetrator $\square$ Protector $\square$ None

c. Character with a communication disorder is primarily:

$\square$ Dependent $\square$ Caregiver

d. Character with a communication disorder is primarily:

Pupil $\square$ Instructor

e. Do other characters fear associating with the character with a communication disorder?

$\bigcirc$ Yes $\bigcirc$ No

f. Do other characters experience feelings of guilt related to the character with a communication disorder?

$\bigcirc$ Yes $\bigcirc$ No

g. What changes take place in character without disabilities as a result of their interactions with the character with a communication disorder?

$\bigcirc$ Positive $\bigcirc$ Neutral $\bigcirc$ Negative

$\begin{array}{lll}1 & 2 & 3\end{array}$

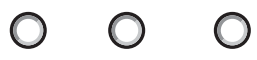

$\begin{array}{lll}1 & 2 & 3\end{array}$

○ 00 


\section{Exemplary Practices}

1. Depicts character(s) with communication disorder having full citizenship opportunities in integrated settings and/or activities (e.g., school, church, neighborhood, work, recreation/leisure).

2. Depicts character(s) with communication disorder receiving services appropriate for their age, skill level, and interests (e.g., teaching strategies depicted meet the needs of the character; therapies needed are provided).

3. Depicts valued occupations for character(s) with communication disorder (if appropriate) (e.g., vocations of their own choice according to their abilities and interests; wages paid are comparable to those without disabilities in similar vocations).

4. Promotes self-determination (e.g., character(s) are allowed to make decisions that impact their lives, solve their own problems, choose their own friends and activities as appropriate to their age and development level), where choices are similar to the types of choices given to nondisabled peers.
Comments:

\section{Sibling Relationships (if applicable)}

1. Sibling(s) of the character(s) with communication disorder experience a wide range of emotions, not just all positive or all negative emotions (e.g., pride, joy, respect, love, embarrassment, frustration, over identification, guilt, isolation, resentment, anxiety regarding achievement, fear of the future).

2. Sibling(s) of the character(s) with communication disorder have opportunities for growth that are not typical for siblings of children without disabilities (e.g., maturity, self-concept, insight, tolerance, pride, vocational choices, advocacy, loyalty).

\section{The sibling relationship is reciprocal, given the age and development differences} between the siblings.

4. The sibling(s) are not given unusually burdensome household and family duties, but engage in family work that is typical for children of the same age and gender that do not have a sibling with disabilities.

5. The sibling(s) appear aware of the nature of the communication disorder and its effects on the character with communication disorder.
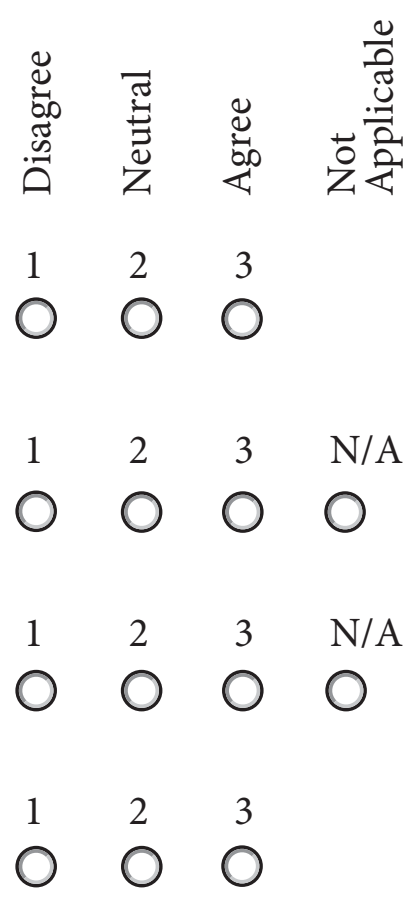
Comments:

\section{E. Impact of Communication Disorder on Plot}



1. Main character with a communication disorder displays appropriate growth throughout the story (e.g., character is not stagnant, but learns, changes, and grows as a result of life experiences).

2. A main focus of the book appears to be to: (a) teach about a communication disorder, or (b) include a character with a communication disorder whose presence does not or minimally impacts the story, or (c) include a character with a communication disorder whose presence and communication disorder impacts the story, or $(\mathrm{d})$ include a character with a communication disorder whose presence impacts the story, but the communication disorder is irrelevant.

\section{Additional information is provided to help readers learn about the} communication disorder (e.g., author's notes, internet addresses, professional organizations).

4. When the communication disorder is integral to the plot the character with the communication disorder models strategies for solving challenges presented $\begin{array}{llr}1 & 2 & 3 \\ 0 & 0 & 0\end{array}$ A $\quad$ B $\quad$ C $\quad$ D 0000 by the disability.

Comments:

\section{F. Impact of Setting on Disability}

\section{Setting}

1. The attitudes and practices portrayed are congruent with attitudes and practices for those with communication disorders during that era (e.g., services available, treatment by others, terminology used).

$\stackrel{\mathrm{Y}}{\mathrm{O}} \mathrm{N}$

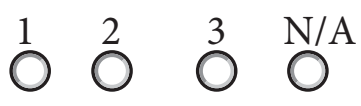

2. The place of the story affects the life of character(s) with communication disorder (e.g., rural/urban, developed/developing nations). 


\section{G. Point of View}

Point of View

1. The point of view, if told by the character with a communication disorder, is realistic (e.g., thought processes and language of a character with cognitive disabilities are realistic).

2. The point of view, if told from a character without a communication disorder, is realistic (e.g., a brother/sister's attitudes/perceptions about the sibling with disabilities).

Comments:

H. Illustrations (if applicable)

1. Portrays characteristics of disabilities accurately in illustrations.

$\stackrel{1}{0} \overbrace{}^{2} \overbrace{}^{3} \overbrace{}^{N / A}$

2. Portrays assistive/adaptive/technology accurately, realistically, and contemporarily in the illustrations.

\section{Illustrations interpret the story well.}

$\stackrel{1}{O} \mathrm{~L}^{2} \mathrm{O}^{\mathrm{N}} \mathrm{O}^{\mathrm{N} / \mathrm{A}}$

4. Style of illustrations is appropriate to the story and age-level (e.g., representational, $\begin{array}{lllll}1 & 2 & 3 & \text { N/A }\end{array}$ expressionistic, surrealism, impressionistic, folk art, naïve art, cartoon art, photography).

5. Plot, theme, characters, setting, mood, and information are enhanced through the $\begin{array}{lllll}1 & 2 & 3 & \text { N/A }\end{array}$ illustrations.

6. Illustrations represent quality art (rhythm, balance, variety, emphasis, spatial order, $\begin{array}{lllll}1 & 2 & 3 & \text { N/A }\end{array}$ unity).

7. Illustrations use color, line, shape, and texture artistically.

8. Layout and design of illustrations and text are visually appealing. 


\section{Appendix B}

\section{National North American Book Awards Won by Books in the Study}

\section{United States' Book Awards}

\section{Dolly Gray Award for Children's Literature in Developmental Disabilities}

Started in 2000, the Dolly Gray Children's Literature award recognizes “authors, illustrators, and publishers with "effective, enlightened portrayals of individuals with developmental disabilities in children's books" (CEC-DADD, n.d., Dolly Gray Award,

para. 2). Given biennially every even year, the award is presented in the two areas of picture books and/or children's chapter books. The award is made possible through the collaborative effort of the Division on Autism and Developmental Disabilities (DADD) of the Council for Exceptional Children (CEC) and the Special Needs Project, which is a distributor of books dealing with disabilities issues (CEC/DADD, n.d., Judging Criteria).

The eligibility and evaluation criteria according to CEC/DADD's Dolly Gray Award, Information and Procedures is as follows:

\section{$\underline{\text { Eligibility }}$}

\section{Books eligible for consideration include:}

1. Children's books that include a main or supporting character with developmental disabilities. Developmental Disability is defined as follows: This condition occurs before a person is 22 years of age and limits him/her in at least three of seven major life activities (e.g., receptive and expressive language, self-care, and economic self-sufficiency). Developmental disabilities may include people with cerebral palsy, epilepsy, autism, dyslexia, 
severe emotional disabilities, intellectual disabilities, and other multiple disabilities; however, for this award, developmental disabilities must align with the mission of the CEC Division on Autism and Developmental Disabilities (e.g., if the character with a disability would likely be served by DADD rather than another CEC division, then its inclusion is appropriate).

2. For the picture book award, the book must be recognized as a picture book written for children in story format. Biographies written in story format are included.

3. For the chapter book award, the book must be recognized as a fictional chapter book (generally a novel divided into chapters) written for children or young adults in story format. This includes easy readers, juvenile fiction, and young adult fiction. Biographies in story format are also included.

4. The book must have an initial copyright date within a predetermined two year period prior to the award date (e.g., 2010-2011 awarded in 2012).

\section{Books that are not eligible for the award include:}

1. Non-fiction books (i.e., books that present factual information not in story format) and books that are intended to primarily teach about a disability (rather than to present a story).

2. Books published through vanity press.

3. Books that present the character with developmental disabilities as an inanimate object, animal, or other non-human. 


\section{$\underline{\text { Evaluation Criteria }}$}

The following criteria will be used to evaluate the books. The greatest weighting will be given to sensitive portrayal of character(s) with DD. The literary quality of the text and the quality of the illustrations are also considered. (More information regarding these criteria is available.)

1. Portrayal of Character with DD

Personal Portrayal

Social Interactions

Exemplary Practices

Sibling Relationships (if appropriate)

Point of View

2. Literary Quality of the Text

3. Illustrations (para. 9-10)

\section{American Library Association Awards}

\section{Schneider Family Book Award}

Established in 2004, the purpose of the ALA Schneider Family Book award is to "honor an author or illustrator for a book that embodies an artistic expression of the disability experience for child and adolescent audiences" (ALA, n.d., Schneider Family Book Award). Three awards are given annually in the following age categories of Young Children's (ages 0-8), Middle School (ages 9-13), and Teens (14-18)(ALA, n.d., Schneider Family Book Award Manual). 
The ALA Schneider Family Book Award Manual (2012) provides the following descriptions and explanations for the award:

\section{$\underline{\text { Terms and Definitions }}$}

1. The person with the disability may be the protagonist or a secondary character.

2. Definition of disability. Dr. Schneider has intentionally allowed for a broad interpretation by her wording, the book "must portray some aspect of living with a disability, whether the disability is physical, mental, or emotional." This allows each committee to decide on the qualifications of particular titles. Books with death as the main theme are generally disqualified.

3. The books must be published in English. The award may be given posthumously.

4. Term of eligibility extends to publications from the preceding years, e.g., 2013 awards given to titles published in 2012 .

5. When a picture book wins the award, the $\$ 5000.00$ will be divided equally between the author and illustrator.

\section{$\underline{\text { Criteria }}$}

1. Content

- May be fiction, biography, or other form of nonfiction.

- Must portray the emotional, mental, or physical disability as part of a full life, not as something to be pitied.

- Representation of characters with disabilities should be realistic avoiding exaggeration or stereotypes. 
- Person with disability should be integral to the presentation, not merely a passive bystander.

- The theme must be appropriate for and respectful of the intended audience age.

- Information on a disability must be accurate.

2. Style

- Should be well written.

- Should be engaging with distinctive use of language for plot and character development and setting delineation.

- Book should be judged on its own merit as a self-contained entity, not as part of a series, and irrespective of supportive materials such as a CD or other supplemental material.

3. Illustration and Design

- Text and images should complement each other, with differentiated contrast between text, pictures, and background.

- Format and typeface must be of age appropriate size, clearly readable, and free of typographical errors.

- Layout should be easy to follow enhancing the flow of the story or information.

- Preference will be given to books that can be made available in accessible formats. (p. 5-6) 


\section{Pura Belpre Award}

This now annual children's book award is in recognition of a Latino/Latina writer and illustrator whose outstanding original literature "portrays, affirms, and celebrates the Latino cultural experience.” The Pura Belpre Award was established in 1996 and is awarded by both the Association for Library Service to Children (ALSC), a division of the (ALA), and the National Association to Promote Library and Information Services to Latinos and the Spanish-Speaking (REFORMA), an ALA affiliate. To be eligible for this award, published books and recipients must be from the United States or Puerto Rico. The award-winning fictional or nonfictional literature may be published in bilingual format, English, or Spanish. Honor books may also be presented. (ALA, n.d., Pura Belpre Award).

The ALA Pura Belpre Award lists online the following additional information about selection criteria:

\section{Criteria for Text}

1. In identifying the author of an "outstanding" book for children, in addition to looking for an accurate and positive portrayal of the Latino culture, the committee members need to consider the following:

- Interpretation of the theme or concept.

- Development of a plot.

- Delineation of Characters.

- Delineation of setting.

- Appropriateness of style. 
- Note: Because the literary qualities to be considered will vary depending on content, the committee need not expect to find excellence in each of the above named elements. The book should, however, have distinguished qualities in all of the pertinent elements.

- Committee members must consider excellence of presentation for a child audience.

2. In considering a book, the committee is to make its decision primarily on the text. Other aspects of a book are to be considered only if they distract from the text. Such other aspects might include illustrations, overall design of the book, etc.

3. The book must be a self-contained entity, not dependent on other media (i.e., sound or film equipment) for its enjoyment.

4. In selecting a book, the committee should keep in mind that the award is for both literary quality and presentation for children, as well as for its portrayal of the Latino cultural experience.

5. Particular attention will be paid to the "insider's voice" and cultural authenticity.

\section{Criteria for Illustrations}

1. In identifying the illustrator of an outstanding picture book for children, committee members need to consider the following:

- Excellence of execution in the artistic technique employed.

- Excellence of pictorial interpretation of story, theme, or concept.

- Appropriateness of style of illustration to the story, theme, or concept.

- Delineation of plot, theme, characters, setting, mood, or information through the pictures. 
- Positive and authentic portrayal of Latino culture.

- Excellence of presentation in recognition of a child audience.

2. The only limitation to graphic form is that the form must be one which may be used in a picture book. The book must be a self-contained entity, not dependent on other media (i.e., sound or film equipment) for its enjoyment.

3. Each book is to be considered as a picture book. The committee is to make its decision primarily on the illustration, but other components of a book are to be considered, especially when they make a book less effective as a children's picture book. Such other components might include the written text, the overall design of the book, etc.

4. The committee should keep in mind that the award is for both distinguished illustrations in a picture book and for excellence of pictorial presentation for children, and for the positive portrayal of the Latino cultural heritage.

5. Particular attention will be paid to the "insider's voice" and cultural authenticity. (ALA, n.d., Pura Belpre Award, para. 15 \& 16)

\section{Mildred L. Batchelder Award}

The Mildred L. Batchelder Award is given annually to an American publisher who translated into English and published in the United States an outstanding book that had originally been published in another country and in a language other than English. This award was established in 1966 and is also awarded by the Association for Library Service to Children (ALSC). Created to promote multiculturalism and recognize 
translations of outstanding children's literature, this award encourages publishers to translate more quality children's books from throughout the world so that more children can read them in English (ALA, n.d., Mildred L. Batchelder Award). The ALA Mildred L. Batchelder Award lists the following three points about Selection Criteria:

\section{Focus of attention:}

Primary attention must be directed to the text. Picture books should be considered only if the text is substantial and at least as important as the pictures.

\section{Relationship to original work:}

1. The translation should be true to the substance (e.g., plot, characterization, setting) and flavor of the original work and should retain the viewpoint of the author.

2. Reflection of the style of the author and of the original language are assets unless in the translation these reflections result in awkwardness in style or lack of clarity for children.

3. The book should not be unduly "Americanized." The book's reader should be able to sense that the book came from another country.

4. Folk literature is not eligible.

\section{Quality of the United States Book:}

1. The textual qualities to be evaluated will vary depending on the content and type of the book being considered. Each book should be evaluated only on the elements pertinent to it. These include:

- Interpretation of the theme or concept

- Presentation of information including accuracy, clarity, and organization

- Development of plot 
- Delineation of characters

- Appropriateness of style

2. In all cases, committee members must consider the book's manner of presentation for and the potential appeal to a child audience.

3. Aspects of the overall design of the book should be considered when they significantly enhance or detract from the text, thus making the book more or less effective as a children's book. Such aspects might include: illustration, type face, layout, book jacket, etc.

4. In some children's books, illustrations are important. In considering such a book, consideration should be given to the retention of the original illustrator's work in the U.S. edition. (ALA, n.d., Mildred L. Batchelder Award, para. 11)

\section{ALA/YALSA Book Awards}

\section{Alex Awards}

The Alex Awards are presented to adult books that have special interest to young adults (12-18). The annual Alex Award was initiated in 1998. The Young Adult Library Services Association (YALSA) is a division of the American Library Association (ALA). The top ten best titles are selected by the YALSA Adult Books for Young Adults Task Force from books that were published the previously year (ALA, n.d., Alex Awards).

According to the ALA's/YALSA's Alex Award Committee Policies and Procedures, the following book eligibility and selection criteria is: 


\section{Book Eligibility}

The Alex Committee considers any title from a publisher's adult list in the calendar year prior to the announcement. The chair is responsible for verifying the eligibility of all nominated titles. A book originally published outside the United States will be considered according to its U.S. publication year. Books published outside of the United States are not eligible unless a U.S. edition is available. Works of joint authorship and editorship will be eligible. Titles that are self-published, published only in eBook format, and/or published from a publisher outside of the US will not be considered eligible until the first year the book is available in print or distributed through a US publishing house. (para. 14)

\section{Suggested selection criteria}

YALSA's Alex Committee looks for outstanding titles that are of interest and value to teenagers. Suggested selection criteria:

1. Titles are selected for their demonstrated or probable appeal to the personal reading tastes of young adults

2. Appeal and popularity are not synonymous In addition to the question of appeal, committee members should consider the following when assessing titles: language, plot, style, setting, dialog, characterization, and design. (para. 16)

\section{Michael L. Printz Award for Excellence in Young Adult Literature}

Another ALA/YALSA book award is the Michael L. Printz Award. This award is a yearly award for a book that embodies excellence in young adult literature. The award is based solely on literary merit. The criteria for eligibility for the award are broad 
allowing literature to be selected from the following categories: fiction, nonfiction, anthology or poetry. The targeted audience, however, must be between the ages of twelve and eighteen. The book may have been published in another country, but it must have also been published in the United States. Another stipulation of publication is that it must have been published in the year before the award is given. The committee may also select as many as four honor books. The Michael L. Printz Award was first presented in 2000 and is sponsored by Booklist. The criteria for selecting books for this award is flexible and changes with time. The committee is looking for quality books with literary excellence that audiences will discuss. The literature may be controversial, unpopular or have a message incongruent with the Library Bill of Rights. The award committee examines such criteria/guidelines as: story, voice, style, setting, accuracy, characters, theme, illustrations, and design. (ALA, n.d., Printz, Policies \& Procedures).

\section{Cybil Award}

The Children's and Young Adults Bloggers' Literary Awards (better know as the Cybil Award) are presented annually in an array of categories by children's and young adult book bloggers. The public may nominate children's and young adult books that fall into one of the following current thirteen categories: Book Apps, Easy Readers, Early Chapter Books, Elementary/Middle-Grade Graphic Novels, Elementary/Middle-Grade Nonfiction, Elementary/Middle-Grade Speculative Fiction, Fiction Picture Books, Middle Grade Fiction, Poetry, Young Adult Fiction, Young Adult Graphic Novels, Young Adult Nonfiction, and Young Adult Speculative Fiction. In order to be eligible any non-fiction 
book must be largely narrative in format. Finalists and winners are selected on the basis of their appeal to children and also literary merit. Anybody may nominate one children's or young adult book per category. To be eligible for the awards, books must be published in the U.S. or Canada in the year before the award is given. They can be in English or be bilingual. The award-winning books must be widely available and also be targeted for children. The Cybil Awards were first awarded in 2006 (Cybils, n.d., FAQ).

\section{Parent's Choice Award for Children's Literature}

This annual children's literature award, which is administered by the Parents' Choice Foundation, was first awarded in 1978. Created to recognize quality children's media and toys, the Parents' Choice Awards is the nation's oldest nonprofit program children's guide (Parents' Choice, n.d., Parents' Choice Awards). Books are just one of ten categories that the Parents Choice Awards judges. The Books category is open for judging in the following areas: Picture/Story Books, Fiction, Non-fiction, Doing \& Learning (Activity), Poetry, Historical Fiction, Homework Helpers, and Reference Book s (Parents' Choice Awards, n.d., Books). The committee is judging products designed for infants through young adults. It is looking for such aspects as: universal human values, age appropriateness, excellent production values, and appeal to children. There are six different levels of awards: classic, gold, silver, recommended, approved, and fun stuff. Wanting to select the best quality products for children that range in age, interest/skill levels, and backgrounds, the makeup of the panel is also diverse having a wide spectrum of jurors and judges (e.g., educators, artists, librarians, teachers, parents, families, 
children, etc.) from different backgrounds who help to select and evaluate the various products. Judged products that do not receive one of the six levels of commendation cannot be resubmitted at a later date for another chance at winning an award (Parents' Choice Awards, n.d., Call for Entries).

\section{Josette Frank Award}

The Josette Frank Award is an annual children's literary award for fiction that honors a book(s) of "outstanding literary merit in which children or young people deal in a positive and realistic way with difficulties in their world and grow emotionally and morally." This award that was initiated to encourage the writing and publishing of quality positive children's literature was formerly known as the Children's Book Award (1943 to 1997). The award is administered by the Children's Book Committee that is currently part of the Center for Children's Literature at Bank Street College of Education (Bankstreet College of Education, n.d., Awards). The approximately 40 volunteer committee members are from different backgrounds that are concerned with the quality of children's books (e.g., writers, illustrators, librarians, teachers, parents, etc.). Books being considered for this award are chosen from books submitted for the Children's Book Committee's Best Books of the Year for Children and Young Adults. For this award, books must be submitted by publishers. All eligible literature must have been published in the United States and/or Canada in English (Bankstreet COE, n.d., Review Guidelines). Other Children's Book Committee considerations/guidelines are:

- Literary quality (Is the text well written and understandable for the intended audience?) 
- Art (Do illustrations support the text? In nonfiction, do the illustrations add information and enhance the text?)

- Presentation (What is the format of the book? Is it appropriate and relevant for the intended audience? Is it clear? Exciting? Unusual? Original?)

- Impact (What is the intended or unintended emotional impact on the child reader/listener?

- Does the story end on a positive note, with hope?)

- Absence of stereotypes and positive treatment of ethnic and religious differences

- Credibility of characterization and plot

- Do the characters grow or change?

- Does the plot move at a reasonable pace?

- Authenticity of time and place

- Age relevance of content

- Originality of the story $(\mathrm{p} 1)$

\section{National Book Award}

Created in 1950, the National Book Award (NBA) recognizes literary excellence and enhances the public's awareness of great books written by American writers. The goals of the award not only advances the careers of this country's emerging and established writers, but also to raise the American cultural appreciation of exceptional writing and increase the popularity of reading in general. Today these American literary 
prizes are presented to recognize achievements in the four following categories: Fiction, Nonfiction, Poetry, and Young People's Literature. Until 2013 judges for these awards were fellow writers, who were known for their great work in the selected 4 genres. The judging panels are now comprised of other professional experts in the field (e.g., booksellers, librarians, literary critics, etc.). The National Book Award is administered by the nonprofit organization, the National Book Foundation.

Only publishers can submit entries for the award. All eligible books for the National Book Award must not only be written by an American citizen, but also must be published in the United States in the calendar year before the award is given (National Book Foundation, n.d., How the National Book Award Works). Other eligibility criteria listed by the National Book Awards Entry Rules and Guidelines is as follow:

- Full-length books of fiction and nonfiction

- Collections of short stories and collections of essays by one author

- Collected and selected poems by one author

- Books by authors who are living at the commencement of the eligibility year

- Self-published books, provided that the author/publisher also publishes titles by other authors (NBF, Rules \& Guidelines, para. 2)

Books are ineligible if they are:

- English translations of books originally written in other languages

- Anthologies containing work written by multiple authors 
- Reprints of books published in previous Award years. Exceptions may be made for otherwise eligible books published outside the United States in the previous Award year, at the National Book Awards' discretion.

- Books published through self-publishing services (NBF, Rules \& Guidelines, para. 2)

\section{Golden Kite Award (SCBWI)}

The Society of Children's Book Writers and Illustrators (SCBWI) has been sponsored the Golden Kite Award since 1973. This non-profit professional international organization currently recognizes excellence in children's literature that encompasses the four genres of: fiction, nonfiction, picture book text, and picture book illustration. Honor books can also be selected for each category. Fellow authors and illustrators, who are members of the SCBWI, determine the winning titles. These annual children's literary awards are literature selected by a jury of peers for their genuine appeal to the interests of children and exhibit excellence in writing (SCBWI, n.d., Golden Kite Awards). Other eligibility rules listed on the SCBWI website are:

- You must be a current member through April of the following year to have a book submitted to the Golden Kite Awards.

- Only books written or translated into English are accepted.

- Please Submit FOUR copies of your book. All submissions MUST BE in completed, bound form. NO GALLEYS.

- You may submit your book to ONE category only, except in the case of Picture Book Text and Picture Book Illustration. 
- If submitting to both Picture Book Text and Picture Book Illustration BOTH author and illustrator must be current members and EIGHT copies must be submitted.

- The book submitted must be published in the previous calendar year (2015 winners published in 2014).

- Individuals and Publishers can submit for the Golden Kites.

- Self-published books are eligible, however you may enter your book in EITHER the Golden Kite or the Spark Award for self-published books. You may not submit the same book to both awards. Please follow the Guidelines for Individuals if you are submitting a self-published book.

- One Golden Kite Award Winner and one Honor Book will be chosen per category. (SCBWI, n.d., Golden Kite Awards, para. 3).

\section{Indies Choice Book Award (ABA)}

The American Booksellers Association's Indies Choice Book Award (ICBA) is an American literary award that honors adult fiction, adult non-fiction, adult debut book of the year, and young adult book of the year. Formerly this award was called the Book Sense Book of the Year Award (2000-2008) and also the American Booksellers Book of the Year (ABBY) Award (1991-99) (Wayne State College Lib Guides, n.d., Children's Award-Winning Books, Indies Choice). The award-winning books of the Indies Choice Book Awards "reflect the spirit of independent bookstores nationwide and also the 
ABA's IndieBound movement" (ABA, n.d., ICBA). The award-winning and honor book titles are nominated by ABA booksellers members to the annual Indie Next Lists. These Indie Choice Book Awards are given to honor/promote books by lesser-known authors that have books published by independent bookstores. These are favorite books that various $\mathrm{ABA}$ members have enjoyed reading themselves and recommendations for their customers. The American Booksellers Association (ABA) is a non-profit industry association founded in 1900 that promotes independent bookstores in the United States and Canada (WSC Lib Guides, n.d., Children's Award-Winning Books, Indies Choice).

\section{IRA's Children's and Young Adults Book Award}

The International Reading Association's (IRA) Children's and Young Adults Book Award was started in 1987 for newly published promising authors in the genre of children's young adult literature. It can only be an author's first or second published book written for children or young adults (ages preschool to 17). Awards are currently given annually in both fiction and non-fiction in the areas of primary, intermediate and young adult books. Children's and young adult books from any country that have been published in English are eligible, but only during their first copyright and/or published year in English. To be considered, books must be submitted by their authors or publishers (IRA, n.d., IRA's Children's \& Young Adults' Book Awards). The award is administered by the International Reading Association, which is an international non-profit professional organization that was created in 1956. Eligibility and selection criteria listed in IRA's Detailed Guidelines for Submission is: 
- The entry shall be the author's/authors' first or second book (ages preschool to 17).

- The book will be submitted during the year of first copyright in English. Thus, a book will be considered but one time.

- This award is intended for newly published authors who show unusual promise in the children's and young adults' book field. When a book by a newly published author is competing against a book by an acclaimed adult author or a juvenile author who has previously won a major award, preference will be given to the newly published author.

- Both fiction and non-fiction books are eligible; each will be rated according to characteristics that are specifically appropriate to the genre.

- The awarded book should serve as a reading and literary standard by which readers can measure other books.

- If appropriate to the genre, the awarded book should provide believable and intriguing characters growing naturally out of the events and actions in the text. Nonfiction books should exhibit excellence in the areas of authority and accuracy, organization, design, and writing style.

- The awarded book should be truthful and authentic in its presentation of information and attitudes as they exist(ed) at the time and place which the story reflects.

- The characters and events in the book should meet the experience and possible expectations of the intended audience.

- The awarded book will be non-racist and nonsexist, as far as the selection committee can determine. 
- The awarded book should encourage young readers to read by providing them with something they will delight in and/or profit from by reading.

- If the award winning picture book (younger reader category) is the first or second book of the illustrator, then the author and illustrator share the award. In all other cases, the author will receive the full award.

- A book may be entered into the award competition by either its publisher or author. (p. 1)

\section{Once Upon a World Children's Book Award}

Created in 1996, the Once Upon a World Children's Book Award is administered by The Simon Wiesenthal Center and Museum of Tolerance Library and Archives. It is presented annually to two outstanding children's books that may be fiction, nonfiction, poetry or picture books. Both members of the public and publishers may nominate children's literature that help to promote tolerance, diversity, human understanding and social justice. Books may either be for Young Readers (ages 6-8) or for Older Readers (ages 9-12). The award was created to inspire readers "to promote positive change in the world" (Simon Wiesenthal Center, n.d., Once Upon a World Children's Book Award). Eligible books must have been published the previous year and in English. These may include translations and multilingual titles. The Museum of Tolerance includes the following selection criteria for Book Award Submissions for 2014:

- Depicts heroic deeds that lead to tolerance and social justice.

- Promotes acceptance of social and personal responsibility. 
- Depicts good communications between people.

- Shows a sense of urgency and empowerment of the individual.

- Conveys the importance of history. (para. 1-2)

\section{Paterson Prize for Books for Young People}

The Patterson Prize for Books for Young People is given out annually in the following 3 categories: Pre-K-Grade 3, Grades 4-6, and Grades 7-12. The prizes are awarded to one book in each category that the judges feel is the "most outstanding book for young people" published in that year (Poetry Center at Passaic County Community College, 2014, Paterson Prize). The literary prize is sponsored by the Poetry Center at Passaic County Community College. This center is a Distinguished Arts Project is funded in part by the National Endowment for the Arts. The Poetry Center has garnered international recognition for many of its prizes, awards and literary series (PCCC, n.d., Support).

\section{Society of School Librarians International Book Awards}

The Society of School Librarians International (SSLI) Book Awards identifies seven best books annually. The awards are presented in three curricular areas:

Language Arts —Picture Books, Grades K-6 Novels and Grades 7-12 Novels; Science — Grades K-6 Novels and Grades 7-12 Novels; Social Studies — Grades K-6 Novels and Grades 7-12 Novels.

To be eligible, books must be for the current year the award is presented. Numerous honor books may also be awarded in the seven areas. The awards are administered by the Society of School Librarians International. Created in 1985, this national, independent 
school library association major purpose is "to speak singularly and forcefully for the unique needs of school librarians in the educational community" (SSLI, n.d., Welcome).

\section{Edgar Allan Poe Awards}

Every year the Mystery Writers of America (MWA) organization presents the Edgar Allan Poe Awards (the Edgars) to the best mystery writers in numerous categories (e.g., novel, first novel, fact crime, critical/biographical, short story, TV episode, etc.) that were produced or published the previous year. Two of the many MWA categories are Best Juvenile Mystery and Best Young Adult Mystery. The first Edgar Award was given in the genre of juvenile literature in 1961. Eligible books for the Best Juvenile Mystery may be hardbound or paperback. The target audience for this award category is from preschool to Grade 7 (age range 5-11). The first Edgar was awarded in Best Young Adult Mystery in 1989. Eligible literature in this category may be hardbound, paperback, or ebooks. These books should be for Grades 8-12 readers (age range 12-18). All books of mystery, crime, suspense and other intriguing fields published in the United States are eligible for the awards. Books that are not published in the United States are eligible if they are widely available on bookshelves in this country (MWA, 2015, Edgar Award Category Information). The authors of submitted books do not have to be a MWA member, but they do need to be able to meet the qualifications to be an active member. For example, they must be a citizen or legal resident of the United States. All publishers submitting work need to be on the approved list of MWA publishers or meet the qualifications to be added (MWA, 2015, Edgar Submission Information). The MWA was 
founded in 1945 to promote the genre of crime writing. The first Edgar was presented in 1946 (MWA, 2015, MWA History).

\section{ForeWord Magazine Book of the Year Award/IndieFab Awards}

The ForeWord Magazine is a trade review journal that was started in 1998. This journal was created to review books that were being published independently (ForeWord Review, 2015, About Us). The awards have been given out for 15 years (2000). Since 2005 the ForeWord Magazine Book of the Year Awards have been known as Foreword's IndieFab Awards. These ForeWord awards were created to recognize the best books published by independent (indie) publishing companies. This includes books published by self-publishing, literary, university and other alternative presses/publishing companies. It excludes the large corporate publishers, such as, Simon Shuster, Harper Collins, Random House, etc. The IndieFab Awards are presented annually in over 60 categories independently (ForeWord Review, 2015, Win a Book Award). The six categories in the Children's Books area are: Picture Books (0-5), Picture Books/Early Readers (5-8), Juvenile Fiction (6-12), Juvenile Non-Fiction (6-12), Young Adult Fiction (13\& up) and Young Adult Nonfiction (13\& up). In each category, gold, silver, and bronze awards are presented. Honorable mention winners may also be awarded (ForeWord Review, 2014, IndieFab Award). Criteria guidelines and judging procedure included in the IndieFab Awards 2014 Registration form are as follow: 


\section{Eligibility:}

Any book in any format —including eBooks — published in 2014. This includes self-published and university press books, and books from small publishers. New editions of previously issued books are eligible with newly issued ISBNs. Reissued editions are not. Submit separate entry for each title. (para. 3)

\section{Judging:}

Judges will take note of the following: editorial excellence, professional production, originality of the narrative, and the value the book adds to its genre. Finalists/Winners will be determined by the Foreword Reviews editorial team, booksellers, librarians, and other industry professionals. (para. 6)

\section{Americas Award for Children's and Young Adult Literature}

In 1993 the national Consortium of Latin Americas Studies Programs (CLASP) established the Americas Book Award for Children's and Young Adult Literature. Focusing on cultural heritage, the award recognizes US published juvenile works that commemorate the portrayal of Latin America in the United States. The consortium annually awards up to two book awards (primary and secondary) along with a recommended list of books to be used by teachers in the classroom (CLASP, n.d., Americas Award). According to CLASP's 2015 Americas Awards criteria for eligible books is:

- U.S. published works of fiction, poetry, folklore, or selected non-fiction (from picture books to works for young adults) that authentically and engagingly portray Latin America, the Caribbean, or Latinos in the United States. 
- Books will be judged for: 1) distinctive literary quality; 2) cultural contextualization; 3) exceptional integration of text, illustration and design; and 4) potential for classroom use. (para. 2 \& 3)

\section{Boston Globe-Horn Book Award for Excellence in Children's Literature (BGHB)}

This children's and young adult book award was first awarded in 1967 by The Boston Globe and the Horn Book Magazine. The BGHB award currently recognizes excellence in 3 areas: Picture Book, Fiction and Poetry, and Nonfiction. In each category awards may be presented to one winner and a maximum of two Honor Books. In the past at least 5 Special Citation awards have be presented as a fourth award. To be eligible all books must have been published in the United States in the previous year since the last award. These books may be written and/or illustrated by authors and illustrators from any country (Hornbook, BGHB awards). Reissued editions, manuscripts, textbooks, e-books and audiobooks are not eligible for the award. New editions of previously issued books will be considered. To be considered books should be submitted by publishers, however the independent panel of three judges may present the award to any eligible book (Hornbook, BGHB submission guidelines).

\section{Canada's Book Awards}

\section{The Canadian Library Association (CLA) Book of the Year Award}

Founded in 1946, the Canadian Library Association (CLA), a national broadbased organization, presents annual book awards to promote literary and graphic 
excellence in children's and young adult literature. The CLA 3 prestigious awards are: Book of the Year for Children Award, Amelia Frances Howard-Gibbon Illustrator's Award, and Young Adult Book Award. Authors or illustrators must be either a citizen or permanent resident of Canada to be considered for these awards. Books must have been published the previous year (CLA, Awards).

The first two awards are for books that appeal to and/or suitable for readers 12 years old and younger. To be eligible for the Book of the Year for Children Award, a work may be any type of creative writing style. For example, literature that is fiction, non-fiction, poetry, retelling of traditional literature, etc. will be considered. Anthologies, collections, and other published formats are also eligible (CLA, Children Award). The second CLA Amelia Frances Howard-Gibbon Illustrator's Award was first presented in 1971. For this award, not only are the illustrations, but also the text of literature is judged. The writing needs to be "worthy of the book's illustrations" (CLA, Illustrator's Award). The CLA Young Adult Book Award was established in 1980 to recognize excellence in literature in the young adult age range (13-18). To be considered for this award, books must be in English, fictional (i.e., collection of short stories or novel) and be either a hardcover or paperback Canadian publication. Graphic novels are eligible (CLA, YA Book Award).

\section{Governor General's Literary Awards (GGs)}

Nicknamed the GGs, the Governor General's Literary Awards (GGLA) is currently administered by the Canada Council for the Arts (CCA). These prestigious Canadian awards, which were originally established in 1937, are presented annually to 
the best books in both English and French in the following seven categories: fiction, literary non-fiction, poetry, drama, children's literature (text), children's literature (illustrations) and translation (from French to English). A Juvenile category existed from 1949-1958. The Children's category was established in 1987 (CCA, GGLA).

Eligibility requirements for this award according to the GGLA Guidelines and Nomination Form are:

\section{Eligibility of Publishers}

Only eligible book publishers can submit titles for consideration. Publishers must:

- $\quad$ publish books based on an editorial selection process

- have at least four eligible titles in print and be committed to a sustained trade book publishing program, consisting of titles by a variety of authors

- pay royalties or financially compensate the author, illustrator or translator for any submitted title

- use appropriate and effective means to market, distribute and create public awareness of their titles

- meet basic professional standards of publishing.

The publisher may publish a maximum of $25 \%$ each year of publications written by owners, family or employees of the publishing house.

Books may be published in Canada or abroad. Foreign or new publishers must provide a historical background, a catalogue of their published titles and a list of Canadian distributors. (p. 2) 


\section{Eligibility of Titles}

Publishers should note that the award is for literary and artistic excellence; they should submit only books that they deem to be outstanding in these regards.

- Books must be first Canadian or first foreign edition trade books.

- Books must have been written, translated or illustrated by Canadian citizens or permanent residents of Canada. They do not need to be residing in Canada. In the Translation category, the original work, written in French, must also be a Canadian-authored title.

- English titles must be published and be available on the market between 1 September 2014 and 30 September 2015 (13 months).

- The main language of all books must be English.

- All books must have an ISBN, be distributed in Canada and be available in Canadian bookstores.

- All books must have a print run of at least 350 copies.

- All books must be at least 48 pages long, except for children's illustrated books which must have a minimum of 24 pages.

- All short stories, essays, poems and plays may have been previously published in magazines. (p. 2-3)

\section{Restrictions}

- Each book must be submitted in only one category

- Books that have been published in French and in English at the same time may be submitted in only one of the two languages. (p. 3) 


\section{Ineligible Titles}

Titles that are not eligible include:

- books that were already submitted to the Governor General's Literary Awards

- selections and collections of poetry, short stories, essays and plays containing material that has previously been short-listed for a Governor General's Literary Award

- books that do not include new material

- reprints or new format reprints of any kind

- $\quad$ self-published books

- textbooks or instruction guides, academic and scholarly publications, academic theses, conference proceedings, illustrated (coffee-table) books, how-to and selfhelp books, guide books, cookbooks, exhibition catalogues, film scripts, testimonials, journals, transcripts of interviews, collected letters, directories, reference books or bibliographies, and books of minimal critical content

- anthologies or collective works that are not expressed in a single voice

- graphic novels, except for titles intended for children which can be submitted to the Children's Literature - Illustrated Books category

- books whose author and/or illustrator or translator (depending on the relevant category) was deceased at the time of publication

- books submitted to the Children's Literature - Text category in which illustrations occupy more than $30 \%$ of the book's space

- books submitted to the Children's Literature - Illustrated Books category in which illustrations occupy less than $30 \%$ of the book's space 
- books submitted to the Children's Literature - Illustrated Books category for which both the author and illustrator are not Canadian citizens or do not have Permanent Resident status

- Books that have been translated from a language other than one of the two official languages. (p. 3-4) 


\section{Appendix C}

\section{Lists of Books by Awards Won}

\section{$\underline{\text { United States }}$}

-- Dolly Gray Award for Children's Literature in Developmental Disabilities

2012 Winner-Waiting for No One; Chapter book; written by Beverley Brenna 2012 Winner-Mockingbird; Chapter book; written by Kathyrn Erskine 2010 Winner-The London Eye Mystery; Chapter book; written by Siobhan Dowd 2004 Winner --The Curious Incident of the Dog in the Night-Time; Chapter book; written by Mark Haddon

\section{--- Schneider Family Book Award (ALA)}

2012 Winner-Wonderstruck: A Novel in Words and Pictures-Middle School Category; written and illustrated by Brian Selznick

2011 Winner--Five Flavors of Dumb - Teen Book Category; written by Antony John 2010 Winner--Anything But Typical - Middle School Category; written by Nora Raleigh Baskin

2010 Winner--Marcelo in the Real World-Teen Book Category; written by Francisco X. Stork

2008 Winner--Hurt Go Happy -Teen Book Category; written by Ginny Rorby 2006 Winner--Tending to Grace-Middle School Category; written by Kimberly Newton Fusco

\section{--Pura Belpre Award}

2011 Winner for Narrative - The Dreamer, written by Pam Munoz Ryan, illustrated by Peter Sis

\section{--Mildred L. Batchelder Award}

2007 Winner-- The Pull of the Ocean written by Jean-Claude Mourlevat and translated from the French by Y. Maudet.

-- Alex Awards (ALA)

2007 Selection--Black Swan Green: A Novel; written by David Mitchell

2004 Selection--The Curious Incident of the Dog in the Night-Time; written by Mark Haddon 
--Michael L. Printz Award for Excellence in Young Adult Literature (ALA)

2001 Honor--Stuck in Neutral; written by Terry Trueman

2000 Honor-Speak; written by Laurie Halse Anderson

\section{--Cybil Award}

2011 Finalist-- Wonderstruck: A Novel in Words and Pictures-Graphic Novel

Category; written and illustrated by Brian Selznick

2009 Finalist--Anything But Typical — middle grade fiction; written by Nora

Raleigh Baskin

--Parent's Choice Award for Children's Literature

2011 Gold Award --Wonderstruck: A Novel in Words and Pictures -Fiction

Category; written and illustrated by Brian Selznick

2010 Silver Honor Award --The Dark Days of Hamburger Halpin - Fiction

Category; written by Josh Berk

2010 Silver Honor Award --The Out of My Mind -- Fiction Category; written by Sharon Draper

--Josette Frank Award

2011 Winner--Out of My Mind; written by Sharon Draper

--National Book Award

2010 Winner-- Mockingbird - Young People's Literature category; written by Kathyrn Erskine

1999 Finalist--Speak--Young People's Literature category: written by Laurie

Halse Anderson

--Golden Kite Award (SCBWI)

2000 Winner-Speak -- written by Laurie Halse Anderson

2011 Honors-Mockingbird -- written by Kathyrn Erskine

--Indies Choice Book Award (ABA)

2011 Honor --Out of My Mind - Young Adult Category; written by Sharon M. Draper 
--IRA's Children's and Young Adults Book Award

2011---Mockingbird - written by Kathyrn Erskine

--Once Upon a World Children's Book Award

2010 Winner--Marcelo in the Real World; Young Adult Category; written by

Francisco X. Stork

-- Paterson Prize for Books for Young People

2003 Winner --Deaf Child Crossing -- Grades 4-6; written by Marlee Matlin

--Society of School Librarians International Book Awards

2003 Honor -- Deaf Child Crossing-- Language Arts-Grades K-6 Novels; written by Marlee Matlin

2000 Honor -- Nick's Secret -- Language Arts-- K-6 Novels; written by Claire H. Blatchford

2000 Honor -- Speak -- Languages Arts- Grades 7-12 Novels; written by Laurie Halsie Anderson

--Edgar Allan Poe Awards

2000 Finalist--Speak-Young Adult category; written by Laurie Halsie Anderson

--ForeWord Magazine Book of the Year Award/IndieFab Awards

2000 Silver-After Hamelin-- Children's Young Adult Fiction; written by Bill Richardson

-- Americas Award for Children's and Young Adult Literature

2011 Winner-The Dreamer - written by Pam Muñoz Ryan; illustrated by Peter Sís.

Boston Globe-Horn Book Award for Excellence in Children's Literature (BGHB) 2010 Honor Book -- The Dreamer -Fiction and Poetry; written by Pam Muñoz Ryan; illustrated by Peter Sís. 


\section{$\underline{\text { Canada }}$}

The Canadian Library Association (CLA) Book of the Year Award 2011 Finalist - Waiting for No One - written by Beverley Brenna 2010 Finalist -- Free as a Bird -written by Gina McMurchy-Barber

Governor General's Literary Awards (GGs)

2010 Short-listed-- Free as a Bird -written by Gina McMurchy-Barber 


\section{Appendix D \\ Children's Literature Comprehensive Database (CLCD)}

The online Children's Literature Comprehensive Database (CLCD) has over 570,000 reviews and more than 50 quality database participants that are used to gather reviews from pertaining to children's literature. Their ever-growing number of book reviews start around 1993 and go to the present. The database includes reviews from well-know leaders of children's literary reviewers, such as, Booklist, The Bulletin of the Center for Children's Books, KIRKUS Reviews, KLIATT, The Lion and the Unicorn, and VOYA, just to name a few. The CLCD also receives varied perspectives reviews from international, regional, and special interest groups sources by supplying reviews from such organizations as, African Access, Books For Keeps (British publication), Canadian Children's Book News, Catholic Library World, the Midwest Book Review, The Newsletter of the Association of Jewish Libraries (AJL), Parent's Guide, etc. Additionally found in the database is information about which literary works have received awards, honors, prizes, etc. and have made the lists of not only the various states' reading lists, but also the annually awarded best books lists of notable organizations such as, School Library Journal, International Reading Association, ALA's YALSA, etc. (CLCD, n.d.) 
Appendix E

Bibliograpical/Demographic Table

\section{Children's \& Young Adults Literature Portraying Characters with Communication Disorders}

\begin{tabular}{|l|l|l|l|l|l|l|l|l|l|l|}
\hline & & & & & & & \\
\hline \\
\hline
\end{tabular}




\section{Appendix F}

\section{Authors/Illustrators that Have Connections with Disabilities}

\begin{tabular}{|c|c|}
\hline Author/Illustrator & Author's/ Illustrator's Relationship to Disability \\
\hline Brenna, Beverley & $\begin{array}{l}\text { Assistant Professor at University of Saskatchewan; College of Education, } \\
\text { Curriculum Studies; worked as a coordinator of gifted programs, a reading } \\
\text { specialist, a special education teacher, and a special education consultant; } \\
\text { Dissertation topic- Characters with Disabilities in Contemporary Children's } \\
\text { Novels: Portraits of Three Authors in a Frame of Canadian Texts }\end{array}$ \\
\hline Blatchford, Claire & $\begin{array}{l}\text { A deaf author; became deaf at the age of six due to mumps; worked for several } \\
\text { years as teacher of deaf children }\end{array}$ \\
\hline Crawford, Brent & Author has ADD as does the main character \\
\hline Draper, Sharon & $\begin{array}{l}\text { This author has a daughter with disabilities; has worked at summer camps for } \\
\text { children with disabilities; has done extensive research to try to understand and } \\
\text { unlock the hidden secrets of her child's mind }\end{array}$ \\
\hline Erskine, Kathryn & Daughter was diagnosed with Asperger syndrome \\
\hline $\begin{array}{l}\text { Fusco, Kimberly } \\
\text { Newton }\end{array}$ & Author is lifelong stutterer \\
\hline Haddon, Mark & Worked with individuals with autism as a young man. \\
\hline Kelly, Tara & Author has ADHD; her brother is on the autistic spectrum \\
\hline Matlin, Marlee & $\begin{array}{l}\text { A deaf author/actress; had always wanted to write a book expressing her } \\
\text { experiences growing up in the early } 70 \text { s in Chicago as a deaf child; wanted to } \\
\text { show that her life was not all about speech classes, hearing aids and frustrations } \\
\text { because she was deaf; more like a Brady Bunch family but with a twist; story is } \\
\text { semi-autobiographical }\end{array}$ \\
\hline $\begin{array}{l}\text { McMurchy-Barber, } \\
\text { Gina }\end{array}$ & $\begin{array}{l}\text { Worked in an institution for people with cognitive disabilities; had a sister who } \\
\text { had Down syndrome. Elementary teacher in Canada. }\end{array}$ \\
\hline Mitchell, David & Semi-autobiographical; author stammerer \\
\hline Selznick, Brian & $\begin{array}{l}\text { Brother was born deaf in one ear like the main character Ben was; many of this } \\
\text { character's thoughts and ideas came from talking with his brother }\end{array}$ \\
\hline Dowd, Siobhan & $\begin{array}{l}\text { Had a close relative that had been diagnosed with Asperger syndrome; watching } \\
\text { relative cope with it; reading to learn more about it }\end{array}$ \\
\hline Stork, Francisco & $\begin{array}{l}\text { In college worked and lived in halfway house/faith-based community where } \\
\text { normal adults and adults with developmental disabilities lived together; also has a } \\
\text { nephew who has autism }\end{array}$ \\
\hline Trueman, Terry & $\begin{array}{l}\text { Author's own son has severe cerebral palsy; overwhelmed by his son's disability; } \\
\text { wrote narrative poem Sheehan about his son; turned into the book, Stuck in Neutral }\end{array}$ \\
\hline
\end{tabular}




\title{
Appendix G
}

\section{Book Annotations}

\author{
After Hamelin \\ Richardson, Bill \\ 2000
}

Annick Press

In his book, After Hamelin, Bill Richardson masterfully continues the traditional European fairy tale of the legendary Pied Piper, which is set in Hamelin, Germany during the Middle Ages. In a series of memories and flashbacks, a feisty 101-year-old harpist Penelope recounts her version of the tragic, mysterious day when the vengeful Pied Piper led away the vast majority of the Hamelin village children by playing an enchanted spellbinding melody on his magical flute when the mayor reneged on paying this musician for his rat catching services. The only children who were left behind in the village were Penelope, who had suddenly become deaf that same morning that the Piper returned, and her harper father's young blind apprentice, Alloway. Having just been made aware of her rare Deep Dreaming ability by the village wise man/town seer Cuthbert, this delightful tomboy heroine, was able to journey across the borders between the waking and dreaming worlds at will and find the fate of the village children at the Pied Piper's home. In her adventurous quest to rescue the children, Penelope is joined by not only an eclectic assortment of characters from her village such as, Alloway, her talking witty cat Scally, and a three-legged dog Ullysses, but also by other imaginative companions that she meets along the way including a rope skipping dragon Quentin and a ski-footed flying Trolavian bird creature called Belle. In this blended legend and fantasy story, much wit, courage, friendship and collaboration was needed by the colorful group as they conquered the many twists and turns of the perilous adventure to return the children to Hamelin. The quest appears to have transformed the young Penelope allowing her to pursue her dream of becoming a harper like her father, even though she is deaf and the it was a male dominated profession during the time/setting of the story.

Discussion guide: Not available at this time.

\section{Aftershock \\ Easton, Kelly \\ 2006 \\ Margaret K. McElderry Books}

In this touching survival book Aftershock, Easton Kelly shows how an individual's life can change in a moment. While driving back from a peace rally with his parents, seventeen-year-old Adam suddenly finds himself the only survivor of a horrific single car accident in the remote woods of Idaho. With a short-circuited memory and post-traumatic 
mutism, this now orphaned teenager manages to endure. As his struggling consciousness drifts in and out, Adam slowly begins to recover snippets of his idyllic pre-accident life with his family, school friends, girlfriend, aunt, and cousin who has autism. Spurred by these poignant memories, Adam begins his road odyssey east determined to get back to his home and family bookstore in Rhode Island. Along the way this teenager encounters a diverse population of people. Some individuals greet him with acts of kindness while others with cruelty. In his journey toward wholeness and trying to reclaim a portion of his past, the often hungry and dehydrated Adam realizes a few important facts, such as, how one thing going wrong can unravel everything and also not to judge people because their plight could be yours some day. He begins to appreciate small things he had always taken for granted like food, drink, a comb, a toothbrush, clean clothes, and a hair cut. In his grim reality state, Adam also discovered that even though his parents were dead, they were actually floating inside of him, resurfacing and defining who he was.

Discussion guide: Not available at this time.

\section{Alvin Ho: Allergic to Girls, School, and Other Scary Things}

Look, Lenore Look; illustrator, LeUyen Pham

2008

Schwartz \& Wade Books

As the book title Alvin Ho: Allergic to Girls, School, and Other Scary Things suggests, the protagonist Alvin is afraid of almost everything: elevators, tunnels, trains, bridges, heights, teachers, girls, shots, scary movies, the dark, kimchi, wasabi, and especially school. Lenore Look shows a young second grader, who is the smallest child in his class, having trouble making friends and speaking in stressful places like school, his piano teacher's house and psychotherapist's office. Being from Concord, MA and a long line of Chinese farmer/warriors, Alvin loves anything that explodes and all superheroes. At home this enthusiastic and loud individual is the make-believe superhero, Firecracker Man. The episodic chapters show various quirky and humorous jams and mishaps this Chinese-American protagonist is always getting into at school and in his community in his quest to have friends and to be a gentleman like his patient and devoted father. After temporarily joining a popular gang of neighborhood boys and trying to pass their initiations, Alvin finds out that not only does he need to make decisions for himself, but close friendships can be as near as a female desk buddy who happens to have the same interests as him. The numerous expressive and animated black and white pictures by LeUyen Pham illustrate the humor and energy expressed in Look's story. The witty and funny Alvin Glossary aids readers in knowing more about various Chinese terms (i.e., edamame, feng shui, kimchi, GangGung, wasabi, yehyeh, etc.), famous people, events, and other terms used in the story.

Discussion guide: http://c.ymcdn.com/sites/www.ilfonline.org/resource/resmgr/201011_yhba resources/alvinho.pdf 
Black Swan Green: A Novel

Mitchell, David

2007

Random House

The book Black Swan Green: A Novel, is a first-person, semi-autobiographical comingof-age British novel that is composed of 13 short stories/chapters that are monthly slices of thirteen-year-old Jason's life. The setting of the story is a 1982 Cold War sleepy Worcestershire village called Black Swan Green that ironically has no swans. David Mitchell vividly describes an internal authentic monologue of the friendly, intelligent, articulate, adolescent Jason as he begins his transition to a young man. The audience experiences the trials and tribulations of this teenager as he comes to terms with his intermittent stammering, his secret writing of poetry, the social popularity hierarchy of his peers, and the his parents' unraveling marriage. The story covers a crucial period of this awkward British teenager life and is told in a meandering pace with all its British slang as he matures, gains a backbone, and learns to stand up for himself against the bullies/extortionists.

Discussion guide: $\underline{\text { http://www.randomhouse.com/catalog/teachers guides/9780812974010.pdf }}$

Carter Finally Gets It

Crawford, Brent

2009

Disney Hyperion Books

An authentic, often humorous, first-person voice of the up and down misadventures of an immature Will Carter, who is trying to navigate his way through his freshman year of high school. Straddling childhood and young adulthood, the impulsive exploits of this fourteen-year-old student, who slightly stutters around females, have readers rooting for him as he deals with such issues as dating girls, parties, peer pressure, parents, friends, etc. Having ADD and being easily distracted by girls, Carter has trouble concentrating in the classroom and in the various varsity sports (i.e., football and swimming) that he participates in. Not making the baseball team, this freshman is encouraged to try out for the school's spring play, where he gets the lead role and the girl. As the school year progresses, Carter develops social maturity, becomes more adept at concentrating, and 
gains the courage to participate in activities that he enjoys (i.e., drama) even when these events are not popular with his peers.

Discussion guide: Not available at this time.

The Curious Incident of the Dog in the Night-Time

Haddon, Mark

2003

Doubleday

In The Curious Incident of the Dog in the Night-Time, the British writer Mark Haddon masterfully presents readers with insight into what life might be like for an autistic teenager who sees and experiences everyday life differently. Fifteen-year-old Christopher excels at math and physics, does not tell jokes or likes to be touched, and relates better to animals than people since he has great difficulty in empathizing with humans. Being a big fan of Sherlock Holmes, this unique teenager decides to find out who murdered his neighbor's dog with a pitchfork one night. Christopher writes a first person murder-like mystery of his investigation for a school journal project even though his father told him to keep out of other people's business. During his logical inquiries, this teenager unearthed some confusing revelations about his mother's death and begins an unprecedented journey alone to London to get answers to the new riddle. After having solved two mysteries, taking a trip by himself outside of his familiar neighborhood, and passing his A levels in Mathematics, Christopher gains more insight into everyday life and begins finding his place in the world. The numerous maps, drawings, logic problems, and diagrams presented in the narrative, provides the audience with an even deeper understanding on what it is like to be this young mathematician who has to analyze emotional complexities and social guidelines so that he can receive meaning and find his way in society.

Discussion guide: http://www.randomhouse.com/teachers/catalog/display.pperl?isbn=9781 400032716\&view=rg

The Dark Days of Hamburger Halpin

Berk, Josh

2010

Alfred. A. Knopf

In The Dark Days of Hamburger Halpin, Will Halpin is a recent transfer student from the school of the deaf, who has to learn quickly how to survive without any interpreters or related services in a mainstream public Pennsylvania high school. Being hefty, hearing- 
impaired, and a newcomer, this sixteen-year-old protagonist finds himself low on the social ladder. Having a low self-image of himself, Will is at first reluctant to ally with another social outcast Devon who befriends him. However, after the murder of the popular star quarterback at a nearby defunct coal mine during a school field trip, Will and Devon team up to solve the mystery of the suspicious death of their classmate. The unexpected duo discover the murderer by lip-reading peers' conversations on the bus and at school and also piecing together evidence after secretly watching students' interrogations on the schools' surveillance cameras. This light-hearted, witty and sometimes sarcastic, dark first person narrative provides the audience with a funny perspective of the high school scene from two unexpected Hardy Boys-like heroes. Josh Berk's coming of age novel also reflects on such elements as politics of deaf culture, personal history, and friendship.

Discussion guide: Not available at this time.

\section{Deaf Child Crossing \\ Matlin, Marlee}

2002

Simon \& Schuster Books for Young Readers

In Deaf Child Crossing, nine-year-old Megan, who is deaf, is craving to have a best friend. Boisterous and extremely outgoing, this young protagonist introduces herself immediately to her new neighbor Cindy when she moves in. Thrilled at having a same-age companion, the two girls soon become inseparable even though they differ greatly personality-wise. Cindy is extremely shy, bookish, and does not like attention. With Megan having opposite personal characteristics of being vivacious, passionate, strong-minded and self-reliant, these two neighbors' friendship is soon tested. Cindy's attempts at helping her friend offend Megan's sense of independence. Other issues also arise when the two young girls attend summer camp together. Cindy is excluded when Megan befriends another camper who is deaf. A period of estrangement occurs after camp, but in the fall with the start of school, the girls' friendship matures and is repaired. Cindy learns how and when to assist her friend, while Megan finally realizes that everyone needs help sometimes and not to be so defensive. The story is told from both Megan's and Cindy's points of view. Marlee Matlin's compelling and heartwarming Deaf Child Crossing is a semi-autobiographically novel based roughly on her own childhood experience of growing up deaf.

Discussion guide: Not available at this time. 


\section{The Dreamer}

Ryan, Pam Muñoz; illustrator Peter Sís.

2010

Scholastic Press

The Dreamer is Pam Muñoz Ryan's vividly sensory, detailed, fictional biography based on the childhood and young adulthood of the Nobel Prize-winning Chilean poet Pablo Neruda. Born as Neftali Reyes, this young boy, who is shy, stutters, but extremely observant and sensitive, tries to make sense of the magical world around him. The spirited Neftali treasures not only small earthy objects such as feathers, leaves, shells, bugs, etc., but also the magic of sounds and the power of words. Fearing his domineering, disapproving father and what he represented, this protagonist overcame his tense early family life and grew into a confident young man who questioned the struggle and social injustice of the indigenous Mapuche people around his Chilean town. Ryan provides additional insight about Neruda's life by including in the endnotes not only a selections of this internationally-known poet's translated poems, but also author's notes, and bibliographical information. Peter Sis' beautiful stippled illustrations compliments Ryan's verse and the magical questioning dream world of the young poet.

Discussion guide: http://www.scholastic.com/teachers/lesson-plan/dreamer-discussion-guide Readers' Theatre Script: http://www.pammunozryan.com/pages/scriptDreamer.pdf

\section{Five Flavors of Dumb}

Antony, John

2010

Dial Books

Angry and frustrated that her parents' robbed her college fund to pay for her baby sister's cochlear implant, eighteen-year-old Piper agrees to become the unlikely manager of the hottest new rock band in Seattle, Dumb. If this smart and savvy senior, who happens to be profoundly hearing impaired, is able to find this high school band a paying gig in one month she can share in their profits. The audience finds themselves rooting for this raw and authentic protagonist as she steps up to the new challenge, thus learning from her numerous mistakes and inexperience at intra-band politics, and discovers not only the rich history of Seattle's rock music icons (i.e., Cobain and Hendrix), but also the true joy and spirit of making music. John Antony's complex and fast-moving Five Flavors of Dumb, is more than the ups and downs and shaping of a young rock band that is composed of band members with extremely different personalities. Taking control of her life, Piper begins a metamorphosis herself and is determined to shape her own future. Several additional themes are woven into this novel, such as, mutual respect in a family, educating family and friends more about the Deaf Culture, and even a budding romance for the protagonist.

Discussion guide: http://www.penguin.com/static/images/yr/pdf/FiveFlavors Guide 11.pdf 
Free as a Bird

McMurchy-Barber, Gina

2009

Dundurn Press

Writing from her experiences of having a sister with Down syndrome and having been employed at Woodland school, Gina McMurchy-Barber's book Free as a Bird is a powerful historical fiction telling readers of a time when society isolated individuals with intellectual disabilities. Abandoned at a British Columbia institution in the mid 1960s by her mother after her caregiver grandmother dies, eight-year-old Ruby Jean begins a first-person narrative of her world. Born with Down syndrome and having a developmental disorder, life was bleak for this protagonist who was warehoused in the so-called Woodland School. Suffering from isolation and physical, emotional, and mental abuse, the once talkative and curious Ruby Jean quits talking and basically shuts down. Things begin to look up years later when she begins to be taken off the ward for life-training classes and is subsequently placed in a community setting with an elderly couple. Ruby Jean begins to speak again and work in a sheltered workshop. After a mix-up and believing that she would be placed back in the institutional setting, Ruby Jean runs away and lives for a while on the streets of Vancouver with the homeless. This protagonist, however, is reunited soon with her adopted parents. Later returning to the site of the old school after its permanent closure, Ruby Jean reiterates her story of life in an institution for the press, visitors and all her friends at the institution who are no longer around to tell their story. This is a story of survival.

Discussion guide: https:/www.dundurn.com/sites/default/files/onixlive/supplementary/ Free As A Bird 9781554884476.pdf

\section{Harmonic Feedback}

Kelly, Tara

2010

Henry Holt

In the book Harmonic Feedback, sixteen-year-old Drea and her mother have to move again, but this time it is to live with her cranky grandmother in Bellingham, WA. Having been diagnosed years before with ADHD and Asperger syndrome, this time around Drea tries to become more socially aware in her new school so that she will be able to fit in better and make some friends. Loving music, this teenager forms a band with her wild purple-haired neighbor Naomi and Justin, who is another new kid at her school. This authentic first person narrative shows Drea making friends, falling in love, and beginning to find her place in the world as she gains a greater understanding of living with Asperger syndrome and ADHD.

Discussion guide: Not available at this time. 
Hurt Go Happy

Rorby, Ginny

2006

Tom Doherty Associates

Having been profoundly deaf since being physically abused by her father, thirteen-year-old Joey finds herself isolated from much of the world since she does not have hearing aids and can only read her mother's lips well. Joey's life changes after discovering a neighbor with a chimpanzee, who knows some sign language. With her neighbor's financial support, this protagonist is able to receive hearing aids, learn sign language and attend a School for the Deaf. Once her neighbor dies, Joey had to rescue the chimpanzee from the drug study laboratory he had been place in. Hurt Go Happy is a heart-warming animal story.

Discussion guide: http://c.ymcdn.com/sites/www.ilfonline.org/resource/resmgr/0910 yhba resources/hurtgohappy.pdf

The London Eye Mystery

Dowd, Siobhan

2007

In the book, The London Eye Mystery, author Siobhan Dowd introduces readers to quirky twelve-year-old Ted, who uses his unique mind to find his missing cousin. The trouble started for Ted and his older sister Kat shortly after they watch their visiting thirteenyear-old cousin Salim board the famous Ferris wheel-like attraction, the London Eye. When the 30 minutes ride ends, passengers disembark from the glass pods, but their cousin has vanished. Even though this protagonist has trouble reading and connecting with people, takes everything quite literally, and has a brain that as he describes it runs on a different operating system, Ted appears to be extremely intelligent and skillful at solving mysteries. Teaming up with Kat, this detective duo uses Ted's complex, analytical mind and eye for details to phantom how their cousin disappeared without a trace and help lead a rescue for Salim from a life and death situation. Ted's first person narrative seems authentic as the audience watches how this young detective's mind works. Even though Asperger syndrome is never mentioned, this main character is portrayed with many classic symptoms of this disorder. However with a loving and supportive family relationship, Ted finds his voice as he learns to trust his abilities and to face his personal challenges.

Discussion guide: http://2ndgradeenglishsection.weebly.com/uploads/1/5/8/9/15890078/ reading guide.pdf 
Marcelo in the Real World

Stork, Francisco

2009

Arthur A. Levine Books

In the book Marcelo in the Real World, seventeen-year-old Marcelo suddenly finds himself forced out of his comfort zone. Having a different cognitive condition that has many similarities to Asperger syndrome, Marcelo not only loves to read religious books and listen to the internal music in his head, but he also enjoys greatly working with the ponies at his private school Paterson. To be allowed to return to Paterson for his senior year and not the local public high school, Marcelo was given the ultimatum by his power-driven attorney father to successfully complete a summer job in his law firm's Mail Room. At first everything is going fine as Marcelo learns new personal relationships skills, how to read both facial and body language better, and to navigate through the real world of self-serving and competitive office politics. However, everything changes and become more complicated when Marcelo finds a photograph of a young girl that was terribly disfigured by the negligence of his father's biggest client. Beginning to question his father's ethics, this protagonist has to make some hard decisions that will affect his hope of returning to Paterson in the fall. Marcelo grows much during the summer as he remains true to the voice inside him and begins to map out his plans for his future life and career.

Discussion guides:

http://www.scholastic.com/teachers/lesson-plan/marcelo-real-world-discussion-guide

http://www.ala.org/alsc/sites/ala.org.alsc/files/content/confevents/alscannual/marcelo.pdf

https://teachinglatinamericathroughliterature.wordpress.com/november-2013-marcelo-inthe-real-world/

Mockingbird

Erskine, Kathryn

2010

Philomel Books

In the book Mockingbird, author Kathryn Erskine enables readers to understand the thoughts, struggles, and accomplishments of ten-year-old Caitlin who has Asperger syndrome and is dealing with the recent violent middle school death of her older brother Devon. In this first person narrative, Caitlin explains her difficulty in being in loud and crowded places, reading faces and body language, and making friends. Mrs. Brooks, Caitlin's school counselor, helps this young student learn how to develop better social skills and begin dealing with Devon's death. Introduced to the term closure, Caitlin's mission becomes to somehow honor Devon's life in order to help her father and herself move on. In the act of finding closure, Kaitlin's life begins to change as she starts making 
friends and helps other families and the community as a whole in her endeavor to find closure for the school shooting.

Discussion guide: https://www.teachervision.com/tv/printables/penguin/tl-guidemockingbird.pdf

Nick's Secret

Blatchford, Claire H.

2000

Lerner Publications

Thirteen-year-old Nick, who is deaf, is having problems with a drug-dealing bully Daryl from his school. Daryl has begun causing trouble at the pet store where Nick works parttime. Wanting to stand up to the bully, Nick agrees to meet Daryl at a burnt out abandoned motel even though a snowstorm is threatening. Fortunately, Nick and his dog Wags, are rescued from Daryl and his gang, by a mysterious girl Ionie, who has visited the pet store before. Stranded by the blizzard, Nick and Wags seek refuge with his rescuer. Ionie has been living nearby hiding her family's pack of valuable sheepherding dogs waiting for her father to return. Helping out his new friend with her secret and attempted dognapping problem, Nick finds food and safety for Ionie and her dogs.

Discussion guide: Not available at this time.

Out of My Mind

Draper, Sharon

2010

Atheneum Book for Young Readers

In the book Out of My Mind, Melody Brooks is a brilliant, funny, imaginative fifth grader that is trapped in an unresponsive body. However, having severe cerebral palsy and being unable to walk, talk, feed herself, etc., does not stop this determined protagonist, who refuses to be defined by her disability. Once she is moved to an inclusive educational setting and receives a talking communicative device, Melody becomes a valuable member of her school's Whiz Kid Bowl, thus challenging the misconceived skepticism of many in the school and community that she also has an intellectual disability. Multiple Coretta Scott King award-winning author, Sharon Draper, presents a very authentic, compelling story of the triumphs and setbacks of Melody as she strives to become her own person and gain acceptance from the other students and teachers.

Discussion guides:

https://sharondraper.com/core/oomm.pdf

http://www.scholastic.com/teachers/top-teaching/2014/05/teaching-out-my-mind

http://books.simonandschuster.com/Out-of-My-Mind/Sharon-M-Draper/9781416971719/ reading group guide 
The Pull of the Ocean

Mourlevat, Jean-Claude; translated by Y. Maudet.

2006 (trans)

Delacourte Press

In this loosely based retelling of Perrault's Tom Thumb, ten-year-old Yann convinces his six older brothers one stormy night that they have to quickly leave their impoverished farm or risk getting killed by their abusive father. The seven brothers begin their odyssey west led by the clever protagonist Yann, who is not only mute, but is also extremely small in stature. The journey's tale unfolds with the various chapters being told by multiple voices, such as, family members, social workers, police, and other people who meet or witness the brother's journey to the ocean. The Pull of the Ocean is an intriguing story of brotherhood and the determination of a young boy to escape his harsh life.

Discussion guide: Not available at this time.

Speak

Anderson, Laurie Halse

1999

Farrar Straus Giroux

In the book Speak, Melinda finds herself a social outcast as soon as she steps through the school's door her freshman year of high school. Her peers shun her, because she called the cops to an end-of-summer party. Melinda becomes extremely depressed, feels isolated and has trouble communicating her thoughts to anyone. As the school year progresses, this student who once was outgoing and had good grades, began doing poorly in school, skipped classes, and quit speaking to most peers and adults. Melinda finds solace only in her artwork and from her passionate art teacher. Slowly as the plot unfolds, this protagonist begins disclosing to readers the real reason she called the cops and feels so disenfranchised. Having been raped by a senior football player at the party, Melody blames herself and never told anyone about the incident. As she begins to heal, Melody once again finds courage and her voice as she stops another rape attempt by the same student. This sarcastic and witty first-person narrative presents an authentic and raw view of life at a large suburban high school with all its cliques of jocks, Goths, Marthas, etc.

Discussion guides:

http://www.penguin.com/static/images/yr/pdf/LessonPlans LHA.pdf

http://projectaccess.uoregon.edu/teachers/behavioral/bullying/Bully\%20Suicide\%20Read \%20Guide\%20for\%20Speak\%20DONE.pdf

https://www.teachervision.com/tv/printables/penguin/speak dg.pdf

http://madwomanintheforest.com/pdfs/speak-out.pdf 
Stuck in Neutral

Trueman, Terry

2000

Harper Collins Publishing

In the book Stuck in Neutral, Terry Trueman richly presents a running internal commentary of fourteen-year-old Shawn's world. Even though this protagonist has severe cerebral palsy and several grand mal seizures a day, Shawn loves being alive. He cannot communicate, walk, or take care of himself, but this witty, intelligent teenager thoroughly enjoys everyday experiences with his older siblings and mother, watching television, his out-of-body experiences that occurs when he has seizures, etc. His parents' marriage broke up early in his life with the stress of caring for Shawn, but his father is still in his family's life. Shawn, however, has become anxious and a little afraid of his Pulitzer Prize-winning father once he became interested in writing a book about a famous euthanasia case where a father killed his young son who had disability similar to Shawn's. Some ethical and/or controversial questions are raised in this narrative that has an open-ending conclusion.

Discussion guides:

https://www.teachervision.com/tv/printables/harpercollins/terry-trueman_tg.pdf

http://als.lib.wi.us/ReadersGuide.pdf

http://disabilityawarenessliteracyproject.wikispaces.com/Stuck+in+Neutral

Sweethearts

Zarr, Sara

2008

Little, Brown

In the book Sweethearts, Jenna Vaugh reinvents herself from a bullied, overweight, lonely, latchkey kid, who had a lisp in elementary school, to a now popular attractive high school senior with friends. Thinking she had left her old life behind after she lost weight and changed her name and schools, Jenna balanced and controlled world is suddenly thrown off kilter with the sudden appearance in her class of her past grade school friend Cameron. Living in poverty and being social outcasts, these two individuals had previously been inseparable having a special bond of friendship that allowed them to survive their bleak home and school life. Cameron, however, had suddenly disappeared without warning from her life. In a serious of flashbacks intertwined with the present, these two friends confront their past and the nightmarish event that they had shared together at the hands of his abusive father. In this first person narrative, Jenna begins to 
explore her identity and who she really is as she sees how shared experiences have shaped their lives taking them in different directions.

Discussion guide: Not available at this time.

\section{Tending to Grace}

Fusco, Kimberly Newton

2004

Knopf

Having taken care of her mother for most of her life, ninth-grader Cornelia suddenly finds her mother abandoning her with an unknown relative so that she can make a fresh start with her boyfriend in Vegas. Cornelia and her great aunt Agatha have opposite personalities, but they have to learn to live together in this rambling house in rural New England. While her great aunt is boisterous, a closet illiterate, and a mad collector of everything, Cornelia, who has a severe stutter, is an extremely shy and neat individual that loves to read. In this coming-of-age book, this protagonist must come to grips with the fact that her mother abandoned and is unable to care for her. Since her great aunt will not speak for her, Cornelia has to come out of her shell and learn to speak up for herself again. The family relationship grows between this great aunt and niece as they begin to build a supportive home environment.

Discussion guide: http://www.kimberlynewtonfusco.com/resources/Discuss Tending to_Grace.pdf

Waiting for No One

Brenna, Beverley

2010

Red Deer Press

In the book Waiting for No One, eighteen-year-old Taylor Jane is trying to become independent and find her place in the world. Having Asperger syndrome, it is difficult for her to step out of her comfort zone, but Taylor Jane knows she must make the attempt if she wants to grow, make friends, be an individual, and not be known as just someone with a disability. With these goals in mind, Taylor Jane applies for a job in a bookstore, participates in dance classes, takes a college biology class, and travels alone by bus to her father's home in Casper Wyoming. Narrated in her own voice, this protagonist provides readers with an extremely honest and sometimes funny perspective of her life as she 
works through her social interaction difficulties and an obsessive and compulsive disorder. Taylor Jane does have ups and downs, but she keeps moving forward making friends and gaining employment.

Discussion guide: http://www.beverleybrenna.com/waiting_guide.html

Wonderstruck: A Novel in Words \& Pictures

Selznick, Brian

2011

Scholastic

In his book Wonderstruck: A Novel in Words \& Pictures, Selznick once again uses his unique richly, layered illustration-and-text format to tell separate, but parallel, intertwining stories set fifty years apart of two children who are both dealing with such issues as loneliness, belonging, and loss. In 1977 having recently lost his mother in a car accident, twelve-year-old Ben travels half way across the country to New York City to try and find his father that he has never met. Back in 1927 Rose also ran away to New York City to try and be reconnected with her famous actress mother. As the story cuts back and forth between the two tales, readers notice the existence of many common reoccurring themes, such as, deafness, running away, storms, parents, stars, museums, etc. in both narratives. Ultimately these two narratives collide and form one story as both protagonists find the connection they were missing.

Discussion guides:

http://www.scholastic.com/teachers/collection/teaching-brian-selznick-including-virtualfield-trip

http://www.scholastic.com/wonderstruck/

http://www.wonderstruckthebook.com/essays.htm 